\title{
Morality and Nationalism
}

This book takes a unique approach to explore the moral foundations of nationalism. Drawing on nationalist writings and examining almost 200 years of nationalism in Ireland and Quebec, the author develops a theory of nationalism based on its role in representation.

The study of nationalism has tended towards the construction of dichotomies - arguing, for example, that there are political and cultural, or civic and ethnic, versions of the phenomenon. However, as an object of moral scrutiny this bifurcation makes nationalism difficult to work with. The author draws on primary sources to see how nationalists themselves argued for their cause and examines almost two hundred years of nationalism in two well-known cases, Ireland and Quebec. The author identifies which themes, if any, are common across the various forms that nationalism can take and then goes on to develop a theory of nationalism based on its role in representation. This representation-based approach provides a basis for the moral claim of nationalism while at the same time identifying grounds on which this claim can be evaluated and limited.

It will be of strong interest to political theorists, especially those working on nationalism, multiculturalism, and minority rights. The special focus in the book on the Irish and Quebec cases also makes it relevant reading for specialists in these fields as well as for other area studies where nationalism is an issue.

Catherine Frost is Assistant Professor of Political Theory at McMaster University, Canada. 


\section{Routledge Innovations in Political Theory}

1 A Radical Green Political Theory Alan Carter

2 Rational Woman

A feminist critique of dualism

Raia Prokhovnik

3 Rethinking State Theory

Mark J. Smith

4 Gramsci and Contemporary Politics

Beyond pessimism of the intellect

Anne Showstack Sassoon

5 Post-Ecologist Politics

Social theory and the abdication of the ecologist paradigm Ingolfur Blühdorn

6 Ecological Relations

Susan Board

7 The Political Theory of Global Citizenship

April Carter

8 Democracy and National Pluralism

Edited by Ferran Requejo

9 Civil Society and Democratic Theory

Alternative voices

Gideon Baker 
10 Ethics and Politics in Contemporary Theory Between critical theory and post-Marxism Mark Devenney

11 Citizenship and Identity Towards a new republic John Schwarzmantel

12 Multiculturalism, Identity and Rights Edited by Bruce Haddock and Peter Sutch

13 Political Theory of Global Justice A cosmopolitan case for the world state Luis Cabrera

14 Democracy, Nationalism and Multiculturalism Edited by Ramón Maiz and Ferrán Requejo

15 Political Reconciliation Andrew Schaap

16 National Cultural Autonomy and Its Contemporary Critics Edited by Ephraim Nimni

17 Power and Politics in Poststructuralist Thought New theories of the political Saul Newman

18 Capabilities Equality Basic issues and problems Edited by Alexander Kaufman

19 Morality and Nationalism Catherine Frost 



\section{Morality and Nationalism}

\section{Catherine Frost}

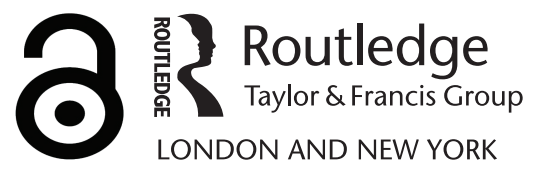


First published 2006

by Routledge

Published 2017 by Routledge

2 Park Square, Milton Park, Abingdon, Oxon OX14 4RN

711 Third Avenue, New York, NY 10017, USA

Routledge is an imprint of the Taylor \& Francis Group, an informa business

Copyright (C) 2006 Catherine Frost

Typeset in Sabon by

Newgen Imaging Systems (P) Ltd, Chennai, India

The Open Access version of this book, available at www.tandfebooks.com, has been made available under a Creative Commons Attribution-Non Commercial-No Derivatives 4.0 license.

British Library Cataloguing in Publication Data

A catalogue record for this book is available from the British Library

Library of Congress Cataloging in Publication Data

Frost, Catherine, 1968-

Morality and nationalism / Catherine Frost.

p. cm. - (Routledge innovations in political theory ; 19)

Includes bibliographical references and index.

1. Nationalism. 2. Nationalism-Moral and ethical aspects.

3. Nationalism-Québec (Province) 4. Nationalism-Ireland.

I. Title. II. Series

JC311.F76 2006

$320.54^{\prime} 01-\mathrm{dc} 22$

2005018117

ISBN13: 978-0-415-37899-4 (hbk) 
For Robin and Sean and Naoíse and Fionn

whose future this concerns 



\section{Contents}

Preface

Acknowledgments

$\mathrm{X}$

xii

1 Introduction

2 The worth of nations 11

3 Nationalism in Ireland 36

4 Nationalism in Quebec $\quad 52$

5 Bifurcated nationalism and the impasse in theory 64

6 Nationalism as representation $\quad 86$

7 Evaluating nationalism as representation 105

8 Applying the theory 127

9 Nationalism and social change $\quad 152$

10 The ties that blind 169

Notes $\quad 181$

References $\quad 193$

Index 201 


\section{Preface}

This project started with my own puzzle over what to think about nationalism. My family is Irish and I spent my youth in the Republic of Ireland. As a schoolchild I learned about the struggle for Irish independence, memorized the names of the heroes of the 1916 Rising, and was taught the Irish language upon first entering school. There could be no doubt in the mind of an attentive student that the birth of the Irish State was an achievement for which one should properly be grateful.

I emigrated to Canada with my family as a teenager. In Canada the future of the State is cast in doubt by the nationalism of Quebec, and the prevailing belief I encountered among Canadians was that nationalism was an undesirable doctrine of strife and dissent. This left me in conflict over what to think about nationalism as a phenomenon. In one country there was widespread acceptance of its legitimacy, in another there was a large body of opinion that felt it was harmful and dangerous.

If the question were put to me today, I would have to admit that I am indeed grateful for the achievement of an independent Ireland. Yet what am I supposed to think of this response? Do I need to liberate myself from an attachment to the idea of an Irish nation; something that I know was an object of indoctrination in my Irish schooling? Am I a bad Canadian if I think Quebec should have the option to go its own way, perhaps to develop itself as a separate political and cultural community?

My object in writing this book was to outline an understanding of the moral worth of nations that could account for my feeling that Irish independence was a genuine achievement, but that did not sanction every extreme to which nationalism has been taken in the past. I am aware of the stifling environment that nationalism can foster, as well as the violence and conflict it can entail. But I am not convinced that 
these difficulties are a necessary part of nationalism, or even that such conduct serves the ends at which nationalism aims.

The problem, as I see it, is that we lack a clear sense of what the ends of nationalism really look like. In turn, moral theorizing about nationalism has been held back by a tendency to rely on a truncated or bifurcated view of the phenomenon. Such theorizing struggles to come to grips with a phenomenon that refuses to conform to the categories developed to contain it. This book is an attempt to find a way out of this impasse. My hope is that it might help restore a fuller picture of nationalism, help explain why we should take nationalism seriously, and help clarify what we should (and should not) be expected to do about it. If it succeeds in making inroads on any of these items, it will have served an important purpose. 


\section{Acknowledgments}

I am indebted to several individuals for their guidance as this work proceeded. In particular, I am deeply grateful to Joe Carens for his support throughout the entire process. I also thank Melissa Williams, Ronnie Benier, and David Cameron for providing a critical combination of personal encouragement and healthy skepticism as the project evolved. And I offer special thanks to Will Kymlicka whose generous feedback on earlier and later versions, proved invaluable.

Tom Garvin, Declan Kiberd, Eiléen Ní Chuilleanáin, Gearóid Ó Tuathaigh, A.I. Silver, Macdara Woods and former Taoiseach Garret FitzGerald all had helpful discussions with me concerning the Irish and Quebec cases, and Will Coleman and Alain Gagnon in particular offered helpful advice. Chandran Kukathas and Bob Goodin provided valuable comments on the breakdown of major theories of nationalism, and I also thank Dan Avnon, The Hebrew University of Jerusalem, and The Harry S. Truman Institute for the Advancement of Peace, for discussions concerning national identity. The Montreal Political Theory Group and the Israel Association for Canadian Studies provided opportunities to present and discuss portions of this work, for which I am grateful.

The research in this book was made possible by funding from The Social Sciences and Humanities Research Council of Canada, the Arts Research Board at McMaster University, and the University of Toronto Munk Center for International Studies. I am grateful for their support and to Paul Fairie at McMaster for keen research assistance. The faculty and staff at McMaster University's Political Science department provided a collegial environment in which to finish this project, and I thank Heidi Bagtazo and Harriet Brinton at Routledge for making the publishing process smooth and efficient.

My family and friends have lent support of every conceivable kind to this project. My special thanks go to David Allaway, Michelle Bonner, 
Megan Kelly, Jenna Sindle, Dagmar Soennecken, and Toby Zanin for support both moral and intellectual. Thanks also to the FitzgeraldO'Flaherty clan and Gerry Buckley for my re-education in things Irish. And thanks to Larry Roberts for providing the essential life-blood of any scholarly exercise - humor, patience, and endless cups of tea.

In the case of my family I most particularly thank my parents, Bryan and Mary, for their steady interest - both practical and philosophical - in how the project unfolded. I also thank Robin and Sean Frost for preferring play-doh over philosophy, and I thank their parents, Bob and Johanne, for home cooking, belly laughs, and perspective. I thank my brother Nick for helping me shake my bookish obsessions once in a while, and my brother Stephen for reminding me that our humanity lies beyond anything we can define or perform, and has a dignity all its own.

Earlier versions of Chapter 1 appeared in 2001 as "The worth of nations" in The Journal of Political Philosophy 9: 481-502. I am grateful to Blackwell Publishers for permission to incorporate this material here. 



\section{Introduction}

It is remarkable to me that so much contemporary theorizing on nationalism pays so little heed to what actual nationalists have had to say on the topic. Perhaps this is in part due to the broad dismissal issued to nationalist writings by the influential theorist Ernest Gellner, who in the early 1980s confidently advised his fellow scholars that "we shall not learn too much about nationalism from the study of its own prophets" (1983: 125). Much though I admire Gellner's work, I respectfully disagree with this pronouncement. For if we do not turn to nationalist voices to help us understand the roots of the phenomenon - its deep motivations and aspirations - then we must rely on other scholars and theorists to represent them for us. Yet if we never check these representations against the original, we can never be sure that the nationalism these theorists are talking about is the same as the nationalism we face in everyday life. Since nationalists are rarely heard in their own voice in the theoretical debate, there has not been much opportunity to confirm how well these theories capture nationalist concerns. This makes the theoretical effort somewhat suspect from the beginning, and it contributes to deep divisions in thinking on the topic.

There is a second reason for going to the source rather than settling for a theoretical rendering of nationalist motivations. By looking at nationalist arguments we can ask whether they have something to say about the moral worth of nations that is missed in existing moral theorizing. As it now stands, nationalist arguments are studied mostly for their historical or sociological insights, but rarely as claims about political or social good. Yet I believe that these arguments reveal a genuine concern for the conditions of the populations involved and this insight may help us to recast our thinking on nationalism.

Moved by these concerns, I began reading the very nationalist writings that Gellner felt were "hardly worth analysing" (1983: 124). 


\section{Introduction}

I turned in particular to two cases that I knew to have a long and rich nationalist history - those of Ireland and Quebec. Both can trace their nationalist activism back over two hundred years and both had prominent figures and movements who served as leading voices for the nationalist cause. My goal in starting this work was perhaps overly optimistic. I hoped to identify a central theme to nationalist argument, and through it to gain better insight into what nationalists felt justified their claim and what they aimed at achieving. As it turned out, nationalist argument presented a more complex picture than I had anticipated, but in the end I believe the effort to make sense of this complexity yields its own rewards.

But of course, such work does not take place in a vacuum. There is much to be learned from existing theories of nationalism especially once we have an appreciation of how these ideas appeared in the thinking of nationalists themselves. Many existing theories of nationalism already recognize that nations can pay dividends at two levels. At the personal level they can provide benefits via a secure sense of one's context and a feeling of belonging and esteem. These benefits have been recognized in the work of theorists such as Will Kymlicka (1995), Charles Taylor (1995b, 1999), and Avishai Margalit writing with Joseph Raz (1990). But often these accounts stop there, at the individual level, and this leaves out an important part of the picture. Because of this, these accounts run into problems when individuals are attached to different national origins, as in the case of immigrants. If nationalism is justified solely at a personal or individual level, then everyone has an equal claim to seeing his or her nationality politically or socially established. This faces us with a situation of almost certain moral stalemate. ${ }^{1}$

There is also a collective level to be considered. At this collective level, theorists such as David Miller (1995) and Yael Tamir (1993) recognize that nationalism pays a dividend in terms of political efficacy. But they attribute this to the existence of affective ties between conationals, and promise that a richer kind of collective life will result. This account proves problematic however, because it cannot explain the origin of these ties without becoming circular - I have ties to my co-nationals because they are my co-nationals (Canovan 1996: 53).

So the first thing that distinguishes the approach taken in this project is that by turning to nationalist argument, it starts from a point that other theories of nationalism overlook. This gives us reason to hope we can bypass some of the intellectual cul-de-sacs that have stymied existing theories of nationalism. The second major feature of this project is that it employs a methodology that aims to keep 
theory close to the ground. This methodology, sometimes called "contextualism" involves using a case-study approach to help understand and evaluate moral phenomena. It's based on the belief that observing real-world experience can provide vital feedback into normative thinking, and it calls on the theorist to pay close attention to how events and ideas unfold in practice (Carens 2000: 1-6).

For this reason I focus on the experience with nationalism in two historical cases - those of Ireland and Quebec, as mentioned. However, what makes these two cases interesting from my point of view is not what makes them engaging for most scholars of nationalism. I am interested in the fact that some aspects of these cases are often thought to be morally uncontroversial. In Ireland, changing the political order to establish an independent state in the twenty-six counties is generally regarded as a morally legitimate measure, even though nationalist efforts to uphold a certain "character" for the population - affecting women's rights, language use, and economic development, for instance - proved problematic. In Quebec, efforts aimed at cultural self-preservation - such as regulating language use and fostering economic development - are often defended as legitimate, but changing the political order is considered more problematic. Because similar measures appear in a different light in these two cases I think they can help highlight factors that establish the moral standing of the nationalist claim.

In addition a distinction is commonly made between these two cases by designating Ireland as a case of postcolonial liberation, while viewing Quebec as part of an ongoing multicultural project. While there is some truth to this reading, there are too many historical similarities between the cases for this explanation to account for all the differences in how we evaluate their nationalist experiences. The ease with which this distinction is commonly accepted, then, raises more questions than it does answers. This means that their respective experiences provide a fruitful starting place for an examination of the national claim.

\section{Chapter outline}

In the next chapter (Chapter 2) I initiate this project by considering previous attempts to theorize nationalism. The chapter introduces the reader to seven major theoretical approaches, assesses their strengths and weaknesses, and uses them to establish a set of criteria that an account of the moral worth of nationalism should meet.

The following two chapters (Chapters 3 and 4) then look at nationalist argument in Ireland and Quebec from 1780 to 1950. 


\section{Introduction}

These chapters find that arguments in defense of the national claim fall into two major formulations, and moreover, that these two formulations are historically distinct. In the Irish case addressed in Chapter 3, nationalism first appeared as a claim to an independent legislature and nationalists argued that good government required legislators to share a stake in Irish conditions. But by the middle of the nineteenth century a second formulation of the nationalist claim appeared. This one focused on creating a strong national character so that a population could express itself and its conditions adequately and authentically.

Chapter 4 then asks whether similar formulations appeared in Quebec. As in Ireland, early Quebec nationalists argued that political representatives should share the conditions of the national population in order to adequately represent its interests. And again, by the end of the nineteenth century nationalist argument was focused on issues of national character (and in particular on language) as a source of authenticity and expression.

While the two formulations start out from different points when it comes to political and cultural life, Chapter 5 cautions against reading these differences as yet another nationalist dichotomy. Reflecting on current work in liberal-nationalism, it argues that this work is premised on a divide between the political and cultural aspects of nationalism that simply cannot be maintained. Theory in this area has developed along two divergent paths, yet neither seems to be able to deliver a viable solution. Instead, to overcome this impasse, theory should focus more closely on the political/cultural dynamic to nationalism and ask how the two sides of the national equation are tied together.

Chapter 6 then sets out to reconstruct the development of nationalist argument as a conceptual history in order to understand its dynamics and to look for common themes through this development. The exercise suggests that the second formulation of the national claim may amount to an inversion of the logic of the first and that the two are inter-related in a manner that cannot adequately be reflected in an approach based on dichotomies or bifurcation. Further, it suggests that the two formulations are connected by a common concern for representational resources. Nations can provide a shared frame of reference for both political and cultural representation, and for this reason they have a claim to moral standing. However, in order to serve their representational purpose, national frames of reference are also characterized by a need for selectivity, currency, and relevancy.

Chapter 7 takes the approach to nationalism that understands it as a claim about representational resources and evaluates it in light of 
existing theory in this field, including contrasting it with republican, multicultural, or post-national alternatives to nationalism. This exercise indicates the importance of establishing limits on a national claim, and the chapter suggests both internal and external limits that should play a part in a representational approach.

Returning to the original case studies, Chapter 8 asks what a representational approach can tell us about the nationalism that unfolded in Ireland and Quebec. Four main areas of interest for the chapter include the appropriateness of political independence; the conduct of nationalist governments; the role of multinational frames of reference; and the experience of minorities. While both cases have their successes and failures, it becomes clear that when understood as a claim about representational resources, nationalism is more constrained in practice than is always recognized.

Beginning in the mid- to late twentieth century both Ireland and Quebec went through a period of dramatic social change, yet the idea of the nation remains a powerful element in both communities. Chapter 9 argues that this process confirms that nations can handle a high degree of change without compromising their representational role. This suggests that from a normative point of view we need to shift our focus away from long-standing social or cultural traits as major markers of nationalism.

The tenth and final chapter reviews the overall arguments of the book and puts them into context by considering the inevitable risks we incur when we engage in representation. We should always be ready, it suggests, to revise our frames of reference in order to capture missing elements. Nationalism need not be hostile to this requirement, but if the line between establishing a frame of reference and reifying one is not observed, then nationalism can become the source of new representational problems.

\section{The argument of the book}

This book argues that while nationalism can focus on different objectives and concerns, one constant in nationalist argument is the role of a shared frame of reference as a representational resource. Frames of reference are important because they are a pre-condition for representation, both political and cultural. The main claim of the book is that nations embody a process that establishes and maintains frames of reference at a very large and very general level. If this account is correct, it suggests that nations are evidence of an adaptive capacity that enables us to re-configure our ways of thinking, 


\section{Introduction}

communicating, and acting together. Acknowledging this, however, does not give carte blanche endorsement to all nationalisms. There are conditions that a national frame of reference should meet in order for it to serve a population. These conditions include relevance (a frame of reference must reflect real circumstances), currency (it must be revisable), and equal moral worth (it must respect individual members of the population). In sum, the book argues that the grounds of nationalism lie in its role in representation, and that the limits of nationalism lie in the conditions for a useful frame of reference.

In pursuing this project I take a long view of the nationalist phenomenon, and cover almost two hundred years of nationalism in the two cases examined. In characterizing the nationalism that unfolded, I take my cue from the arguments of the leading figures and movements. This raises an important question. How seriously should we take the arguments of these elite figures as statements about normative political aims? Might such nationalism merely reflect a political project of the governing powers or elites, with the rest of the population swept along in its course? The difficulty with this reading of events is that it diminishes the agency and activism of a large portion of the population. Instead, one scholar, when examining the rise of British nationalism, made a point of addressing both its mass and elite aspects. Linda Colley's findings confirm that nationalism requires the support and involvement of a range of groups. Britishness took root as a concept, she stresses, because it resonated with the larger population, "not just because patriotism was recommended from above" (1992: 371). ${ }^{2}$ If we assume that Colley's analysis of the British experience touches upon a dynamic that plays out in other nationalisms as well, then we must be wary of suggestions that nationalism can be accounted for as an elite project. As Colley argues, the main ideas may have been voiced by elites, but to have significance they needed to engage the broader population. Without their participation, nationalism would have none of the transformative power it demonstrated in the British, or for that matter, the Irish and Quebec cases.

As noted in the chapter outline, the investigation in this project revealed that in the Irish and Quebec cases nationalism appeared in two distinct formulations. If, as I suggest, the second formulation amounts to an inversion of the logic of the first, then this tells us that the central claim of nationalism must be contained in what is common to both formulations. For this reason I suggest that leaning too heavily on dichotomies to make sense of nationalism can lead us into even greater difficulties. Focusing instead on commonalities leads us to consider the role of shared frames of reference in representation. 
Arguing that representational issues are at the center of many nationalist claims does not automatically establish anything from a normative point of view. Yet the claim that shared frames of reference are necessary to collective life, and that political structures should be sensitive to these needs, is not unique to nationalist argument. Similar ideas appear in the work of Nietzsche (1980), Arendt (1968, 1972), and Niklas Luhmann (1979). From these works we learn that, at their best, frames of reference serve to focus our attention on those aspects of reality that are most relevant, and therefore provide a kind of epistemic short-cut that manages the otherwise overwhelming potentiality of our world. At their worst they can obscure reality and handicap a population in its activities. Yet employing frames of reference is not really a choice, since in their absence we would have difficulty communicating about our world. How we build and employ these systems, however, is a matter of choice. So while nationalism does indeed raise a claim with which we should be concerned, we must also be concerned with the constraints on this claim.

The central idea developed though this work, therefore, is that the moral worth of nationalism arises in its role as a shared frame of reference that enables representation. The national frame of reference can serve as a mechanism for selecting and combining relevant information about a population's common circumstances. Nationalism attempts to establish this broadly held frame of reference by means of either the political order or the population's self-understanding and conduct. Since its moral worth is owed to the benefits it may secure for a population, nationalism can, under certain conditions, be an instrumental good. The capacity to create and re-create shared frames of reference (national or otherwise), however, is an attribute which is intrinsically valuable, in that it makes collective life possible.

\section{Definitions and terminology}

The choice of terminology is a critical part of any argument. Since discussions of nationalism are especially prone to problems in this area, I want to outline what I mean by a few of the basic terms I employ, and also explain why there are certain other terms that I avoid. For the purposes of this discussion, the term "nation" indicates an ideal type of community, rather than an actually existing one. "National," however is a qualifier than can be used to describe an attribute of a real community. "National" indicates that aspect of a community that involves a self-consciously shared history and future, some common association to a homeland or source-land, and 


\section{Introduction}

particular ways of relating to others that are seemingly best understood and appreciated by others within that community.

Because it refers to an idealized status, the nation does not lend itself to easy measurement or assessment. But we can talk about a population's sense of "nationality" or "nationhood," by which I mean that it understands itself as a national community and desires to have this self-understanding recognized and confirmed in its dealing with others. I prefer the term "nationality" to the more common "national identity" for two reasons. First, because identity is an ambiguous term, already overused in the literature on nationalism (Brubaker and Cooper 2000). Second, because nationality has an irreducibly collective dimension whereas "identity" can be used to suggest an individualized experience. It is the shared dimension of the national experience that I am interested in investigating here.

I should, of course, explain what I mean by the term "nationalism." The difficulty is that I would much rather wait and see how nationalists themselves understood this concept, and I am wary of prejudicing the discussion in favor of certain kinds of content or intentions. What I can say at this point, however, is that by "nationalism" I mean the doctrine that seeks the embodiment of a nation - that idealized community based on shared ideas, experiences and/or circumstances - as a concrete social, political, or cultural presence.

With these major terms addressed, I next want to explain my use of certain other phrases that I employ as part of this work. In the discussion that follows I talk about the national "claim" and suggest it may have "moral standing" under certain conditions, so let me explain what this means. First of all, I believe the moral claim of nationalism is related to, but distinct from, the logic appealed to by nationalists. It is not a claim in the sense of comprising the details of what people are asking for, but rather a claim on our moral understanding. Second, I have chosen to use terms like "claim" and "standing" because even where I argue that there is some moral worth to nations, I do not mean to imply that this moral value should prevail over other concerns. For this reason I am uneasy casting the discussion in the language of rights even though others adopt these terms. Since we know nations to be historically contingent, it strikes me that we place rights on shaky ground if we award them on this basis. If there is a right involved here it is a right to something more fundamental. Nationhood may, for the time being, be the chief instrument for realizing these rights in many situations. It may even be a remarkably versatile instrument under certain conditions. But I do not believe it merits the status of a right. 
The most we can say, I think, is that nationalism or nationhood may be an instrumental good in so far as it helps support morally desirable outcomes. If we accept Isaiah Berlin's proposition that there are a plurality of values and therefore of morally valuable outcomes (2002: 216), we must also accept that moral decisions will require us to weigh competing claims, and we must pay attention to how these claims play out in a particular situation. In advance of addressing any specific moral challenge, however, we can determine whether a moral claim has standing - that is, whether it should weigh into the process of decision-making at all. My goal is not to prescribe the precise moral standing nationalism should always and everywhere have vis-à-vis other things we value, it is only to argue that it has sufficient moral standing to merit consideration, and in some cases perhaps, accommodation.

I want to acknowledge, however, that I make one exception to this stance. In specifying that nationalism should be characterized by an equal respect for persons I am suggesting that a concern for a fundamental kind of equality should not be sidelined in favor of nationalist objectives. Of course equality can be defined more or less broadly, but I use it here to indicate equal freedom from civic restrictions. Such equality is, I argue, a pre-condition of the kind of moral conversation in which we must engage in order to assess the legitimacy of a nationalist claim.

Another term where there is room for confusion is that of "independence" as a political status. The way I use the term, independence is not an absolute measure - you either have it or you don't - but rather can be present in varying degrees. So when I ask about the appropriateness of independence for Ireland or Quebec, what I am concerned with is the move towards increased independence and autonomy, and with how far that process should go. I am concerned to clarify this term because for some people nationalism necessarily implies the goal of a nation-state. This is not my understanding of nationalism. If nationalism were defined in terms of the goal of complete statehood this would, for instance, lead us to undervalue a vast portion of what is normally accepted as Irish nationalist history. In fact, if it were defined exclusively by state-seeking activity, Irish nationalism would barely register throughout much of the nineteenth century when constitutional and cultural nationalism flourished. While in Quebec, we would have to dismiss the role of leading figures such as Louis-Joseph Papineau and Henri Bourassa, who articulated their national claims within a Canadian context. Clearly such an understanding of nationalism misses something important. 


\section{Introduction}

Finally, I do not discuss nations as ethnic groups. This is because I don't believe nations are ethnic groups or vice versa. I understand "ethnic" as an anthropological term for identifying population groups based on descent. ${ }^{3}$ While ethnic groups also have their unique social forms, this is not sufficient to make nations synonymous with ethnicity. As Ernest Gellner observed there might be plenty of social groups in the world that have potential for nationhood, but only a fraction ever assert themselves in this way (1983: 49). Ethnic groups may, therefore, as A.D. Smith has argued, provide fertile ground for the birth of nations (Smith 1988) but what makes a nation a nation is ultimately something beyond ethnicity. ${ }^{5}$ These, then, are the terms I will use (and those I will avoid) as I pursue this discussion.

\section{Conclusion}

This is an ambitious project even given the considerable work that has been done in this field already. Still, in reviewing that work I could not escape the feeling that the pieces were not all fitting together. Either the nation was cast as so essential to our ability to survive and thrive that we could hardly do without it, or it was cast as a dark inheritance that we needed to grow out of - or sometimes it could even manage to be both. From what I had seen of nationalism in my own life I understood it to be a powerful force when it came to bringing a population together, but I believed its course was still directed by the way people chose to employ it. I wanted to see an account that reflected this dimension of the phenomenon, as well as provided some guidance on how to engage with nationalism in a morally responsible way. What follows is my effort to develop such an account. 


\section{The worth of nations}

On what (if anything) do we base the moral worth of nations? In the discussion that follows I identify and critique seven theory-types that concern themselves with this question. Six suggest a certain moral worth to nationalism and one suggests the absence of such worth. My main claim in this discussion is that these theories, while right in part, prove unworkable on some dimension. I attempt to outline where the particular problems lie, and based on this analysis I specify criteria which an account of the moral worth of nationalism should be expected to meet.

Nationalism does not appear in the same light in each of these theories. Understanding what these theorists mean by nationalism therefore becomes part of the exercise. However, in most cases we can say that nationalism involves a call for expanded political or cultural autonomy for a population that shares certain political or cultural circumstances. The nation, meanwhile, appears in these theories as a largely socially constructed set of relationships that the population involved tends to regard as a fundamental part of their collective lives.

I begin the discussion with the family of theories that answers the question of nationalism's moral worth in the negative. These are theories that see nationalism as catering to the darker side of our natures. These "dark side" theories point to the problems of ethnic conflict, to the subordination of the will, and to the need for stability and order. Any one of these factors is thought sufficient to render nationalism a dangerous doctrine, and they suggest that while its appeal is undeniable, its morality is dubious.

Second are remedial right theories which, in effect, attempt to bypass the question of nationalism's moral standing by focusing instead on the question of rights. They argue that where rights are harmed in a systematic and group-wide way, there may be a case for secession. However, this approach has unavoidable consequences for 


\section{The worth of nations}

the status of nations and the movements that champion their cause. Somewhat optimistically, remedial right theories suppose that the issues raised by nationalism can be solved without having to address nationalism head-on. This position, I argue, proves untenable.

Third are what I am calling "dysfunctionalist" theories. These are theories that argue that nationalism helps us cope with the demanding economic and social conditions of modernity. It does so by providing a new social structure attuned to the knowledge and mobility requirements of the new economy - both domestic and international - and by compensating for the ills of anomie and inequality. Such theories suggest that without nationalism we would, at a minimum, be unable to realize the promise of modernity in all its industrial and liberal glory, and that we could even face some kind of social or economic collapse without the nation to shelter us.

Fourth are social trust theories, which suggest that shared nationality tends to foster relationships that enrich our moral and political lives by boosting the essential ingredient of trust. Trust born of common nationality is thought to be the key to deepened commitments and to the realization of distributive justice.

The fifth type - self-esteem theories - is akin to the "dysfunctionalist" type of theory in that it suggests that we cannot get along very well without healthy nations. But these theories connect nationalism to the more intimate arena of self-esteem rather than to economic or social structures. Secure identity and belonging is so fundamental to individual wellbeing, they argue, that whatever serves to ground these factors acquires value in virtue of its contribution to self-esteem, including nations.

Sixth, I consider an autonomy-based theory that grants, somewhat obliquely, a certain moral standing to national cultures. Will Kymlicka holds that "societal cultures" - which include national minorities provide a way of making choice meaningful, and are therefore essential to individual autonomy. Consequently, everyone should have access to a secure societal culture, as this is the foundation of personal autonomy.

The seventh and final theory-type views nationalism as a means to cultural preservation. Nationalism has moral worth, it argues, because it promotes intergenerational memory, honors ancestral endeavors, and supports an enlivening and potentially elevating desire to leave a lasting mark on the world.

I will set out each of these theories as a separate claim about the moral standing of nationalism, and discuss how they fare on this score (though particular authors often make use of elements from more 
than one of these theory-types). This is not intended as a comprehensive reading of any one of them, however, and I don't pretend to be able to do justice to them in the space allowed. What I aim to do is identify what each has to say about why we should (or should not) accommodate the claims of nationalism when we encounter them, and then consider how well these answers hold up under scrutiny. I suspect that they all point to some dimension of the truth about nationalism, but it is just as important to know the limits of these approaches and where they fall short as explanations of the worth of nations. An awareness of how these accounts run into difficulties may, in turn, help clarify what we should be looking for in a fully workable theory.

\section{Nationalism as our dark side}

Ernest Gellner called the account of nationalism that reduced it to "atavistic forces of blood or territory" the "Dark Gods" theory, and he promptly dismissed it as untenable (1983: 130). Yet it is not so easy to banish those associations and some theorists still regard "bloodand-soil nationalism" as the only credible reading of the phenomenon (Barry 1999: 131). So while Gellner is right to remind us that barbarity is not unique to the age of nationalism, it is still legitimate to ask whether nationalism has a tendency to feed (or feed on) backwardness, hatred, repression, or chaos. In other words, is nationalism about indulging the darker side of our natures? And even if nationalism could be dissociated from the evils of ethnic hatred or totalitarianism, our basic interest in living in a system characterized by stability and predictability might still militate against regarding nationalism as anything but downright dangerous.

Before I address the arguments of these theories, I want to point to a problem in the way they are sometimes employed. This idea of nationalism as catering to our darker natures is often used to describe movements that challenge existing states. But it is implausible to apply "dark side" theories as if only those already excluded from the club of states can fall victim to the contagion. If that is how the theories are employed, the approach looks suspiciously self-serving. Yet the community based in a purely civic attachment is an ideal that has rarely, if ever, been realized. So if there is little chance of realizing a truly neutral order and the civic nation is, as Bernard Yack has argued, a myth (1999), then nationalism returns as a pressing question for all states, whether existing or aspiring. If it is morally illegitimate then the chances are we are all implicated in its guilt. 


\section{The worth of nations}

But if we accept that they apply equally to the nationalism of existing and aspiring nation-states, "dark side" theories are worth investigating. To make the case against nationalism "dark side" theories come in at least three variations, based on different accounts of what constitutes darkness. The variations I review here center on ideas of progress, the will, and social order. In the case of progress, the concern is with the maximization of social utility via enlightenment and liberalization. In the case of the will, the concern is with selfdetermination as the highest good, and questions how this can be preserved in a system that involves multiple wills - to wit, politics. In the case of social order, the concern is with the value of stability and predictability as a crucial pre-condition of other social goods. As noted, nationalism can be variously construed as threatening progress, subjugating the will, or undermining the basic order of politics, and therein supposedly lie its dark tendencies.

John Stuart Mill recognized the value of nations as the setting for representative democracy, but he also felt that they could be obstacles to the progress of society by encouraging sulking over innovation (Mill 1972: 395). On Mill's terms the utility yielded through progress is what justifies both a liberal order and representative democracy. Thus where it opposes a liberal and progressive order nationalism should be considered a retrograde or regressive force. Canadian Prime Minister Pierre Trudeau, for example, used such logic to criticize what he saw as the backwardness of Quebec nationalism. ${ }^{1}$ Yet contemporary Quebec nationalism is closely associated with the liberal and progressive "Quiet Revolution" in that province. So the first thing to observe is that nationalism is not an inherent enemy of social progress. At most, it depends on the particular circumstances involved.

However, there is a more fundamental problem with this account of nationalism's moral standing. The problem is that it assumes a linear and recognizable path to this thing called progress, and assumes that the socalled advanced nations know better how to run society and politics for the general good. Thus the Millian-inspired condemnation of nationalism as backwardness cannot hold as a moral evaluation without also endorsing a kind of civilizational hierarchy that invokes the specter of imperialism in all its misguided optimism. And if we cannot legitimately maintain a political order on the grounds of imperial-style progress, the corollary would seem to be that neither can we call illegitimate those political projects that break with the established order, simply because of claims that this order embodies progress.

Still this is not sufficient to exonerate nationalism of its dark associations. Elie Kedourie, for instance, held that nationalism was 
based on an ultimately self-negating subordination of the will to a greater social whole. ${ }^{2}$ The central role that will played in the new nationalist ethic, he argued, meant that nothing could legitimately obstruct its national embodiment. As a consequence, nationalism "By its very nature... ran to extremes" (1993: 10).

But there is reason to think that the nature of the phenomenon is more complex and more varied than this "triumph of the will" argument suggests. Without denying that nationalism has its extremist and absolutist forms, it still needs to be established that this is the only and inevitable form it can take. In other words, if there are instances where nationalism has not led to rampant political excess or relied upon the subjugation of the will this would disprove the thesis. I would submit that the nationalism of contemporary Quebec is one such case. Establishing this point is not enough to make nationalism a morally desirable doctrine, but it does mean that the critique of nationalism that claims it requires the submergence of individual will does not hold against all varieties of nationalism.

Kedourie raised another concern regarding nationalism, however. This one concerns the idea that nationalism has a built-in chaos factor. By endorsing the idea of nationalism we are opening Pandora's Box and no one will be spared the consequences, or so the argument goes. Ernest Gellner reinforced this idea of the insatiability of nationalism with his famous argument that there simply isn't room on earth for all the potential nations that are out there (1983: 2). Allen Buchanan uses a similar formulation (he calls it the "Infeasibility Objection") to rule out the legitimacy of secession-seeking national self-determination, suggesting that our common interest in stability overrides any such claims (1996: 291-3, 1997: 46-7).

I think there is some truth to this argument. Most nationalist movements are seeking some kind of change, and change undeniably involves disruption. But order and predictability are not absolute values. We often decide that we are better served by systems that are open to change. Why else would we hold regular elections? To establish the legitimacy of the existing international order on the basis of the fact that it is precisely that - existing and orderly - is to take up a Hobbesian view of relations in the international sphere, and makes of the international system a new Leviathan.

Allen Buchanan may offer us a Lockean-like escape clause from this system when he argues for the legitimacy of secession where there is rights abuse, but like revolution, this is a rare and extreme recourse in Buchanan's world. Where the abuse is not sufficiently widespread or clear-cut, change is not justified. Like Locke's lone revolutionary, 


\section{The worth of nations}

titleless or insufficiently victimized national groups can do little but “appeal to Heaven” (Locke 1960: 426). I will return to Buchanan's arguments in a following section, but here I want to acknowledge that the doctrine of nationalism certainly involves change. While prudence argues for making changes as painlessly and responsibly as possible, it cannot make change - no matter how much of it is involved - inherently wrong. As with the argument concerning the subordination of the will, the most this argument can do is circumscribe the way in which nationalism can be legitimately pursued. It is not, I believe, sufficient to render it morally wrong.

In the end, these "dark side" theories of nationalism are not as misguided as Gellner suggests, but neither do they score a decisive victory against nationalism. It is legitimate to be concerned with stability, individual will, and even progress, but each of these can become harmful in its own right if we construe them as moral "trumps." Unless nationalism cannot but descend into chaos, repression, and backwardness - and this characterization is not borne out by historical experience - then we cannot dismiss it out of hand. Therefore, we must continue to pursue the question of its moral worth in instances where these factors are not present.

\section{Nationalism as remedial right}

If the best that can be said for the "dark side" theories is that they tell against some forms of nationalism, then we are left with the question of whether there are other instances where nationalism is legitimate. One instance where nationalist claims are granted more consideration is where national independence is seen as a way for populations to escape a systematically abusive or exploitative situation. Allen Buchanan's remedial right theory of secession is an example of this logic at work. ${ }^{3}$ Before I discuss Buchanan's account, however, I should first acknowledge that he does not actually set out to make a case for the moral standing of nationalism. ${ }^{4}$ Still, nationalism is more often than not the doctrine that sets afoot the kinds of claims that Buchanan is addressing, and to that extent, what he has to say about those claims has a bearing on the standing of these movements.

Buchanan argues that where there is a clear case of abuse or exploitation of a group, and where there is a valid claim to territorial title, and where withdrawing the territory in question would not compromise the rights of others, and where there is "no reasonable prospect of relief short of secession," then secession can be a legitimate action (1997: 44). He suggests there may also be instances where 
cultural survival justifies secession, but these are very rare and again require that the seceding group has no other recourse, and that it has legitimate claim to the territory that it wants to take with it. But since all habitable territory on earth is already considered to be under the valid title of some state or another, it seems unlikely that circumstances will ever arise to meet Buchanan's requirements in this category. ${ }^{5}$

The rights abuse formula does not run into the same territorial roadblock, however, because in Buchanan's account it serves to overturn title to territory as part of the remediation package. Buchanan also rules out the idea of secession being justified by simple consent or rather, by the withdrawal of consent to participate in the existing state. Buchanan believes an individual's consent does not carry with it valid title to territory and so while a group may wish to secede, and under consent theory, should be allowed to do so, the title to the land they occupy would remain with the prior state. Territorial title thus becomes the linchpin of any secession effort. Where it is not a case of liberating a conquered territory, it seems that in the vast majority of cases territory can only be transferred to the exiting group when the original title holder negates it through abuse, or voluntarily relinquishes it.

As noted, Buchanan rules out national self-determination as grounds for secession, and in addition to the main problem of territorial title, he cites two objections. The "Infeasibility Objection" repeats Gellner's argument about lack of space and the proliferation of conflict and instability. The "Equal Respect Objection" questions why nations should get special treatment when there are many significant sources of identity for individuals in modern society (1996: 293-9). The "Infeasibility Objection" I have already addressed, in so far as it concerns the value of social order. With regard to the idea of "feasibility," Buchanan's argument here seems to rest on a conviction that there is a minimal critical mass for effective sovereignty, but I have yet to see any evidence to support this common claim. With all the complex forces that affect the viability of political authority and economic performance in the current era, why argue that size is such a deciding factor? Given heightened international interdependence sovereignty is increasingly circumscribed for even the mightiest of states, meaning a more level playing field for all concerned. In the face of these developments there needs to be some more convincing evidence provided for the "Infeasibility Objection" before it can be taken seriously.

The "Equal Respect Objection," however, does raise a significant challenge to the recognition of nationalism as a doctrine. But it merely 


\section{The worth of nations}

amounts to asking the question that Buchanan uses as an essay title: "What's so special about Nations?" (1996). Buchanan is here taking aim at theories of nationalism that defend its claims on the basis that it provides a valuable source of identity, belonging, and esteem. $\mathrm{He}$ requires, rightly I think, that more than this must be provided in order to validate the doctrine in its fullest implications.

To sum up: under Buchanan's account nationalism is associated with a legitimate cause effectively only when it serves a group with a valid claim to remediation and where the group either already holds, or has claim to hold, valid territorial title. And it should be reiterated that it's decidedly not the nationalism but the remedial right that's doing the work here. Next, I want to consider how well this account works and ask what it can tell us about the worth of nationalism.

First, it is necessary to clarify the role nationalism plays in this account. As noted, its worth is decidedly derivative, but I think some worth needs to be acknowledged. If nothing else, nationalism is the movement that points people to a way out of their abuse or suggests a means to reclaim their rightful territory. But I assume Buchanan would be uncomfortable with even this minimal concession to the moral worth of nationalism. This is because he wants to argue for national secession in some instances without acknowledging that there is anything special about nations, fearing the implications of the conclusion that nations or nationalisms have a moral claim of their own. Clearly this is a tricky position to maintain and I think his remedial right theory ends up in certain inconsistencies as a result.

Take the issue of territory for instance. His attention to this most basic of considerations is certainly welcome, however, I don't believe he can maintain a position that separates political consent from territorial title. If, as a group, we can bring territory into the state by our consent to participate, why can't a group take some of it out again, if it opts to exit in favor of a new political project? Why is political title to territory a one-way street? There may be terms to such exit; including for instance, compensation for loss of shared resources for the remaining population. But these concerns constitute conditions on, rather than prohibitions on, the recovery of title.

Consider, also, the ambiguity of Buchanan's argument for restoring stolen lands to independence. If nations are not special, then why worry about restoring their political independence? Why isn't it sufficient to, say, compensate for losses and guarantee equal treatment of the newly incorporated national minority? This outcome would have the virtue of causing less upheaval. One could object this might encourage attempts to take over other people's lands. But again, if 
nations are not special and the outcome is bigger (and perhaps more viable) and ultimately non-discriminatory multinational states, then while we can criticize the means of expansion, once it has happened there are compelling reasons to leave it be. And while we might agree that some punitive damages are in order, if we deny that there was something special about this group's independent cultural and political life, we have no reason to make restoring that independence a special priority. It is because we feel that there is something more at stake in these cases that we cannot consider such an outcome morally acceptable. Buchanan's theories fail to capture what this added value of the nation might be.

In the end the remedial right theory suggests that nationalism can, in some cases, serve a worthy cause. But in most cases it depends on other people's abusive actions to trigger this validation. Seeing nationalism as legitimate-by-association when it coincides with certain narrowly defined political projects is still a step up on the position articulated in the "dark side" theories discussed earlier, yet this approach still does not come to grips with the central question of the moral worth of nationalism. Even if we conclude that nationalism has derivative worth where it serves the cause of remediation, this still falls short of an adequate moral assessment. Meanwhile, the restoration of statehood to conquered, exploited, or even endangered peoples is, I believe, inconsistent with a position that denies nations any special political standing on prudential or principled grounds.

\section{Nationalism as dysfunctionalism}

Certain sociological or historical accounts suggest we should understand nationalism as a functional corollary of the modern social and economic setting. This approach suggests that nationalism facilitated the arrival of modernity by reconciling the individual to the conditions that modernity brought about. Whether nationalism first made modernity possible by producing individuals attuned to its requirements, or whether nations were an adaptive response to the conditions already created by modernity, the same basic relationship stands: modernity makes nationalism viable and nationalism makes modernity workable. This is a functional rather than a causal relationship, and it presumes a level of interdependency in the absence of which neither side could flourish. By extension, I will argue, this approach suggests a kind of dysfunction, whereby we can't be expected to thrive without our nations, and this dependency underpins nationalism's claim to moral standing - as that which keeps us going in modernity. 
Perhaps the classic example of such an account of nationalism is that put forward by Ernest Gellner in Nations and Nationalism (1983). Gellner relates the rise of nationalism to the requirements for an effective education system to support a modern industrial society. The homogeneity that a common high culture can secure is a necessary condition for economic survival, and this "inescapable imperative" ultimately "appears on the surface in the form of nationalism." The nation is one of modernity's most innovative tools for productivity. In Gellner's view, what it produces is industrial man - mobile, literate, and ready to face a division of labor that is "complex and persistently, cumulatively changing" (1983: 24-39).

Gellner is not alone in attributing nationalism's rise to economic developments in the modern era. Tom Nairn, for instance, concludes that the origins of nationalism lie "in the machinery of world political economy." In the face of marginalization and inequality, nationalism acted as a "compensatory reaction." It is a kind of "pathology" but one that equips people to face "the ordeal of 'development" (1981: 335-59). In Nairn's view, nationalism serves an important purpose as an international economic leveling mechanism, but it is the regrettable fact of inequality that dictates our need for it in the first place. $^{6}$

The two accounts discussed earlier, while they express the relationship differently, have in common the belief that nationalism serves some necessary purpose that arose only in modernity. What does this suggest about the moral worth of nationalism? Perhaps first it should be acknowledged that the examples I have given are both sociological theories and as such, they make no pretence to provide moral direction. ${ }^{7}$ But it is not far to go from the descriptive claim that nationalism is a functional necessity in modernity to a prescriptive argument which holds that nationalism has moral worth since it holds together the body and soul of modern society. If this is the prescriptive corollary of "dysfunctionalist" theories (and theorists like Charles Taylor have already borrowed heavily from this approach ${ }^{8}$ ), then it is, I think, fair to consider this position for its moral implications.

Again, the claim is that nationalism serves to compensate for the difficult conditions of modernity. The strongest statements of this argument, such as Gellner's, claim that nationalism serves to forge a populace better suited to the requirements of modernity. Under nationalism, a populace can function effectively even in the absence of those strong social systems and predictable economic behaviors that had held societies together and kept them running smoothly in previous eras. 
But buried within this argument is another idea. This idea suggests that nationalism is not just functional in the Gellnerian sense; it is in some ways indicative of dysfunction. We need nationalism because we cannot deal with life on the scale in which modernity presents it to us: that is, a global scale. Nationalism, then, is in some sense an admission of failure. It is a concession to our limited capacities and our limited imaginations. We can only extend those capacities by means of a solution that reduces the scale down to more manageable proportions, compensating for our shortcomings. Gellner uses an analogy that poignantly illustrates this idea. He talks about modern man as "an artificially produced or bred species which can no longer breathe effectively in the nature-given atmosphere." Nationalism, he tells us, is the "breathing chamber" (1983: 51) that keeps this fragile species alive.

Though hardly flattering, I think that this account captures an important truth regarding our need to keep life to a manageable scale. But my concern is that any defense of nationalism based in this account rests to a great extent on the debilitating consequences we would face in its absence. By accepting this account we may find ourselves in a situation where we can almost never legitimately challenge nationalist claims or conduct. For to attempt to impose limits in an effort to curb more wayward forms of nationalism would mean, under "dysfunctionalist" logic, that we run the risk of undermining the essential economic or social fabric of a society. Surely then the presumption should be in favor of nationalism? Or so the stronger statements of this approach would seem to suggest. ${ }^{9}$ Given that, as the "dark side" theories point out, nationalism can take on undesirable forms, it seems to me that we need to be able to specify conditions under which nationalism loses its special standing. So although the approach that stresses the functional connection between modernity and nationalism may have great descriptive power from a historical or sociological viewpoint, this does not mean we should accept it as the basis for prescriptive assessments.

Furthermore, while this account credits nationalism with considerable value in the context of modernity, it is a compromised kind of value. As Gellner illustrated, the moral worth of nations is in large part a product of our unenviable circumstances. Is there any great value to nationalism if it's part of a system that is productive but inescapable? In other words, the account that casts nationalism as modernity's "coping technique" manages simultaneously to underand over-play its importance. It does so by casting nationalism both as something that merely re-orders our social systems for productivity 
reasons and also as something that preserves us from the adverse conditions of modernity.

More to the point, moral theorizing about nationalism should not start out from the perspective that we really can't do without it. For if that is the case, the discussion is over before it begins. As with Gellner's "breathing chambers," we may lament our circumstances, but we can hardly contemplate leaving them. Unless we mean to give carte blanche to nationalists, we need to keep open the possibility of the denial of nationalism or nationalist claims. This means we must look elsewhere than to "dysfunctionalist" theories for a guide to the moral worth of nationalism.

\section{Nationalism as social trust}

Another way of arguing for the moral worth of nationalism is to claim that nationality supports relationships that enrich our moral and political lives. The common bond of nationality, it is said, deepens commitments and obligations between those who share in it and also provides the essential "motivating force" behind our civic commitments (Scruton 1990: 303). I call this the "social trust" defense of nationalism.

Yael Tamir uses this approach to argue for a version of nationalism that stays within liberal bounds and that is enacted primarily within the cultural arena. Drawing on Dworkin's account of "associative obligations" (1986: 195-202). Tamir argues that "deep and important obligations flow from identity and relatedness" (1993: 99). She applies this to nationalism to conclude that membership in a nation generates deeper moral relationships than can be derived from "general moral duties" (1993: 134). For this reason it has moral value.

David Miller uses a similar argument in his defense of nationalism, but goes further than Tamir by saying that under the conditions of modern economics the level of moral commitment required for a just democracy is unsustainable without the solidarity born of common nationality. A sense of common identity and shared beliefs, as well as a history of participation in the joint project of politics, foster a level of social trust that in turn makes redistributive measures possible. It is advisable then, to conduct politics in ways that tend to reinforce nationality where it coincides with the state's redistributive responsibilities, and this includes protecting, perhaps promoting, the national identity and requiring that immigrants "come to share" in that identity (Miller 1995: 26).

Clearly there is something to this line of argument. A shared national identity can make politics simpler by removing one potential 
source of distrust. It's also true that most of us do feel some special obligation towards those with whom we share a country. Although it can be hard to establish how much of this is attributable to being part of a shared political project - in which case, bare statehood can do the job - and how much to the pre-political national connection. In other words, it is still not clear how obligation arises from co-nationality.

So the first objection to note is that if nationalism's moral worth arises in the social benefits it makes possible though social trust - both in psychological and material terms - we still need to be sure that existing states can't generate the same results. Otherwise why not build up social trust around the existing state project, whether national or not? Even Miller's own championing of the British cause seems to support this position, since for many people Britain is more of a multinational than a national project. In fact, one commentator has suggested that an approach like Miller's would have provided grounds for Britain to veto Ireland's secession from the United Kingdom (O'Leary 1996: 447). This strikes one as a peculiar endorsement of nationalism.

But, in fact, this is nationalism - and the nation Miller wants to see confirmed is a British one. Yet is it necessary to endorse nationalism in order to uphold the project of a socially and economically progressive British State? Miller would argue that you are unlikely to get those results without a shared national identity. Perhaps this is the case, but this still leaves a significant step in the argument obscure. Why is it that nationality can produce a level of trust that citizenship cannot? What is the alchemical power of such attachments that they can turn co-existence into commitment?

Miller may be right about the trust dividend of common nationality, but he hasn't spelled out how this dividend comes about. Next, let me address what I see as some of the other ambiguities of social trust theories. The first of these concerns the question of scope. In other words, who gets counted into the national community and therefore into the bonds and rewards of obligation? National ties are based on an "imagined community" not just in the sense that we don't personally encounter those to whom we are obligated, but also because we imagine these communities into being. But if that's the case, why not imagine the whole world as your community? Or at least try to work upwards in scale? ${ }^{10}$

Benedict Anderson - who gave us the term "imagined community" also suggested that such imaginings were ultimately based on the geographically specific political circumstances of these new communities (1991). However, if we look to shared political circumstances to 
ground our national imaginings, then we return to the problem of distinguishing states from nations and must explain why nations produce a different kind of moral relationship. Or to put it another way, if they are not based in geo-political circumstances such as state borders then how do we determine the boundaries that define our nations? If the answer is "By asking whom we share an identity with," the argument is in danger of becoming circular. To the question "What makes our co-nationals special (and therefore entitled to our trust and obligation)?" we can only answer: "They're our co-nationals."

Margaret Canovan makes a similar observation on the circularity of culture and membership with regard to Yael Tamir's attempt to separate nation and state (1996: 53). Canovan criticizes Miller and Tamir for too quickly endorsing nationalism yet she would agree that we have underestimated its role in constituting moral communities. Canovan argues that we should understand nationhood as something that mediates between people in a way that gives political authority and political community a sense of naturalness critical to democracy, liberalism, and social justice. For this reason she sees liberalism as "parasitic" upon the social and moral resources that nations can generate (1996: 41). She adds, however, that the "dialectic" of nationhood (1996: 106) means that nationalism will undermine itself even as it propagates. So she concludes that the "likely costs are so great and the benefits so uncertain" that while we may recognize it has significant benefits where it is "actually established," we should not endorse national self-determination as a general principle (1996: 124).

Aside from questions of whom we trust and why, there is also a legitimate question to be raised about the value of trust itself. Both Tamir and Miller take it to be a good thing, because of the attachments and obligations it grounds. But trust can also be the basis for relations of injustice and exploitation (Eisenberg 1999). Relations of deep trust can go hand in hand with established hierarchies or entrenched patterns of discrimination that we don't necessarily want to endorse.

Moreover, there is nothing inherent to internal bonds of identity and trust that prevents them from also involving indifference or even hostility to outsiders. If your claim to participate in the social benefits of the national project is derived from how my co-nationals and I feel about you, then what happens if we decide we don't trust you, or identify with you? As a newcomer, an immigrant is dependent upon those who already share a nationality to acknowledge that he or she has become enough like the rest to belong among their number. Prior to extending that trust, those who share a nationality have limited 
obligations to outsiders. ${ }^{11}$ And it is not clear to me whether one of those obligations is to let them in, even when they live alongside us. To make a case that they are entitled to share social benefits because they contribute to the economy, cohabit in our state, or even simply are dependants on our doorstep, requires a basis for social justice other than nationality. So either we base redistributive justice on some other obligations, or we leave open the possibility that we can have a damaging failure to extend trust.

I agree with Miller and Tamir when they argue that nations are ethical communities, but I am not convinced that they have given us a complete account of their moral basis. I also think there is considerable evidence for the supposition that shared nationality makes the job of politics easier and more effective (Moore 2001). But it's still an open question whether the kind of politics that will be pursued is something desirable. In short, I think the social trust account of nationalism is still not adequate to explain the moral worth of nationalism. For one, it fails to show why nations can yield relationships that states cannot. It also fails to explain why the boundaries of nationality fall where they do, and why they cannot simply be reimagined at will. And finally, it is not clear that the outcome of greater trust will always be greater justice. Thus for all the insights they provide, social trust theories still seem to leave significant gaps in their account of the moral status of nations.

\section{Nationalism as self-esteem}

It is not only at the broad social or economic level that nationalism is thought to pay a significant dividend, however. Nationalism has also been credited with upholding personal self-esteem in the modern setting by providing a secure sense of belonging and a means to recognition and self-respect. This defense of nationalism's moral worth has much in common with "dysfunctionalist" theories when it argues that under the circumstances of modernity we need nationalism to compensate for the demanding changes being introduced. In this case however, the theories are concerned with systems of identity and personal status more than with industrial organization or broad-based social patterns. Put another way, this account is concerned with the working of the ego, not the economy.

Charles Taylor is arguing from this perspective when he claims that the transition to modernity involved changes in the concepts of time and social order - or what he calls the "social imaginary" - that made the achievement of stable and secure self-esteem considerably more 
difficult (1999: 224). This combines with uneven international development, leading domestic elites to suffer from feelings of inferiority when they compare their lot with that of their counterparts in other parts of the world. Their response is to defend their self-respect via a "call to difference" which in many cases is expressed as nationalism. What is at stake here is "a matter of dignity, in which one's self-worth is engaged" (Taylor 1999: 224-34), which explains its visceral power.

Margalit and Raz take a similar tack to Taylor's when they argue that the "moral importance of the group's interest depends on its value to individuals" (1990: 450). They go on to give reasons why "encompassing groups" like nations are especially valuable to individuals. One reason is that when membership "is a matter of belonging not achievement," it meets our need for identity "at the most fundamental level," and secure identity is, in turn, an important factor in individual wellbeing (1990: 447-50). Indeed elsewhere, Margalit, writing with Moshe Halbertal, says that an individual has "an overriding interest in his personal identity," and that this interest grounds his or her right to see the cultural context of that identity preserved. Thus a concern for "individual dignity and self-respect" motivates our concern for the nation (1994: 499-505), since nationality is a kind of encompassing identity.

Neither Taylor nor Margalit and his co-authors Raz and Halbertal are suggesting that nationalism's association with identity makes it morally unassailable. Margalit and Raz, for instance, conclude that national self-government cannot be "insisted on at all costs" (1990: 461). What these accounts have in common, however, is that they point to the instrumental value of nationalism and suggest how this value arises in its ability to support - perhaps even restore - self esteem.

Does this work as an account of the moral worth of nationalism? We have already encountered possible objections to this approach in the writings of Allen Buchanan. His "Equal Respect Objection" asks why nations should get special consideration as identity- and esteemsupporting groups. Margalit and Raz's attempt to define encompassing groups may have been an effort to anticipate such objections, but it's not hard to imagine groups other than nations that fit their criteria, in which case identity and esteem can't account for the distinct moral standing of nationalism. ${ }^{12}$ Taylor even winds up including religious fundamentalism as another possible response to the dignitythreatening "waves of modernity" (1999: 239-40), making it difficult to claim nations have a unique capacity to shelter identity and esteem. In the end, I think Buchanan's objection holds against these theories. If the value of nationalism rests on its connection with identity and 
esteem, it still needs to be explained why national identity is a special case among identity types, and how this justifies nationalism a place on the political scene.

But even if we accept the argument that nationality is especially valuable to individuals because of its role in identity and self-esteem, this still may not translate into a workable defense of the moral worth of nations. First of all, there is the problem of making emotional security the yardstick for moral success. Since it is a subjective condition anyone can use it to question the legitimacy of a regime under which they feel their dignity is not sufficiently respected. To maintain legitimacy under this regime we will need either to deny these people's ability to judge their own emotional security, or deny their claim to enhanced conditions for self-esteem. ${ }^{13}$

Meanwhile if measures like national self-determination are justified by their instrumental worth to individuals, then where individuals with different national attachments share a political community, a condition of immediate conflict is set up. And since there are precious few locations on earth where some mixing of nationalities has not occurred (and these are the few places where nationalism is not an issue), then recognizing nationalism as derived from individual esteem-needs means facing a situation of moral stalemate. ${ }^{14}$ Your claim to have your nationality recognized runs smack up against mine. And since we can assume identity and self-esteem to be equally valuable to all individuals, and since it is so fundamental to wellbeing that it constitutes "an overriding interest" (Margalit and Halbertal 1994: 505), then why should some people get their esteem-needs met and others not? Yet this seems to be an unavoidable outcome of measures like national self-determination or establishing a politics of recognition based on nationality. Moreover, I don't think trying to translate individual self-esteem claims into a collective claim can save this position. If we say that groups are important because they are the source of our sense of belonging and esteem, then the groups' standing is still only instrumental to, and derivative of, individuals' needs. There must still be a reason why even one person's fundamental identity and esteem-needs should lose out before the group.

I suspect that this is what has made the pairing of multiculturalism and nationalism such a tricky combination, as Canadians and Quebecers have discovered. If nationalism is based on individual esteem, then while every individual has general grounds to make a claim to recognition, it's hard to make an argument for the special status of any particular nationality. Multiculturalism is at least consistent in that it aims to give the same esteem opportunities to all individuals, even if 
it means modifying the setting for national self-esteem in a way that may reduce its eventual impact.

Thus esteem-based theories of nationalism may give us insight into how nationality has value for individuals, but they can't explain why nationalism is a good thing in general. There is reason to think that groups other than nations can provide important esteem and identity benefits without making the political demands that nationalism involves. And there is also reason to think that when it's grounded in individualized identity claims, nationalism is headed for stalemate in the only setting where it is likely to be an issue - where there are different national identities already in play.

\section{Nationalism as a context of choice}

The next theory I want to consider is one that was not explicitly intended as an assessment of the moral worth of nationalism. Instead, it is concerned with the value of culture. But to the extent that the culture in question is a national culture or the culture of a national minority, it can furnish an argument on behalf of nationalism, by suggesting that something of worth is at stake in such cases.

Will Kymlicka provides an account of culture as something that provides the foundation for autonomy. He argues that "societal cultures," 15 which include national minorities (and even those majorities into which immigrants are to be integrated) provide a way of making choice meaningful and are therefore essential to individual autonomy (1995). This autonomy-based theory has implications for the moral standing of nationalism since it suggests that cultures, even national ones, are intimately linked to the realization of a liberal order.

This is a powerful and persuasive account, but there are two reasons I doubt it can be applied to argue that nations have some special value. One of the reasons is an analytical objection, and asks whether an individual-centered approach can generate a sustainable defense of a collective entity in the face of increasingly complex populations. The other is what I would call an operational objection, and queries how the context-autonomy relationship plays out in real life.

But before getting into these issues it is worth reiterating that Kymlicka's theory is not primarily designed to champion either nations or nationalism. As Allen Buchanan has argued, Kymlicka does not defend nations "as such" (1996: 301). Where Kymlicka does call for special rights for national minorities, these rights are justified primarily by either historical agreements, like treaties or federalism, or by historical wrongs, like conquest or exploitation. In which case, 
as Buchanan points out, a remedial rights theory can do the job equally well (1996). But even if Kymlicka does not structure the argument in this way, his theory does suggest one reason for accommodating the claims of national minorities, since like other "societal cultures," nations provide their members with a context of choice and thereby the basis for autonomy. It might also be argued that Kymlicka is following the "dysfunctionalist" type of approach, in that his account points to the difficulties associated with the denial of one's original societal culture. Yet difficult as such an adjustment is, Kymlicka does not suggest we can't go through it. In fact, he tells us there are circumstances where we should go through it. He argues that immigrants are not entitled to the same kind of rights as national minorities, because they have voluntarily departed their original culture, recognizing that they will have to adjust to a new one (1995: 95-6).

Clearly the original societal culture of an immigrant is every bit as important as that of a national group in terms of being a system for investing choices with meaning. Yet even if we disagree with the specifics of his logic in the case of immigrants, ${ }^{16}$ the underlying idea - that national or cultural identity is not an inescapable condition - demonstrates a high level of confidence in the capacities of the individual to at least move between "societal cultures." 17

The reason I think Kymlicka sticks by the claim that immigrants have essentially contracted away their rights to their societal culture is because an autonomy-based theory runs into the same difficulty that esteem-based theories do. It raises the prospect of moral stalemate. If culture, national or otherwise, is what makes meaningful individual autonomy possible, and we think it's wrong to strip people arbitrarily of such important attachments (Kymlicka 1989: 175), then when we have a population with multiple cultural attachments we face a problem in giving people what they are owed. And if a meaningful culture requires that certain elements of life should be held in common ${ }^{18}$ then in the case of a mixed population this requires us to either discount the claims of newcomers, or face autonomy rights gridlock. Therefore Kymlicka needs to account for why the societal cultures of individuals who are immigrants don't get accorded the same treatment as those who make up the majority.

As with esteem-based theories, however, it could be argued that because autonomy-based accounts rate the value of identity groups so highly, this translates into special standing for collectivities. In which case, these should not be considered strictly individual-centered accounts and the potential for stalemate is minimized. But since the only yardstick that ultimately counts in these theories is the 
individual, and value is built up from that level, I think the possibility of stalemate is never convincingly removed.

My "operational" concern with the autonomy-based defense of cultures, including those of national minorities is as follows. I believe that under Kymlicka's rendition of this argument the emphasis is on the side of the equation concerned with the individual and this may lead us to lose sight of the context as an ongoing factor. If we need a "societal culture" to provide a context of meaning before we can make meaningful autonomous choices, this seems to suggest that there are two parts to this process. One part is where we acquire a sense of meaning from our cultural environment, and another where we draw upon our internalized social learning to exercise individual autonomy.

It could be said in response that these two sets of actions are effectively fused in everyday life. But if this is so, then we are more constantly indebted to, or enmeshed with, our cultural context than a discussion emphasizing individual autonomy would suggest. What this in turn means is that there is never a moment when we've been sufficiently equipped with a context of meaning and we graduate to the status of fully autonomous individuals in the sense that our choices can be considered as having transcended the constraints of our context. I don't mean to suggest that Kymlicka claims such a moment exists, but I think he does leave the matter somewhat ambiguous, so that one could plausibly draw this idea from his work. The "context of choice" argument makes a substantial contribution to our thinking on the problem of culture, national or otherwise. But it cannot be used to suggest that we can privatize the system of meaning that culture provides, and then go on to act autonomously on that basis.

If our cultural context is an ongoing, rather than just a foundational, factor in people's lives then we need to modify our thinking about individual autonomy in light of this factor. I don't want to quarrel with the value of individual autonomy, however, nor do I mean to suggest that it is a fiction. But to the extent that a focus on individual autonomy leads towards the idea that we can privatize a context of meaning, I think there is a danger of sliding back into the liberal atomism from which Kymlicka has done so much to extract us. This, together with a concern over the rights gridlock that would follow from recognizing individual autonomy claims, especially if we remove the bar on immigrant claims, leads me to question whether an autonomy-based approach has the answers we need. It cannot, I think, clearly indicate the moral standing of nations or tell us when efforts to change the political order or integrate those within a population are legitimate. 


\section{Nationalism as cultural preservation}

The final theory-type I want to consider argues that nationalism is about the preservation of meaning, not just among a living community, but across time. Nationalism, it is believed, provides a rich cultural framework for current generations and gives them hope that their endeavors will have lasting significance.

Chaim Gans believes that this argument provides the hitherto missing element for a full defense of nationalism. His reasoning, like that of Allen Buchanan, is that an autonomy-based account can only justify having "some culture or other" and cannot explain why preserving one's own culture is significant (Gans 2003: 41). Arguments that suggest cultures provide their members with "the materials to construct their own lives," meanwhile, do not explain why this culture should inform the lives of subsequent generations (2003: 50). So although national claims generally involve an intergenerational dimension, the explanatory power of identity- and autonomy-based arguments is generationally limited.

Gans claims that nationalism's intergenerational claim rests upon people's interest in having the meaning of their endeavors preserved over time. He qualifies this defense by adding it does not extend to preserving "obsolete" practices or "turning cultures into fortresses" (2003: 55-6). Nonetheless people "need to be able to hope that what they do has some prospect of enduring and/or being remembered" (2003: 56). ${ }^{19}$ Gans outlines the institutional structure that he believes follows from this thesis. However, the structure proves problematic on two fronts. The first involves a series of operational objections which suggest that the institutional order Gans outlines is unlikely to function as he expects. The second involves a conceptual objection concerned with the dangers of setting up preservation as a virtue.

Gans' institutional arrangement goes as follows. He rejects the connection between nationalism and states as unduly dangerous, and concludes that nationalism should operate at an inter-statist and substatist level, with the state level acting as a neutral arbiter between its internal populations. Intergenerational memory is served by the preservation of endeavors in specially identified sub-statist "homelands" to which inter-statist diaspora groups can look for inspiration, or "return" under favorable immigration laws (2003: 83-6). Those in the homeland, meanwhile, receive recognized self-government and self-determination rights to ensure the preservation of their culture.

The ultimate vision, in other words, is one of cultural fulfillment combined with liberal and multicultural justice. But each part of 


\section{The worth of nations}

Gans' tripartite structure shelters a set of problems. First, his concept of inter-statist nationalism unevenly distributes both the burdens and the benefits of cultural preservation. It puts those who live in the homeland under a more immediate and concentrated responsibility to uphold the endeavors of the "ancestors" than those in the diaspora (2003: 57); ${ }^{20}$ while those who live outside the homeland have their cultural claims discounted, on the basis that these claims are accommodated elsewhere (2003: 65, 96). Even were people willing to accept this inequity as part of the cost of cultural preservation, Gans' requirement that diasporas have input to the self-government of the cultural homeland is ill-advised, given the potential for emigrant nostalgia to warp the politics of a land they left behind.

Turning to the sub-statist level, here again Gans' approach runs into difficulties because the elimination of any territorial requirement leaves group membership underspecified, or worse, leaning heavily upon ethnic criteria. ${ }^{21}$ Gans believes ethnic origin may on occasion be relevant to deciding membership, but says that national membership is not an exclusive birthright (2003: 29). We might conclude, then, that membership involves a commitment to a given culture, an attachment to its heritage and the efforts of its forebear. But this still does not alleviate the membership conundrum. If a commitment to collective memory is the defining feature for group membership, it means that national membership amounts to a state of mind and that the rights associated with it are, in theory, there for the taking.

To avoid the kind of cultural free-for-all this implies we might say that group membership also requires mutual recognition (Margalit and Raz 1990: 445). What this means is that the sub-statist level would be charged with ensuring group coherence through the awarding or withholding of membership and its associated rights. How likely is it, we have to ask, that this membership structure will avoid leaning heavily on ascriptive and ethnic criteria in managing the process of mutual recognition? To put this problem another way, Gans criticizes Kymlicka's autonomy-based defense of nationalism on the grounds that it could only justify having "some culture or another" (2003: 41). Yet Gans' own defense based on intergenerational memory can only justify having some descendants or others. It cannot single out a particular successor group without the addition of some other principle and in the absence of territorial residence requirements there is a good possibility that, in practice, this principle will be an ethnic one.

Which brings us to the third and intermediate level in Gans' institutional order - the state. One leading alternative to nationalism, 
constitutional patriotism, has been criticized for underestimating the role of social and cultural solidarity in achieving a liberal society (Canovan 1996; Yack 1999). Yet Gans' arrangement seems to compound the problems of such an approach. Instead of removing national attachments from the political arena, Gans gives them pride of place. He then requires the neutral, non-national state to carry out demanding tasks such as cultural accommodation and economic redistribution, even though many of the important decisions about resources, membership, and the requirements for self-preservation reside with the national groups, along with the most powerful forms of social and cultural commitment. Should the national groups prove unwilling, it is hard to see how a state could successfully carry out its role as multicultural referee.

Turning to the conceptual objections against a cultural preservation approach, the chief problem presented by Gans' theory is that while cultural preservation may have some personal and social value, it cannot become a moral principle without entailing unacceptable risks. Continuity or stability is not the only element necessary for a healthy cultural structure. Cultures must also adapt to new circumstances, innovate new practices and solutions, and generally behave like the vital and evolving entities they are. In other words, individuals have an interest in living in cultures that are flexible and open to change. Yet nothing in Gans' system is focused on protecting this interest. He acknowledges that cultural preservation is a choice for individuals but says that it is a "public duty" for groups to maintain institutions that allow for the preservation of their culture (2003: 58). So while an individual might legitimately opt for change, it's not clear when a group could do so. This places group members, especially those in the homeland, in a position of considerable risk. The risk is that the public institutions will do their job too well, reproducing the same culture from generation to generation until what is passed on is no longer a vibrant cultural heritage but an outdated husk of dogma and routine. I don't believe that anyone's expectations regarding their endeavors can oblige others to face this risk.

Gans has taken an innovative step in developing a defense of nationalism that recognizes its intergenerational dimension. However, his attempt to elaborate a theory of cultural nationalism reveals the difficulties involved in basing a moral defense of nationalism on the value of cultural preservation. The institutional order he outlines unfairly casts some group members as cultural caretakers and provides fertile ground for a politics of nostalgia. It suggests a significant role for ascriptive criteria in the assignment of membership, and it 


\section{The worth of nations}

hollows out the institutional order responsible for distributive justice in favor of national groups whose inter-group responsibilities are unclear. Finally, recognizing national cultures as temporally extended means recognizing that they are characterized by change as well as continuity. An approach that loses sight of this delicate balance may leave national populations struggling to work with rigid and ill-suited cultural institutions. As such, it cannot provide a full defense of nationalism since it cannot justify the risks involved.

\section{Conclusion}

In the preceding discussion I reviewed seven sources of arguments about the moral worth of nationalism. These theories have taught us that nationalism has its dark associations, and that we must be cautious to avoid unwittingly endorsing them. Nationalism also quite properly comes into play as part of an answer to group-based abuse or exploitation, and it has social and economic features customtailored to the modern setting. Shared nationality, we learned, can make politics more effective (perhaps even more just) by the way it makes people feel towards each other, and it can also effect how people feel about themselves. Finally, by investing the context of our lives with meaning, cultural groups such as nations make having the freedom to determine one's own life a worthwhile thing, and can tie generations together through their efforts to develop and pass on these cultural resources.

In the course of this discussion nationalism has gone from something that dictates to the will to something that empowers it. Clearly a great deal of ground has been covered here. But the exercise is a useful one in that it suggests certain features that should be part of a moral account of nationalism. We need, it seems, an account of nationalism that: (1) specifies the conditions under which it is legitimate; (2) explains why nations are special kinds of groups; (3) credits us with adaptive capacity including the capacity to do without our nations; (4) posits a base for social trust and for setting boundaries to its extent; (5) provides a way to deal with individualized claims; (6) recognizes the collective as well as the individual dimension of autonomy; and (7) sees nationalism as a vehicle for collective transformation as well as cultural continuity.

Having reflected on the insights as well as the limitations of these theories I will venture, in this book, an alternative approach to the 
question of nationalism's moral standing - one based on its role in representation. As with the other theory-types discussed here, it will have its strengths and weaknesses but my intention is to suggest a new way of thinking about the question that can help overcome some of the problems encountered in these previous approaches. 


\section{Nationalism in Ireland}

The Irish case makes an interesting study because it is simultaneously a colonial nationalism and a European one, and because when it comes to nationalist activities, Ireland had it all - revolutionary nationalism, popular movements, constitutional nationalism, cultural revival, and finally independent statehood. This range of history means that there is a rich body of writings, publications, speeches, and experience to consult on the nationalist cause.

Perhaps the first thing to observe about Irish nationalism, however, is that it drew on an extensive range of arguments, some based on a concern with oppression, economic or social development, selfesteem, etc. Yet these nationalist arguments appeal to principles that do not necessarily entail a national solution. For example, principles such as fair or equitable treatment, opportunities for development, and secure self-esteem can all be addressed without reference to national status. Discriminatory laws or practices can be reformed and social and economic development can be made a priority under an existing political arrangement. Likewise, enhanced collective esteem might as easily be served by pursuing an imperial arrangement, as a national one. Whatever the likelihood or desirability of these other solutions, the point is that such arguments are not uniquely nationalist in orientation. Even when voiced by committed nationalists, arguments that rest on a concern with these factors do not yield a claim uniquely associated with the national idea. What I am interested in, therefore, are arguments about nationalism that entail some kind of national solution or arrangement.

Equipped with these criteria, it appears that there are at least two formulations of the nationalist claim from the period under consideration (covering the late eighteenth to mid-twentieth century) that merit further attention. One formulation is what I call the "good government" formulation and focused on the political situation. 
It argued that unless there was a shared frame of reference between the governed and the governing, political mismanagement would be the likely outcome. It therefore called for political change to better represent the different circumstances of the Irish population. The second formulation is what I call the "national character" formulation and it focused on the emotional and psychological situation of the population itself. It argued that without a common idiom and a known inheritance of cultural and historical achievements, the Irish could not thrive. Advocates of this formulation, therefore, tended to direct their energies towards changing the national consciousness of the population by reinforcing or re-introducing certain national traits, identified in terms of language, social conduct, artistic pursuits, etc.

In this chapter I will illustrate these two formulations of the nationalist claim, and show that they fall into different historical periods. As I proceed I'll provide some historical background to give some sense of the setting within which these arguments and claims were advanced. This exercise is not designed to be a comprehensive review of nationalism in Ireland, however. Such a compressed account will be selective in the figures and forces it highlights and will inevitably oversimplify an immensely complex situation. ${ }^{1}$ It is intended only as a starting point for discussion. The ultimate aim of the exercise is to ask how nationalists justified their own cause and what steps they thought should be taken to assure its realization.

\section{Nationalist argument in Ireland}

The roots of nationalism in Ireland are often traced back to the republican movements of the mid- to late eighteenth century, although this connection can be overstated (Small 2002: 27). In fact, nationalism in Ireland represented a qualitative shift away from these early republican movements, which had encountered great difficulty in initiating a republican project in a country where so many of its followers held ambivalent views over who should count as the "people." More specifically, early Irish republicanism was largely resistant to the inclusion of the Catholic masses in the patriotic project (Small 2002: 134-5), leading republicanism to stall in the Irish setting. In the process though it opened up fertile ground for a new movement, one that defined the political project in broader terms. In the late eighteenth-century Ireland had an independent parliament, now known as Grattan's Parliament for the leading figure who had championed its cause. Only Protestants could enter this parliament and to all intents and purposes, only Protestants could vote. Backed by this 
political monopoly, the island was under the effective authority of a "Protestant Ascendancy." It was the Ascendancy that gave Ireland one of its first prominent nationalist figures in Henry Grattan (1746-1820), a one-time Patriot who not only lobbied for a more autonomous Irish parliament, but also opposed its dissolution in the 1800 Act of Union. ${ }^{2}$

Grattan's resistance to union arose from his conviction that that a union government lacked the competence to govern Irish affairs. He argued that Irish "interests" and "sympathy" were distinct from those of the English, and would be better served if Irishmen governed the country. ${ }^{3}$ Under a union government, he warned, these interests and sympathies could only be "alienated" $(1865: 255)$. For this reason he held that: "there is no body of men competent to make laws to bind this nation except the King, Lords, and Commons of Ireland" (1865: 76). He therefore called on the Irish to "become a nation" that they might rightly claim this responsibility $(1865: 48) .^{4}$

It was from the same Protestant community that the revolutionary nationalist Theobald Wolfe Tone (1763-1798) rose to prominence. With his humble upbringing, Tone was familiar with the poverty and frustration experienced by the majority of the Irish population excluded from the benefits of Ascendancy. In response he agitated for a non-sectarian republican revolution inspired by (and he hoped, aided, and abetted by) the French example. It was largely fear of Tone's United Irishmen movement, and his repeated attempts at leading a French invasion, that convinced Imperial authorities to dissolve Grattan's Parliament in favor of legislative union with Britain. The hope was to better secure the island from revolution.

In defending his revolutionary course, Tone argued that the King had never visited Ireland, nor had many of the Peers, proving, he felt, that the English political leadership had "no common interest with the people." He held that Ireland's right to independence rested on the "axiom" that "an independent nation will better regulate her own concerns." And like Grattan he felt that remote government was poor government. Or as he put it: "In order that life and heat should be equally distributed to all the members of the body politic, the government, the heart of society, ought to be in its own centre" (Tone 1998: $680,685,707)$.

Tone's revolutionary efforts met with failure, and as noted, legislative union was the response. The next major Irish nationalist leader was a Catholic who first championed relief for Irish Catholics from the discriminatory Penal Laws and later spearheaded a movement for repeal of the union. Daniel O'Connell (1775-1847) led a movement that was committed to non-violence and clearly identified with the 
Catholic population. Indeed, it was funded by a "Catholic rent" which consisted of small but widespread contributions from the Catholic population. His methods involved mass popular organization and mass demonstrations of up to 200,000 in what were called "monster meetings." This popular support was used to influence elections by mobilizing those Catholics who qualified to vote as freehold leaseholders. ${ }^{5}$ His election in 1828 to a parliament where, as a Catholic, he could not take his seat, precipitated a political crisis and Catholic emancipation followed in 1829. But together with these measures, laws were introduced to restrict the voting public that O'Connell had so effectively mobilized, reducing it by over 80 percent and disenfranchising large numbers of Catholics in the process (Hoppen 1999: 22).

Like Grattan and Tone before him, O'Connell's arguments focused on the competence of a London-based government to recognize, understand, and serve the interests of the population in Ireland. O'Connell held that Ireland could not get good government from London because the Imperial parliament took insufficient interest in Irish affairs. He believed there were unique features to the Irish situation that framed political issues for the island in a way that was distinct from the way the same issues appeared in England. O'Connell realized that the English were often mystified by the unrest they saw in Ireland, but this bafflement was, in his mind, further evidence of the problem. He said of English politicians' disbelief in the face of Irish demands:

I believe it is because they are unacquainted with the state of Ireland that they feel as they do. But our great complaint is that they will not take the trouble of being informed; and if there were no other reason of showing the absolute necessity of Repeal [of the Union], it would be found in this, that the governing people of this country are radically and perversely ignorant of the wants, of the wishes, of the situation, of the feelings, of the distresses and of the determination of the Irish people. It is that we complain of.

(As reported in The Nation, November 4, 1843)

The distinct situation in Ireland had not been well represented under Imperial government, O'Connell claimed. Irish interests either went unrecognized, or they were over-ruled by English or British interests. The solution, as he argued in a speech reported in The Nation newspaper of September 30, 1843, was to "transfer our legislation to a body knowing, living in, and solely occupied with Ireland." 
O'Connell believed that for politics to serve the people, the governing body must share in the situation and the interests of the governed. As he explained

Is it not evident that no person can have so great an interest in there being good laws in Ireland, as the inhabitants of Ireland? Having then, the most deep interest in there being good laws in Ireland; having our properties, our lives, our comforts, our liberties, all at stake in the good government of our country; must we not be the most fit persons to take care of those properties by wise laws; to protect our lives by just institutions, to attend to the promotion of our comforts and by salutary regulations, to establish our liberties by sound legislation? Who else can have the deep, the entire, the perpetual interest we have in these things?

(O’Connell 1842: 40) ${ }^{6}$

While O'Connell lobbied for emancipation and Repeal, another issue was taking on added significance and fostering its own brand of activism - the issue of land use and ownership. Under the Englishstyle land tenure system, landlords were traditionally expected to take an interest in the welfare and fair treatment of their tenants. But this tradition did not carry the same weight in an Irish context where it was easier to avoid such responsibilities. The high rate of absentee landlords combined with perverse incentives in the prevailing land law resulted in the impoverishment or eviction of tenant farmers and the general degradation of the rural sector culminating in a series of devastating famines.

By reducing the peasantry to a diet based on the potato - the only staple that provided a sufficiently high yield on small plots of land the land system primed Ireland for a food crisis. What became known as the Great Famine occurred between 1845 and 1849 and is blamed for one million deaths due to starvation and disease. The accompanying emigration exodus accounted for another million, reducing the Irish population by almost one-fifth. The famine also coincided with the rapid decline of the Irish language, which was spoken by an ever-shrinking minority in the post-famine years.

For many nationalists evidence of the Imperial government's inability to appreciate the Irish situation was decisively and tragically provided by the inadequate response to these successive famine crises. The experience led one Northern-born Tory, Isaac Butt (1813-1879), to re-issue the call for an independent Irish legislature. Echoing Grattan and O'Connell's arguments, Butt felt that the Imperial 
parliament had demonstrated by its mishandling of the crisis that it did not grasp the Irish situation. Even when the full extent of the famine crisis was finally recognized, it was left to Irish property alone to shoulder the burden of famine relief. So not only was there a problem in appreciating the Irish situation, Butt concluded, but the English also felt limited responsibility when it came to assuring Irish welfare. Butt's movement went on to become the celebrated Home Rule cause under the leadership of parliamentarian and nationalist leader Charles Stuart Parnell (1846-1891).

Throughout the nineteenth century, opposition to the land system continued to be intimately tied to the Irish nationalist cause and therefore also to the Home Rule movement. It should be noted, however, that the land use movement was also associated with secret societies known for their intimidatory and often violent tactics. These movements aimed at enforcing non-cooperation with the land system, such as the refusal to pay rent, to take land from which another family had been evicted, boycotts, ${ }^{7}$ etc. This non-cooperation campaign was known as the Land War and although it was championed by constitutional nationalists like Parnell, it carried with it a considerable element of rural violence and local coercion.

Following O'Connell's death in 1847, the Irish nationalist cause took two directions. One focused on the constitutional route and centered on the elected members of the Irish party at Westminster, reaching the height of its influence under Parnell. Parnell's Home Rule movement was arguably one of the most celebrated and successful of Irish nationalist initiatives. ${ }^{8}$ The Home Rule movement echoed earlier arguments about the need for first-hand knowledge of the Irish situation, and the need for governors to share an interest in Irish affairs. However, it was consistently opposed in the North including the organization of a Loyalist paramilitary force in 1912 to resist its introduction. This resistance, combined with the consequences of a 1916 uprising attempt in the southern counties, sealed the fate of constitutional nationalism. Although a determined House of Commons finally forced the measure through Parliament, Irish Home Rule was overtaken by events and never implemented.

The other direction taken by Irish nationalism in the latter half of the nineteenth century took the form of new movements concerned with Ireland's cultural and social welfare. These movements did not have the towering figures of earlier nationalism, but they still had an identifiable voice through particular publications and organizations. The Nation newspaper of the Young Ireland movement, for instance, articulated a desire to re-establish an Irish civilization and 
sought to promote awareness of, and attachment to, Irish history and manners.

The Young Irelanders created The Nation with the aim of readying Ireland for political independence, by making or re-awakening the Irish nation. The tools at their disposal were popular history, public monuments, maps, manners, and the arts - in other words, materials calculated to generate a renewed pride in all things Irish. As one Nation writer complained in the 1840s the Young Irelanders felt that "the materials of nationalisation... are scanty and defective." But they were intent on changing that. The writer pledged to develop "the seeds of permanent nationality" and to sow them "deep in the People's hearts" (Writers of The Nation 1844: 5).

Clearly there is a self-consciously constructivist bent to this approach and the idea of heady young intellectuals campaigning around the country in order to invent a tradition of nationality may not lend much credibility to the nationalist cause. But while the Young Irelanders were making a calculated effort to encourage a national consciousness, the materials they were basing their work on, however "scanty and defective" were real enough in their opinion. Take the case of Irish history; in an effort to point out that there was no distinct Irish civilization one skeptical correspondent challenged a Nation writer by asking, "Where's your history?" The answer given was to point out that Ireland had a long and busy history by any standards, and what was lacking was the awareness of this history. This awareness was only beginning to rise, meaning Ireland was "young as a nation" (Writers of The Nation 1844: 75). In other words the historical raw material was there, but work needed to be done to inject it into the common consciousness. As one Nation writer put it, "In other countries the past is the neutral ground of the scholar and the antiquary; with us it is the battle field" (Writers of The Nation 1844: 156). ${ }^{9}$ Young Irelanders' arguments about the existence of a distinct Irish history reflect a belief that there were real differences in Irish circumstances, but that these were poorly reflected in the popular consciousness, except as a consciousness of inadequacy. It was felt that only by re-embracing these features of the Irish condition could the population expect to achieve what other peoples were achieving.

Beginning in 1893 the Gaelic League movement of the late nineteenth and early twentieth century added revival of the Irish language to the cultural nationalist agenda. While the "Gaelic Revival" of this latter period is often associated with the literary output of such figures as W.B. Yeats, A.E. Russell, or J.M. Synge this literary 
productivity was, in fact, part of a broad-based drive to cultivate domestic social and cultural resources.

The Gaelic League intended to inspire a return to the original "Irishness" of Ireland, with a special emphasis on the language. Gaelic Leaguers believed that at the root of Ireland's intractable social and political problems was a kind of existential disconnectedness. The Irish had lost touch with the historic civilization that once provided a frame of reference for life on the island, but they had not succeeded in making the English civilization fit Irish circumstances or the Irish personality. Thus League founder Douglas Hyde (1860-1949) wrote of the "curious certainty" that an Irishman would never adjust to English rule, "even though it should be for their good" (1989: 82) This inability to assimilate to a new political reality left people without a context. The Irish were, he said, "cut off from the past, yet scarcely in touch with the present" (1989: 84). In attempting to re-establish or even re-introduce identifiably Irish traits and characteristics, the Gaelic Leaguers were trying to provide a set of cultural resources for the Irish population that they felt more suited their circumstances.

Moreover, it was no use blaming the British for their situation, Gaelic Leaguers argued. The Irish had helped create their own dilemma by trying to imitate English ways but the attempt had ended in failure. It was now time to try another approach, if the Irish were to have any civilization at all. D.P. Moran (1869-1936), a leading voice for the movement put it thus:

[W]e must make the population of Ireland either thoroughgoing English or thoroughgoing Irish. No one who knows Ireland will entertain for a moment the idea that the people can be made English; the attempt has been made, and a country of sulky, dissatisfied mongrels is the result. Ireland will be nothing until she is a nation, and as a nation is a civilization, she will never accomplish anything worthy of herself until she falls back on her own language and traditions, and, recovering there her old pride, selfrespect, and initiative, develops and marches forward from thence. ${ }^{10}$

(1901: 39)

The Young Ireland movement spawned a failed rebellion attempt in 1848, but it was the Gaelic League that ironically had the most impact in motivating revolutionary types. ${ }^{11}$ Ironic because the League steadfastly rejected all traditional forms of political activity. 
However, many among the leaders of the 1916 Rising - perhaps the most symbolic, if not the most significant event in Irish nationalist history - were Gaelic League members. Moreover, the leader of the insurrection, Pádrig Pearse (1879-1916), took the Gaelic League idea of disconnectedness and turned it into "disinheritedness" and "dispossession" of both a spiritual and material kind. He thought the "cleansing and sanctifying," experience of bloodshed would lead the Irish to "re-enter" their "mystical birthright" (Hepburn 1980: 80). While not representative of the mainstream of Irish nationalist thought, Pearse's ideas are evidence of how far this logic can be taken.

In 1914 the implementation of much-awaited Home Rule measures was suspended in light of both the war and an armed standoff developing in the North, and progress on legislative independence was postponed indefinitely. In Easter 1916 a small band of republican nationalists led by Pearse began what they hoped would become a widespread revolution by occupying the General Post Office building in Dublin. ${ }^{12}$ The revolutionaries were forced to surrender after a few days of much over-matched fighting, which involved heavy casualties among the insurgents and among the civilian population caught in the crossfire. Although initially popular opinion was against the revolutionaries the ensuing clampdown by British authorities, including the execution of the rebel leadership and the widespread use of a paramilitary force known as the Black and Tans, quickly turned opinion in their favor.

The British response also boosted the electoral fortunes of a small, left wing republican party called Sinn Féin by mistakenly blaming them for the Rising. The party went on to sweep the polls in the 1919 general election, all but wiping out the Home Rule party. Sinn Féin delegates then refused to take their seats in Westminster and instead met in Dublin as a rival legislature. They declared this body to be the sole legitimate political authority in Ireland, and the official successor to the Irish Republic that had been declared in the 1916 Easter Rising. This was the first Dáil, the independent legislature of Ireland.

From 1919 to 1921 a guerrilla war was waged against British forces in Ireland, alternately known as the War of Independence or the Anglo-Irish War. When Sinn Féin candidates also went on to sweep local elections in 1920, the breakaway Dáil began to exercise de facto control over local administration. An alternate justice system known as Dáil courts was established, and gained popular support, while striking railways workers refused to transport British troops throughout the country to quell nationalist resistance. After sectarian riots in Belfast indicated continued Loyalist resistance in the North, the 
Government of Ireland Act was proclaimed in 1920. The Act established a separate parliament and administration for the six counties of Northern Ireland, and was designed to assure Loyalists that they would not be placed under the authority of a Dublin government. In 1921 talks began between the British government and Dáil officials with a view to ending the conflict in Ireland. The outcome was a treaty that granted Ireland a degree of political autonomy modeled on Canada's Dominion status. This status involved considerably more powers than Home Rule had offered, but it continued partition in the North and denied Ireland's claim to the status of Republic.

The treaty was seen by some as a betrayal of the Irish Republic declared in 1916, and the ensuing debate divided the country. When the treaty passed in a close vote in the Dáil (64-57) the forces aligned with the anti-treaty side refused to accept the outcome and began insurrection afresh. The pro-treaty side took action against the antitreaty "irreconcilables" and civil war followed from 1922-1923. Dwindling public support for the anti-treaty opposition led to the end of the conflict in 1923, and the way was now clear for the new Irish State to begin the difficult business of establishing itself.

The first decade of Irish government has been described as "authoritarian" (Foster 1988: 519), but in many respects it was remarkable in its continuity with the previous regime, especially as regards the dayto-day management of government affairs by a professionalized and influential civil service. In 1932 the anti-treaty activists (organized as the new Fianna Fáil party) swept the elections, overcame their objection to the oath of loyalty (sworn to the British crown by all Irish legislators, under the terms of the treaty), and entered the Dáil, where they formed the new government. ${ }^{13}$

Once the Irish State began its oddly gradual process of formation (beginning arguably in 1916 and ending arguably in 1949) the need for national renewal became a constant theme in domestic politics. A leading figure in this period was Eamon de Valera (1882-1975). A veteran of the 1916 Rising, de Valera was also the leader of the first Dáil, the leader of the anti-treaty side in the civil war, and the man who dominated Irish politics for most of the new State's first fifty years. Through it all he remained convinced that that the Irish needed to remain attached to certain Irish and Catholic characteristics. In one speech he cited the Young Irelanders' call to develop the material and spiritual resources of the nation, saying that it was "the solemn, unavoidable duty of every Irishman" to do so (1980: 467). In particular he singled out the restoration of the Irish language as a priority and his reasons for this are instructive. The Irish language was critical 
to Irish nationhood, he said, because:

In it is stored the accumulated experience of a people, our people... To part with it would be to abandon a great part of ourselves, to lose the key of our past, to cut away the roots from the tree. With the language gone we could never aspire again to being more than half a nation.

(1980: 467)

Eamon de Valera led Ireland from 1932 to 1959, with only two threeyear periods out of power. While in government he gradually dismantled the connection with the crown and launched a punishing "economic war" with Britain by refusing to make payments for land annuities and for the pensions of British officials who had served in Ireland. In 1937 he introduced a new constitution inspired by the idea of a virtuous and Catholic "Irish" Ireland, and later maintained Ireland's neutrality during the Second World War to establish that Irish affairs were distinct from those of Britain. The prolonged process of separation from Britain was formally completed on Easter Monday 1949, when Ireland withdrew from the Commonwealth and the Republic of Ireland was officially inaugurated.

\section{Two formulations of the nationalist claim}

The aim of this exercise was to identify nationalist arguments that uniquely require a national solution to the concerns they raise. But instead of yielding one argument that meets this criterion, it seems that nationalist argument in Ireland yields two distinct formulations associated with two broad historical periods. The first - the "good government" formulation - begins in the late eighteenth century and continues through the nineteenth century and sets its sights on reforming political arrangements to better represent the population's circumstances and interests. The second - the "national character" formulation - begins in the mid-nineteenth century and continues well into the twentieth century and focuses its efforts on recuperating the cultural resources of the population. But both formulations hold that something is lost in the transmission when a population is forced to relay their affairs through a political and cultural order that has limited appreciation for their distinct circumstances.

Nationalist argument begins with Grattan's call for a parliament that would sufficiently appreciate the Irish situation (albeit with special representation for the Irish Protestant situation). A figure like 
O'Connell echoes these themes and adds the idea of interests to the concern with local knowledge. Governors whose interests lie elsewhere, who do not share a stake in how a community fares, he argues, are unlikely to serve that community well. So representatives should be tied to the community they represent, on this account, by their local knowledge and shared interests, something that for these figures is captured in the idea of a national community. In other words, for these early nationalists, the distinct interests and situation of this population served to underpin the call for a national solution in the form of an independent Irish legislature. ${ }^{14}$

But politics was not the only object of nationalist concerns. Nationalists also called for changes that would serve to distinguish and reinforce unique Irish circumstances. Thus Grattan calls for the Irish to "become a nation" (1865: 48) years before cultural nationalism became a phenomenon unto itself. The concern for cultural matters took on greater prominence in the latter half of the nineteenth century, and appears to have dominated political matters in the first half of the twentieth century. Becoming and staying a nation was for many nationalists a crucial element in the equation that justified their cause. These differences were worth holding on to because they were associated with cultural resources that were suited to the Irish situation in a way that no outside culture would be. The only setting in which this population could hope to excel, they argued, was one built around Irish traditions. Anything else would leave them handicapped in ways they could not expect to fully overcome.

This is how the two formulations of the nationalist claim appeared in the arguments of Irish nationalists. But before closing this discussion, I want to turn a critical eye on these formulations to ask if they are worthy of further consideration. Leading nationalists voiced these formulations, and they are uniquely nationalist kinds of argument. This makes them, at a minimum, of historical interest. But my object is to ask whether they are also of normative interest. Might they represent a claim that we should take seriously from a moral point of view? Or do they lack the kind of substance that we require for a normative claim? To address this question, I will take each one in turn.

\section{The "good government" formulation}

This formulation rests on the idea that a London-based government could not sufficiently appreciate the Irish situation, and therefore would not be able to provide adequate government. In a certain light, however, this may not look like much of a claim at all. "You just don't 
understand" is a facile defense that can be used to cover an inadequacy in argument. But I believe that the "good government" formulation suggests something more than a difference of opinion or perspective, although it is that too. The emphasis on having people visit Ireland to experience it first hand suggests that these nationalists were confident that there were real and tangible differences in the Irish situation that could be experienced, witnessed, and even understood by those who were prepared to learn about them. The problem was not a gap in comprehensibility; it was a gap in attention or awareness.

These differences in the Irish situation, therefore, ground the "good government" formulation in the actual and observable circumstances of the population. These circumstances included the economic situation, the legal regime (which, because it discriminated against the Catholic majority, functioned differently than in England), and social and cultural features like language, demographics, etc. These are the differences that would confront a visitor, and they are the real and practical factors that set a distinct frame of reference for Irish politics. The "good government" formulation, therefore, is properly understood as the claim that to govern well, the political order should be in touch with the tangible circumstances of the governed.

So the first thing we can say is that the formulation goes beyond simple relativism. Second, the local-knowledge requirement is not only found in the arguments of nationalists. It forms part of the reason John Stuart Mill rejected multinationalism as a basis for liberal politics. The problem was not just his oft-cited concern that smaller nationalities presented an obstacle to social progress. In his view, the more basic problem was that different national settings meant politics itself took on different meanings and therefore had different consequences within these settings. Like Grattan and O'Connell, Mill suggests that where there is a divide in "fellow-feeling" and especially where there are also language differences "the united public opinion, necessary to the working of representative government, cannot exist." The reason he gives is that different "books, newspapers, pamphlets, speeches" are in circulation and that as a consequence each party is ignorant of the opinions and concerns of the other. Even with the best of intentions the "same incidents, the same acts, the same system of government, affect them in different ways" (1972: 392). Governing well, for Mill, meant either overcoming these differences by assimilation (preferably a gentle and benevolent process) or if necessary by separation (1972: 398). Ignoring the cross-national disconnect, he suggested, was not an option. 
But we might still ask if it is appropriate to consider the "good government" claim as a distinctly nationalist formulation. The emphasis on reforming governance can make this form of nationalism sound like a mode of republicanism, an impression supported by the fact that leading figures such as Grattan and Wolfe Tone openly identified as patriots and republicans. Is it necessary, therefore, to create another category to explain their aims and efforts? Despite the apparent parallels, there is a significant difference between republicanism and the "good government" formulation of nationalism.

The difference is that republicanism is a theory of government, and one to which many leading figures in Ireland were drawn. But when it came to the Irish case, they still needed an argument for why this population as a whole should be represented, why these boundaries in particular should be the ones that outline the bounds of a newly defined or redefined political project. That broader argument was lacking in the republican formulations of the period, and it took the rise of a more nationalist formulation to furnish it. In other words, republicanism is about a type of government, while the "good government" claim is about the boundaries of the political community and, more importantly, about their relevance to governance whatever the form. Nationalism can accommodate itself to many types of government, republican included. But in this case we need to distinguish the two in order to see that the arguments of early Irish nationalists were not merely republican, and therefore are not already accounted for under those theories.

\section{The "national character" formulation}

The "good government" formulation held that politics must change to come into better accord with the distinct circumstances of the Irish population in order that government might understand and better serve the interests and aims of that population. The formulation that followed, however, seems to take that argument and turn it on its head. The "national character" formulation argues that the Irish population needed to become more distinct, so that they might realize common achievements, provide secure personal identity, and even so that the case for having a separate legislature could be reinforced. The danger is, of course, that such a formula will slide into essentialism, the suggestion being that the Irish can't be anything but Irish-speaking, farm-dwelling, devout consumers of Irish cultural products if they want to thrive. This indeed appears to have been a problem with the nationalism of the early Irish State. But for many of the originators of 
the "national character" argument, the causes they championed were about re-acquainting the population with resources suited to their circumstances.

The idea that nations can provide valuable cultural resources cannot simply be dismissed as self-aggrandizement or a willful retreat from reality on the part of Irish nationalists, however, for this idea also appears in the work of contemporary theorists of nationalism. Yael Tamir argues that a nation's distinct cultural context can serve to make its members' lives "better and more meaningful." Acts undertaken within the collective setting of the national community have, she suggests, "extra merit" because the "national framework" contextualizes the acts, offers additional options for self-fulfillment, and deepens mutual intelligibility (1993: 84-5). Like the Young Irelanders and Douglas Hyde, Tamir believes that whatever its political manifestations, this cultural concern is the true aim of nationalism. Where Tamir would differ with many "national character" nationalists, however, is in the idea that nationalism entails an immutable cultural heritage. Nor does this idea seem to be borne out in fact. Irish, for instance, was never effectively revived as a common language, but it appears that in its absence Irish nationality has done better than de Valera predicted.

This is a mystery worth contemplating, because it suggests that while a distinct idiom may be important, nationalism may not require that national traits remain static. For now, however, I will limit my comments to what nationalists themselves had to say about the nature of the national cause. For these nationalists, the history, language, and arts of Ireland preserved an appreciation of the Irish situation that no foreign civilization could adequately reflect, and re-acquiring such traits and characteristics was key to psychological and cultural achievement. While the dangers of essentialism will never be very far from such a claim, the core concern is important enough to merit further consideration of this formulation. That concern is to preserve a setting within which a people can access cultural resources that are suited to their situation.

\section{Conclusion}

The two formulations, then, while not unproblematic, raise issues of normative significance. This makes them worthy of serious consideration but does not amount to any kind of endorsement. It is also worth acknowledging at this stage that these two formulations appear to echo long-standing distinctions made between civic and ethnic 
nationalism, or alternatively between political and cultural nationalism. But these are not two completely distinct types of nationalism; they are instead two angles or statements on the same problem, and they exist in a certain tension with one another. I will have more to say on this point in Chapter 5. But next I want to look at another case, that of Quebec, to see how nationalist argument appeared in that setting. 


\section{Nationalism in Quebec}

The Irish case gives us a great deal to think about in terms of how the national claim was formulated. But it is possible that these formulations were unique to a particular setting and environment. So I want to look at a second case of nationalism to see whether similar themes appear. If they do, then this lends weight to the case that we should consider them for their merits as moral claims.

In this chapter I discuss the case of Quebec. Like Ireland, it was brought under British governance, faced settlement and colonization, and the normalization of political relations was seen as resting on the elimination of distinctions that set the population apart. But there are two reasons why nationalism in Quebec makes an interesting contrast with the Irish case. First, because it was a New World nationalism, and didn't have the option of calling on an ancient history within its territory as the Irish did. Second, the political response to Quebec nationalism took on a different form, involving a level of federal co-existence that was never effectively attempted in Ireland.

This raises a question. Does the fact that Quebec has traditionally worked within a federal arrangement with the rest of Canada (once modern Canada came into being) diminish the analytical value of this case as an example of nationalism? I do not believe so, because I do not believe that the only true nationalisms are those that have as their goal full independence or statehood. In the Irish case many early nationalists would have been happy to see a confederal arrangement introduced to allow Ireland govern those issues most relevant to its own situation while maintaining the British connection in other regards. The willingness to accept such an arrangement does not negate the original nationalism. Instead the commitment to upholding some degree of political autonomy organized around a national community reinforces the significance of nationalism as a factor. As an example of nationalist argument and aspirations, therefore, the 
Quebec case is helpful precisely because it illustrates that national political arrangements and objectives can take a variety of forms.

Differences in political arrangements do influence nationalist expression, however. For most of the period under consideration Quebec had an independent legislature that included representation for the population's Catholic majority. This means that much of the nationalism of the period was expressed through these institutions in a manner that could not be duplicated in Ireland. It also means that Quebec nationalists were constrained by this institutional structure in a way that Irish nationalists were not. For much of the period under review Irish nationalists were either largely excluded from the franchise or the institutions of power, or were addressing audiences that were. This presumably lessened their incentive to modify the arguments or rhetoric they might employ.

In short, the settings for the expression of Quebec and Irish nationalist argument were quite different. This only serves to make the similarities that do exist all the more remarkable, and similarities there certainly are. Quebec nationalists were concerned with the same themes of governance and cultural distinctness, and formulated their idea of the nation in ways that are already familiar from the Irish example. In this chapter I attempt to provide a synthesis of the events that inform those perspectives, and provide a sense of how the nationalism that unfolded was expressed. It is a radically digested version of events, touching only briefly on what are complex historical questions, and as with the Irish case it is intended only as a starting place for discussion. ${ }^{1}$ And once again, I am not attempting to represent all that nationalists had to say about their cause, because of course, they said a great deal. The real value in examining nationalist argument, I contend, lies in identifying those arguments that uniquely call for a solution organized along national lines.

\section{Nationalist argument in Quebec}

In 1791, thirty years after its conquest by British forces, the Constitution Act divided the territory of New France in two. ${ }^{2}$ The measure was designed to accommodate the growing population of Loyalists, who had fled the newly independent American Colonies and who were increasingly unwilling to live under the traditional French institutions left in place after the British victory. The portion of New France that became the primary refuge of the colonial loyalists was known as Upper Canada (and later Ontario); the portion that went on to become Quebec, and that continued to have a French-speaking 
majority, was known as Lower Canada. The Act also established a bicameral legislature in Lower Canada. The Lower House was elected and therefore dominated by French-Canadians, who were allowed the franchise. However, its powers were severely limited by the concentration of authority in the appointed upper house, which was almost exclusively drawn from the English-speaking community.

The elected assembly gave rise to a political faction that claimed to represent the Canadien ${ }^{3}$ population of French ancestry (as opposed to "the English"4). At first they were known as the Canadien Party, and later as the Patriote Party. Heavily influenced by liberal European thinking and the ideals of popular sovereignty, the movement was made up of professionals committed to the promotion of commerce and industry. And although it would be going too far to call the party anti-clerical, it opposed the dominance of the Catholic hierarchy in so far as this hierarchy tended to hamper economic development. Among the leading figures of the party was Louis-Joseph Papineau (1768-1871), who became Speaker of the (Lower) House and leader of the Canadien Party in $1815 .{ }^{5}$ Papineau and his followers had as their objective the achievement of reforms that would grant Lower Canada more autonomous management of local affairs within the context of the British Empire.

Papineau was one of the first widely recognized voices raised on behalf of the Canadien cause. As Speaker for the Legislative Assembly, he set out to challenge the limitations on the power of the elected house and the concentration of authority in the hands of an appointed few drawn from an unrepresentative minority. He appealed to the ideals of European liberal thought and to the example of the American Colonies to argue that political change was imperative. To a great extent Papineau's logic was that of a liberal and republican-style reformer arguing for enhanced democratic measures. But there was another strain to his argument. Papineau stressed not just that the colony had received only a poor shadow of the English constitution, but also that the English constitution, however well enacted, would never suit the Canadian situation. The practicalities of life in Canada were just too different. He explained, in none too complimentary a fashion:

Institutions suitable to an old country, where laws, customs, and practices differ from our own; where the distribution of wealth is unequal; where, more than anywhere else in the world, one finds on the one hand pride of opulence, and on the other the degradation of beggary - these cannot be right for a new country, where the inhabitants are scattered over a vast territory, where hard 
work is the only way for anyone to attain some degree of comfort, where luxury is unheard of. Such people need institutions different from those of Europe.

(Forbes 1985: 19)

Papineau pointed to the fact that the head of government in Lower Canada was a foreigner who often lacked a background in Canadian affairs. He wrote that the Governor of the colony arrived "sans affection pour les pays, sans liaison avec ses inhabitants [without attachment to the country, without connection to its inhabitants]," and that he would invariably install in power men with "aucune connaissance de lois [no knowledge of the law]" (Papineau 1970: 49). ${ }^{6}$ Worse still, he claimed, these men had little intention of staying and sharing in the colony's future. Instead, as he put it, they were "set over it for a season, to enrich themselves at full gallop and afterwards to digest their enormous acquired gains three thousand miles off" (1837: 9).

The root of the problem, according to Papineau and fellow Quebec politician, Nielson, was an Imperial legislature that was too distant for the colonists to participate in, and that was too remote "to legislate for the internal affairs of the Colonies with advantage" (1824, 5-6). Papineau felt this problem was especially evident in the 1840 decision to unite Upper and Lower Canada under a single legislature. Appealing to the British authorities to reconsider the decision, he argued that given the differences and distances involved between the two colonies, any representatives would lack the capacity to understand and address effectively all the issues under their jurisdiction. For a member of the legislature to address "local circumstances and wants of the place for which they are constituted," Papineau and Nielson wrote, "Local knowledge is an indispensable qualification" (1824: 5-6).

Thus while championing liberal rights of representation, Papineau appended to these arguments the idea that good government requires a genuine appreciation of local affairs. To realize all the advantages of representative government it was necessary to have representatives who shared in the circumstances of those governed. And it was not just geographic distance that was the problem, it was also social distance. As with O'Connell in Ireland he felt a government needed to have a clear stake in the society being governed, and ideally to live in that society, in order to know it and govern it well. If governors were not drawn from Quebec society and did not plan on living in Quebec past the term of their appointment, then they would have less appreciation for the situation of the population there and less interest in seeing it improved. 
An increasing incidence of deadlock between the two legislative chambers, and an increasing sense of impotence among the FrenchCanadian representatives contributed to building frustration and animosity on the part of both the Canadien and English communities. By the 1830s this frustration was playing itself out in the form of armed volunteer movements among both populations. In 1834 the Legislative Assembly under Papineau issued the "Ninety Two Resolutions," an ultimatum calling for, among other things, reform of the legislative system to ensure American-style accountability to elected representatives. When it became clear that reform was not in the offing, a group known as the Fils de la liberté led a series of rebellions in Lower Canada between 1837 and 1838, but the uprisings met with limited tactical success. Condemned by the clergy, the insurgents succeeded only in having the Canadien political leadership temporarily exiled. Papineau had supported the revolutionaries and had endorsed their position until almost the moment of rebellion. Even though he was not directly involved in the uprisings that followed, Papineau fled to avoid prosecution.

In the wake of these rebellions, British attention was fully focused on their troubled Canadian colonies. ${ }^{7}$ This attention took the form of Lord Durham's 1839 investigation into the state of affairs in Canada. He concluded that the Canadian problem resided in having "two nations warring in the bosom of a single state" (1992: 23). Durham's recommendation was, in essence, to do away with the lesser nation by assimilation. ${ }^{8}$ To that end the two colonies were re-unified under the Union Act of 1840. Despite a population differential that favored the Canadiens, the same number of legislative seats were assigned to each of the Canadas in the hope that the English community would dominate the new entity, and that the French presence would be blended out.

The assimilation initiative did not work out as planned. The union resulted in an entente cordiale between the leaders of the two old colonies, and for almost all of its twenty-six-year existence the re-unified Canada was administered by a ministry jointly led by one Canadien and one English political leader. Canadien leader LouisHippolyte LaFontaine (1807-1864) was one half of the duo that led the first stable ministry of the newly unified Canada. ${ }^{9}$ Since the Canadiens' main concern was to avoid assimilation, LaFontaine's strategy was to work with his anglophone counterparts as a means to preserve the Canadien identity and interests within the broader framework of union. But this strategy meant accepting that Canadiens were destined to be the lesser power under the new system both in terms of population and political clout. It is at this point that the Canadiens become 
French-Canadians - a minority within the larger Canadian political sphere.

At the same time as LaFontaine was seeking a means of co-existence with English political power, others were exploring alternate solutions to the problems of the French-Canadian community. Les Rouges were a group of nationalist activists that drew their inspiration from Papineau's politics, and who advocated repeal of the union and annexation to the United States, believing that Americans would be less hostile to the French identity and more open to liberal reforms. Their militantly anti-clerical views often brought them into conflict with the other nationalist movement of the day - known as ultramontanism. Ultramontanism was characterized by a dogged attachment to the Catholic faith and to parish-centered rural life. It argued for the primacy of Catholic thinking in political life and for Church control of social services. Although it was not immediately successful in its goals, under the influence of this movement the national identity became fused with the Catholic faith and it would be over a century before the two were again disentangled.

In 1867 legislative union was replaced by Confederation, ${ }^{10}$ a new political pact intended to expand the political and economic opportunities of the British colonies in North America. Confederation granted each province significant autonomy under a decentralized federal arrangement and French-Canadians saw the pact as a way to repeal Lord Durham's legislative union and regain their own separate governing authority, albeit one limited by the terms of the federal connection (Silver 1997). However, in the early days of Confederation the always delicate relationship between French and English political power was shaken by a series of events that were taken in Quebec as evidence that the French presence in Canada still faced a hostile English majority. Like the Land War and the famine experience in Ireland, these events came to symbolize the great gap felt to exist between the two communities in the country.

Among the first and most dramatic of these events was the decision to hang Louis Riel. Louis Riel was the leader of the Métis, a group born of European fur trader and native Canadian origins that hunted buffalo on the western lands then owned by the Northwest Company. Between 1869 and 1885 Riel was involved in a series of small-scale revolts against the purchase and planned colonization of this Frenchand native-speaking territory by an English-dominated Canada. Riel's efforts at first won recognition for the Métis in the form of the Manitoba Act of 1870, which established bicultural rights in the new province. But unrest continued in the territory until the Métis 
insurrection was decisively put down in 1885. In that year Riel was arrested and sentenced to hang. By 1885, however, the French-speaking and predominantly Catholic Métis had earned considerable sympathy in Quebec, and because there was increasing evidence that Riel was mentally ill, French-Canadians called for the sentence to be commuted. ${ }^{11}$ At the news that Riel's sentence had been carried out, 15,000 protested in Montreal, where Honoré Mercier (1840-1894) addressed them. Out of the outrage over the events in Manitoba the Parti nationale was born and under Mercier's leadership came to dominate the political scene in the new province of Quebec. As Premier, Mercier made provincial autonomy the watchword of his administration and ran the government of Quebec as a national government to the greatest extent possible while seeking to push the boundaries of provincial authority. ${ }^{12}$

Meanwhile outside Quebec, on four other occasions in the period between Confederation and the First World War, French and Catholic education rights were revoked or reduced in the other provinces of Canada. ${ }^{13}$ This reinforced a sense within Quebec that the Canadian project was hostile to the French fact. In 1899 yet another event shook French-Canadian confidence in their position under the Canadian federation. It was the first of three controversies over military participation that would divide French and English in Canada. In each case French-Canadians strenuously objected to the commitment of Canadian troops to what was seen as a British war.

In the first case, a decision was made to send Canadian volunteers to support Britain in the Boer War in 1899. It was this dispute that prompted Henri Bourassa (1868-1952) to found la Ligue nationalist canadienne to promote the concept of Canada as arising in a pact between two founding races. In the second case, conscription was introduced in 1917 to support the Allies in the First World War. When the decision was protested in Quebec, troops were sent in to restore the peace and in 1918 troops opened fire on a Montreal crowd resulting in five deaths. The conscription scenario was played out one more time in 1942. After a prior commitment to avoid wartime conscription (largely out of consideration for French-Canadian feeling on the question), then Prime Minister Mackenzie King held a nation-wide plebiscite to approve "releasing" him from that commitment. The plebiscite passed in Canada as a whole, but was rejected in Quebec by over 70 per cent of the population. Canadian troops were once again dispatched overseas against widespread French-Canadian objections.

As mentioned, the first of these crises brought to prominence the nationalist leader Henri Bourassa. Bourassa makes an interesting 
contrast with Papineau, because his political doctrine was focused on the affairs of the Canadian federation as well as those of Quebec. While clearly an advocate for the Quebec national cause, Bourassa is also claimed by federalists as a leading voice in the construction of a uniquely Canadian arrangement. This is possible because Bourassa managed to argue simultaneously for the increasing independence of Canada within the Imperial context, and the enhanced autonomy of Quebec within the Canadian context.

Bourassa was first moved to address the Imperial link by the decision to send Canadian troops to the Boer War. In response to the argument that Canada had a responsibility to support Imperial wars, Bourassa offered what was, in a way, a version of the "good government" argument. If Canada had no interest in other Imperial colonies, no stake in the Imperial system, and no say in the Imperial government, then it should not be involved in Imperial wars that had no bearing on Canada, he argued. Bourassa pointed out that seven million Canadians had less voice in Imperial policy, "than one single sweeper in the streets of Liverpool or one cab-driver on Fleet Street" (1970: 64). ${ }^{14}$ This, in Bourassa's view, justified Canada's refusal to participate in supporting Imperial ventures.

Since it is about questioning an external commitment, this argument is a more self-serving version of the "good government" formulation than that which focuses on the need for local understanding and shared interests to ensure good laws. However, it has in common the logic that political authority and political responsibility call for a genuine connection to the interests at stake. It was the absence of that connection that was felt to disqualify (or exempt) Canada from involvement in Imperial wars.

Bourassa straddled not only Canadian federalism and Quebec nationalism, he also voiced arguments that appealed to the two major nationalist formulations already identified in the Irish case. While his defense of Canadian independence from British policy drew on a version of the "good government" formulation, his defense of Quebec autonomy leant towards a "national character" type of formulation. $\mathrm{He}$ argued that the provincial domain should retain authority for "all that is essential to the maintenance of our national character" (1970: 104).

Bourassa held that the preservation of the French language was "absolutely necessary for the preservation of the race, of its genius, its character and its temperament" (1970: 104). In language that is reminiscent of Douglas Hyde's concern with the Anglicization of the Irish, he claimed that nothing would be achieved by attempting to 
assimilate the French in Canada, because

[T] he day we lose our language we lose precisely this very peculiar character, these special faculties which can make us a desirable element in the construction of the Canadian nation... The day we lose our language we will perhaps be mediocre Englishmen, passable Scotsmen or bad Irishmen, but we will no longer be truly Canadian.

Bourassa had a complex kind of bi-level nationalism. He thought that "the normal development of the powers of self-government" would lead to Canada becoming "an absolutely independent nation." So that alongside the national character of the French-Canadians, Bourassa envisioned all Canadians developing "a civilization of our own, a mental development of our own, an intellectuality of our own" (1970: 77). Although French-Canadians might be concentrated in one part of Canada, he believed they were attached to the entire entity. He argued: "The fatherland, for us, is the whole of Canada... The nation which we want to see developed is the Canadian nation" (1970: 107). ${ }^{15}$

This appears to present something of a contradiction. How was the national character of French-Canadians to be preserved while a new Canadian nationality was constructed around it? This contradiction is less stark than it appears. Bourassa's image of Canadian nationalism was based on what he saw as the inherent duality of the Canadian situation. In his words, Canada was "a nation of two elements separated by language and religion and by the legal arrangements necessary for the preservation of their respective traditions, but united by a sentiment of brotherhood in a common attachment to a common country" (1970: 107). This kind of nationalism need not imperil the French fact, he felt. This raises the question of whether you can have one nation nested within another, and have both grow and thrive, nevertheless this was precisely what Bourassa had in mind. He believed that the true "Canadian" way involved a sort of "live and let live" attitude among the two major communities. What's more, he believed that French-Canadians were the most "Canadian" of any group in the Dominion (1970: 107, 177). ${ }^{16}$ And in a twist on Lord Durham's predictions, Bourassa believed that once the relative newcomers (the English, Americans, and other Europeans) were finally assimilated to the point of view already held by French-Canadians, national harmony would be secured. 
Bourassa's vision of two thriving and complementary national communities was dealt a blow when depression hit in the 1930s, as Quebec proved especially vulnerable to the downturn. A conservative ethos dominated among the population, making it difficult to launch state-sponsored relief efforts. Instead, the Catholic Church became the biggest player in the social support system, dominating the arenas of education, social services, and unionization. Nationalism in the post1930s period showed a decidedly Catholic cast and tended to celebrate attachment to the land and to the past. Clergyman and teacher Lionel Groulx (1878-1967) became a leading spokesman for this perspective and was well known for his efforts to build up the discipline of Quebec history at the University of Montreal. In particular Groulx preached the miracle of "la survivance" - the idea that the French-Canadian nation had been preserved by divine Providence first from the godless French Revolution, and then from assimilation by the English. French-Canadians were therefore called upon to honor this miraculous cultural salvation by continuing in their traditional way of life.

If Bourassa represented a complex bi-level nationalism, Quebec's national character had few more single-minded champions than Lionel Groulx. Groulx entered the nationalist debate just as Bourassa was retiring from it, and his arguments accorded well with the socially conservative style of the thirties, forties, and fifties. Groulx had a racially based idea of the French-Canadian nation and he cast the national character in mystical and teleological terms. He promoted an image of the devout French-Canadian family and claimed it epitomized the essence of Quebec's cultural inheritance. Yet perhaps his most enduring legacy was his impact on the revival of FrenchCanadian historical studies. Groulx believed that a lack of awareness of their history and achievements was at the root of French-Canadian political and economic subordination. He wrote that he was "convinced that our indifference arises from ignorance of our history. We lack patriotic conviction because we do not really know our own country," and he felt that it was imperative that they begin the task of "exhuming" this history (1973: 77).

Groulx felt that the history of French-Canadians illustrated the differences between their nationality and other groups in Canada. $\mathrm{He}$ eulogized the French-Canadian "agricultural vocation" (1973: 149), their sense of adventure and "missionary spirit" (1943: 8), the role of the family (1973: 101-20), and as noted, the miracle of "la survivance." These features, when added to a distinct economic and juridical framework and compounded by linguistic and religious differences made 
Quebec a province apart. Holding on to these differences was, he felt, the key to preserving the French-Canadian nation. In case there was any doubt about what was at stake, Groulx warned of the fate of those nations that strayed from their national calling. They could look forward, he said, to "incoherence, disintegration, acceptance of mediocrity and servitude, the impossibility of a collective life, the triumph of every kind of individualism - all signs of ultimate doom" (1973: 156). Alternately, by being true to their inherent character, FrenchCanadians could realize great gains. Groulx promised that "through faithfulness to their origin, history, culture and inborn strength will they be able to create the most favorable climate for developing their human and cultural personality and for acquiring the pride and dignity of a free people" (1973: 159).

Like the Gaelic Revivalists, Groulx focused on spiritual or cultural achievements that were outside regular political channels. But unlike many of the Gaelic Revivalists, Groulx was not shy about staking a claim in the political realm as well, and he made explicit arguments for national institutions in Quebec. The ultimate goal of the FrenchCanadian people in Canada must be self-government, ${ }^{17}$ he argued, because political independence was necessary in order to realize "the survival and flowering of our particular personality" (Groulx 1973: 182). The aim was, on the one hand, to acquire increasingly independent institutions, on the other, to check Canadian aspirations for a unified or blended people. So unlike the "good government" formulation of Papineau, which held that the distinct circumstances of the French colony merited special political structures, Groulx argued that political autonomy was necessary to keep Quebec distinct. The alternative was to let their national character seep away, squandering their potential for spiritual or material achievement in the process.

Moved by calls such as Groulx's, the idea of a distinct national character served to inform political decision-making in Quebec in much the same way as it had in Ireland between the 1930s and the 1950s. And as in Ireland, the idea of the national character constrained political solutions under the leadership of a dominant political figure - in this case, the provincial Premier Maurice Duplessis. But unlike the experience in Ireland, this nationalism did not translate into an effort to decisively detach from the larger union. Such sentiments arose later with the passing of Duplessis' regime and yielded an influential independence movement in the 1960s. What was clear by the 1950s, however, was that Quebec had decisively established itself as a political community that managed its own affairs in accordance with its self-understanding as a national community. 


\section{Conclusion}

As with the Irish case, two formulations of nationalist argument can be distinguished in Quebec, and the two correspond with two broad and partially overlapping periods. Beginning in the nineteenth century a formulation that questioned the capacity of existing institutions to properly represent French-Canadian interests is evident in the arguments of figures such as Louis-Joseph Papineau and later Henri Bourassa. Starting in the early twentieth century another formulation appears, this one focused on the preservation of national traits and characteristics. The theme appears in the writings of nationalists such as Lionel Groulx, for instance, as well as in those of Bourassa.

These formulations suggest a parallel with the "good government" and "national character" formulations outlined in Chapter 3, and I will use the same categories to discuss both cases. But as with the Irish case, neither formulation is a watertight category in Quebec. For instance, we have, in Henri Bourassa, a figure that readily draws on both formulations. One explanation for this could be political opportunism on Bourassa's part, reflecting a readiness to use whatever arguments had the most power in a given situation. But it may also indicate that some kind of connection exists between these two formulations, a connection that made it possible for someone like Bourassa to use them to defend both a Canadian and a Quebec-based nationalism. It may also be that, despite the obvious differences in approach, both formulations have something fundamental in common. In other words, some kind of shared dynamic seems to have been at work in the Quebec case, just as with the Irish one.

Since they make up part of this dynamic, the differences between these two nationalist formulations deserve closer consideration. In the next chapter, therefore, I consider whether these two formulations support the idea that nationalism has an essentially dichotomous nature. I conclude not only that dichotomies are unlikely to help us fully understand nationalism, but that these two formulations are inherently inter-related, and that each has roots in the other. 


\section{Bifurcated nationalism and the impasse in theory}

The goal in reading nationalist writings was to see if it was possible to detect a central theme to nationalist argument in these cases. Instead I found that the nationalist claim was articulated in not one but two ways. One focused on securing "good government" through knowledgeable governors with a stake in the affairs of a given population. The other focused on defining and upholding a "national character" that would distinguish and sustain this population. This finding, of course, complicates the theoretical picture. Yet the two formulations appear to reflect at least one aspect of contemporary thinking on nationalism. They seem to confirm the idea that we should expect the variety of nationalist conduct or nationalist objectives to line up along a divide, either a civic/ethnic divide or perhaps a political/cultural one.

These divides, and especially the one involving politics and culture, have taken on special significance in recent years, because the possibility of distinguishing the political from the cultural features of nationalism has served as the starting point for new theories of nationalism. In this chapter I ask what the two formulations of the national claim can tell us about the applicability of these divides and the theories they have inspired. What they tell us, I argue, is that the bifurcation suggested by such approaches is not fully reflective of the nationalism encountered in actual circumstances. We should therefore employ such dichotomies with caution.

The problem is not that the "good government" and "national character" formulations do not align with political/cultural or civic/ ethnic divides to a certain degree. In so far as it is possible to identify civic and ethnic, or political and cultural, aspects in a given case these distinctions can help us understand the composition and disposition of that nationalism. The problem is that these nationalist formulations cannot be bounded within the divisions implied by either the civic/ethnic or political/cultural distinctions. What appear as discrete 
categories from an analytical perspective prove difficult to maintain from the perspective of nationalist history.

Yet the divisibility of nationalism is a seductive idea. Even liberalnationalism, a mode of theory that in principle accepts the interpenetration of political and cultural life, can fall under its spell. Several major works in this area exhibit a tendency to emphasize one aspect of nationalism at the expense of another. Yet theorists disagree on which side of the divide should be the focus of attention and accommodation, presenting a challenge for the progress of theory in this area. Without a full picture of the phenomenon to work from, the accommodation strategies that result face an uphill battle. To overcome the problem, theories of nationalism, and especially those that seek to reconcile nationalism with liberalism, should focus not only on how to distinguish the different implications of civic and ethnic, or political and cultural nationalism, but also on addressing the complex dynamic that runs between them.

\section{The civic/ethnic divide}

Civic ideals and those that arise in an ethnic understanding rest on very different concepts of what makes a population a nation. The former implies a principled attachment that can be logically defended based on some concept of justice or the public good. The latter implies a non-reasoned, almost primordial condition, that can only be defended in somewhat incoherent, romantic, or even exclusivist terms, and one which is almost inevitably based on a falsely constructed idea of what people hold in common. This dichotomy, therefore, represents a real distinction in the basis for collective life, as founded on either chosen civic commitments or the discovery of an ethnic inheritance. ${ }^{1}$ But as I will argue, we should be careful when this distinction is employed as a moral guide, because although they represent discrete categories in theoretical terms, in lived experience the chosen and inherited aspects of nationality are interwoven.

Theorists such as Yael Tamir and David Miller recognize the messiness of the national reality when it comes to membership. Both want to retain the idea that nationality can be regarded as an object of choice (Miller 1995: 43-5, 115; Tamir 1993: 20-32) and both deny that an individual is obligated to affirm a national identity simply because they are born into a particular national setting. Yet both also argue that a pure choice model of nationality makes little sense, because very little in life actually meets that standard (Miller 1995: 44; Tamir 1993: 22). This tension between choice and what Tamir calls 
"discovery" (1993: 21) echoes the nationalist formulations identified in Ireland and Quebec. In both cases they combine a choice-based emphasis on political principles and personal commitment on the one hand, with discovery-based concerns over pre-existing conditions on the other.

To illustrate, the "good government" formulation may at first blush look like a classic case of civic nationalism. It is, after all, about the rationally understood benefits of citizenship and how government can be re-organized to better serve the interests of a given population. Creating a new political structure to better realize those benefits seems like a worthy civic goal. Thus far the formulation seems close to a republican ideal. But if civic nationalism is understood as the idea that "the nation is nothing over and above willing individuals" (Seymour et al. 1996: 3) then the "good government" formulation does not fit the bill. Instead of nationalism being a principled choice and something that rises above mere necessity of circumstance, it argues that distinct circumstances and distinct ways of thinking about these circumstances make change imperative. This unanticipated element explains the effort Irish republicans made at the end of the eighteenth century to "restructure" their political language when the civic ideal proved unable "to fully explain the problems of Irish society" (Small 2002: 14). For these reasons it is not straightforward to characterize the "good government" formulation as a civic mode of nationalism.

Consider also the arguments of Quebec's Papineau in the nineteenth century. Papineau based his arguments for "good government" on the need for local understanding. In his view it was the unique conditions in Quebec that made reform imperative, not just the civic intentions of the population. This emphasis on local circumstances means that more than choice or political commitment is involved. Further complicating the picture is the fact that many of those who voiced the "good government" argument also called for the population to actively reinforce its sense of nationhood in order to further justify political change. As noted in Chapter 2, Henry Grattan called on Irishmen to "become a nation" in order that their right to an independent parliament might be asserted (1865: 48). This encouragement of national cohesiveness pushes the bounds of the civic ideal, by promoting an active program to exhibit the features of nationality in a robust way. I'll explore the significance of Grattan's call in Chapter 6, but for now, what is important is that what looks like civic nationalism on the surface does not maintain an exclusively civic trajectory in real life. 
The ethnic conception of nationalism, meanwhile, is thought to involve "more or less objective features of our social lives," and the nation is a body which "transcends each individual" (Seymour et al. 1996: 3). In many cases this is taken to mean kinship or shared descent, but as with the civic model, this proves unrealistic. As Rogers Brubaker put it, if ethnic nationalism is interpreted narrowly as descent then "there is very little ethnic nationalism around" (1998: 457). Rainer Baubock, meanwhile, points out that the idea of membership by descent is not a self-sustaining principle. If you go far enough back you will necessarily come to someone who earned their membership by residence or consent. "There is a strong emphasis on choice and autonomy," he says, "in the narratives about the transformation of ethnic communities or 'peoples' into nations" (1994: 40, 43).

But if we understand ethnic nationalism more broadly, as involving an ethnocultural inheritance rather than strict biology, the "national character" formulation may appear to meet this description. It argues that a population has at least latent characteristics that set them apart and that establish their case for political independence. But while it may initially suggest such associations, the "national character" formulation in both Ireland and Quebec does not completely fit the ethnic label. "National character" arguments developed out of a concern that these supposedly objective or transcending features were in danger of passing away, leaving the population ill-equipped to face the future. It took active participation to re-establish these characteristics, for the reason that they provided a good guide to the population's experiences and circumstances, or at least a better one than the practices of any foreign civilization could.

So for instance, we find Quebec's Lionel Groulx appealing to practical differences in the historical and geographic circumstances of Canada's populations to explain why it was unrealistic to think Canadians could be well governed under a single unified authority. Groulx expressed pessimism about the prospects for Canadian confederation, saying: "Since our country has been built as it has, with geographic differences, a mixture of races and beliefs, the federal character of its political constitution, let us ask objectively what can be humanly achieved" (1943: 16). What could be achieved, Groulx suggested, was a political connection between the peoples of Canada, but one that did not attempt to submerge their distinct characters and situations under a common model. While couching his claim in ethnic terms, even Groulx turns to conditions outside of the population's origins to ground his concept of nationality. It is the fact that Quebec is, in practical terms, different, and not just because the population is 
Québécois that furnishes the full justification for their nationalism in his account.

Likewise, the insistence of Gaelic League thinkers such as Douglas Hyde and D.P. Moran that the Irish could never effectively become Englishmen is explained in terms of the different original circumstances faced by the two populations. And still they voiced the fear that the Irish could stop being Irish. For these nationalists, Irishness was not something that transcended the individual. Instead, it vitally depended on the choices of individuals, and on whether they would adhere or not. Admittedly there was a mystical and mystified element to the "national character" formulation, and the romantic, emotive appeal is certainly evident. But the nation was not so objective or eternal that it could not be lost if people stopped participating. This fear of assimilation, Tamir suggests, confirms the role of choice in nationality. "In practice," she says, "nationalists admit that individuals are indeed capable of changing their national affiliations" (1993: 26).

If people do not choose to continue their attachment to particular shared ways the nation that grew from those circumstances can fade away. This belief in our capacity to exit a critical condition of nationality suggests that the ethnic idea can not fully account for the thinking of the "national character" type of nationalism. So again, what looks like a clear case of ethnic nationalism turns out to have a more complicated trajectory in nationalist argument. It is not just the population's ethnic origins, but also its circumstances, and notably, its choices that matter under this account.

The formulations of nationalism encountered in Ireland and Quebec contain recognizable civic and ethnic elements. But they do not directly echo the civic/ethnic dichotomy because they do not maintain the conceptual purity imagined by this template. "Good government" is not purely about choice; "national character" is not purely about discovery. Of course, the real world rarely confirms our conceptual categories with any great precision, and this does not mean we should abandon concepts and categories every time they fail to capture the full complexities of everyday life. But this kind of dissonance does send a message about how we should use these concepts. An argument might be made, however, that the two formulations should not be expected to align with the civic/ethnic dichotomy for the reason that this dichotomy concerns the basis of communal membership while the formulations, in contrast, concern the goals and justification of nationalist movements. In other words, perhaps they function on different levels and finding an ethnic nationalist arguing for good government or a civic nationalist who is interested in 
national character should not trouble us. But this is not quite what was encountered. Instead we found, on one hand, that apparently ethnic nationalists were concerned with the role of choice (when ethnicity is supposed to be premised on discovery and transcendence). On the other hand, civic nationalists were concerned with the significance of non-chosen conditions (when civic principles are supposed to be a function of choice, reason, and the will).

The two formulations, in other words, are indeed concerned with why we find ourselves in certain collectivities, and what we chose to do about that fact. They do contain ideas about membership and these ideas may lean more in one direction or another, but they still prove more entangled than the civic/ethnic dichotomy reveals. So either the civic/ethnic dichotomy needs to be redefined in order to capture this complexity - a project Rogers Brubaker has already dismissed (1998: 257-60) - or we need to re-evaluate how we employ this divide in our moral thinking. Despite initial similarities, the "good government" and "national character" formulations do not easily align with a civic/ethnic divide. This should come as no great surprise since several theorists have pointed out that the civic/ethnic divide does not easily align with the messiness of national reality. ${ }^{2}$ Nevertheless the idea that membership can appeal in varying degrees to principled, chosen attachment or to given, non-chosen conditions is a valuable distinction in what Kymlicka calls the "terms of admission" (1999: 107). And as Yack observes the distinction is inspired by our concern to "preserve national politics from ethnic exclusiveness and chauvinism" (1995: 180). But recognizing the importance of tools to evaluate membership regimes should not lead us to conclude that these approaches are exclusive.

If, as the Irish and Quebec cases suggest, you can find elements of both civic and ethnic ideas in most nationalisms, then even when they appear in what looks like the most classic of civic and ethnic forms we must exercise special caution in employing these terms. Otherwise calling nationalism civic or ethnic can lead to a kind of oversimplification that obscures the realities behind the structures of political power. Margaret Canovan believes nationalism is in some way to blame for this oversimplification because it manages to make political power in general, and liberal-democracy in particular, "seem easy and natural" (1996: 107). Theorists, she argues, too eagerly embraced the assumption that civic commitments can be created by an act of will. It is to the discredit of many successful liberal projects that they so often obscure or deny the "natal quality" of nationhood, because of a general discomfort with its implications (Canovan 1996: 56). 
Canovan rejects the idea that we can opt for either a natal or an elective variety of nationhood because in "the overwhelming majority of cases, if people belong to a nation it's because their parents did so" (1996: 56). If we recognize ethnicity as a social construct, we must likewise recognize civic communities as constituted by more than individual acts of will. As Canovan puts it, my nation may be "all in the mind" but it's not "all in my mind." It matters "how one is defined by others" (1996: 55). The fact is that accidents of birth, along with measures of social recognition, play a large role in the constitution of national populations. Canovan's work suggests we would be better off to acknowledge this reality, and develop theory on this basis, than in elevating ideals that are nowhere achieved.

As it now stands, the civic/ethnic divide "reflects a considerable dose of ethnocentrism" (Yack 1999: 105) and serves largely to "distinguish one's own good, legitimate civic nationalism from the illegitimate ethnic nationalism of one's neighbours" (Brubaker 1998: 257). ${ }^{3}$ Employing the civic/ethnic divide as a moral indicator can therefore have troubling consequences if the two sides are construed as "competing ideal types" (Yack 1995: 180). Instead, the Irish and Quebec cases furnish instances of ethnic nationalism that emphasized choice. This should come as welcome news both because it confirms Tamir's and Miller's claim that we can reflect even on our inherited nationality, and because the vast majority of mankind comes by its nationality by accident of birth and not by an identifiable exercise of personal commitment (Canovan 1996: 55-6). There were also instances of civic nationalism that invoked inherited circumstances and obligations. This should come as no surprise, however, because as Canovan points out, even ambitious civic projects such as classic republicanism must seek to shape citizens with a strong sense of loyalty and commitment (1996: 93). For this reason we should not assume that a national project with an explicit civic focus would automatically favor choice over discovery.

In sum, it is not just what you commit to or affirm that matters, but also the conditions under which the commitment or affirmation is entered into. In the nationalism of Ireland and Quebec, choice was not the exclusive territory of civic politics nor was discovery the exclusive territory of ethnicity. Having identifiable civic or ethnic elements, therefore, should neither put nationalism in the clear, nor lead us to condemn it out of hand. The indivisibility of choice and discovery in collective life does not mean that these ways of defining membership are interchangeable, or diminish the significance of how they are employed. Yet we must be mindful as we engage this terminology not 
to use it as a labeling process that short-circuits the exercise of close moral scrutiny for individual cases.

\section{The political/cultural divide}

Bernard Yack traces the roots of the civic/ethnic ideal to a still more fundamental divide in communal life. He says its roots lie in the two ways we view nations: both "as a distinctive form of political community and as a cultural community of origin" (1995: 180, italics added). This may account for the recent shift in theory away from the civic/ethnic divide and towards a political/cultural distinction as the most fruitful way of understanding and evaluating nationalism. The shift makes added sense when we consider Rogers Brubaker's point that the normative value of the civic/ethnic divide "pivots on the ambiguous place of culture" (1998: 258). Depending on how we see it playing into the equation, culture can either redeem ethnic nationalism from an obsession with bloodline, or condemn civic nationalism as the pursuit of social homogeneity. Getting clarity on the role of culture in nationalism, therefore, is a critical task for political theory.

In turn this puzzle sits within a broader development in political theory. Among the greatest challenges facing contemporary democracies, according to Will Kymlicka, is developing a theory of justice that reconciles universal with minority rights, forcing liberal theory to come to terms with the role of culture (1995: 1). Kymlicka groups the body of theory that takes on the challenge of minority rights under the title of "liberal culturalism" (2001: 39), but liberal culturalism also takes in theories that seek to reconcile liberalism and nationalism. Because national minorities often seek a more extensive range of rights than other minority groups, liberal-nationalism highlights questions about the appropriate relationship between political and cultural accommodation.

Perhaps as a consequence, liberal theory has developed a renewed interest in nationalism in the last ten years, with some arguing that under the right circumstances it can help set the stage for liberal justice. A new class of theorists, eager to reconcile nationalist claims with the preservation of liberal rights, argues that the problem is not nationalism per se, because under the right circumstances nations can support things that liberals should value - like secure identity (Margalit and Raz 1990; Taylor 1999), ethical commitments (Miller 1995; Tamir 1993), and meaningful autonomy (Kymlicka 1995). Besides which, forcing people to give up their national attachments would, in any case, require a level of coercion incompatible with 


\section{Bifurcated nationalism}

liberal-democratic principles. Yet simply granting national claims blanket accommodation could mean putting vulnerable group members beyond the reach of much-needed civil protections, an outcome that Ayelet Shachar has termed "the paradox of multicultural vulnerability" (2001: 3). This raises a dilemma for those who would seek some reconciliation between liberalism and communal identities.

The challenge has been to identify a way to retain the advantages thought to be associated with nationalism, while domesticating its expression and conduct in such a way that they remain within liberal bounds. The focus of liberal-nationalist theory, therefore, has been to reconcile nationalism with liberalism under two important constraints. First, these theories must avoid claims to cultural neutrality that plagued the concept of civic nationalism (the prior, but problematic, theoretical solution to reconciling liberalism and nationalism). Second, these theories should not require liberal societies to throw the gates open to nationalism in any and all forms, and so must contain some guidance on how to distinguish its acceptable from its undesirable expression.

It is this second constraint which is the source of emerging problems in the ongoing development of this field. In essence, the effort to explain how to appropriately accommodate nationalism in action has led several theorists to fall back on a view of the phenomenon as functionally divisible between its political and cultural aspects. Several important works in liberal-nationalist theory reflect the view that while nationalism has both political and cultural aspects, and while both represent genuine and in some ways valuable expressions of nationalism, they do not carry the same weight from a liberal perspective. One side of the political/cultural equation, it appears, has greater salience when it comes to accommodating national claims in a liberal setting. Nationalism can be compatible with liberalism, they say, once we realize that the political and the cultural dimensions of collective life make different kinds of claims upon us. We are not required to accommodate both these aspects in equal or equivalent ways because only one side contains the real root motivation for nationalist movements.

So despite the insights of liberal culturalism, one observer calls the effort to sever the connection between politics and culture "a major goal" of the liberal-nationalist approach (Yack 2001: 503). By distinguishing between these two areas and then accommodating the "true" concerns of nationalism, the hope is we can avoid the unintended and sometimes perverse outcomes associated with national or multicultural measures. This approach, in other words, leans towards 
a kind of bifurcated or "divide and contain" strategy for the liberal accommodation of nationalism. ${ }^{4}$

The problem is that when it comes to the political/cultural distinction, theorists differ on which side holds the key to liberal accommodation. For some, a cultural claim lies at the heart of nationalism and the real motivation is a concern with preservation, belonging, and cultural meaning. For others it is a political one, and the concern is with issues of jurisdiction, solidarity, and political identity. This striking disagreement does not bode well for either approach but setting this difference aside for a moment, the resulting accommodation strategies look remarkably similar. Both sides hold that by accommodating what really matters to national communities (either the political or cultural aspects) potential excesses can be avoided and liberal standards secured. So despite commitments to an expanded understanding of the role of culture in liberal societies, it turns out that a great deal is riding on whether a political/cultural distinction can be maintained and on which of the two modes better represents the central claim of nationalism.

In keeping with the arguments of leading liberal-nationalist theorists, the two nationalist formulations encountered in the Irish and Quebec cases do seem to align with an approach that sorts nationalism into its political and cultural iterations. Yet at a practical level it proves no easier to separate political from cultural life than it was to separate choice from discovery in national membership. From the point of view of the two formulations, replacing one divide with another does not appear to offer a workable theory of nationalism especially if these theories repeat the mistake of thinking we can opt for one style or form of nationalism while sidelining the other.

In nationalist argument the "good government" formulation with its evident political flavor was historically prior to the "national character" formulation with its focus on culture. However, this order was reversed when it came to developing new theories of nationalism in the wake of the liberal culturalist challenge. New culturally based arguments for reconciling nationalism with liberalism took clear shape in the mid-1990s, with politically based argument following them as we entered the new millennia. In order to outline the development and thinking that went into these theories I will approach them in the same order that the theories appeared.

Given the significance of the political/cultural distinction to this discussion it may be helpful to begin by clarifying how it appears in the works under consideration. Margaret Moore represents the political side of nationalism as being "concerned with the institutional, 
structural, and constitutive principles" of the national community. The focus is taken to be on issues of jurisdiction, and the goal of nationalist movements is understood as institutional separation to ensure "common political institutions" and a "common public framework" expressing the national identity (2001: 15, 107). Yael Tamir, meanwhile, thinks cultural nationalism expresses "a desire to assure the existence and flourishing of a particular community" (1993: xiii). The focus in this case is on a "particular way of life" as expressed in "culture, tradition, and language" (1993: 69, xiii). The goal of nationalist movements in this case is taken to include intergenerational continuity. The purpose of this continuity, Chaim Gans explains, is to preserve the moral bonds and rich sense of meaning associated with a national culture (2003).

It is also important to emphasize that all the theorists discussed here would argue that the political and cultural aspects of nationalism are related in important ways. Yael Tamir for instance insists that despite an emphasis on the cultural aspects of nationalism she does not mean to "divorce nationalism" from the kind of "political activity" that involves acting "in the public sphere with the intention of influencing political institutions" (1993: xiii). My argument is not that she doesn't observe this commitment. My argument is that this political "acting in the public sphere" is cast in a secondary and instrumental role, while cultural aims are put at the center of her understanding of nationalism. As Tamir puts it, even when we see such activity we should recognize that "political power is the means, while the end is cultural" (1993, xiii). When it comes to nationalism, in other words, political acting is prompted by, and from a liberal point of view justified by, cultural concerns. Margaret Moore, while she would share Tamir's recognition that both political and cultural activities regularly surface as part of nationalism, inverts the relationship that Tamir observes and instead puts political aims at the center of her account, as the prime goal and motivation of nationalism.

In essence, the concern with these major works in liberal-nationalist theory is that they suggest that nationalism's harmonization with liberalism involves placing a special emphasis on one or other side of a political/cultural divide. In doing so, I argue, they re-introduce a view of nationalism as either inherently or operationally bifurcated, a view which stands in contrast to the initial commitments of the liberal culturalist approach. The experience with nationalism in Ireland and Quebec, however, raises doubts that one or other aspect of nationalism should be characterized as its true form or regarded as a more salient feature for liberal societies. Instead, we must not only accept 
that nationalism has both political and cultural implications (as these theorists already do), we must also be wary of the temptation to employ the distinction as part of the accommodation strategies developed through a liberal-nationalist approach.

\section{The cultural-side view of nationalism}

One of the most explicit examples of the theoretical strategy outlined earlier appears in the work of Yael Tamir. Tamir's 1993 book Liberal Nationalism outlines in broad terms what a liberal-nationalist regime might look like, and offers a series of arguments for the value of national commitments to liberal society. But the real theoretical innovation to her work is not the ambitious effort to hybridize liberal and national regimes; it is the conceptual move she makes in order to clear the way for this effort. Tamir insists that before we think about accommodating nationalism we must first recognize that at base it is about cultural ends not political ones (1993: xiii). Politics is sometimes the means by which these cultural ends are pursued, but we should not be misled by this association.

Nationalism becomes an issue when more than one nationality lives under the same political roof, because the culture of the minority is often at a disadvantage, she explains. This can lead to political mobilization among the minority culture but the source of this effort, Tamir stresses, is the desire to preserve some public space for their culture. Different national groups can live under the same political roof, however, if their respective cultural lives are secure and respected in the form of a "public sphere in which they constitute the majority" (1993: 150). In this way, "drawing a line between the political and the cultural spheres," as she puts it, proves the key to managing multinational unions (1993: 10). The anxieties of the national community will be headed off by the provision of rights where it really matters in the cultural sphere. Regardless of how it manifests then, either as a cultural effort or as an ostensibly political one, Tamir concludes, "at the core of nationalism lies a cultural rather than a political claim" (1993: xiii).

Tamir asks what should be done to accommodate this nationalism and to secure the benefits of ethical community that it can convey. What we need, she says, is national self-determination. But since nationalism is really about culture, Tamir concludes that national self-determination is about preserving and directing that cultural existence. The right to national self-determination "stakes a cultural rather than a political claim," she says, "namely it is the right to 
preserve the existence of a nation as a distinct cultural identity." It is not to be mistaken for "the right of individuals to participate in a free and democratic process" (1993: 57). The implications of this claim are enormous. If national self-determination is not about democratic government, then we can give national minorities the self-determination they seek without much if any disruption to the prevailing political institutions of a liberal-democracy. Provide nations with a secure public sphere where they can cultivate their culture, as she advises, and the true ends of nationalism will be met. It's an appealing vision, but is it a plausible account of nationalism?

With its focus on cultural preservation and communal ties, the "national character" formulation of nationalism seems to back up Tamir's theory. Even where they sought political ends, these nationalists often defended their strategy in terms of cultural aims, saying they desired political authority to protect indigenous cultural resources. This confirms her claim that we should not misconstrue political manifestations as the true ends of nationalism. There are difficulties in fully reconciling Tamir's theory with nationalist argument, however. The first difficulty is, of course, that the "national character" formulation was one of two formulations encountered in Ireland and Quebec. The other was decidedly political and focused on claiming rights to political self-determination, rights that Tamir insists are not part of the real aims of nationalism.

Yet in fact there are points where Tamir's firm definition of nationalism as culture appears to waver. At times she writes as if there genuinely are political versions of the phenomenon but that the cultural version is the better version for liberal purposes (1993: 58). This is an important modification for if nationalism has other forms of expression then we cannot claim to be accommodating it entirely under her system. We are just accommodating what we can live with. Tamir's work then suggests that the political/cultural distinction has great significance. It serves, in her work, to divide nationalism into two kinds of claims, one of which we can and should accommodate, and another that we hope will be defused through our actions towards the first.

The problem is that separating politics and culture has never been easy. As noted, Tamir directs that the first step towards achieving reconciliation between liberalism and nationalism is to "draw a line" between the two spheres (1993: 10). This step is essential to her account because it enables her to keep a single liberal political project together, while enabling the maintenance of separate cultural lives for the national communities within it. Yet Tamir's project, like that of other liberal culturalists, is premised on the belief that state neutrality 
is a convenient myth, and that we cannot avoid bringing culture into the political domain (1993: 148-9). This presents a puzzle. If she accepts the inseparability of politics and culture in the political realm, how is the line to be observed in a multinational state? As Bernard Yack asks with regard to Tamir's theory, is it conceivable that national cultural communities would keep themselves "out of politics" given that they have "in practice encouraged a whole new range of political demands and conflicts" (1995: 173)? It seems plausible that the two drives she identifies - the drive to secure public space for one's national culture and the natural seepage of culture into politics - would mutually reinforce one another, setting the stage for more rather than less conflict.

Moreover, if Tamir is correct in her observation that political nationalism is sometimes about cultural ends, is it not possible that we could also be misled about cultural nationalism? Might the concern with cultural preservation sometimes be serving a strategic political purpose? Rainer Baubock suggests that we sometimes misread the claims of national minorities when it comes to cultural issues. Sometimes maintaining national characteristics is, he says, about maintaining group distinctiveness or shoring up a national claim at least as much as it is about culture (2000). Indeed in Baubock's view cultural preservation is a secondary national priority. As he puts it, "Rather than self-government being a means to preserve cultural difference, this difference is more often preserved as a means to justify the claim to self government" (2000: 384). If this were a credible reading of nationalism, it would refute Tamir's claim that nationalism is a cultural phenomenon, or that it can be addressed on cultural terms alone.

The experience with nationalism confirms some of Baubock's concerns. While some "national character" nationalists saw traditional political avenues as a needless distraction from the work of re-building the cultural nation, there were others like the Young Irelanders who supported the re-establishment of national characteristics as a means to political change. Their aim was to achieve the "good government" that political figures like Grattan and Papineau espoused; but they took culture as the starting point for that effort. In other words, just because the focus is on the cultural character of the population, it cannot be assumed that the ambitions of the movement are limited to the cultural sphere. Admittedly, some nationalists made the cultural cause their sole concern but their efforts certainly do not suffice to purify nationalism of its political associations. ${ }^{5}$

Moreover, the cultural aspects of such movements cannot be neatly separated from their role as self-conscious creators of infrastructure 
and know-how in the interests of political reconstruction. The Gaelic League in Ireland is a case in point. It was typical of a new "self-help" style of movement that proliferated in the nineteenth and early twentieth centuries in Ireland. ${ }^{6}$ These were voluntary groups that bypassed traditional institutional channels and instead aimed at "doing for themselves." In addition to supporting cultural activities in the areas of arts and languages, there were nationally inspired self-help movements in the areas of education, sports, and agriculture (Mathews 2000). By promoting the exchange of knowledge and resources, these movements served to fill a gap left by a political regime that took a limited interest in these matters.

That the cultural nationalism of the "national character" formulation had a distinctly political echo is also clear from the Quebec example. The significance of the French language was, for Bourassa, intimately tied to Quebec's role in the Canadian political union, while the culturally focused Groulx freely supplied ideas on how key political infrastructure should be delivered. To realize cultural goals, therefore, meant having an opinion on, and sometimes an influence on, political affairs. This is hardly surprising since the pursuit of cultural goals is rarely an apolitical act. We can divide the two arenas conceptually, but in practice they are co-mingled.

Tamir's point that we should not misconstrue political manifestations as the true ends of nationalism is well taken and there are examples in both Ireland and Quebec that support her claim. The difficulty is that there are also instances of nationalism that clearly are political in focus, and that are concerned with claiming decidedly political rights, rights that Tamir suggests are epiphenomenal to the real concerns of nationalism. Even though "national character" nationalism seems like a prime example of cultural nationalism, we discover on closer examination that it often contained political elements. So while it accords with Tamir's description of nationalism in some regards, it cannot support her claim that nationalism is a fundamentally cultural phenomenon, or that it can be addressed on cultural terms alone.

Tamir is not alone in her cultural-side reading of nationalism. Consider, for example, Kai Nielson's assertion that "All nationalisms are cultural nationalisms of one kind or another. There is no purely political conception of the nation, liberal or otherwise" (1999: 127, italics in original). Or Chaim Gans' insistence that "Without resorting to common culture and history, loyalty to common political principles cannot be considered nationalism, not even civic nationalism" (2003: 12). The same problems that arose with Tamir's account apply to these other works. Culture is not the whole story when it comes to 
nationalism, and the attempt to sideline or underplay the political motives associated with it is not helpful. These kinds of difficulties have led other theorists to respond by emphasizing what this approach purposely minimized - the political side of the national claim.

\section{The political-side view of nationalism}

The difficulty with the cultural-side approach to nationalism is that by granting culture too great a role in national claims it overlooks a pressing aspect of nationalist reality. Moreover, granting nations a "public sphere" as Tamir recommends is sometimes hard to distinguish from granting them some kind of political status. ${ }^{7}$ More recently, theorists have raised concerns about the cultural-side approach to nationalism. By making cultural preservation central to the national claim, critics point out, we run the risk that a population will veer towards essentialism. Culture is fluid, they argue, but if we make accommodation measures dependent on cultural identity, then there is an incentive to create a sense of "immutability" to these identities (Levy 2000: 11). Worse still, there is concern that the recent emphasis on cultural rights will turn public policies into instruments "for maintaining contested cultural traditions," effectively "immunizing internally oppressive communities from interference" (Baubock 2001: 320). Some theorists respond to these difficulties by calling for more carefully structured regimes that can create checks and balances on multicultural or national accommodation (Shachar 2001). Others recommend a shift in thinking away from the ideal of cultural pluralism and towards the prevention of inter-group harm (Levy 2000).

The most radical response to this problem, however, comes from those who challenge the original assumption behind this branch of liberal-nationalist theory. They disagree that the claim to accommodation centers on the role of culture. Instead they argue that the political aspect of nationalism should be the focus of attention, because the best arguments for nationalism are political rather than cultural. The problem, they say, is that the first wave of liberal-nationalist and multiculturalist theory too closely associated cultural and national identity (Baubock 2001: 324), when in fact the claims and the modes of accommodation appropriate to each are very different. The political/ cultural distinction remains key though, because we must again distinguish the political from the cultural side of collective life in order to accord national claims their due.

Dissatisfied with the cultural-side account of nationalism, theorist Margaret Moore developed a theory of nationalism that advocates in 
favor of a political understanding of the national claim. She rejects the culture-based defense launched by liberal-nationalists like Tamir, ${ }^{8}$ saying that national identity has been wrongly conflated with the idea of common culture when in fact it's about issues of political recognition and self-government (2001: 73, 124). Cultural difference, she maintains, is "not a crucial or even necessary element" for national identity. Nations, Moore argues, are "primarily political communities" (2001: 53-73). The only way to accommodate them then, "is through the kind of institutional separations that nationalists typically seek" (2001: 129).

Moore and Tamir agree on one point. They both believe that the claim to accommodation is grounded in the instrumental value of nationalism. For Moore, though, that claim is political rather than cultural, and its instrumental value arises in its role in supporting "the proper functioning of democratic institutions" by facilitating "two constituent goods of democracy: representation and participation" (2001: 85). Once the proper political configuration is achieved, she suggests, national identity will be adequately protected, at which time a nation's culture can take its own course, to change and evolve as best fits the population. The state founded on the basis of a national identity should, therefore, be agnostic towards the cultural comings and goings of its population.

The "good government" formulation of nationalism accords in several regards with Moore's arguments. Its defense, like hers, lies in the significance of nationality or nationhood to effective and just political governance. But there are difficulties with her approach that become clear when we consider the experience with nationalism in Ireland and Quebec. The first problem is that, as with Tamir's approach, it reflects only one of two formulations of nationalism encountered in these cases. And as was discovered with regard to the cultural-side approach to nationalism, the two formulations don't observe political/cultural boundaries very cleanly. Just as "national character" nationalists were not above getting into politics, "good government" nationalists recognized and enlisted the resources of culture in making their case.

Consider for instance the problem faced by would-be Irish nationalists in the seventeenth century. If what is relevant about nationalism is its role in political identity rather than cultural experience, how do you recognize a nationality that doesn't (yet) have its own political representation? Or what if you are laboring under a hybrid form of representation designed to meet the needs of an unrepresentative minority? The practical reality is that when it comes to identifying 
nations we usually take either cultural or territorial factors into consideration, or some combination of the two (Boran 2001). And this was precisely the position adopted by early Irish nationalists who turned to cultural and territorial distinctions in order to set the population apart and help build their case. Nationhood was not just about accommodating existing identities for these nationalists, because these identities were not firmly established to begin with, or could not adequately represent the populations involved. ${ }^{9}$ For many nationalists, therefore, nationhood is not just about accommodating existing identities; it is about generating a sense of shared identity sufficient to support a national movement. National identity in other words, is a resource that supports claims to a revised political life by providing a basis of mobilization that in some cases anticipates the political dimension.

If this is the case, then what is relevant about nationalism cannot be fully captured by the elements of an already established political identity. Instead, as Bernard Yack explains, the nation is imagined by a population in order to provide an antecedent to this kind of political project. The nation serves as the pre-political body that constitutes the project through an act of collective will. Seeing the nation in these terms means "you have to think of its members as sharing more than political relationships," leading to an emphasis on cultural community (2001: 525). If, as Yack suggests, the nation is from the very beginning imagined as an entity with generative qualities, it may found a shared political identity without being reducible to it.

Another difficulty is that, as Moore herself recognizes, the business of politics has unavoidable cultural implications because the state is "inextricably linked with the reproduction of values and cultures." In fact, she defends the right of states to "shape the public culture" in order to provide a "common public framework" (2001: 112, 107). Just as Tamir conceded that the political state could not be neutral towards culture, Moore says that the state "cannot be neutral with respect to national membership" (2001: 14-18). Yet if national membership has cultural aspects, as she acknowledges, isn't it reasonable to expect the state to take an interest in the cultural development of a national community? How can a state be agnostic towards the fate of a national culture (or cultures) when that culture is implicated in the very definition of national membership, towards which it cannot maintain neutrality? Again, the problem is that no clear line can be plotted between the politics and the culture of national identity.

The political arena is clearly of great interest for cultural nationalists because of the resources it can offer to cultural development and 


\section{Bifurcated nationalism}

mobilization. Hardly surprising then that a kind of crossover effect between politics and culture prevailed in both the Irish and the Quebec cases. This effect helps explain, for instance, why so many of the leaders of the 1916 Rising and of the early Irish State began their careers with the supposedly culturalist Gaelic League. Indeed it has been estimated that half of all government ministers and senior civil servants in the first fifty years of the Irish State had been Gaelic League members in their youth (Foster 1988: 450). In short, political nationalism proves, in reality, hard to disentangle from the cultural activities of the population involved. Given problems in defining national identity without reference to culture or other pre-political forms of solidarity, and in disentangling political and cultural mobilization, we have to wonder how plausible it is to separate the two sides of nationalism or base an accommodation strategy on this approach.

Moore's is not the only account that puts the emphasis on the political meaning of nationalism. Rainer Baubock suggests that the best arguments for national language rights, for instance, "derive from claims to territorial self-government" and not from claims about the role of culture in liberal societies (2001: 321). The moral weight that we accord to national claims, in other words, should reflect the political dimensions of those claims.

The account of nationalism developed by Moore and Baubock echoes ideas encountered in the "good government" formulation. It captures its concern with jurisdiction and justice, and reflects the argument that solidarity or shared identity is essential to political life. But the "good government" formulation was premised on inherent differences in a population's circumstances, interests, and attachments, and the nationalists who articulated it took an active interest in cultivating and maintaining that distinctiveness. In other words the "good government" formulation is concerned with addressing the needs of (or perhaps even the need for) a pre-political context. For this reason, it is not straightforward to characterize such nationalism as, at root, a political claim, or to evaluate it primarily on these terms. Further complicating the political/cultural divide is the fact that many of the nationalists who achieved political advances in Ireland and Quebec had decidedly cultural motivations. They recognized the role of the state in developing the public culture, and made politics their goal for these reasons. No matter how beneficial nations prove as a political force, then, it does not seem likely that we can develop a sense of nationality or national identity that is agnostic towards cultural development. 


\section{The potential for impasse}

The theoretical effort to present the essence of nationalism as involving either a culturally centered or a politically centered claim is complicated by the fact that nationalist argument involves elements of both. The crossover effect witnessed in Ireland and Quebec led cultural nationalists to seek political authority and political nationalists to cultivate cultural awareness. The effect was common enough to cast serious doubt on any theory that requires us to view nationalism as one kind of claim or another. It is especially curious then that we have advocates of liberal-nationalism adopting such divergent readings of the phenomenon, and it suggests that the liberal-nationalist project may be headed for troubled waters. The bright line between politics and culture that Tamir believes we must observe fades quickly in the light of day and the multiculturalist vision of domesticated nationalism begins to look like a dangerous chimera. For this reason Margaret Canovan takes to task those who seek to contain nationalism within the bounds of liberal theory, calling such efforts "selfdefeating" (2001: 203). She is unconvinced by cultural-side solutions that aim to divorce nations from states in favor of a "rich plurality of semi-autonomous communities presided over by a benevolent but impartial regional authority." This solution amounts, she says, to little more than liberal "dreaming" (1996: 117).

This "dream" might equally well apply to Moore's political-side solution, because what fails is the attempt to distinguish political from cultural motives. Any attempt to enact this dream, Canovan believes, would merely re-establish the political/cultural connection at a new level, and would "further politicize communal identity, while depriving the political structure of the affective support it needs to be able to command allegiance" (1996: 117). We might add that the political level is unlikely to escape becoming an object of mobilization, so any neutrality achieved at that level would be short-lived. In other words, no matter which end you begin at, the kind of "divide and contain" strategy encountered in these works fails to deliver the anticipated results.

Is the liberal-nationalist project therefore doomed to incoherence? Should it be abandoned as Canovan suggests? We need not conclude this. The chief weakness of the theories discussed here is not so much that they have misunderstood nationalism, it's that they're only giving us half the story. The distinct political and cultural aspects of national communities are real, and this is borne out in the nationalist formulations in Ireland and Quebec. But nationalism appears to be the glue 


\section{Bifurcated nationalism}

that holds them together, rather than the operation by which we can set them apart. Despite the key insights of liberal culturalism, and despite the expressed commitments of these theorists to incorporating this approach into a renewed liberalism, the theories discussed here focus on one aspect or motivation of nationalism at the expense of another. This translates into significant differences in their accommodation strategies, with one promising political peace through cultural consideration, and the other, cultural freedom through political recognition. Yet while the political/cultural distinction has analytic value, from a prescriptive point of view it is risky to pin our hopes on a strategy that involves viewing one aspect of nationalism as its central motivation. Too much of what is important in national claims defies such finite categorization.

\section{Conclusion}

The two formulations of the nationalist argument encountered in Ireland and Quebec tell us something about the value of two of the more commonly employed divides when it comes to theorizing about nationalism. In the case of the civic/ethnic divide, the formulations help dispel the myth that nationalisms are born as pure types based on either choice or discovery, or that national projects are likely to maintain a purely civic or ethnic trajectory. Nonetheless, the distinction does draw our attention to the mechanisms of membership and the different qualities of chosen or inherited commitment. In the case of the political/cultural divide the formulations serve to confirm that there are significant differences in the way actual nationalists focus their efforts and justify their cause. Although, again, a firm line cannot be maintained and nationalist reality proves messier than the dichotomy suggests.

The fascination with dividing nationalism into its good and bad forms may be at the root of a new problem emerging in the area of liberal-nationalist theory. The liberal-nationalist approach is distinguished by its appreciation of the inter-penetration of political and cultural life, and its aim is to reconcile nationalism with liberalism under appropriate terms. Because of a tendency to emphasize either a political-side or cultural-side reading of nationalism, however, liberalnationalist theories can come to confront one another head-on. Yet neither side of the debate can create a fully workable account because, as the Irish and Quebec experience demonstrates, nationalism rarely honors the conceptual boundaries that prove helpful in the theoretical realm. Both sides can use these problems to raise powerful critiques against the other, making it hard to move forward. The impasse that 
results has the potential to stall the progress of liberal-nationalism as a whole.

Examining nationalist argument drawn from a real-world context, I suggest, can illuminate the roots of the current impasse. We discover by re-examining nationalist writings that although the two formulations differ on how they define and justify their nationalist goals, each to some degree entails the other, bringing the two much closer together than a bifurcated approach supposes. While the political/ cultural distinction has some descriptive value it is wrong to expect that either one of these formulations can single-handedly capture the "true meaning" of nationalism. Political theories that adopt this view will fail to resolve nationalist claims and may even do more harm than good. To overcome this difficulty, I argue, it is necessary to focus on what is common to both political and cultural forms of nationalism. By asking what ties the two sides of the national equation together we can focus on the concerns that motivate nationalism in both its formulations, without supposing they can be reduced to either a strictly political-side or cultural-side account.

But if we allow both sides of nationalism back into the picture at full strength we are faced with even more difficult questions: How do the two sides of the national claim relate to one another in a liberal setting? Need we be wary of how this relationship operates, and what kinds of measures might be necessary to both accommodate and manage this relationship? What we need, in other words, are theories that can help us manage the political-cultural relationship to nationalism as a fully fledged dynamic. Rather than being viewed as a complicating factor when it comes to liberal justice, then, the tight relationship between the political and cultural aspects of national claims should serve as the starting point for rethinking our theories on nationalism.

The political/cultural dynamic to nationalism is, of course, a delicate one. If not carefully managed it can have perverse consequences for the populations involved, by empowering cultural groups to restrict the political rights of their members, for instance, or by establishing political systems that reward cultural homogeneity. In the face of these risks, it is not enough to suggest we can detect and maintain some line between the political and cultural sides of national life. Instead, the best way forward involves developing a better understanding of how this interaction operates both from a theoretical and empirical perspective. My next task, therefore, is to return to the two formulations already identified and examine more closely the nature of their relationship. This is the aim of Chapter 6 where I begin the work of investigating a common theme or central claim between the two. 


\section{Nationalism as representation}

The aim of this chapter is to reconsider the two formulations of nationalism encountered in Ireland and Quebec to see if they can lead us towards a better understanding of what is at stake in national claims. I argued in the previous chapter that the two formulations contained both political and cultural elements. But the nationalism involved traveled a long way from an original formulation that stressed political concerns to a later once centered on cultural priorities. One way to examine the political/cultural dynamic to nationalism, therefore, is to examine how this process unfolded. Reconstructing this process as a conceptual history can put us in a better position to see what holds the political and cultural aspects of nationalism together even as its specific form undergoes change.

The common theme that emerges from this exercise, I argue, is a concern for representational resources. But representation is simultaneously a political and cultural process, so to address representational issues means combining these two areas in one way or another, and this is what nationalism aims to do. This drive can lead to an inversion in logic and priorities as nationalism unfolds, creating what appears to be an entirely new cultural nationalism out of the original concern with government and political representation. If we are interested in understanding the political/cultural dynamic to nationalism then we need to consider its role in representation.

Indeed it appears that nationalism and representation share important links. Not only do they have common conceptual origins, as I will discuss in the following sections, both are premised on the existence of a shared frame of reference. In essence, nations may serve as kinds of epistemic framing systems that support shared representational acts. Yet even if the moral claim of nationalism derives from this representational role, there are still important caveats to be observed. To be effective, framing systems should have certain qualities such as 
currency and relevancy. Moreover, in order to help deal with complexity they are unavoidably selective. If we take nationalism to be a claim about representation or representational resources, this suggests we need to observe important limits to how nationalism is enacted or accommodated, as well as accept that there are constraints on what we can expect nationalism to achieve.

\section{The political/cultural dynamic as conceptual history}

The striking thing about the two formulations under discussion is that they are almost directly reversed when it comes to their relative weighting of political and cultural concerns. So while they share common elements, some kind of inversion appears to have taken place between the first formulation and the second. Yet how or why does nationalism produce a reversal in its own apparent logic and priorities? To address this question I propose to return to the nationalism observed in Ireland and Quebec and consider in more detail how this inversion developed. In doing so I am interested not only in how the inversion of priorities and logic took place but also in what, if anything, remained constant throughout these developments. In other words, does something hold the two iterations of nationalism together and could that factor hold an important clue to why nationalism operates as it does? Rather than being an additional hurdle to deciphering nationalism, then, the inversion and splitting of nationalism into two historical formulations may help point us in the right direction. For it puts us in a position to ask what is common to both formulations and what kinds of concerns feed the dynamic movement between them.

I will begin by considering how the political and cultural aspects of the national concept appeared in the arguments of Henry Grattan. I should note that these early statements of Irish nationalism have no direct parallel in Quebec, although this is hardly surprising. In this period the population in Quebec was a small, caught up in the aftereffects of conquest, and still coming to terms with its political losses. But when nationalism did become a distinct presence among this population in the eighteenth century, its nationalism reflected many of the same themes that Grattan develops.

In making his case for national self-government in Ireland, Grattan stressed both the marginalized interests of the island and the status of the Irish as a nation (1865). The first argument is clearly politically focused, while the second is vague and unfocused, so this nationalism presents itself as a primarily civic and politically oriented formulation. Yet why the emphasis on national status? What did this mean for 
Grattan? Liah Greenfeld argues that in the eighteenth century nationhood had certain elevating associations that account for its role in the rise of popular sovereignty (1992: 5-9). The Irish as a population may have had distinct circumstances, they may even have had ancient self-governing practices. But in the thinking of the period, to merit participation in the new form of representative government they needed to establish that they were also a national group to confirm that they were fit to represent themselves. Nationhood in Grattan's speeches therefore reflects an attempt to claim worthiness for collective self-rule.

This position immediately raises a difficult question, however, and the effort to address it provides the drive behind much of the nationalist developments witnessed in these two cases. If nations are groups that have a prima facie claim to popular sovereignty, then how can a population demonstrate their nationhood? Grattan makes two sets of appeals to address this question. In one, he appeals to the authorities in London to recognize the distinct sympathies and interests that prevail in Ireland (1865: 255). In other words, he points to unique local circumstances, both practical and emotive. But his appeal is made not only to English audiences. He also addresses himself to his compatriots in Ireland, telling them to "become a nation" (1865: 48). In these two brief passages is captured a powerful logic the implications of which would unfold over the ensuing years. For in them are contained two realities of nationhood: that on the one hand circumstances create a nation and that on the other, a population does. ${ }^{1}$

The nationalists that followed Grattan had their work cut out for them. They needed to establish both to their own populations, and to outside authorities, that they had distinct circumstances and a distinct basis of solidarity to underpin the claim to nationhood. The necessity to demonstrate these features of nationhood motivated the efforts of nationalists such as O'Connell in Ireland and Papineau in Quebec. These figures focused on rallying and organizing political action in their respective populations, while simultaneously raising consciousness about the differences in the Irish or Quebec situation. Focusing on issues such as Catholic emancipation, land tenure practices, or legislative rights served two purposes. There was always the possibility that some reform might be achieved, but these issues also served to highlight the asymmetry in the situations faced by these populations as compared to others under the same political regime.

Thus we begin with two main conceptual elements to nationalism nations as an indicator of fitness for political self-representation and nations as distinctly situated populations. Both are subject to demonstration, and this becomes the chief task of nationalist figures. Grattan 
issues a vague call to become a nation, and stresses distinct interests and sympathies, while figures like O'Connell and Papineau give this idea more concrete reality by emphasizing specific legal/institutional differences. Nationalists of the period therefore added to the initial idea of popular sovereignty the idea that good government (or more precisely, good representative government) required local knowledge and a shared interest in the wellbeing of a population.

Given the idea of nationalism that prevailed it should come as little surprise that nationalists soon turned their attention to cultivating the population's self-understanding as a distinct group. In essence, they were filling out Grattan's call to become a nation, by building on the idea of distinct circumstances and taking it into the cultural/ psychological realm, encouraging the Irish or French-Canadians to think of themselves as a nation, and their differences as national differences. The process implied education and exhortation and not a little invention if necessary because the intent was, at least initially, to make an external point. In large part, this was nation as performance, and it aimed at demonstrating suitability for the responsibilities of government through nation-like identity and conduct.

And it should be stressed that although cultural activism was a significant innovation in these cases, it amounted to opening up a second front rather than inventing a new form of nationalism. For if they were to be recognized as a cohesive group with the moral character to self-govern, then a population needed to have the character of a nation - it needed a national character. Creating and reinforcing that national character became the work of this second front and the nationalists associated with it. This culturally focused development, then, flowed directly from the original logic of the national idea which centered on claims to representative government.

It is important to stress that this development not only made strategic sense, but that there was also considerable continuity between the older and newer nationalist concerns. The nationalists who adopted an approach based on national character shared with their predecessors the conviction that there were real differences to their population's situations, and that these translated into differences in their "interests and sympathies," as Grattan would put it. And they were well aware that people's behavior could reinforce the political case by demonstrating cohesiveness and solidarity. So they set about rallying the people to this cultural movement, in much the same way as O'Connell and Papineau had rallied people to their political movements. But part of rallying people involves giving them something concrete to rally around. The first task of these "national character" 
nationalists, therefore, was to identify a particular understanding of the nation as well as suggest ways to mobilize behind it. In other words, they needed to define what national behavior looked like, and to promote this definition. ${ }^{2}$

Movements like the Young Irelanders attempted this definitional task. And their motivation is clearly linked to the question of moral fitness. Their emphasis on manners, history, literature, and landscapes suggested things that defined a population, set it apart, and gave it standing. This definitional drive also helps make sense of the paradoxical logic encountered in Henri Bourassa's call for FrenchCanadians to retain their language so that they could be a worthy part of the Canadian national project (1970: 134). By maintaining the language, he argues, the population can maintain its claim to be a national community, fit to manage its own affairs. Both populations therefore needed to embrace and elevate their sources of difference to claim the benefits nationhood had to offer. At this stage of the process (in the mid-nineteenth century) the national character definition remained relatively open, and for good reason. The aim was to recruit adherents, to foster that which could solidify a population, and to overcome that which might divide them. In Ireland, for instance, the national character could not be religiously exclusive without defining out most nineteenth century nationalist leaders, who were not of the majority Catholic religion. So language, manners, and historical consciousness all proved useful for defining the national character because they can be acquired, but also set one apart.

Regardless of the emphasis on history and heritage the efforts of these nationalists were focused on creating change. They wanted to change how Ireland and Quebec were seen by outsiders and by the populations themselves. By taking nationalism into the cultural realm, therefore, nationalists were shifting the focus to a new kind of representation. As with politics, the cultural representation of Ireland and Quebec was largely the work of non-Irish and non-Quebec figures. Ireland was cast, as Declan Kiberd has argued, as the land of England's unconscious, both more magical and more depraved than the solid, rational, English self-image (1995: 29-64). Quebec on the other hand, was Canada's mental block. It was the land that people (those outside Quebec) wanted to forget. Its very presence was supposed to have been erased by the measures recommended in Lord Durham's Report. Because it had a bearing on their perceived fitness to govern, the nationalist effort began to take a conscious interest in the image of their population that was being presented to the world. Their goal was to rehabilitate that image so that it supported the claim to nationhood. 
In Ireland this effort yielded a remarkable cultural renaissance in the form of the Gaelic Revival. The movement aimed at creating a national literature that could replace old and unflattering stereotypes with a new appreciation of the Irish situation. It was quite clearly, a $r e$-presentation of Ireland to audiences at home and abroad. The effort to define the national character, and to re-present the population as a cultural presence, meant returning to local history and practices as an alternative source of material. The need to tie the representation effort to local conditions and circumstances suggested that what was being represented was in some way closer to the people, and more suited to their situation.

The drive to define the national character and to establish its inherent indigeneity also paid dividends in terms of national mobilization. Having one true ideal of the national character makes it easier to concentrate collective resources on a single performative effort. Once this conceptual element is added to the mix - that only this national character will do, and that only through it can a people flourish - then the pieces are in place for a complete inversion of the nationalist logic. An essentialist variant then easily flows from the desire to define a national character, and more specifically, to rally people around a particular understanding of the nation.

So even though originally the concern with national character was intended to serve the effort for enhanced political representation, the cultural cause eventually became the centerpiece of the nationalist effort. No longer merely a justification for self-government, nationhood becomes a goal unto itself. In fact, it becomes a reason for seeking political authority. For if adherence to the national character is to people's benefit, because it uniquely reflects and is suited to their circumstances, then surely politics should serve this aim. Achieving political power is therefore a way to protect and promote the national character. With this development, the inversion in nationalist logic is complete. ${ }^{3}$ Distinct circumstances were no longer the source of the nationalist imperative, they were its objective. And good governance, once the chief concern of nationalists, was now secondary to securing the population's national character.

\section{Nations and representation}

In looking for a common theme or factor in nationalism we are looking for something that appears in both formulations, and that may have had some hand in the dynamic that leads one to transform into the other. Having reviewed the conceptual development of 
nationalism in Ireland and Quebec, I am going to suggest that a common factor throughout these developments is a concern with representation. But it begins with representation as representative government and ends with representation as cultural practice. Throughout the process the struggle is always to define, to organize, the system of representation in a new way.

Simply put, the goal for many nationalists was to re-appropriate the representation of their population, on the grounds that the existing representation system was omitting or misrepresenting critical elements. But reclaiming representation requires action on two fronts. On the one hand, political nationalism assumes the availability of cultural resources when it pre-supposes some pre-political community that, through its generative powers, posits the political project. On the other hand, cultural nationalism assumes some public or political resources will be available even if these resources take the form of a public sphere or collective cultural rights. Both of these situations involve attempts to generate resources for representing some aspect of collective life. So what's common to the nationalist dynamic between politics and culture appears to be the drive to develop representational resources.

The focus on representation that I argue emerges from a conceptual history of nationalist argument is in keeping with some of the arguments already encountered in liberal-nationalist theorizing. Margaret Moore, for instance, identifies nationalism's role in facilitating representation in democratic institutions (2001: 76) and David Miller cites it as a factor in achieving deliberative democracy (1995: 96-8). Tamir, Kymlicka, and Gans, meanwhile, all emphasize its capacity to serve as a carrier of social meaning (Gans 2003; Kymlicka 1995; Tamir 1993). What these approaches have in common is that they suggest a relationship exists between nations and some system of representation, in one case democratic governance as a system of representation, in another, cultures as systems of representation. It's possible for representation to appear as a concern in both forms of nationalism, then, because representation is not the exclusive terrain of either culture or politics.

This is just one possible explanation for the dynamic between the politically and culturally focused modes of nationalism. But the idea that representational issues sit at the heart of nationalism is lent credence by the fact that the two terms - "nation" and "representation" may share a common conceptual origin. Hannah Pitkin, a leading theorist of representation, and Liah Greenfeld, a leading theorist of nationalism, both begin their seminal works by addressing the evolution over time of the key term for their study. And both trace the 
origins of their respective terms ("representation" for Pitkin and "nation" for Greenfeld) to the same development. Both argue that their term first takes on political salience with the sending of university experts to church councils in the thirteenth and fourteenth centuries, as "representatives" from the "nations" (Greenfeld 1992: 5; Pitkin 1967: 3)

If true, then these two terms derive from the same pre-modern development. What gives rise in Pitkin's account to "the rights of Englishmen" and thence to representative government, gives rise, according to Greenfeld, to the kind of nationalist thinking that included claims that the "rights of Irishmen" called for a national parliament and later, cultural security. These shared conceptual origins, along with the role of representation in political and cultural arguments for nationalism, suggests that it may be the common denominator between the cultural and the political drives of nationalism. This link may in turn explain nationalism's tendency to slide between these different arenas in terms of priorities and logic, as well as its eventual inversion in formulation. The question is, what are the representational issues that nationalism aims to address? And more importantly, does nationalism have any credibility as a response to these issues? If the answer to the last question is no, then while it may have noble intentions, nationalism falls short of having moral standing. Addressing these questions means taking a moment to consider the problem of representation as a process.

\section{The problem of representation}

Representation can present a moral problem in itself. Plato suggested that all representation was a form of misrepresentation or lying because it could never be anything more than a poor imitation. Any attempt to capture truth in a human community, no matter how sincere, will always elide some element of truth's perfect form, he warned (1991). Yet without some form of representation we would be reduced to a life of solipsism and isolation. To investigate the central claim of nationalism, therefore, we may not need to consider the value or worth of collective representation per se. This is fortunate, for at the present time there is limited basis for such work in the field of political theory (Canovan 1996: 25, n. 12). Instead, if representation is necessary for collective life then the most we can do is heed how the process of representation takes place, and under what conditions. This focuses our attention away from perfect but unrepresentable Truth, and towards the question of representational practices. 
This interest in the conditions for representation brings us face to face with a new problem. The problem is that for representation to be intelligible to participants, they need to already share some common frame of reference. Johann Gottfried Herder, the man most often cited as the first philosopher of nationalism, used this idea to refute the Condillacian theory of language formation. For language to have originated between two children in a desert by means of pointing and grunting, as Condillac proposed, would mean that the children already shared a sense of the significance of sound as a representational tool, and would have understood its association with an indicated item. In other words, Herder argued that Condillac's theory assumed precisely what it was supposed to explain (Herder 1966; Taylor 1975: 19) Representation cannot begin from nothing, Herder insisted, it pre-supposes shared concepts or shared ways of apprehending the world. Some frame of reference must exist that equips us to make sense of these representational acts by telling us what we should pay heed to in a world of otherwise vast possibility. In short, we need something that enables us to "decode" information in relevant ways. ${ }^{4}$ If this holds true for both our political and cultural lives, then representation requires frames of reference for both these areas.

The capacity to develop a representational structure to help us interpret one another and our experiences in life, therefore, is critical. And it may be this quality that has made nationhood a critical pre-condition for the pursuit of demanding ideals such as liberalism and social justice. In essence it helps create the kinds of communities where these aims are possible. Reflecting on this relationship Margaret Canovan concluded that we should understand nationhood as primarily a "mediating phenomenon" akin to Hannah Arendt's idea of the way a table mediates between separateness and relatedness (Canovan 1996: 69). Citing Edmund Burke, Canovan argues that nations introduce a kind of "as if" quality to our political and cultural lives (1996: 70) thereby creating stability and continuity out of unlimited contingency.

There is an important lesson here, as Canovan observes. It is that nations are about "shared ownership of something outside us" rather than "similarities inside us" (1996: 72). Arendt's "in-between-ness" and Burke's "as if" qualities come together to produce a group that feels as if what is between them is stable, comprehensible, and significant. But Canovan concludes that this quality is too elusive to sustain any further examination. She cautions, "The delicate structure of mediation involved does not lend itself to philosophical dissection" (1996: 135). Her unwillingness to theorize the process is not, I think, the right response. If it provides grounds for liberalism and social 
justice, for democratic political and cultural representation, then how can we not press further? The representational process she describes should not be considered beyond the reach of either our analytical or our critical attentions.

Again, the two formulations of the national claim may help us unravel this process. The "good government" formulation of the national claim, for instance, suggested that to adequately represent a population the political process should align with that population's "interests and sympathies." But the reality is that all populations are a mix of interests and attachments. What do we gain from a representational point of view by the introduction of the idea of the nation? One thing might be that, as Hannah Arendt suggested, politics requires a setting within which action can take place and have meaning. In order to appear to others and to have one's actions immortalized in the stories that historians tell, she says, we need two things. First, there must be a basis for mutual understanding, since the "sharing of words and deeds" is what gives birth to politics (1958: 198). And second there must be boundaries that hold this sharing experience together. As Arendt explained in The Human Condition:

It is as though the walls of the polis and the boundaries of the law were drawn around an already existing public space which, however, without such stabilizing protection could not endure, could not survive the moment of action and speech itself.

(1958: 198)

Arendt tells us that we extract ourselves from the necessities of the factual world through politics. In doing so we create a kind of falsehood, but it is only through this exercise that we can make ourselves manifest in the world, by escaping the web of "necessary development[s]" (1968: 259) that threaten to ensnare us. This falsehood is what the storyteller gives a final polish to when they create history. So politics, it seems, requires us to devise a new account of our place in the world, something that sidesteps raw facts. And the outcome of this process must be something we can share.

Could this need for a shared account of the world be met by a collective frame of reference that is summed up in the idea of the nation ${ }^{5}$ The problem is that this seems to grant the nation too much moral standing. If nations are serving as the system that enables the very possibility of politics then they take on profound importance. Yet even given their fundamental role in collective life, Arendt suggests there are natural limits on the necessary falsehoods of politics. 
Arendt cautions that they must stay within reasonable bounds, because taking the falsification process too far means undermining the politics you aim to enable. So even though as political animals we are born liars in Arendt's view, she warns that any attempt to entirely manipulate facts "out of the world" will prove futile in the end, and will lead to the destruction of politics (1968: 259).

Turning to the national character formulation, this formulation argued that people would feel more connected, and that they would have a basis for collective efficacy and personal esteem through the cultural establishment of their nation. This is a tall order, but nations clearly have a cultural dimension, and this dimension relies on affective and imagined ties at least as much as on any specific knowledge. For instance, nations can connect people with a historical past from which they draw inspiration. Nietzsche believed we could learn from history that people like us, in situations like ours, were once capable of great things. Thus when presented properly, he said, history serves "the purpose of life" (1980: 23). By establishing a historical frame of reference from which a population can draw strength, in other words, a nation can connect people with sources of esteem that support individual and collective acts.

And it's not just history that matters to collective self-representation. A population that is exposed to literature or arts in which they appear in some degraded form is a population that has a representational problem. Either art and literature are not reflecting reality, which short-changes that population on an important resource of collective life, or they must relate themselves to this degraded status. Hardly surprising then if a population relates to this representation by starting an alternative representational effort. Thus a national literature or arts movement may be born out of the effort to create a selfrepresentation that serves the "purpose of life," as Nietzsche would say. The move to create national cultural resources, in other words, is motivated by the sense that a previous representational order has failed to capture the true dimensions of a population's experiences.

The idea that the nation is a focal point around which a more supportive representational order can be mustered suggests it may have important value. But as with the political dimension, it also threatens to allow too much importance to nations. Is nationalism a concession to our limited imaginations? Is it more about ameliorating emotional weakness than about facilitating new resources? Not necessarily, not if we view the effort to extract relative stability and meaning from the raw facts of the world as a creative and adaptive capacity. In this case, it is as if in the presence of the national idea, all that is air crystallizes 
into solid and in the process we gain some firm ground on which to stand. And this process may pay dividends beyond mere emotional security. By injecting a sense of constancy into some elements of our world we can free up personal resources to direct to other efforts. Niklas Luhmann, for instance, observes this dynamic at work in the case of trust, which begins by positing a belief in the predictability of others' conduct, thereby freeing up energies that can be directed towards other challenges and opportunities in life (1979).

But as with the political dimension, there is a built-in check on the frame of reference that can develop in the cultural realm. A cultural life that is too far out of touch with reality will have limited value for a population. Like the falsehoods of politics, cultural forms are extractions from reality, but they too need to reflect people's life experiences. Nations provide a sense of connectedness for many people, and can provide a framework within which people can direct their affective attachments in terms of history and cultural expression. This cultural capital can then be called upon to help negotiate future challenges. ${ }^{6}$ But if this becomes an effort to shield a population from change, or sustain collective esteem through self-aggrandizing history or arts, the representational value of the nation is diminished.

This discussion suggests that nations are the reflection of an important representational process within a population. Where a population shares certain conditions it will likely develop a shared frame of reference that goes along with them and their representational acts will reflect this. Nationalism, in this case, can be understood as the claim that there needs to be a better fit between the representational forms available to a population and a frame of reference that is currently in use among that population. ${ }^{7}$ Or it may in some cases be the claim that a frame of reference needs to be developed and shared. Ultimately, the moral weight of this claim is tied to the role that frames of reference play in enabling representation in collective life. If this view of nationalism is correct, it suggests that nationalism should be understood as a claim about representational resources.

\section{Nations as frames of reference}

If nationalism is about having a shared frame of reference to support representational acts, then the next question is, what is being framed in terms of the nation and why? In his work Imagined Communities Anderson suggests that nationalism is the surface manifestation of an underlying "form of consciousness" (1991: 23) and that it is only the latest in a historical succession of what he calls "modes of 
apprehending the world" (1991: 22). Anderson believes we can learn a lot about nationalism by considering the kind of consciousness it replaced. In the pre-modern era, he tells us, three forces "crossed" to create a mode of consciousness steeped in religious content (1991: 4). These forces involved a particular way of viewing time, a specific system of territorial authority, and a distinct basis for collective and ontological authority (1991: 24-36). The fate of these three components is linked somehow, since all three weaken once the powerful combination of printing and capitalism arrives on the scene and a new compound takes their place. This new conceptual mix makes it possible to "imagine" the nation. But, as it turns out, the base composition of the new mode of consciousness again involves our ideas about time, territorial sovereignty, and social organization.

In place of the previous cyclical idea of time, for instance, Anderson suggests that the modern consciousness is characterized by an awareness of simultaneity, or a linear understanding of time (1991: 24). Likewise when we move to the modern consciousness sacred communities were "territorialized" (1991: 19). Borders become the defining feature of territorial sovereignty, displacing the previous mode based on high centers of power and influence. Finally, sacred languages that had served in the past to shape and uphold a fraternity and administrative structure based in religion were replaced in the modern era by vernacular languages that rose to prominence through the influence of publishing. This solidarity of the book- and newspaper-reading public, he says, engendered a new principle of social organization in the form of the nation.

Anderson's account suggests that the sacred and the modern modes of consciousness have in common particular ways of thinking about time, space (as reflected in territorial authority), and social relations. If we can call the social realm a dimension of sorts, then we might term these the three dimensions of human life. ${ }^{8}$ This may put us in a position to answer the first question about nations as framing systems. Nationalism provides an integrated way to reframe our thinking about these three dimensions. But this only answers the question of what is being framed in these frames of reference or modes of consciousness. We still need to understand why we take this approach in the first place.

Anderson's explanation is that we form and re-form these modes of consciousness because they offer us ways to deal with the many arbitrary turns of fate we encounter in life. Making sense of the conditions we face in life is a considerable task. It is made easier when there are ways of imagining such fatalities into a system of order and meaning. 
According to Anderson, the pre-modern sacred consciousness and the modern national consciousness have in common that they "rooted human lives firmly in the very nature of things, giving certain meaning to the everyday fatalities of existence (above all death, loss, servitude) and offering, in various ways, redemption from them" (1991: 36).

The national consciousness, then, is like the sacred consciousness in its capacity to transform "fatality into continuity" and "contingency into meaning" (1991: 4). Anderson tells us that there is a fundamental question people ask themselves as they pursue their various journeys through life. It is: "Why are we ...here ...together?" (1991: 56, ellipses and italics in original). If we take "we" to address the social dimension, "here" the spatial one, and "together" to suggest temporal coincidence, then the question identifies the three basic categories for which we must find content. The answers we develop to this question then outline the shape and type of any new imagined community.

If we accept Anderson's view that the national consciousness organizes content and meaning along three main dimensions of human experience, this lends support to the idea that nations have to do with providing a shared frame of reference. But knowing the categories or dimensions that constitute the structure of this frame of reference is only half the story. Frames of reference also serve to focus attention in particular directions and on certain kinds of information and attachments rather than on others. We know nations to be selective in terms of their content and in terms of what they will recognize as belonging to the national type. We now need to ask whether this selectivity is a necessary part of the process.

One way to approach this question is by looking at how selectivity acts to shape the national content, and asking what might be driving this process. I am going to suggest that selectivity is an inevitable part of frames of reference because these framing systems serve as mechanisms to reduce an excess of possible information down to something manageable on a day-to-day basis. Time, space, and social relations, without some kind of horizons to bound them, can become overwhelming in their demands on our comprehension. To illustrate this process I will consider each of the dimensions in turn, and ask why selectivity in content might be necessary to how the national framing system works.

For instance, time is important not only because we are beings that live in a temporal flow, but because the way we think about time affects how we live. At the most basic level, the content of the past helps indicate what to expect in the future. For this reason it may seem that the more knowledge we have about the past, the better we 
can guide our future actions, but it is not necessarily that simple. Nietzsche, in reflecting on the role of history, claimed that too much or too accurate history would exact a high price. We need to select our historical knowledge carefully so that we don't overdose on a "surfeit of history" (1980: 28).

Nietzsche argues that the modern fascination with history as scientific knowledge has had a crippling effect, reducing the positive power of history and making it instead something that hinders us. We need history to inspire us, but in order that the past does not "overgrow" man (1980: 10), we also need to know how to forget. This act of forgetting is how we establish horizons to our existence and as Renan pointed out, forgetting is one of the critical tasks of the nation (1996: 18). Such measures are necessary, Nietzsche instructs, because "every living thing can become healthy, strong and fruitful only within a horizon." If we do not select our historical knowledge then "everything which once was rushes in upon man" and we are weighed down with "indigestible knowledge" (1980: 23-4).

There is another level to our thinking about time that raises the issue of selectivity. It concerns our ideas about the structure of time itself. Anderson's work already points to the contrast between cyclical and linear ideas of time. In the change from cyclical to linear concepts of time we are increasingly conscious of the capacity for time to double up, with two or more events happening simultaneously at different geographic points. When the temporal frame of reference permits this simultaneity, it becomes possible to contemplate other lives and other social worlds as parallel developments, following their own independent narrative. This can generate a sense of pluralism through a consciousness of these multiple narratives, but it also means there is a vast increase in possibilities for what is unfolding at any given point in time. This multiplication creates the same problem of excess that so concerned Nietzsche. Some principle for sorting between these multiple possible narratives, therefore, is part of working with the new understanding of time.

It is perhaps easier to recognize how we have imposed a selective order upon space through processes such as surveying, mapping, or the idea of territorial jurisdiction. But the framing of the spatial dimension involves more than just how we color in maps. Communications theorist Harold Innis claimed that how we manage our relationship with space and time determines the kind of civilization we create, a theme that is echoed through more recent work by Manuel Castells (2000). ${ }^{9}$ Innis felt that the modern era had an obsession with space, shrinking the world through new technologies of transportation 
and communication (1995: 390-426). But as with Nietzsche's history, it's possible to overdose on too much space. While technically possible, centralized control of large territories for corporate operations, political management, or social organization, has not always proven desirable (Innis 1995: 407). Selecting what space is significant for us, therefore, becomes an important process. ${ }^{10}$

Finally, the social dimension also calls for selection and interpretation if we are to achieve a minimum of order and meaning. One way of doing this is through recognizable social roles and indicators. From the basics of everyday courtesy to the relative ranking of social standing, certain aspects of the social dimension need to be stabilized to some degree in order to avoid misunderstanding, insecurity, and distress. Of course, some of these social structures may also create insecurity and distress, by stipulating gender roles or promoting racist or ethnic discrimination. This means we need to we pay close attention to the kind of social factors that a nation embraces. Nonetheless, social roles and rituals can help shape our dealings with the people around us, help inform our own identity, or help interpret the identities of others we encounter.

Indeed such social information can even help us in dealing with strangers that we may never encounter but whose conduct affects us all the same. Increased interdependence is one important feature of modern existence but it is often dependence on nameless others. One basis for solidarity with these strangers can arise from shared circumstances and shared idioms. So when it comes to the social dimension it is important not just that there is selectivity in information, but also that we share this same selection with those around us. ${ }^{11}$ Because if the frame of reference is shared it can support the representational acts that are the basis of collective life. If not, representation will be a more difficult process, and may even fail.

This idea of selecting the content and focus of social knowledge has already been anticipated in theories concerned with complexity reduction in a social context. Like Nietzsche, Niklas Luhmann argues that "a surplus of complexity" leaves an individual "incapable of action" (1979: 71). Luhmann believes that we create systems that can select from among complexity the "possibilities of experience and action" on which we focus and in relation to which we can "orient" ourselves (1979: 32). Luhmann suggests, for instance, that trust is one mechanism we have developed to reduce the complexity of our social world, but it is not the only one, and it cannot work in isolation. Trust works best when other mechanisms of complexity reduction are taking up some of the burden. In fact, Luhmann says that trust cannot work at 
all without a system to structure our understanding of time (1979: 10). This again confirms that the social dimension is inter-related with our ideas of time at a very basic level.

This suggests an explanation for the trust between co-nationals found in theories of nationalism such as David Miller's (1995). If conationals are people who already share a frame of reference in terms of time, space, and social relations, then they are likely to have more resources free to devote to social trust than otherwise. Note that this does not guarantee that trust will develop, but it could increase its chances. What's more, this does not cast nationalism as an expression of social trust, rather it is a mechanism that functions like trust by increasing security and efficacy among a population.

One more question that is worth addressing is the idea that complexity is a special problem of modernity, making selectivity especially relevant for modern collectivities. To put it another way, under the modern reign of complexity might nations serve, in Ernest Gellner's evocative metaphor, as the essential "breathing chambers" (1983: 51) that sustain us under inhospitable conditions? It seems reasonable to think that life was also complex for pre-modern peoples. And the search for meaning or efficacy was hardly an invention of the industrial age. So why do nations make their appearance in modernity?

It may be that collective frames of reference were once more given, less evident, and less interrogated than they are in our day and age. Given that rapidly changing circumstances are a common feature of life under modernity, we find we must revise or reconstruct our frames of reference more often, making us increasingly conscious of the part they play in our lives. In short, rather than being less functional under modernity, we may of necessity become more conscious of how we $d o$ function. We need not conclude, therefore, that we create frames of reference because we can no longer confront life in its fullest reality. If it is part of our normal functioning to imagine communities out of the conditions we experience in our lives, then we do not adopt this behavior simply because we find modernity hard to live up to, or live under. And this means nationalism is not a modern pathology.

In sum, the selectivity of a frame of reference foreshortens our view of reality by positing horizons that influence where we focus our attention. But it also provides a way to reduce the complexity we encounter in everyday reality and in doing so makes it possible for us to live in, and makes sense of, a world of otherwise limitless potentiality. There is a downside to selectivity, of course, and it is that foreshortening can also serve to misinform us or blind us to important realities. This raises another aspect of the framing process that should 
be considered. I am going to suggest that while selectivity is always part of a frame of reference, there are other attributes of framing systems that are relevant to how we think about or evaluate national claims.

Luhmann tells us that one necessary feature of complexity-reduction systems is that they must have relevance for the situation at hand. Speaking of trust, for instance, Luhmann argues that it cannot be willed ex nibilo, that "a minimum of real foundation is required" (1979: 55). Otherwise, where relevant circumstances are overlooked they can come back to invalidate the system (1979: 43). But given conditions of constant change it is not just the one-time relevancy but also the ongoing currency of the system that matters. Reflecting the original context in full accuracy is not an option, for this would replicate complexity not reduce it (1979: 80). Still, there needs to be enough alignment between system and circumstances that it can be differentiated from them, while remaining attuned to them (1979: 26). The bottom line is that the advantages of a framing system can only be counted upon when the frame of reference stays within certain parameters defined by the situation within which it is employed. If it gets too far out of touch with the actual circumstances that it is trying to reflect (albeit in a simplified and artificially stabilized way) then a framing system may hinder more than help the population that employs it.

Bringing the points of this discussion together, we can argue that nations can be viewed as a representational resource because they serve as a shared frame of reference that provides selective content on key dimensions of human life. In doing so they help populations avoid overwhelming complexity and potentiality, and also free up resources for other priorities and processes such as social trust. As such, they are an adaptive not pathological response, but to provide a useful basis for representation, the national frame of reference needs to stay in tune with the circumstances of the population that is employing it. I am not suggesting that the national idea can never break loose from its roots in the reality of a population's situation, however. Only that when such drift occurs, the nation loses value as a framing system.

\section{Conclusion}

This chapter argues for understanding nationalism as a strategy for enhancing representational resources through a shared frame of reference. Yet even if we need a shared frame of reference for representation, and even if the national frame of reference may be especially relevant to representation in the modern setting, we are not obliged to 


\section{Nationalism as representation}

accept any nationalism that happens to develop. That would be the same as saying that we are obliged to trust any person that came along, just because we know that we need trust in our lives. Sometimes people don't deserve trust, and sometimes the claims that nations make do not deserve moral standing. Knowing when to accommodate national claims and when not to, just as with knowing when to trust certain people, is a complex calculation in its own right. So even if we can identify the moral claim of nationalism as arising in its role in representation, we must still evaluate the worth of this claim, in light of other possible concerns. 


\section{Evaluating nationalism as representation}

I have argued that the formulations of nationalism encountered in Ireland and Quebec hold two important lessons about nationalism. The first is that there is a political/cultural dynamic to how the phenomenon unfolds, and so it is not realistic to envision a nationalism based primarily on one or other element. The second is that these two formulations are linked by a shared concern with the conditions for representation among a population. Because the nation indicates a select set of information and ideas that can serve as a shared frame of reference, nationalism can be understood as the desire to establish or protect a collective representational resource.

Yet even if we understand the motivation for this claim, this does not mean it is automatically just or legitimate. We need to evaluate it as a moral claim in its own right to make this assessment. It is useful therefore to ask how this understanding of nationalism stands up against other theories that might evaluate the claim differently. I begin by comparing this account to other theories that argue for the broad legitimacy of national claims, and ask what a representational approach can bring to this field of theory.

Not all recent theoretical work on nationalism has been in favor of its accommodation, however. It is useful to ask, therefore, whether an approach to nationalism as representation can help respond to some of the issues raised in this larger body of work. Arguments for national accommodation have been countered in at least three ways. The first way points out that people have complex identities with many social markers (such as gender, age, sexual orientation, religion, etc.) that can each create a uniquely situated population. So the question is, why should national cases be accorded more consideration than these other kinds of differences? In today's complex world, isn't a multicultural approach the only fair way to go? 


\section{Evaluating nationalism as representation}

The second set of arguments against national accommodation suggests that even if nations once held a special position in the social and political order, the world has moved on, and it's no longer necessary or even appropriate to make national accommodation a priority. New, more evolved forms of group accommodation such as post-nationalism or transnationalist alternatives are better suited to addressing contemporary problems. A third set of arguments suggests that there is a milder version of particularist political attachments available, a version that can achieve the same ends as nationalism without incurring the same risks in terms of violence and discord. By substituting patriotism for nationalism, so the argument goes, we can keep the good and lose the bad while still maintaining defined and cohesive political communities. These are powerful and important challenges and I will address each one separately.

Seeing how a representational account would respond to the arguments raised in these other theories is one way of evaluating its contribution. Another is by focusing on the question of limits, and this is the work of the second part of the chapter. While accommodating a population's desire for a representational resource is a legitimate concern, it should not be pursued at any cost. This means nationalism must be limited in important ways. I suggest that there are both internal and external limits that should apply. Some of these are already implied in the logic of nationalism as representation, while others flow from our concern that other things we value, such as the moral equality of persons, should be respected regardless of the context of a particular claim. With these limits recognized, a representational approach to nationalism can be consistent with other moral priorities that prevail in liberal-democratic societies. Since it also brings something to the debate on nationalism that is not fully accounted for in the other theories addressed in this chapter, this suggests the representational approach has value as an understanding of the moral claim of nationalism.

\section{Alternate theories of nationalism}

The approach to nationalism that views it as a claim about the conditions for representation serves to complement existing work on liberal-nationalism, since it suggests that liberal theory should take an interest in national claims. But it differs in important ways from the approach found in several leading works in this area. For one thing, it aims to work with the link between the political and cultural aspects of nationalism, rather than focus on how they can be divided. At the 
same time it suggests grounds for rejecting approaches to national identity that center on particular cultural characteristics or traits.

As discussed in Chapter 5 some liberal theorizing on nationalism has leant towards what I called a bifurcation approach. Much of this theory, I argued, seeks to categorize nationalism as either a primarily cultural or primarily political claim, and the motivation for this approach is understandable, as the link between politics and culture can lead to problems in both areas. But when it comes to nationalism the connection persists nonetheless. When construed as a claim about political identity and solidarity, as Moore suggests, the satisfaction of a national claim is likewise thought to rest within that area. Alternately when it is thought to be about cultural security and propagation, as Tamir recommends, it makes sense then that efforts at accommodation can properly be focused on this arena. The problem is that the representational process cannot be assigned exclusively to either arena. Viewing nationalism as a claim about the conditions for representation may make the phenomenon more challenging to work with but it better reflects its political/cultural dynamic and steers us away from approaches that do not prove viable in practice.

Still, a representation approach to nationalism is not a dramatic departure from work in this field. The approach shares with several theories of nationalism or multiculturalism an assessment of national cultures as significant to identity (Norman 1995; Taylor 1995a), meaningful life-options (Kymlicka 1995), or mutual intelligibility (Tamir 1993: 128). But it explains these relationships in a slightly different way. If national cultures are cast as the direct source of these qualities, we risk over-prioritizing national claims. If our personal identities, our capacity to make meaningful choices, or our ability to make ourselves understood to others is dependent on the secure continuation of a given culture, we would have good cause for protecting those cultures and accommodating the national claims to which they give rise. But we would also face difficulties when it comes to revising those cultures, or rejecting or modifying those national claims if required by, say, a counter-claim from another national population. The theorists mentioned have not argued for reading national cultures under these extreme terms. The difficulty is that their work does not clarify why, if they are critical to fundamental needs, we should stop short of seeing nations as fundamental priorities.

Alternately, if we recognize nations as facilitating representation through a framing system, we can see how it would play into factors such as self-identity, meaningful choice, and mutual intelligibility, without seeing it as their sole grounds. For example, under this approach 
we can view national cultures as facilitating the representation of life choices, without suggesting they present the sum of these choices available for any given population. For this would either limit our potential for choice (suggesting we are handicapped when it comes to choosing outside our cultures), or imply some kind of comprehensiveness to culture (my culture will address all the choices I need). Neither claim is plausible, but we do not need to see culture in this exaggerated light, to recognize its role in rendering choice meaningful.

Will Kymlicka writes that national cultures not only provide life-options but also supply a "shared vocabulary" through which we can approach these choices (1999: 114). As a vocabulary, the social and cultural practices associated with a national group can "render vivid to us" the point of the activities we see around us. Cultures are, he says citing Dworkin, the "spectacles through which we identify experiences as valuable" (1999: 114). Or as Daniel Weinstock puts it, some kinds of membership "provide us with frameworks within which we lead our lives, rather than pointing towards goals that we set for ourselves in the leading of our lives." In other words, they provide "reference points and self-understandings" that we use to orient ourselves (2005: 235). In the same vein we could say that national frames of reference are not about stocking people with a particular, identifiable set of choices. They are, instead, mechanisms for representing choices and the environment within which they are made.

Yet does this approach, by recognizing nationalism's role in establishing a shared frame of reference, run the risk of repeating the error of over-privileging national claims? Representation may be a more demanding task without the aid of a particular frame of reference. But understanding nationalism as a framing system does not imply that it exhausts the means of achieving representation, although the costs and risks involved in other approaches may be higher. We know, for instance, that people are capable of changing their national attachments, living with bi-national or multi-national identities, or identifying as cosmopolitans that regularly move between different national settings. In Linda Colley's colorful phrase "Identities are not like hats," we "can and do put on several at a time" (1992: 6). Because of the additional risks and costs involved, changes in the conditions for identity should not be imposed on populations lightly. Where a good reason exists, however, the approach to nationalism as representation suggests this additional effort can be fairly required without decisively undermining a population's psychological, moral, or interpersonal resources. 
An approach that links nationalism to representation would also take a slightly different approach to assessing national claims than some contemporary theories on nationalism or multicultural accommodation. Often these approaches place considerable emphasis on shared identity or on cultural traits such as language. But a representational approach does not prioritize these concerns. Instead it argues that while we should give serious consideration to the role that existing cultural forms play, we can legitimately require revisability as a quality of a national frame of reference, because this tells us something about its prospects for retaining both currency and relevancy for the future. If a national claim cannot meet this requirement it is unlikely to serve the representational needs of the population in the long term, reducing its moral status.

In other words, this approach suggests that in assessing a national claim we should not be focused on the need to preserve particular traits, rather we should focus on how those traits relate to the presence of a representational facility among that population. So in contrast to theorists such as Chaim Gans, who sees the justification of cultural nationalism arising in the intergenerational preservation of a cultural heritage (2003), this approach requires that these representational resources should be respected and accommodated only so long as they are serving their original purpose. This leaves open the possibility that the representational needs of a population will evolve, and that their cultural and political representational institutions should change along with them.

Gans acknowledges that the preservation of particular cultural practices should be conditional on their continued meaningfulness, but also suggests that at a "pervasive" or "societal" level cultures will continue to have meaning, and so will have a persistent claim to preservation (2003: 55). An approach to nationalism as representation does not go quite so far. It does not offer assurance that a national culture should be preserved against change or transformation. Instead it aims at preserving the role that a national culture plays, by ensuring that representational resources, rather than their particular form at any given time, are what is protected through accommodation. In some instances, that will effectively mean accommodating particular national traits, such as language or religion. But it does not make national status dependent on the continuation of those traits, nor is their preservation the aim of accommodation. The aim again is to preserve the representational facility that is, at any given point in time, iterated through particular cultural and political forms.

Looking at nationalism from a political perspective, this approach again suggests new criteria for assessing a national claim. While 


\section{Evaluating nationalism as representation}

shared nationality can facilitate representation in the political realm, as with culture, this process is not above scrutiny. David Miller endorses an understanding of the national claim based on the belief that co-nationality enhances the prospects for social trust, solidarity, and social justice (1995). But this presumes a nationalism that strives to fairly represent the population involved. It is possible, however, for nationalism to be deployed in a way that undermines the political representation of some within a population, and in this case we might not want to recognize it as having the moral standing Miller suggests.

Under a representational approach to nationalism, by undermining the political representation of any populations within its purview, nationalism can undercut its own moral claim. This means that in asking about the appropriateness of politically accommodating a national claim it is legitimate to ask how everyone involved in a given situation is represented within that national frame of reference. If minorities or traditionally disadvantaged groups face diminished representation under a national system, then this must count against that claim, at least in so far as this claim is understood as a claim about representational resources.

\section{Nationalism and multiculturalism: mutually modifying}

Multicultural theory shares with theories of nationalism a concern for secure cultural identity. But because it argues for accommodating these needs within existing political regimes, it does not raise the same prospect for political divorce that nationalism does. So it is reasonable to ask, given the rise of multiculturalism and its increasing acceptance in both theoretical and political circles (Kymlicka 2001: 39-48), do we even need a theory of nationalism at this stage? Or can multicultural theory provide solutions that will work for national as well as immigrant or multicultural populations, without entailing the disruptions that nationalism involves?

Nationalism's emphasis on political or cultural autonomy can seem divisive when the drive of multicultural theory is to find ways for different cultures to live together in equality and justice. Suggesting that some populations can solve their difficulties through a form of exit seems like an abandonment of multicultural principles, and moreover, champions a solution that is available to some but not all minority cultures. Since multiculturalism is premised on the idea that states should not promote a single cultural identity, as this privileges the dominant cultural group and unfairly marginalizes and disadvantages others (Kymlicka 2001: 43), there is a danger that nationalism will 
merely recreate this unfair arrangement in a new political order. In other words, if the national claim simply involves trading places in terms of cultural or political dominance, then it presents a problem for multicultural justice.

Further complicating the picture is the fact that nationalism is often defended on the same terms that multiculturalism itself uses - secure identity, individual autonomy, recognition, etc. Multiculturalism can also lay claim to a role in representation, so when national and multicultural issues appear together, as they often do, there is no clear sense of which approach should take priority. Should national claims bow to the aim of developing a just multicultural order? Or should multiculturalism concede to the aim of pursuing a national project? I am not sure we can decide between these two options in the abstract. But I want to suggest that the two aims may not be mutually exclusive, rather they may be mutually implied.

Both multiculturalism and nationalism address representational issues but they emphasize different aspects of the process. On the one hand, multiculturalism reminds us of the importance of recognizing difference, and finding appropriate ways to accommodate and represent the differences that matter to people. Nationalism, on the other hand, is focused on securing a basis for shared representational acts. These are in fact complementary goals. Omit either one and your representational system is likely to run into trouble. In pursuit of sharedness it will fail to represent relevant differences, or in pursuit of difference it can fail to provide a shared basis for mutual representation.

So it may not be a matter of deciding between nationalism and multiculturalism. Instead they should be regarded as mutually modifying principles. Where multiculturalism emphasizes the role of culture in individual autonomy, for instance, nationalism emphasizes its role in collective autonomy. Where multiculturalism stresses that barriers to integration and participation should be minimized, nationalism stresses that some integration should take place nonetheless, and indicates what that may involve (Miller 1995: 138). Multiculturalism may require that national cultures are revised towards greater openness and accommodation. Yet to revise any culture towards a more open and inclusive stance means having something coherent to revise in the first place. It also suggests that there should be an identifiable outcome, one that the population or populations involved can recognize and adopt as a new cultural and political form. Nationalism and multiculturalism then, because they share a concern for representation, share a concern for revisability, which will require that both change and stability play a part in a population's political and cultural life. 


\section{Evaluating nationalism as representation}

Nevertheless, we might grant that the national claim has its roots in a concern with the conditions for representation, and still conclude that what is called for is better representation within the existing order, rather than something that threatens to fracture an existing political project. Anne Phillips has developed an account of what she calls "the politics of presence" which argues that for many previously excluded groups enhanced representational presence within the existing political order can help meet the needs of their situation (1995). Why shouldn't this also be the case for national populations?

Phillips develops a powerful argument based on several points but the most compelling argument, she believes, is the potential for a politics of presence to lead to policy transformation (1995: 175-6). Phillips stresses that not all policy options can be worked out in advance, therefore it is important to have a diversity of voices at the table when final details are being decided (1995: 157). Phillips' arguments, therefore, are motivated by a concern for good government. Yet instead of the politics of presence, the national claim can lead to a politics of absence. It potentially involves a withdrawal from shared politics and culture that, if Phillips is correct, promises to thin out the policy agenda not only of the break-away nationalist population but also of the rump population. To put it another way, is it preferable to address national claims through a politics of presence, rather than more expansive political or cultural restructuring?

Phillips discusses the question of national minorities and selfgovernment claims in light of the politics of presence, and addresses the Canada/Quebec situation in particular (1995: 115-45). Her conclusion is that there is no easy fit between the two sets of representational concerns, and she admits that the politics of presence proves "wanting" when it comes to certain national questions (1995: 121-2). These include the "pressing concerns" that national minorities may have "about sustaining cultural or linguistic identity," concerns that a politics of presence may "sideline" in the pursuit of its own goals (1995: 141). Phillips does not take the discussion of the national claim much further than to recognize this "potential incompatibility" between national and minority/gender claims (1995: 125). Her interest is in working out the implications of the representational argument for groups seeking inclusion and integration, rather than those who feel their situation demands new arrangements.

However she does appear to contrast the assumption of heterogeneity associated with a politics of presence with the concerns for cultural and linguistic identity that arise for national populations, and she defends the right of groups to hold these latter priorities 
(1995: 142). In this she may seem to come closest to defending a national claim, but I want to suggest that a commitment to cultural and linguistic stability is neither required by an understanding of nationalism as representation, nor is it implied by the principles of a politics of presence.

Phillips is correct in saying that many nationalists are motivated by a concern for cultural resources and it is true that the national claim has often been voiced in terms of preserving a specific national character. But if we take it that a desire for cultural stability is valid, then this jars with Phillips' firm rejection of essentialism, and is out of step with her emphasis on maintaining an open policy agenda. If keeping policy options open is a significant political principle it should be observed both within national minorities and self-government projects, as well as in more heterogeneous or multicultural settings as Phillips herself insists (1995: 126). This might seem to run counter to the aspirations of many nationalists, whose expressed aim is to establish a particular political and cultural order, but I will argue that Phillip's emphasis on openness and deliberation actually aligns with the concerns of nationalism as representation.

Drawing on Phillips' thinking on presence and deliberation, we can craft the argument thus: Her argument is that we need to create a setting within which the full range of policy options can be voiced and considered. Nationalists in turn argue that in some cases the same goal may require setting up a separate political order to address the situation of a differently situated group which no longer has confidence in, or a desire to be incorporated within, a larger majority. This may be because they have found they cannot achieve the full range of options they desire under the prevailing system. It may be because they were not incorporated by choice and resist the arrangement in the name of historical autonomy. But if it is founded on a concern for representational resources, then creating a new representational system does not give this entity the right to limit the policy agenda in other ways, for example by enshrining particular religious, ethnic, cultural, or linguistic terms as non-negotiable. As Phillips points out, ideas and presence both play a part in the representation process. So if we enhance representational presence through political or cultural changes, then we should in return be able to open the field of ideas, not restrict it.

This emphasis on openness may seem to be in tension with the national frame of reference's inherent selectivity. But the tension is more apparent than real. Selectivity is an ongoing process, constantly being revised and adjusted to suit changing circumstances (akin to 


\section{Evaluating nationalism as representation}

Phillips' final decision-making stage in the policy process). While we may recognize the role of selectivity, this does not mean any particular selection should ever be regarded as immutable. What is critical is not the selection itself, but the process of collective deliberation that reaches some shared selection. Ensuring you have the best resources to engage in that process is a concern that motivates both Phillips' politics of presence, and the account of nationalism that understands it as a representational claim. In other words, nothing in this understanding of nationalism calls for the thinning out of the policy agenda, or the marginalization of certain voices in the process. Instead, the emphasis is on creating a space within which issues can be effectively addressed, and where representational resources can be translated into broader political and cultural imaginations.

\section{The post-nationalist challenge}

I have argued that a shared frame of reference is necessary for shared representational acts. But nations are not the only entities that frame our shared experiences. This begs the question: what's so special about nations, even if they are providing a shared frame of reference? ${ }^{1}$ They are clearly not the only framing systems we collectively employ. Plenty of groups may have their own frames of reference, without taking on the political or cultural significance to which nationalism lays claim. For some observers, therefore, nations seem unduly privileged over other attachments that may be equally important to people (Buchanan 1996). So why should nations have a special place in questions about representation that something like, say, religion does not?

The answer, I think, comes not from the nature of nationalism, but from the nature of modern politics. In the modern era politics has been "territorialized" (Anderson 1991: 19) and set within borders. We define political authority primarily in geographic terms and sovereignty, jurisdiction, and citizenship are by-and-large tied to particular spaces. This was not always the case, and this territory-authority connection is not a universal rule. It may one day be surpassed by new thinking on space and authority. For the time being, though, the frames of reference with most relevance for modern politics continue to be those that bring with them a secure and clear attachment to a set of territorial information (Murphy and Harty 2003: 192).

But territory alone does not found the modern political project. Nations combine their territorial connections with concepts of history and social relations in a way that few other frames of reference replicate. The integrated package of information that the nation represents, when shared by a population, provides a special kind of territorial 
attachment - one that can, quite literally, ground political authority. The advantage that nations have over other framing systems, in other words, is that they bundle together the social, temporal and spatial dimensions. Meaning that nations offer what today's politics needs a reason for setting boundaries in a particular place and for keeping them there. So to answer the question of why nations are special kinds of framing systems: from a strictly moral perspective, they are not. Yet even if they are not inherently more significant than other framing systems, their structure and content means they align well with the needs of a political order based on collective legitimacy and territorial sovereignty, because they integrate territorial jurisdiction with other aspects of our collective lives. For as long as our political system is territorially focused and premised on representational legitimacy, nations will have a significance few other such systems can match.

Some critics of nationalism might concede that its qualities made it uniquely suited for modern politics. But they point out that politics itself continues to evolve, becoming more global, more transnational in orientation (Murphy and Harty 2003: 183). In light of shifting relationships that open up new and possibly more emancipatory or flexible forms of political community, might there be better representational resources, better framing systems, to be recommended? One possibility, for example, is the idea of a post-national basis for collective cultural and political representation. Post-nationalism involves the suggestion that something new can evolve out of a previous nationalism, when attachments to ethnic essentialism, or territorial integrity are given up in the name of greater diversity, stability, or justice. The contemporary Republic of Ireland, for instance, is sometimes cited as an example of this evolution in process. The Republic has seen both a loosening of territorial claims towards the North and a re-definition of the national character away from exclusivist religious or ethnic categories and towards an open, pluralist, and European-oriented society.

I will suggest in Chapter 9 that these developments can be overinterpreted, and that in the Irish case we are more likely to be witnessing a nationality being redefined rather than retired. What an approach to nationalism as representation can tell us about the prospects for postnationalism, however, is that any new political form would still face the same problem that the original nationalism addressed. To provide a basis for representation, the new form would need to ensure some shared frame of reference was available among the population in question. The difficulty is that by defining post-nationalism in terms of what it is not - not socially restrictive, not territorially fixed all that post-nationalism can point to is the absence of shared reference points. It is not impossible that new forms will evolve out of 


\section{Evaluating nationalism as representation}

nationalism, forms that have the capacity to ground cultural and political representation in worthwhile ways. But in so far as postnationalism is defined by its tendency to transcend the bonds that defined the national frame of reference, it gives us little guidance as to how it might generate new representational resources.

In other words, if nations have the significance they do because of the role they play in facilitating representation, we cannot regard postnationalism as a plausible alternative until one of two things happen. Either we develop ways to engage in representation that minimize our use of frames of reference without requiring an onerous additional effort be devoted to representational activities. Or post-nationalism develops its own framing system which, while distinct from the national form, could provide enough of a basis to facilitate representational acts. Neither of these developments is beyond the realm of possibility. They are, however, long-term and large-scale developments that are unlikely to offer us practical resources in the near term to help address immediate problems for national populations (Kymlicka 2004).

Similar difficulties arise with a transnationalist alternative to nationalism. While this may indicate a future direction for political developments there is little to suggest that a transnationalist structure exists that is ready to assume a role in collective representation. Transnational democratic institutions have turned in disappointing results when it comes to capturing the loyalty or allegiances of the multinational populations they serve (Kymlicka 2004: 257-61). Such institutions may be established, and often with the best of intentions, but representation cannot be imposed on a population. In the absence of a pre-existing frame of reference that reflects this structure, a multinational or transnational representational order is unlikely to have much meaning or legitimacy for a population. And at present any transnational or multinational frameworks that exist (such as the European Union, for instance) are weak as compared to national ones (Kymlicka 2004: 258; Murphy and Harty 2003: 186). While they may present a more pluralist alternative to nationalism, then, these new political forms may also reduce the representational resources a population can bring to bear on its political and cultural life. So at the very minimum, this should be a choice a population makes for itself, rather than one we can fairly impose as a requirement of justice.

\section{The patriotic alternative}

Post-nationalism is not the only political form held up as a preferable alternative to nationalism. The other alternative turns out to be as old as 
post-nationalism is new. By cultivating a patriotic or republican stance towards our political projects, some argue, we can replace nationalism with a healthier form of political attachment. If we can resuscitate patriotism as the love of liberty embodied in a particular project, we can dispense with national attachments in favor of a more "generous" political stance (Viroli 1995: 2) grounded in an alternative form of belonging such as "constitutional patriotism" (Habermas 2001).

One of the first things to note in assessing the patriotic alternative to nationalism is that advocates of patriotism position their approach as an alternative to an exclusivist and descent-based ideology associated with nationalism (Habermas 1992: 4). In contrast, the commitments associated with patriotism are presented as politically focused and centered on the development and maintenance of a particular population's civil rights and privileges. As Margaret Canovan has put it this distinction amounts to "a contrast between art and nature" where patriotic citizens are "united by their commitment to liberal democratic principles," while nationalism is a matter of "ethnicity and culture" (2000: 415-16). This relationship heavily echoes the distinction between civic and ethnic versions of nationalism.

But by retaining the common root in nationalism, these terms at least have the virtue of reminding us of the unavoidably adulterated origins of our liberal projects. Moving to the language of patriotism, however, may give a false sense that these origins and the practices associated with them (such as citizenship by birth) are now firmly consigned to a collective past (Canovan 1996: 92-7). Indeed this is just what the patriotic alternative seems primed to do. This new mode of patriotism promises to deliver the binding power of nationalism without any of its exclusivity. So long as cultural or ethnic concerns are kept out of politics and the focus remains on the cultivation of shared political liberties, the advocates of patriotism conclude, the political project can combine both commitment and openness with none of the dangers that nationalism entails.

Thus a common theme in the republican approach is that it favors questions concerning the form of government over pre-political questions of membership or defining the people. As it happens, such an approach was already attempted in the Irish situation and the results help illuminate the difficulties with deploying republicanism as a response to national claims. At the end of the eighteenth century republican ideas were spreading rapidly in Ireland and promised to dramatically re-shape the political landscape. The revolutionary nationalist figure Wolfe Tone was among the more radical Irish republicans of this period, but there were others who were loyalist in their 


\section{Evaluating nationalism as representation}

commitments while still seeking significant political reforms (Dickinson 1997). Thus they were republican and reformist without being separatist or nationalist, a seemingly ideal combination.

Stephen Small has written a revealing account of the political thought of this period, focusing on the experience with republicanism (2002). The early republican experiment fails in Ireland, he says, because it had an inevitable tension at its heart, one that its adherents were unwilling to address. That tension concerned the question, "who are the people?" Or to put it another way, in whose name is government to be reformed? Reformist republicanism took root in Ireland among individuals who were largely of English and Protestant extraction, a group already privileged under the prevailing laws. They recognized that republicanism required a civic body imbued with civic virtue, but many concluded that the mass of the Irish population was unsuited to full citizenship due to their religion, poverty, and lack of property ownership.

So while there was commitment to reform the system of Irish government, there was often, in Small's words, "ambivalence towards Irishness" (2002: 38) on the part of these patriots such that "the most fervent Irish republicans were likely to be strongly anti-Catholic" (2002: 135). They sought reform of government, while hoping they could avoid addressing the issue of political membership. This, Small concludes, is the reason Irish republicanism proved incoherent, ultimately splitting into Protestant Ascendancy on one side, and radical nationalism on the other. For as he put it "Constant appeals to 'the people' could hardly avoid indefinitely the issue of whether the Catholics were included in this definition" (2002: 139). Lest it appear that eighteenth-century Irish Protestants were alone in their tendency to view republicanism in self-interested ways it is useful to recall that republicanism made another appearance on the Irish scene more than a century later with the 1916 Rising. In this case, republicanism aimed at establishing a regime that would confirm membership based on Catholic virtues, an approach that left Protestants at a civil disadvantage.

It might be suggested that republicanism is a perfectly good theory that was simply ill-used in the Irish case. But I don't think this is sufficient to set aside the problems that this example raises. Both instances of republicanism in Ireland show that the question of membership has profound consequences for the kind of republicanism that results. The lesson that can be taken from the Irish experience, therefore, is that the question "who are the people" is unavoidably prior 
to questions concerning forms of government. Left in abeyance, the problem does not go away, instead it may take on added urgency.

The omission of this question from recent discussions of republicanism, therefore, is especially perplexing. Philip Pettit has sketched an appealing political alternative based on the republican idea (1997). And as with Habermas and Viroli, Pettit's account largely assumes that there is already consensus on the membership issue. This does not diminish the value of his work in outlining a republican theory of government. Still, it does make it less than straightforward to introduce it in situations where there is disagreement on the people question.

Pettit recommends a system that puts the ideal of non-domination at the center of the political order (1997: 51-78). And his republicanism is not necessarily hostile to minority accommodations even when those groups have a distinct national identity (1997: 146). Indeed his work may even sanction exit under extreme cases of irreconcilability. ${ }^{2}$ Yet the balance of his argument assumes these disagreements have been resolved and that clarity prevails regarding the composition of "the people." This clarity, however, was glaringly absent in the Irish and Quebec cases, and without it, there can be deep disagreements over what non-domination requires.

The difficulty is that while non-domination may have the potential to make things better by removing arbitrary power, in the wake of those reforms it offers little resources for indicating who should administer power over whom even if it is through rule of law in a well-governed polity. To put it more pointedly, when it comes to introducing republicanism into cases of national conflict, we can't say in advance what kind of outcome republicanism would more properly support. On one side we have the political autonomy option (as a means to reduce arbitrariness and enhance just government (1997: 68)), on the other, the cultivation of virtuous attachment to the larger state under reformed terms (so people won't experience government as domination (1997: 97)). Strong arguments can be developed on either side, and in the Irish case republicanism turned up in both Loyalist forms that favored the attachment route, and separatist forms that favored the autonomy solution, confirming its ambiguity on this point. Thus it appears that republicanism is at its best when it is recommending a form of government. It seems to have limited resources for addressing the more fundamental question of how to decide what population group should be represented under which political project to begin with. ${ }^{3}$ 
The difference between republicanism and nationalism, therefore, is that nationalism reveals that an important link runs between the political and cultural (or pre-political) life of a population, a link that plays a fundamental role in the conditions for representation in both areas. The question is whether patriotism or republicanism can assume the role that nationalism once played in terms of particularist political attachments without also coming to terms with the connection between the political and cultural aspects of membership. It seems reasonable to conclude that this dynamic will persist regardless, but neither a patriotic nor a republican approach seems prepared to respond to it, preferring to sideline the issue while addressing more classically political matters.

When understood as a claim about representational resources, nationalism indicates the presence of an important dynamic between politics and culture, a dynamic that plays a part in the pre-political connections that undergird a representative political project. Accommodating nationalism, of course, requires us to question the ways in which this dynamic plays out, and ask where it may be appropriate to limit or reject the claims that a national group may advance. Patriotism, in contrast, promises we can rise above these relationships while republicanism suggests we can treat them with benign neglect. Adopting either course risks replacing caution with complacency, and may put populations at greater risk than under an approach that favors careful assessment and accommodation of national claims.

\section{Internal and external limits}

Having evaluated nationalism as representation in light of other important approaches in the field, the next relevant question is whether an approach to nationalism that centers on its role in representation entails any limits on the phenomenon. I am going to suggest that we can look for these limits in two areas. The first set of limits is implied in the logic of nationalism as representation. The second includes those that we may decide are necessary to modify the claim in order to protect other principles we value. The first I call internal limits, and the second I call external, because even though there may be intimations of these limits within a representational approach, they should not be conditional on a particular reading of nationalism.

There are two major candidates for internal limits or conditions associated with a representational approach. The first arises in the idea that the requirements for currency and relevancy in a framing 
system are linked to its functionality or effectiveness as a basis for representational acts. If this understanding of nationalism is correct, then nationalism is not about the maintenance of a particular set of ideas or characteristics. It is about having a way of adequately representing what a population's shared ideas or characteristics look like at any given time, and about representing the kinds of experiences and circumstances that members of the population may encounter in their daily lives. And it should also serve as a basis for representing ideas that originate outside the national frame of reference. A representational resource that could only support a limited slice of the real and extended world would be unlikely to support the full range of representational acts in which a population may need to engage. These conditions therefore suggest an important limit on nationalism. To serve as a representational resource nationalism should neither be closed to outside content nor essentialist in regard to its own content. It must be flexible and responsive to changing circumstances since these changes may entail new representational needs.

This is, of course, a difficult balance to strike. The need to modify the national frame of reference in response to changing circumstances stands in tension with the need to preserve enough of it to support its representational function. Nonetheless, the requirement focuses our attention on this relationship and gives us some means of evaluating its impact. Yael Tamir, for instance, stresses that in recognizing a right to a national culture we are also recognizing a right to "re-create it" (1993: 49) and David Miller stresses that accommodating nationality must leave room for critical reflection and "selective endorsement" (1995: 45). In both cases these requirements are motivated by a concern that nationalism should not compromise liberal autonomy. By viewing nationalism as a representational resource, however, we are able to explain why critical reflection and revisability is a relevant requirement for all nationalisms, liberal or not. It is built into the logic of nationalism as representation that it should evolve as a population's circumstances evolve.

The second internal limit on nationalism as representation concerns how nationalism construes the standing of others - both inside and outside the national frame of reference. At one level, the very act of representation is premised on the ability of both parties to appear as intelligible to the other, given the right conditions. This in turn suggests that the act reflects a belief in a certain level of equality. For both the effort to represent to another, and the expectation of success, assume that the other party to the process is worth engaging in this manner. This, I suggest, sets a certain baseline for moral equality 


\section{Evaluating nationalism as representation}

associated with nationalism as representation, if it is to be consistent with its own premise.

On a broader scale too, claiming that representational needs are what ground a national claim requires a broader level of mutual respect, because the claim is being made on the basis of representation as a universal good. If one group's national claim is worthy of consideration because of its role in representation, then so is the national claim of other groups, including those groups which may be situated within, or mixed among, a larger national population. The claim, in other words, is reiterative, not just because nationalism is reiterative but because representation is. It implies a claim that can be made by any population that understands itself in these terms.

The second type of limits I mean to address are those I class as external to nations. Since the national claim must be weighed against other things we value we can set out limits that we consider nonnegotiable moral standards. Chief among these, I propose, is the requirement for equal respect of persons. I want to approach the question of external limits by way of three important objections to nationalism. The first argues that the national frame of reference could represent pernicious content, that any given nation might well be based on a frame of reference that incorporates discrimination, domination, or self-aggrandizement, and that accommodating this nation can put us in the position of endorsing these ideas. Let's call this the discrimination/domination objection.

The second objection arises in cases where there are internal minorities or where some of the national population is left outside the effective boundaries of the national project. In these cases there may be people inside the territorial boundaries of a nation who do not want to participate in the national project and this can leave such people socially or politically excluded. Let's call this the mixed populations objection. The third objection concerns the fact that there are other frames of reference that can be equally important, or sometimes more important to people than the nation. Or there may be at least two national frames of reference in play, with some people attached to both. Privileging one national project over other attachments can force an unfair choice on people, or can mean the sacrifice of an important collective resource. Let's call this the multiple frames objection.

These three objections - the discrimination/domination objection, the mixed populations objection, and the multiple frames objection strike us as problems because they all violate a common moral principle. In each case, the concerns and wellbeing of some people are not granted the same weight as those of others. 
If nationalism necessarily leads its adherents to privilege the well-being of some above that of others, then there is a significant problem with its claim. Yet there are some that believe nationalism is all but defined by such a drive, and that at the root of most claims to cultural accommodation both national and multicultural is a desire to engage in "old-fashioned discrimination" (Barry 1999: 143). ${ }^{4}$ If this is the case, then while nationalism may offer significant resources for a population it may come at too high a cost in terms of the potential for abuse, inequality, and disadvantage. The question, therefore, is whether an approach to nationalism as representation can help address these issues.

Attempts to deny the reality of a mixed population, multiple frames of reference, or internal minorities, involve an attempt to deny the actual circumstances in which a population lives. By going too far outside the reality of the situation in an effort to undo some parts of it, exclusionary nationalism devalues itself in terms of currency and relevancy. Thus I expect that for prudential reasons alone such nationalism would prove a counterproductive strategy, in addition to departing from the moral grounds on which the claim is established. Nonetheless given the prevalence of such problems in the historical experience with nationalism we might be ready to insist that the requirement for equal respect for persons should always act as a limit on the moral claim of nationalism, even if we view it as an external limit. So while equal respect may already be a functional requirement of nationalism as representation, this is not the main reason we insist on this limit. We insist on it not to make nationalism more effective, but because there are other moral priorities that we are concerned with observing. If nationalism cannot meet these terms, we are right to reject it.

Still, why should we expect nationalists, or at least the most extreme nationalists, to accept such a limit? The reason is that our willingness to consider a national claim can fairly be premised on a principle of reciprocity. Unless we already acknowledge people to have equal standing, and acknowledge that they can come together to make collective claims, nationalism's moral claim is weakened. A basic level of reciprocity is built into the process of representation itself, and this means that populations with similar claims should be treated similarly. This suggests that non-national frames of reference too should be accorded the same consideration as that claimed for nations, which raises the possibility of moral stalemate. Can we not claim that to be shown respect, and to be protected from degradation and alienation, each individual has an equal claim to have their own 


\section{Evaluating nationalism as representation}

frame of reference politically or socially established? Can we realistically expect to support that many frames of reference? Or can even just one person veto the accommodation of a national claim on the grounds that it does not fully reflect their own frame of reference, national or otherwise?

While frames of reference have value for an individual, it is important to stress that they are not individualizable goods. They are irredeemably collective; they function and have value only at a shared level. This means that no one gets a complete guarantee that his or her frame of reference will be protected or promoted. What they should be guaranteed is an equal opportunity to initiate such a claim in cases where enough people around them share the same goal. But this opportunity will of necessity be limited by the circumstances in which these people find themselves. If the number is too small to support the range of cultural or political activities to which they aspire, then they may not be able to muster the resources to retain that frame of reference. This is not a failure to show respect for persons, however. It is merely that to establish a framing system for collective representation, you need the collective that goes along with it.

One final question arises from this matter of limits. Does the addition of the requirement for equal respect for persons mean that what's acceptable is a cleaned-up, liberal-style nationalism, rather than nationalism per se? Not necessarily, not unless we believe that equal respect is a principle exclusive to liberalism. And since it's possible to imagine communitarian ways of life that also require equal respect for persons, there is no reason to think that this approach merely hybridizes nationalism with liberalism in order to make it morally palatable.

These three objections point to the potential for nationalism to lead to undesirable outcomes if it is not limited in certain ways, and they focus our attention on the most difficult aspects of accommodating the nation. These challenges include: ensuring that national content does not involve harm to either insiders or outsiders; balancing the claims of different population groups; and protecting a space within which other frames of reference can operate. Suggesting that nationalism raises a valid claim to accommodation based on its role in representation should in no way diminish the significance of these concerns. Nor am I suggesting that addressing these challenges would be simple. Many conflicts persist, as will be illustrated in Chapter 8, where I ask what the moral scheme described here might call for in practical terms. Nonetheless, experience suggests that it is possible, and what's more, that these are the minimum requirements for retaining, in 
a morally acceptable way, the advantages of a shared frame of reference that are at stake in these claims.

\section{Conclusion}

Understanding nationalism as a claim about representational resources can open a new perspective on nationalism. It highlights the drawbacks of bifurcation, justifies our concern with revisability and openness, and explains the source of enhanced social trust among co-nationals. Its relationship to territory also explains why nations continue to have relevance in contemporary politics, and why accommodating them is not granting undue favor to certain kinds of identity over others.

If nations have a bearing on the conditions for collective representation, then their resilience in the face of global and transnational trends becomes understandable. This in turn helps explain why otherwise attractive theories of transnational, post-national, or patriotic approaches to political community have faltered in real terms. In fact, it suggests that we should approach these alternatives with considerable caution, since they may unwittingly compromise the representational resources these populations need, or may foster complacency about representative functions that could lead populations into even greater difficulties.

A focus on the representational role of nationalism can likewise shed light on an important tension. National and multicultural politics can, quite literally, lay claim to the same territory. Asking which of these approaches should win out in a given context, however, may not be as helpful as it seems. If both have a role to play in representation then both can contribute value for a population, mutually modifying one another towards a maximal representational outcome.

The fact that nationalism should be modified to reflect the conditions of a multicultural population turns our attention to the question of limits. Limits flow both from the internal logic of nationalism as representation, as well as from external concerns that we may rank as prior to our concerns with representational resources. In the former case, these limits include the requirement for revisability and for a minimal level of moral equality. In the latter case it appears we need to clearly affirm the idea of moral equality in order to definitively forestall problems that may develop with regard to discrimination/ domination, mixed populations, or multiple frames of reference. These limits, while not exclusively liberal in their focus, do bring nationalism into line with liberal theory. 


\section{Evaluating nationalism as representation}

The idea of nationalism as representation relates in fruitful ways to existing work in the field. Yet it's also relevant to consider how it relates to the reality of nationalism, as encountered in Ireland and Quebec. In other words, it should be possible to return to these cases and consider how the nationalism that unfolded lived up to, or transgressed, the logic of the national claim when understood in these new terms. This should, in turn, help make the discussion more concrete regarding what this approach to nationalism calls for from a normative perspective. 


\section{Applying the theory}

Asking how a representational approach responds to the issues and challenges raised in the theoretical literature offers one way to evaluate it. Another way is to ask how it responds to some of the more intractable issues associated with nationalism in practice. In this chapter I ask what a representation-based approach to nationalism tells us when we look back at the experience in Ireland and Quebec. Since it was developed from these cases, one would hope it has value in terms of assessing this experience, but it is worthwhile taking this step explicitly.

The theory can be applied by asking about how these cases measure up on four interrelated issues. These issues have been formulated as questions to help frame the discussion. The first, "Must nations become states?" asks about the morality of political divorce, and whether it is ever justified for representational issues to be resolved through the breakup of representational political institutions. The second, "Must nations preserve the national character?" concerns official efforts to support a specific idea of the national character and asks if they would be supported by an approach to nationalism as representation. The third, "Must we pick winners?" asks about the fate of multiple or multinational frames of reference under a national project. And the fourth, "Must minorities conform?" concerns the status of internal minority and national groups under these projects and asks what is owed to them and what can fairly be asked of them. By determining where the limits of nationalism were reached, and in some cases, crossed, in these two situations, we can learn something about how a representation-based approach to nationalism would work out in actual cases.

What the application exercise makes clear is this: if we are trying to assess a national question using a representational approach, what matters is whether the national frame of reference is helping the 


\section{Applying the theory}

population or populations involved relate to their actual circumstances and to each other. In short, does it support efforts to use culture and politics as a representational resource in their collective life? Ireland and Quebec have had both their successes and failures in this regard, but both have legitimate claims and it is right that these claims be considered carefully.

\section{Must nations become states ${ }^{1}$ Political independence and autonomy}

Nationalism is sometimes portrayed as a doctrine that is incomplete unless full and unqualified sovereignty is achieved for the national group. In Ernest Gellner's terms this is the suggestion that every nation should have "its own political roof" (1983: 43), leading Elie Kedourie to conclude that the doctrine was inherently prone to excess (1993: 10). In contrast to both these approaches, the independence claims raised in both Ireland and Quebec, for the most part, aimed at a moderated form of sovereignty. In Ireland, the dominant nationalist movements aimed at establishing an independent legislature under the British crown using a model akin to Scottish devolution. This was the position of the Irish constitutional movement for over a hundred years, before republican and separatist movements took the lead. In the Quebec case, the nationalist movement began as a constitutional effort for political reform and responsible government. While some form of separation from the rest of Canada is now an expressed goal of many Quebec nationalists, this aim is combined with a desire to negotiate some form of "sovereignty association" with Canada. So as with Ireland, nationalism in Quebec is not defined by the pursuit of sovereignty as a single-minded priority.

Today there is an additional question to be considered when it comes to national independence, which is whether any state is truly sovereign or independent anymore, given a globalizing and increasingly interdependent world. It may be that we are moving into a "post-sovereign" era in which concepts of independence become obsolete in favor of more cross-cutting and hybridized form of co-existence (Fagan 2003; Murphy and Harty 2003). Nonetheless state-hood still indicates an important political status and Ireland - to the degree that any state can claim to have - has achieved it, while Quebec has not. Given that there are notable parallels in the national histories of both populations, this offers us an opportunity to ask what a representation-based approach to nationalism can tell us about these outcomes. Did Ireland overstep the legitimate bounds of 
nationalism when it declared itself an independent republic? Or has Quebec been short-changed in its political fortunes by failing to achieve the same result?

More to the point, is separatist self-government a legitimate goal for nationalism if it will reduce the sphere within which representation takes place? Separatist nationalism almost always involves wrenching apart populations that have become integrated to some degree or another, meaning some people will have their representation compromised by such a change. This is a compelling argument for caution when it comes to the question of political independence. But it is not the only representational issue to be considered. Although a long history of political co-existence can mean that different populations come to share circumstances and identities, significant differences may also remain. If the existing political system proves unable to adequately represent these differences then even if it is doing a good job of representing those concerns that are shared, the political order may not be fully meeting the needs of a population.

In comparing Ireland and Quebec on the independence question, the first response is often to distinguish the cases by classing Ireland as a post-colonial nationalism, while Quebec is seen in a different light (Buchanan 2003: 251). But there are remarkable parallels between the experiences of the two populations. And if colonialism is related to conquest, then surely it should matter that Quebec is the more recently conquered territory (1759 in Quebec versus 1690 in Ireland, if not earlier). Still, an argument might be raised that Quebec's integration into the Canadian political union moderated any colonial factors. Yet if political integration mitigates colonial status then it is also relevant to note that Irish representatives held seats in the British Parliament. And while Quebec has traditionally had semi-independent governing institutions, this was true of other colonial states as well. In short, if Ireland represents a clear case of colonial nationalism, this should lead us to ask why Quebec does not. While Quebec under Canada may not have suffered the extreme privations that Ireland faced under the Empire, it was conquered, political rights were restricted, and a sincere attempt was launched from Britain to extinguish French-Canadians as a distinct cultural group. The fact that this population has made the best of their situation, even if this required the active participation and support of the rest of Canada, is not a legitimate reason to dismiss these historical facts. ${ }^{2}$

An approach to nationalism as representation, however, does not require us to negotiate claims about what constitutes post-colonial nationalism. Because the moral force of the argument depends not on 
past marginalization, but on the significance of a given national frame of reference to the political and cultural representational acts of a population in the here and now. While the development of a national frame of reference may owe a great deal to a history of discrimination, the relevant question is whether political independence is or was necessary in order to secure adequate representation for the population of the day.

The "good government" formulation of the nationalist claim raised the idea that differences in circumstances lead to differences in perspectives and interests. When those differences are profound enough it becomes necessary to ensure that the relevant understanding and perspective informs the political decision-making process. But if distinct views and perspectives are not being represented in the dominant political system, or if the representation that does exist systematically goes unheeded, then we face a situation of representational failure. The origins of the problem may not necessarily involve intentional domination, discrimination, or disregard, but if the problem persists over a long duration, and populations have been systematically denied the chance to make themselves and their interests known through effective representation, then the problem becomes more than one of misunderstanding. In the words of Charles Taylor, although it may start with a once-manageable difference in perspective, a representational failure of this kind can, given time, "graduate to the ranks of a harm" (1995b: 64).

In the Irish case it is hard to say whether Home Rule might have achieved sufficient accommodation of Irish representational needs. Admittedly the track record was not promising. The mishandling of civil rights issues, land reform, and economic development, combined with a series of famine crises, suggests that serious representational failures were in evidence. To the degree that British authorities were unable to adequately represent the Irish situation, or were unwilling to heed Irish arguments concerning the need for change, then the more the case for independence was strengthened. ${ }^{3}$

But traditionally there is reluctance to recognize nationalism as entailing, even under limited circumstances, a valid claim to political independence. Margaret Canovan, for instance, concludes that where it is already existing in the form of a nation-state, nationalism is acceptable. But she is wary of endorsing national self-determination as a principle, because of the uncertainties involved (1996: 135). Canovan's response is firmly risk-averse and there is some merit to her position. The difficulty is that if representational problems already exist for national populations, her position offers us no way to redress 
them. Yet we might still ask why such problems should not be remedied within the existing political system, say by the reform of political representation? If we could just be more generous and accommodating in our representative institutions, if we were more genuinely deliberative in our democratic processes, then might we not overcome differences in circumstances, even differences in perspective?

Had Britain recognized and accommodated the need for better representative resources to reflect the distinct situation of the population in Ireland, then this would effect how we evaluate the drive towards independence. And this is where a representational approach departs from an approach to nationalism as remedial right. Under a remedial right approach, taken at its most straightforward, once sufficient harm has been done a moral right to exit is created and can be exercised at the discretion of the population. ${ }^{4}$ Under a representational approach, a change in representational conditions should be reflected in the moral assessment of a national claim. That said, if sufficient representational harm has taken place, there might be additional barriers that should be considered, such as the failures of trust cited by Melissa Williams in the case of Black Americans (1998). Where there has been a history of representative failure, where the grounds for trust have been undermined by years of disappointment, it is unfair to ask those already disadvantaged by the system to extend even more trust and goodwill. Note, however, that it is the representational difficulties that make independence or special representation a legitimate option, and not lingering remedial rights.

In sum, the approach to nationalism as representation says that the degree of independence Ireland needed from Britain in order to adequately represent the circumstances of the Irish population evolved along with the Irish situation. But it is fair to say that it needed more representation than it had been granted prior to 1920 . Of course, this assessment says nothing about the partition that took place in 1920 as a consequence of the drive to independence. There was no way to pursue political independence in the Irish case without effecting an internal population of committed Loyalists, and so their concerns become a relevant factor in evaluating the representational resources at stake. Because the issue of minorities or internal national groups is a significant topic unto itself, I mean to give it specific consideration under its own heading. But it is important to stress that it is linked to our assessment of political independence.

Turning to the question of independence in Quebec. On many terms, today's Quebec has a better case for independence than Ireland had in the 1920s. Its population speaks a different language than 


\section{Applying the theory}

those from whom it seeks independence and it has a proven track record of responsible self-government. However, unlike Ireland in the eighteenth and nineteenth century, Quebec has not recently been subject to systematic discrimination and the argument is made that secession cannot be mandated on remedial grounds (Buchanan 2003: 241). Moreover, in the Canadian case Quebec independence would mean the end of an important political partnership. Many Canadians would experience this as a wrenching disruption in their own frame of reference. ${ }^{5}$ As with the issue of internal minorities, this is an important factor that should make a difference in how we assess the impact of national independence on representational resources throughout the populations involved (Miller 1998: 69). Again, I will specifically address this question in a subsequent section, but I want to note here that these various considerations all interplay in an overall evaluation.

Yet we also know that independence would come at the expense of a broader Canadian frame of reference that, like Ireland, would likely require a difficult and conflict-prone separation of minority populations, while disadvantaging those stranded inside a different national project. Still, Quebec's distinct cultural and political setting indicates that their national frame of reference constitutes a valuable representational resource, and that it may be uniquely positioned to reflect the reality of the population involved. In addition there have been notable experiences of misrepresentation though the history of the Canadian union, experiences that have left a lasting mark on federal relations. Seeking to have politics explicitly reflect the national frame of reference, therefore, cannot be deemed a priori an illegitimate objective of nationalism in Quebec. Yet because the Canadian system has made significant efforts to adapt to the Quebec frame of reference, the case for political independence is not as strong as in the Irish case.

As Joseph Carens observes with regard to Quebec nationalism, in thinking about these questions we need to distinguish between what may be morally permissible and what is a moral good for a community (Carens 1995a: 22). In cases of persistent representational failure, it may be permissible to seek alternate political representation, even if we might consider it a higher goal to pursue a renewed political order. The representational approach reminds us that the national situation can evolve. While British accommodation of Irish national claims could have moderated the extent of those claims, in the Canadian case the response of the Canadian union to Quebec nationalism should impact how we view the Quebec situation. Already the province has more political and cultural autonomy than was accorded to 
Ireland under the Empire, and these accommodations were at least partly in recognition of Quebec's special situation. In so far as similar representational efforts continue, they should be considered in evaluating the independence question.

In discussing the Quebec case Charles Taylor argues that we should understand the difficulties between Canada and Quebec as involving a failure of recognition. Although important accommodations have been made, he suggests they would not have been sufficient to fully address Quebec's needs (1995a: 64). Given that both a representationbased approach and an esteem-based approach share a concern for recognizing people's self-understanding and the sources of meaning for a population, how do they differ when it comes to questions of political autonomy? One difference is that recognition puts a great deal of power in the hands of the other party, from whom recognition is sought. Nationalism as representation, in contrast, suggests that the critical task is the initial representational one and that responsibility for the process is shared.

The important lesson this idea holds for the Canadian situation is this: nationalism is not just about feeling secure in one's self-esteem. There are practical Quebec-based issues that need to be represented, for which the national frame of reference should prove a valuable tool. Symbolic gestures or nominal constitutional recognition will have limited impact, therefore, if they do not offer enhanced representational opportunities for Quebec. It also matters whether these responses are embraced in Quebec. This means that the question of independence does not entirely turn on how Canada responds to Quebec nationalism, no matter how generous or well intentioned. As with Ireland, the representational situation must be evaluated as a whole, with neither the greater union, nor the separatist national population, holding a monopoly on the moral status of the project.

At the same time political separation is not a viable option for populations or groups that are tightly intermingled with another population and lacking majority status in any particular territory. For these it is critical that we develop strategies for representational reform along the lines that Phillips (1995) and Williams (1998) discuss. So it is not that national groups have a claim that is morally stronger than other misrepresented groups, or that representational harm of this type merits a more dramatic response; it is simply that the resources available for remedying these representational problems are different. Nationalism makes possible an alternate way of addressing representational problems, and in cases where these problems have been severe enough, it is unfair to insist that populations be 


\section{Applying the theory}

denied this alternative. To do so may perpetuate a kind of double standard whereby national communities that already have a state to reflect their frame of reference are granted an advantage over those that have been thus far denied that opportunity (Murphy and Harty 2003: 187-8).

\section{Must nations preserve the national character? Equal respect and revisability}

If nationalism is about preserving a representational resource that has both political and cultural implications, indeed if a defining feature of nationalism is the dynamic that runs between these two arenas, then we need to consider both political and cultural aspects in making an evaluation of a national claim. The question of political independence was addressed in the last section, and in this one, I want to ask what a representational approach to nationalism means for efforts to preserve a population's national character.

Again there are both parallels and differences in the two cases under consideration. Because it has traditionally had separate political representation officially sanctioned efforts at supporting national characteristics were a possibility in Quebec for much longer than in Ireland. In contrast, the pursuit of independence in Ireland was in part defended as a means to preserve the national character, and the early Irish State clearly saw establishing or re-establishing the national character as part of its popular mandate. At the same time, the national characteristics associated with both populations in the pre-1950s period have a good deal in common. Both emphasized the ideal of the nation as a rurally based, patriarchal, and Catholic community, distinguished by a history of conquest and a unique linguistic heritage.

But by the first half of the twentieth century these two populations were facing changed circumstances that went largely unrecognized in the nationalism of their political and cultural leadership. If the value of a frame of reference arises in its role in representing and making sense of the population's experiences, then it should change as those experiences change. The authoritarian traditionalism that developed in both these cases, and that dominated the political scene for a time, was hostile to this kind of evolution. However, the attachment to the national character can present at least as many problems, if not more, than a drive towards political independence.

One example of how this character building nationalism can go astray, for instance, grows out of Lionel Groulx's articulation of the French-Canadian way of life in Duplessis' Quebec. Groulx's image of 
a devout, rural, non-materialistic population was not representative of the changing reality of his time. Yet it was used to justify limiting political resources to assist with depression era hardship. By ceding responsibility for an enormous range of social services including health care, child services, and education, to the clergy, Quebec political leaders upheld the Catholic dimension of the national character at the price of ill-regulated and often inadequate public services. This was markedly out of step with the changing circumstances of the Quebec population, which was fast becoming an urbanized population ${ }^{6}$ with the attendant needs and expectations. Yet the response was often to isolate the Quebec population from the surrounding North American culture as a means to preserve the national character.

As the twentieth century progressed, the attempt to keep the characteristics of both the Irish and Quebec population unchanged had the effect of creating maladjusted cultures and political systems that were ill-equipped to deal with the real circumstances the population faced. Nationalism that takes this form, then, is undermining its claim to moral standing. These were problems faced by the broad-based society in these cases. Yet in both Ireland and Quebec there were populations that faced inequality or discrimination under the terms of the national character being championed by the state. In some cases this took the form of stipulating social roles and life-options, and in others it made it impossible for populations to maintain alternative frames of reference. In the Irish case, women and the Protestant minority were the most likely to be disadvantaged by the national frame of reference. While in Quebec, it was women, religious minorities, and new immigrant populations that stood to lose out before the nationalist drive. ${ }^{7}$ These groups, to the degree that they were disadvantaged, weigh against the national claim in both cases. Although this touches on the separate issue of minorities, I want to raise it here as a question of revisability because it reflects the need to adjust frames of reference to better reflect a population's circumstances.

Consider the Irish experience in this regard. In 1937, the new Irish constitution granted the Catholic Church a "special position" in Irish politics (O'Day and Stevenson 1992: 195), a power which it later used to block the introduction in 1950 of a scheme to provide free health care to mothers and children under sixteen (Hepburn 1980: 138). ${ }^{8}$ The constitution also stipulated that a woman's place was in the home. This was in addition to the existing requirement that women leave public sector employment upon marriage, and the 1935 Conditions of Employment Bill whereby a maximum level was set for the proportion of women in the workforce. Indeed the bill reserved 


\section{Applying the theory}

for the minister the right to entirely prohibit women in the workforce (Foster 1988: 546).

There is no inherent reason nationalism should be hostile to gender equity. But the degree of disadvantage associated with nationalism is not a constant. Irish nationalism could, at times, be remarkably progressive on women's issues. It was, for instance, Irish nationalists who first elected a woman, Countess Markievicz, to a seat in the British House of Commons. Markievicz never took her seat opting instead to attend the breakaway Dáil Parliament, and for this reason is rarely recorded as the first woman MP in the British system. ${ }^{9}$ But even given that discriminatory conditions can vary, it is still important to heed them, and to recognize the ways in which they will affect the legitimacy of the national claim. Gender-discriminatory and xenophobic tendencies were, at points, part of both Irish and Quebec nationalism, and to the extent that they remained active elements they limited the claim of that frame of reference to accommodation. Considering the experience of the Irish population under their new national government, nationalism was undeniably used to justify legislation that both marginalized certain groups in society, and failed to recognize and respond to the changing circumstances of the entire population.

Too much of the early Irish State's legislation crossed the limits that require currency and relevancy of the national frame of reference as well as equal respect for persons. In its economic agenda, for instance, the early State made agriculture a priority with the goal of preserving the virtues of the rural lifestyle. Regardless of promises about good governance, and in fact regardless of the actual needs of the country, the new government expected its population to accept ever greater sacrifices for the cause of common nationality. Only this can explain the remarkable statement made by one minister defending his government's agenda. He explained that because the government faced financial limitations in pursuing its nationalist agenda: "People may have to die in the country and die through starvation" (Fanning 1983, 100). For this reason the early days of the Irish State proved a difficult period for the population involved. More importantly, the effort to establish a national character that it enacted is not defended by an understanding of nationalism as a claim about representational resources.

It is important to stress that this assessment comes from the State's failure to recognize real circumstances and respect equality and not from a reluctance to embrace economic development. We should be wary of thinking that the "good" in "good government" can only mean a focus on material prosperity, a modernized economy, and 
secular and liberal social mores. While these features have their undeniable appeal for modern liberals, we should not project them on to others, unless those people demonstrate that these goals are relevant for them. It is difficult to argue with the fact that the Irish population in this period had a decidedly traditionalist bent. The country repeatedly returned to power leaders who took a conservative direction on economic and social measures. The two major parties of the early Irish State both followed similar economic and social agendas, while other parties with more progressive agendas did not have a comparable constituency. ${ }^{10}$ It is legitimate for a population to express its democratic preferences on how the political community deals with its circumstances. But for this process to work effectively, the national frame of reference should represent the reality of those circumstances and should not marginalize elements within the population.

In Quebec, meanwhile, the national approach often took the form of clerical deference in the area of social services, but in recent years it has also involved extensive legislation of language issues in the province. The earlier legislative stance, which left the province ill-equipped to deal with modern social and economic conditions, cannot be considered a legitimate form of nationalism for the same reasons discussed with regard to Ireland. But the recent question of language is more difficult. Even though the major developments on this issue fall beyond the periods under review, a discussion of national character in Quebec would be incomplete without addressing the place of French in the national claim.

An approach to nationalism as representation suggests we should ask the following question about the language issue: Do the measures under consideration genuinely represent a shared frame of reference in the population? French really is the language of most public life in Quebec (in contrast Irish was a minority language at the time of Irish independence). For this reason an expectation that new members of the population should gain competency in this language is not unreasonable. Being required to use that language in commercial displays and favoring speakers of the language in immigration selection raises some questions about equality of respect, yet even these fall within the bounds of the permissible (Carens 1995a: 56). Likewise it is appropriate for both political and popular authorities to support and encourage cultural and literary expression that grows out of the continually evolving Quebec experience, since it helps inform and fill out that frame of reference. But such a measure is legitimate only so long as it realistically includes new segments of the population such as 


\section{Applying the theory}

immigrants, or fully represents the history that is shared among long-standing segments of the population such as English-speakers, minority religions, etc.

An approach to nationalism as representation suggests that it is acceptable to promote fluency in the national language or to promote cultural expression as a national resource, but how these measures are enacted plays a large part in determining their justifiability. The province had its share of nationalist public policy, sometimes manifesting in legislative inaction rather than action, and early twentieth century nationalist legislation too often aimed at reifying idealized cultural features. Where it denied the real circumstances of the population, where it sought to freeze it in time, or where it came at the expense of the equal respect due to persons within that population, such nationalism had limited moral standing. That said, more recent legislation that recognizes the need for ongoing adjustment and evolution, as well as for reflecting the realties of the population, brings these measures within the bounds of acceptable national representation.

We cannot look at efforts at cultural renewal and say they are illegitimate or inappropriate in all cases. Having a cultural self-understanding that lends meaning to a population's experiences and confirms its worth is just as understandable a goal as the desire to have political representation that fits a population's circumstances. But efforts to solidify the image of the nation, or to demonstrate national character, can become disingenuous when they are employed for political ends. The natural elasticity and malleability of a population's frame of reference can be obstructed in the effort to demonstrate constancy. In this case, culture becomes a means to another end, rather than a resource in its own right. Faced with this scenario the approach to nationalism as representation suggests we need to respond on two fronts. First, we need to give up the idea that cultural constancy is a hallmark of legitimate nationhood, thereby removing one incentive for this approach. Second, we must carefully circumscribe efforts to rally or reinforce culture for political ends.

Thus the concern for revisability, and the limits on how national character issues can be approached, suggests an important difference between understanding nationalism as representation, and understanding it as a means to cultural continuity. In contrast to a theorist such as Chaim Gans (2003), a representational approach does not suggest there is special value to preserving a particular national culture over generations. Any value must be derived from how well a national frame of reference can help those generations engage in cultural and political representation within an evolving situation. 


\section{Must we pick winners? National and multinational frames of reference}

By looking at nationalist argument we learned that nationalism derives its moral claim from the importance of a shared frame of reference as a basis for political and cultural representation. But in Ireland and Quebec there were multiple frames of reference in play. There was an Imperial/British frame of reference in the Irish case that saw Ireland as part of the United Kingdom, and there was a colonial/ Canadian frame of reference that saw Quebec as part of a colonial territory and then federal union. This raises two questions. First, so long as people have access to some political and cultural frame of reference, should we be dogmatic about which one it is? Second, what happens if a population has attachments to more than one national or multinational frame of reference? Are we forced into an either/or situation in granting moral standing to nations?

Consider the Irish case, for example. The impact of British rule on the Irish population was pronounced, and the Irish came to share in the broader Imperial frame of reference to some degree. English was the main language of the Irish population by the 1850s, the British parliamentary system was the basis for the Irish system of government (with a few modifications), and economic and cultural ties between the two countries have always been extremely close. In the same spirit, Quebec, because it shares a history with the rest of Canada, shares certain political ideals and practices, and has close economic ties with the other provinces. In short, it participates to an important degree in a Canadian frame of reference. In fact, the very project of Canada was itself once seen as the major political heritage of French-Canadians, and there is still significant attachment to that idea in Quebec (Silver 1997).

But if we think back to nationalist arguments, their contention was not that the various populations involved had nothing in common. Instead, change was called for because the circumstances of one population were distinct in important and underrepresented ways, and they needed some way of recognizing this politically and culturally. The moral claim of nationalism comes into play when an existing frame of reference fails to reflect, or mis-represents, important realities of a population's situation.

Ireland had, for most of the period under consideration, significantly different circumstances than her British neighbors. As a general rule, the economy of Ireland was significantly less industrialized, with the exception of parts of Ulster. The distinct historical experience of 
the population included: a history of religious discrimination through the Penal Laws; difficulties in the land system that related to high rates of absentee landlords; a pattern of high population growth; severe famine; extensive emigration; and a recently displaced indigenous language. Turning to the Quebec case, here there was a distinct language, a separate legal code, and a high degree of provincial autonomy that allowed public policy to evolve in its own direction. Until the 1960s, Quebec's economy and social services system were relatively underdeveloped, and an English-speaking elite controlled most business.

But nationalism involves more than a question of circumstances; these differences must also have translated into differences in interests and sympathies, in Grattan's terms (1865: 255). Thus nationalism can grow out of a sense that the two segments of a larger population are not on the same wavelength. In Canada this is where the term the "two solitudes" comes from, but the relationship may not always be as benign as that term suggests. If one population is cast as the alter ego to the other, someone has to pay the price in terms of self-esteem. The Imperial frame of reference, for instance, was based on an English ideal and the supposedly wild and impulsive character of the Irish was contrasted unfavorably with a concept of the English personality as staid and steady (Kiberd 1995). The process was further complicated by religious difference. Linda Colley argues that Britishness coalesced around a common commitment to Protestantism, a commitment that took Catholicism as its alter ego (1992: 11-54). So religion provided yet another layer of difficulty in reconciling the Irish and the Imperial frames of reference. ${ }^{11}$

In Canada the effort seems to have been to deny or submerge the alternate identity. The first serious attempt to do so was made in the wake of Lord Durham's Report that aimed, in his words, at "obliterating" the French fact in Canada (Durham 1992: 154). More recently, Pierre Trudeau's design for a bilingual Canada was in part motivated by its potential to submerge the linguistic divide that set Quebec apart (McRoberts 1997: 65). Yet if all that a frame of reference can offer a populations is status as a lesser item in the cultural landscape, then it will be difficult for that framing system to serve as a basis for their political and cultural representation.

Still, a great many Canadians outside Quebec have a deep attachment to a Canadian project that includes Quebec, and believe that the political relationship was never intended to be exploitative. Canadians, it might be argued, are more sincerely attached to Quebec than the British ever were to Ireland, so that separation in this case would have 
a more profound and personal impact for the "rump" population. These attachments can't simply be discounted, because in the Canadian case they reflect shared circumstances and a shared history embodied in a joint political and economic project.

Political separation in Quebec would mean dividing not just populations, but also dividing a common interest in the national territory and the common resources developed through the joint political and economic project (Buchanan 2003: 242; Miller 1998: 67-9). So although Quebec might drive the separation process for a reluctant Canadian population, it cannot ignore the needs of the population outside its borders, both for the explicit legal reasons that Buchanan cites and for the reason that the broader Canadian frame of reference also represents shared circumstances. In short, if a separation process is initiated in cases where some larger frame of reference overlaps with the separatist national frame of reference, then the process should aim to maximize the representation of existing attachments and shared circumstances, including those that take in the larger population. In other words, where frames of reference overlap, new national arrangements should too.

In cases such as these, where a difficult process of co-existence needs to be worked out, there may be a temptation to regard the larger frame of reference as somehow less national or perhaps not national at all. In other words, if Quebec is a national project then Canada cannot be one too. Insofar as it accommodates Quebec's national project, then, should Canada be considered an example of some higher-order belonging like patriotism, alongside a more cultural or pre-political idea of the nation? This question, however, arises in a misreading of both nationalism and patriotism.

If we accept that people can have multiple frames of reference, it is not clear why multiple national frames of reference should be unthinkable either. Granted it is possible for these attachments to conflict, but this is true of other frames of reference too. The way to resolve them is not by trying to put closure to the question once and for all by picking overall winners and losers among those framing systems. Since circumstances change we can expect identities and cultures to change with them, meaning that no single resolution can ever be reached. Better instead, to work out structures to represent and if necessary arbitrate these conflicts when they arise.

Yet even if we accept that different frames of reference can co-exist, might a patriotic alternative still be a better option in the Canadian case? There are two problems with this suggestion. The first is that one of the most important lessons of nationalism is that it is much 


\section{Applying the theory}

harder to separate politics and culture than many theorists recognize. Too often patriotic measures in reality amount to nationalism without the attendant scrutiny or criticism. To recommend this risk-laden approach to Canada, given the difficult political challenges it faces, seems unhelpful.

The second problem is that by ruling out the development of a shared cultural or pre-political frame of reference for the Canadian project, this approach undermines the resources that can be brought to that project. We know from the Canadian experience that a multinational frame of reference is a high maintenance exercise. The process requires considerable commitment to mutual understanding and political generosity. In other words, it requires a great deal of social trust among the populations involved. According to David Miller, one of the politically relevant features of nationalism is its ability to support social trust (1995). The Canadian project, in other words, cannot be cast as post-national or non-national without giving up on the pre-political frame of reference that yields the social trust needed to keep the project alive.

Thus far we have considered the multiple frames scenario as it involves relations with populations outside a national project. What about the case of populations or nations that are situated within the scope of the national claim? In essence it is the same problem writ small but it highlights some of the expectations involved in making the process work. How should a self-conscious national project, then, even a multicultural one, respond to the presence of other nations within its population? In other words, what about the situation of nations within nations? Must one settle for second-best status? Or can nationalism as representation help indicate an appropriate alternate arrangement?

David Miller suggests that in some cases it is possible to maintain overlapping nationalisms, saying that one nationality may be "nested" within a larger but equally national context (2001). But he suggests certain expectations be placed on the populations involved. There should be "proper recognition" of the various layers of nationality, for instance, and this may include special political arrangements such as the devolution solution applied in the Scottish case (2001: 317). Nesting one nation within another would mean addressing a manifold set of needs in terms of both political and cultural representation. It would also mean finding ways to reflect the different frames of reference of the national populations involved, as well as any overlapping or "convergent" (2001: 311) frames of reference that develop. Nations that choose to co-exist are likely to work out either 
complementary framing systems, as Miller observes in the case of Scotland and Britain (2001). Or they may even develop towards one another, filling out a third, overarching national idea. But since framing systems are, of necessity, living and evolving resources, they are always open to adjustment and re-alignment, in order to meet the needs of a population.

The representational focus of nationalism suggests, however, that this process must reflect a real set of circumstances, a genuine sense of shared fate or political commitment among a population. If on the other hand, a national framing system supports the "obliviousness" (Miller 2001: 313) of one national group towards another, then this arrangement (often reflecting the nationality of the majority national population) is unlikely to serve either group particularly well. For this reason an approach to nationalism as representation, while it would accord with Miller's idea of nested nationalities and would endorse efforts at political recognition, would not restrict the use of independence referendums as Miller would (2001: 315). We would not want a national population to take this decision lightly, however. We would want to ensure all interested parties are heard, and that their concerns are fairly weighed into the decision. This suggests that independence questions should be addressed over a sustained period, perhaps even trans-generational in scope, and that they should take in perspectives beyond the immediate national one.

Miller's concern is that overlapping identities or converging interests should not be swept aside in a single heated decision, and it is a legitimate one. Where the nations-within-nations arrangement has persisted in a post-imperialist world, it is usually because careful adjustments and re-evaluations have been made, in the name of more fully representing this delicate balance. The continuation of these arrangements, however, does not benefit from the suppression of the national claim of any party to the process.

The experiences of Ireland and Quebec indicate the following: if two or more national-type frames of reference can accommodate each other, providing mutual representation and recognition, then it may be preferable for these framing systems to co-exist, using either a "nested" (Miller 2001) or "deep diversity" (Taylor 1995a) approach. If this is not achieved it may be necessary to make arrangements to live separately in order to ensure that people have access to the kinds and levels of representation that are called for by their circumstances. But in separating the frames of reference, the best approach will involve arrangements that reflect as much of the original circumstances and attachments as possible. 
To the degree that the early Irish State aimed to repudiate its shared history with Imperial Britain, or denigrate attachments among its population to the British frame of reference, it was exceeding what nationalism as representation could properly support. This is not to suggest that the discrimination or exploitation experienced under Imperial rule should be disregarded, merely that this does not constitute a reason to ignore multiple attachments among a population. The inability to navigate this difficult compromise gave rise to the partition solution in the North of Ireland, an outcome that has not served anyone particularly well. The responsibility for this outcome, however, is shared among both British and Irish parties to the separation process.

In the Irish case, when these two frames of reference failed to find ways to co-exist, the solution applied was separation, and it was a painful process for those caught in between. The Canadian national project, however, has followed a different path. A sustained effort has been made to find ways of accommodating the Quebec frame of reference within the Canadian one. So when we consider the tension between national and multinational frames of reference there is nothing in the understanding of nationalism as representation that requires us to choose between them, if they are both valid reflections of the population's situation. Instead, favoring one or other exclusively could, as the Irish situation illustrates, strip great numbers of valuable representational resources. If we are concerned with preserving and advancing such resources, we should, in fact, put effort into ensuring these different frames of reference can accommodate one another.

\section{Must minorities conform? Mixed populations and nations within}

Thus far I have discussed the questions of political independence, national character and multinational frames of reference as if the national population was a single coherent group. But of course this is rarely true and certainly was not the case for either Ireland or Quebec. There were two kinds of minorities located within the national population under discussion. One kind was a territorially concentrated group with sufficient numbers and/or historical presence to launch a counter-claim to the majority nationalist movement. The second involved dispersed populations that were dependent on the national frame of reference to determine the conditions for their co-existence.

In response to the first situation, as suggested in the previous section a representation-based approach requires that a national frame of reference should adjust to reflect these alternative frames of 
reference or be prepared to part with both the territory and the population involved. In response to the second situation, since exit is not an option for this population, the onus is on the national frame of reference to incorporate this population in a way that shows equal respect and that ensures this population has access to the representational resources it needs.

As geographical territories, both Ireland and Quebec contained a majority population attached to one national history, and a minority population or populations attached to another. In the Irish case this minority population came to the territory as settlers who displaced part of the indigenous population, giving rise eventually to the Loyalist opposition to Irish independence. In Quebec, the settler population is now the majority and the Native population has voiced its opposition to Quebec independence. In both cases there are extensive grounds for grievance between the indigenous and settler population and there are ongoing tensions and disputes between the groups. Asking who is more at fault in these disputes is not my object here, however. My concern is how the presence of these mixed populations bears on the moral claim of the nationalism that unfolded there.

To think about the case of mixed populations, we need to go back to the original basis of the national claim, when understood as a claim about representation. The basic idea is that where enough people have a distinct frame of reference, and can make a claim as a territorially based, historically extended, and solidaristic collective, then because of its role in representation they have a claim to having that frame of reference accommodated. But this principle holds just as much in the case of Irish Loyalists and Quebec Natives, as it does for any other population. Just as Irish nationalists argued for their nationalism because of their distinct circumstances, Loyalists in Ulster were concerned that a Dublin government would not adequately appreciate their circumstances. Consider the 1893 comment from a Loyalist that "the manufactures and commerce of the country will necessarily be at the mercy of a majority which will have no real concern in the interests of the vitally affected" (O'Day and Stevenson 1992: 122). It closely echoes the arguments voiced by nationalists in the name of good government.

When these populations claimed that the frame of reference advanced under the majority's nationalism did not adequately represent their circumstances, the claim needed to be taken seriously. The circumstances of Loyalists in Ireland or Natives in Quebec cannot be set aside because another population is in pursuit of their own national project (Buchanan 2003; Whitaker 1995). Either the two frames must 
be adjusted to recognize and represent one another at an adequate level, or some means of separately accommodating them must be devised. ${ }^{12}$

Taking the case of Ireland under this requirement, Loyalists had legitimate concerns about their representation under an Irish frame of reference and were in sufficient numbers, in an identifiable territory, to make a collective claim of their own. If the new State could not manage to reflect their distinct circumstances then this change threatened the representational resources of an internal population and therefore the legitimacy of the national project. Instead of offering a response to their concerns, the commitment to a Catholic, rural, and agrarian Ireland that characterized early twentieth-century Irish nationalism remained overtly hostile to Loyalist circumstances and attachments.

Where a distinct population will have its representational status adversely effected by a change in the political regime, this factor should be considered in assessing the status of the national claim (Whitaker 1995) meaning that Loyalist concerns were a significant factor in evaluating Irish nationalism, especially when political independence was put on the table. Yet this factor should not be overstated. When considering a similar, if not stronger, claim by Native Canadians in the case of Quebec separatism, Allen Buchanan concludes that even internal nations cannot wield a veto over legitimate secession. What is called for, he stresses, is special participation in the negotiation process that should accompany secession (2003: 264). So Loyalist objections called for special negotiations of their status to ensure that their representational concerns were addressed, but did not constitute a veto over Irish independence.

In the end, the solution adopted in Ireland was partition. This had the virtue of accommodating Loyalists to a degree, but the manner in which it was implemented created further problems by maximizing the territory and the non-Loyalist population retained under British rule. In doing so it succeeded in recreating the problems of a mixed population on a smaller scale. In the Irish case both independence and partition left a great number of people isolated within a political order that did not coincide with, indeed was premised on the need to break with, a frame of reference important to their representation. One thing we can say, then, is that where some means of political separation is employed, the goal should be to minimize the number of people left in this position and maximize their position within the new political structure. This principle was not observed in the case of Irish partition and it therefore casts doubt on the legitimacy of that measure. 
This still leaves unanswered the problem of Loyalists stranded in the twenty-six counties, however. In comparison to the North, the Loyalist population in the new Irish State was smaller and more dispersed. Nonetheless they had a right to expect equal respect under the new national system, which needed also to represent this group in order to maintain its claim as a national frame of reference for what was, in reality, a religiously and historically mixed population. So nationalism in Ireland should have made a serious effort to recognize and represent Loyalist, Anglo-Irish, and Protestant experiences as part of the national reality. No such effort was made and many among this population chose to leave the twenty-six counties rather than take their chances with the new national project. That they felt the need to do so represents a mark against the nationalism of the early Irish State.

In Quebec, the question of mixed populations has not yet been brought to a head, but the province may soon face similar kinds of challenges to those that Ireland has lived through in the twentieth century. There is the potential, therefore, to do a better job of responding to both national and minority claims by heeding the Irish experience. Given the wrenching experience of partition, and given that it is never possible to precisely separate populations, it is worth the effort in Quebec to investigate the possible alternatives. What this means is that Quebec must find a way to represent indigenous and minority reality in both the cultural and political realm in its national frame of reference, and must do so in a way that makes sense to the people who are living in those circumstances.

In point of fact, Quebec has no worse a track record in regard to its minorities than any other jurisdiction in Canada (Adelman 1995; Carens 1995b: 3). It is also worth noting that the main minority in Quebec - English-speakers - were traditionally an ascendant group, an elite with significant economic and political clout. While they may have lost standing as Quebec nationalism unfolded, this does not necessarily constitute some kind of discrimination. Other groups such as religious minorities, however, did face specific discrimination under nationalist legislation aimed at upholding a Catholic national character, so the potential is always there for the national frame of reference to be narrowed in a way that is unwarranted.

This issue takes on added importance when we think about it in terms of an independent Quebec. The argument here is that independence will disconnect people from rights they would otherwise enjoy under the Canadian system, leaving minorities at the mercy of a population with an agenda that favors Quebec nationalism over Canadian multiculturalism. Admittedly, while there is no reason to 


\section{Applying the theory}

believe that today's Quebec has less commitment to responsible liberal principles than does the rest of Canada, there are no guarantees as to its conduct under a regime of full independence. However unlikely, is this uncertainty sufficient to rule out independence as a political goal, in the interests of the minorities involved? This is a difficult question and requires us to consider the past, present, and future of the nationalism involved.

Nationalists in pre-1950s Quebec did place an emphasis on upholding a specific idea of the national character, leading to discrimination against minority populations, especially religions. This nationalism would neither be a good risk for independence, nor would it carry much moral weight in terms of adequately representing the evolving circumstances of the population. Today's Quebec has moved beyond this stance and so our assessment of contemporary nationalism would need to reflect this enhanced representational reach. Nevertheless, if there are grounds to doubt the future conduct of a newly independent Quebec, it may be necessary to make specific representation protections part of separation negotiations, to ensure that the nationalism which follows lives up to the terms of the moral claim under which it is recognized.

An approach to nationalism as representation, then, includes a moral requirement that internal national minorities be considered and accommodated either inside, outside, or alongside an independent Quebec. Likewise a concern with dispersed internal minorities requires the revision of a national frame of reference to ensure that these groups too have access to a framing system that can support their representational acts. Regardless of whether the province remains within Canada or not, the Quebec frame of reference must allow representation of the diverse circumstances of its population, and accord due respect to all members within it. The willingness of Quebec to continue to address these questions in concert with its own minorities reflects a restrained and promising stance on achieving national accommodations.

The requirements on representing minorities have much in common with an approach to nationalism that emphasizes its role in liberal autonomy. Both see national groups and societal cultures as critical to exercising choice, because they supply either a range of meaningful life-options, or a means by which options from a variety of sources can be represented and framed in meaningful ways. For this reason the goal of both approaches is to accord respect to national claims while ensuring that accommodation does not come at the expense of minority populations. Where they differ is that an autonomy-based 
approach favors a more explicitly multicultural arrangement as the best protection for minority cultures. So long as a national frame of reference can be inclusive and provide adequate representation for those among its population, however, an approach to nationalism as representation does not require us to prioritize culture types in this way.

In reality, the difference between these approaches is one of emphasis. Whereas an autonomy-based approach emphasizes minority difference, a representation-based approach focuses on the overall frame within which populations operate. In essence, it focuses on what a population needs to share in order to support collective representation, while recognizing there will be differences that should not be submerged under any such arrangement. It may turn out that inclusive nationalism looks in practice very much like a multicultural approach and as already noted, they may function as mutually modifying approaches. Yet without a parallel emphasis on integration, the different emphasis to multiculturalism can leave internal minorities feeling like permanent outsiders. As one study of immigrants in Quebec observed, while there is resistance to a uniform civic identity that would not accommodate diverse cultural attachments, an ideology of difference has its own risks. While they appreciated efforts at multiculturalism, several immigrants in the study felt the need to ask when they could expect to be recognized as full and unqualified members of their new community (Labelle and Salée 2001: 307). When it comes to minorities then, the representational approach adds to the multicultural effort an explicit requirement regarding the achievement of integration within any societal culture, through revisions to the national frame of reference.

\section{Conclusion}

Putting these considerations together, the picture is as follows. In the Irish situation there was a legitimate case for separate national representation, which may or may not have required full independence. But when independence was attempted, it certainly did require separate institutions for the Loyalist community in light of the narrow Irish frame of reference of the day. Not as many people should have been retained through partition as were, and people on both sides of the border, stranded within an inhospitable national project, paid the price for this arrangement. The early Irish State used its new-found political power to introduce legislation and policies that, because of its unwillingness to confront the changing reality of the population, 
often ill-served that population's needs and unfairly discriminated against some people within it. In sum, establishing a political and cultural system that recognized an Irish national frame of reference was a legitimate goal for this population, but the effort was in many ways badly carried out.

Quebec also has a valid national claim, but has adopted a more cautious approach, modifying and revising its goals and practices in light of the concerns it has encountered. Quebec may have a legitimate claim to separate national representation, but some aspects of this claim have already been accommodated through the Canadian federal structure. Historically, populations within Quebec have faced discrimination in the name of the national character, although this seems to have been superseded by a more open and inclusive approach. Should independence continue to be a nationalist goal, however, the process would require the explicit participation of both Canadians outside Quebec, and the Native populations within it. It may also require specific representational guarantees for dispersed internal minorities.

In contrasting the two cases, it could be argued that Ireland faced harsher treatment under a more intransigent government, that a higher toll was exacted in terms of oppression and loss of life, and that therefore it required a more immediate and dramatic solution. In contrast, some of the advantages of the Quebec experience are attributable to Canada's responsiveness in the situation, illustrating that the nationalism process is not merely a function of the actions and intentions of a single national population. Nonetheless, Quebec itself may still show us a better way to approach such challenges by pursuing innovative, hybrid solutions to retain the advantages of a multinational frame of reference where possible.

This discussion has taken up and considered explicit instances where nationalism took on problematic forms and I have argued that much of this conduct runs contrary to the representational drive of nationalism. The effort to undermine the standing of a minority population through discrimination or dominance, to deny or denigrate minorities within a mixed population, or to foist a set of attachments on a population already happy with their frame of reference - none of these are consistent with a representational approach. Instead these practices run counter to the value of the national frame of reference as a representational resource by making it unrepresentative. So aside from an external limit in the form of equal respect for persons, we can also rule out such conduct by specifying that a national frame of reference should live up to its representational mandate. 
But even if it is true that a national project should also be prepared to be a multicultural one, when this is what properly reflects the situation of a population, this cannot rule out a priori any claim for political separation. Whether this is an appropriate means of addressing a situation of representational harm depends very much on the context involved. Nevertheless, it is possible for representational failure to constitute a severe enough issue of justice that the possibility should remain on the table. In other words, in the final analysis, when severe representational harm is involved the issue must be left to the people who face it. It may be admirable if they can commit to the re-negotiation or renewal of a multinational alliance, but it cannot be fairly required of them.

In developing and assessing this theory, I restricted myself, by and large, to the experience with nationalism pre-1960s. The main exception is the question of language policy in this chapter, which arises too often in discussions of nationalist legislation in Quebec to be easily set aside. But beyond that, I avoided saying much about the post-1960s experience because I think there is something significant going on in this period that merits a separate discussion. In Chapter 9, I address this recent period, and I will argue that the dramatic changes witnessed in these two populations tell us a great deal about the logic of representation that we see unfolding through the process of nationalism. 


\section{Nationalism and social change}

I started this project by asking what, if anything, nationalist argument could tell us about the morality of nationalism. The fact that nationalist argument came in at least two distinct flavors at first appeared to complicate this exercise. But I argued these two formulations instead hold the key to nationalism's moral claim, because what they have in common is a concern for representation. Because nations are a reflection of the shared frame of reference that populations use to make sense of their lives and experiences, nationalism is an expression of a population's efforts to ensure their circumstances are adequately represented in their collective political and cultural institutions.

Thus the unfolding representational dynamic generated a desire on the part of national populations not just to reform their political representation but also to demonstrate their nationhood by upholding particular cultural and social traits in the population. The drive to rally people to the national character was a natural outgrowth of the idea that what justifies self-governance is a population's distinct habits and circumstances. But there is a danger to the "national character" idea and it became increasingly clear as I considered the experience with nationalism in Chapter 8 . The danger involves the temptation to officially define and demonstrate the national character once and for all in order to mobilize populations to the cause. In practice, then, this aspect of nationalism can foster essentialism (involving a loss of both relevancy and currency) and authoritarian government, even though these are developments that undermine any national claim.

Margaret Canovan has suggested that modern nationalism has a self-destructive impulse, and that the dynamic of nationalism undermines itself through its own efforts at nation building (1996: 106-10). If there is a dynamic that drives nationalism towards a reified national character enforced by authoritarian government then 
we have to ask is Canovan correct? Is nationalism doomed to be morally self-defeating? Will the representational dynamic that unfolds from the idea of good governance through the national character always culminate in a political order that is unresponsive to, if not downright hostile to, the natural evolutions we can expect in any population?

The answer, I will argue, is no. The experience with nationalism in post-1950s Ireland and Quebec shows that there is no inevitable end-state to nationalism. In these two cases nationalist governments of the early to mid-twentieth century launched efforts to inculcate and institutionalize a particular definition of the national character. Key features of this definition included the role of the church, the role of women, economic development strategy, education policy, demographic patterns, and language policy. Yet there followed a period of such profound change that the original national character is no longer recognizable in these populations. So pronounced are the changes that if nationality is genuinely dependent on the maintenance of a particular form of the national character then they should mark the beginning of the end of nationality among the populations in question.

While they clearly touch on the most basic definitions of the national idea, I believe we should not read these transformations as indicating a move away from nationalism or nationality. Rather than the end of nationalism, the process of social and political change instead entailed a shift towards a more "relaxed nationalism" born of self-assurance and the feeling that the national identity is well established and secure. ${ }^{1}$ Instead of the decline of nationality then, this experience suggests that nationalism can achieve a more balanced state when it is characterized by strong representational resources in both the cultural and political arenas.

To illustrate this process I will begin by discussing the outlines of the national character ideal that was upheld in these two cases, followed by their experience with social change. Finally I will consider how the sense of nationality is faring in the wake of change. In the end, I believe the discussion in this chapter points to an important conclusion: that national groups can handle a high degree of change, and that a population's collective character need not be immutable in order for it to survive and thrive as a national community. But recognizing this dynamic requires a shift in thinking both among nationalists and among those tasked with responding to national claims, because it shifts the focus away from long-standing cultural or social traits as evidence of national pedigree. 


\section{Nationalism and social change}

\section{The "Celtic Tiger" in Ireland}

Throughout his life, Eamon de Valera never lost his conviction that the Irish needed to be re-confirmed in their distinct character, which amounted to a patriarchal, hard-working, rural lifestyle, within a devout, Irish-speaking state. ${ }^{2}$ With the attainment of political independence, this sense of mission was carried over into the political realm, now with the force of legislation behind it, and in 1937 de Valera introduced a new constitution modeled on the idea of a virtuous and Catholic "Irish" Ireland.

Perhaps the most notable feature of de Valera's constitution was that it granted the Catholic Church a "special position" in Irish politics and the Church's prohibition on divorce, abortion, contraception, and censorship were all mirrored in the law of the early Irish State. As noted in Chapter 8, Article 41 of the 1937 constitution also confirmed the Church's view that a woman's role was in the home (Republic of Ireland Const: Art. 41, Sec. 21, 2.2), and legislation was introduced to regulate women's participation in the workforce.

Because the national character was defined as involving an important rural element, agriculture was made a priority in the new State, and policies were developed accordingly, including holding labor rights to a minimum. The government's concern with upholding a rural, deferential ethos in Ireland also meant education was a marginal issue. As late as 1961 , for instance, only 15 percent of 17 year olds were in full time education (Ó Riagáin 1997: 217). The school system, meanwhile, was viewed as a means of confirming Catholic values and promoting the Irish language. Since rural living was defined as part of the national character, preserving the unspoiled nature of rural life also justified a low level of activity in infrastructure development.

One item that was firmly on the early Irish State's agenda, however, was the resuscitation of the Irish language. Even though by 1922 the number who could speak Irish was estimated at only 200,000 (Lee 1989: 134) the government made competency in Irish a qualification for civil service employment. Irish was also required curriculum in all recognized primary and secondary schools, and an attempt was made to make it the primary language of instruction in all schools. Although the full immersion effort did not last long, Irish proficiency was made a requirement for intermediate secondary school qualifications in 1927 and for the Leaving Certificate qualification in 1933 (the Irish equivalent of a high school diploma). Throughout this period Ireland continued its pattern of high birth rate and high emigration, and in keeping with the rural self-image, 61 percent of the population lived 
in rural areas in 1926, a number that basically held steady for the next twenty-five years (Ó Riagáin 1997: 217).

In the latter half of the twentieth century there was a remarkable turnaround in the social and economic patterns prevalent in Ireland, and these changes have in turn led to a conscious re-examination and re-definition of the national ethos. As evidence of this change it is interesting to note how many of the legislative or constitutional provisions aimed at institutionalizing a certain concept of the national character have been undone. In 1972, for instance, the "special position" of the Roman Catholic Church was abolished by referendum. In 1973 the marriage bar to public service employment for women was formally removed, and employment equity and anti-discrimination legislation later followed. In 1985, the sale of contraceptive devices was legalized and ten years later divorce was legalized by referendum. In 1992 a referendum was held on Ireland's restrictive abortion laws and while the ban stayed in place, related restrictions on a woman's right to travel and right to information were removed. By 2002 another referendum on the abortion issue again favored a qualified pro-choice position.

In what at first glance looks like a return to more traditional nationalist thinking, a 2004 referendum was held on Irish citizenship law with the aim of restricting the right to citizenship by birth. The referendum was approved, making it possible to restrict citizenship to children of those who were either resident in Ireland or already entitled to Irish citizenship. Interestingly enough, the reason Irish citizenship law had been so expansive up to this point was in order to award Irish citizenship to those born in the North of Ireland. The willingness to change this provision again reflects a growing detachment from a previous ideal that saw Irish nationalism as taking in the entire island territory.

Many of these legislative and constitutional developments reflect on the changing status of the Catholic Church in Ireland, a change that is also evident in church attendance rates. As late at the 1970s Ireland was reporting 90 percent church attendance rates, but that number dropped throughout the 1980s when several high profile sexual and child abuse incidents became public and by 1995 was below 65 percent. Yet even this is a relatively high rate that does not tell the whole story of religion in Ireland. As one commentator explained, the change in contemporary values, especially sexual standards, seems to have "seeped through Irish Catholicism rather than swept it aside." So although the Irish have not abandoned their Catholicism they have, as he put it, "redefined" it (Fahey 1998: 64). 


\section{Nationalism and social change}

In addition to the removal of discriminatory legislation, women in the Republic won an important symbolic victory with the election of committed feminist Mary Robinson to the presidency in 1990, followed in 1997 by the election of Mary McAleese. Together these two figures have been credited with helping to "redefine and empower the Republic's most conservative political institution" and with "laying the ghosts of an Ireland of the past" to rest (Galligan 1998: 107). Participation of women in the workforce also increased over this period rising from 26 percent of the workforce in 1971 to 38 percent by 1996. Notable within this development was the rise in the number of married women in the workforce, going from 14 percent of the female workforce to about half, over the same period (Galligan 1998: 109).

When it comes to economic policy, agriculture - once considered the premier Irish industry - has had to make way for a strategy aimed at cashing in on the knowledge economy. A series of economic development plans beginning in the 1960s transformed the protectionist, agriculture-based economy to that of a "small open economy" emphasizing trade and investment, so that by 1991 agriculture accounted for only 16 percent of the workforce (Hardiman and Whelan 1998: 68). In its place, technology development and trade accounted for 20 percent of Ireland's GDP by the 1990s and by the turn of the millennium Ireland ranked second only to the United States in software exports (Crotty 2002: 7).

The 1965 introduction of a free education scheme increased participation at the secondary and tertiary levels and there was no requirement for Irish competency in the new technical colleges and national institutes that were part of the initiative (Ó Riagáin 1997: 239). In 1968 secondary education was made compulsory and the number of students staying in school until the completion of their secondary education rose from 20 percent in 1960 to over 85 percent by 1997 . In addition, 40 percent of this group went on to tertiary level education (Schmitt 1998: 213).

Turning to demographics, Ireland's once-high fertility rate is now below replacement level. Especially notable for Ireland with its tradition of exodus is that the emigration rate has also dropped off dramatically. At the same time, reported births outside marriage went from 3 percent in the 1960s to 25 percent in 1996. This trend is even more pronounced among younger mothers, with a full 70 percent of births to mothers aged 20-24 being non-marital (Fahey 1998: 55-9). And, in a turnaround from the previous pattern, urbanization has reached the point in Ireland that a full one-third of the population is living in the Dublin area alone (Hardiman and Whelan 1998: 70). 
In 1973, the compulsory Irish language qualification was dropped for public sector employment and for secondary school graduation. Yet there is still a sense that it is externally recognizable traits like language that best confirm Ireland's status as a national community. As one recent study on the language issue explained, Irish remains "the most effective basis" for nationality because of its "capacity to signal the valid claims of membership in a distinctive peoplehood" (Tovey et al. 1989: 29). The persistence of this idea may help explain the small revival in all-Irish schooling that has taken place in recent years. What is remarkable about this revival is that it has been driven by parents' groups rather than government, which has increasingly backed away from compulsory Irish education measures in favor of voluntary arrangements (Ó Riagáin 1997: 24, 281). Likewise, while there has been a decline in the everyday use of Irish in homes and workplaces, there is increased support for its ceremonial or symbolic use, such as in legislative debates, public signage, and ironically, qualification for public service (Ó Riagáin 1997: 185).

These changes in Irish politics and society have led to its becoming a highly educated, urbanized, and secularized society, as well as to the increasing ceremonialization of the Irish language. Taken together they suggest that there has been a significant shift in the national character that the Irish population presents to the world. To indicate that this is not an isolated case, let me also outline the experience with national character in Quebec over the same period.

\section{The “Quiet Revolution” in Quebec}

In the first half of the twentieth century, Quebec was an economically dependent province where the Catholic Church played a key infrastructure role. Out of this environment was born the Union nationale party, which brought to power the socially conservative leader Maurice Duplessis. ${ }^{3}$ Duplessis governed in accordance with a national image of Quebec as the home of a devout, deferential people with a taste for the simple life defined by parish, land, and language. In contrast to Ireland, the effort to uphold the national character in Quebec was not approached through legislative measures to the same degree. Rather it focused on shielding the population from external influences while granting the Catholic Church considerable scope to shape economic and social conduct via its role in unions and social services.

Duplessis felt that the idea of the national character called for a relatively "hands off" policy on the part of the Quebec government, 


\section{Nationalism and social change}

in favor of the more traditional system of Church authority. The importance of the family to the transmission of religious and cultural values meant motherhood was viewed as the "sine qua non of national survival" (Lamoureaux 1987: 59). Large families were encouraged, and a woman's role was generally defined as either motherhood or community service through entering a religious order.

Clerical deference meant that the Quebec State was minimally redistributive and economically non-interventionist prior to 1950 (Gagnon and Montcalm 1990: 18). The dominant Duplessis regime followed a laissez faire policy characterized by an investment-friendly strategy of low taxation, balanced budgets, rhetorical support for agriculture, low prices for resource rights, provincial autonomy, and the suppression of labor rights. Minimum wage was kept low, as were social or employment benefits and standards.

The low priority placed on education was evident in 1951 when 70 percent of Quebec schools were one-room schoolhouses, 60 percent had no electricity and 40 percent had no running water or indoor toilets (Linteau et al. 1991: 244-7). In that same year Duplessis refused grants from the federal government intended to support universities in the province on the grounds that it was federal interference in a provincial area. And as late as 1958 only 36 percent of francophone Quebecers started secondary level education and only 13 percent finished it. In contrast to Ireland, Quebec was already 60 percent urbanized by 1931, yet the government continued to emphasize a land-based lifestyle, even launching a series of initiatives in 1932 and 1935 aimed at settling the province's northern regions.

Along with the role of the Catholic Church, the French language was defined as another key component in the national character in this period. It is interesting to note, however, that it was not until after the Duplessis era that major legislation to promote the use and display of French was introduced in the province. Until the 1960s the preservation of French was largely a by-product of the separate social world maintained in the province by the Catholic Church as a bulwark against the seductions of North American society.

The effort to hold the outside world at bay did not succeed, however, and Quebec's experience with social change was so dramatic and pronounced that it earned its own title: the "Quiet Revolution." Strictly speaking the Quiet Revolution is used to indicate the years 1960-1966, and it marks the opening of a period in which the ideal of the national character and the means by which it was to be upheld underwent radical transformation. In the years following the Quiet Revolution, education, health care, and social services were increasingly taken over from clerical control, and this coincided with a rise in 
secularization in the province. By 1985 the number of practicing Catholics in the province had dropped by almost half, down to 38 percent of self-identified Catholics, while membership in religious orders dropped by a third (Langlois et al. 1992: 317).

And in a trend that pointedly indicates the decline of Catholic Church influence in the province, rates for common-law marriages, divorce, and births outside marriage, have increased steadily since the 1960s. A 1986 study, for instance, found that among women in their twenties, between one-fifth and one-quarter were in common-law relationships. Meanwhile, divorce rates quintupled between 1969 and 1987 (going from 9 to 45 percent), and the number of children born outside marriage increased by a factor of seven, accounting for nearly one birth in every three in 1987 (Langlois et al. 1992: 13, $16,110-1)$.

The role of women in Quebec society also underwent significant change as greater control of reproductive choices was followed by higher participation in employment and education. By 1991 women made up 44 percent of Quebec's paid workforce, and 63 percent of women with children in the home held paid employment. Women's participation in higher education likewise increased and women accounted for 57 percent of the degrees granted in Quebec in 1990. In the legal arena, a 1964 law repealed several gender discriminatory provisions in the Quebec legal system by recognizing the fundamental equality of spouses as well as establishing equal rights and responsibilities as regards children, the marital home, and parental authority. Finally, a 1970 reform of marital law was followed in 1989 by laws providing for the equal distribution of family assets at separation (Lemieux 1994: 473-97).

Beginning in the 1960s, the Quebec government committed itself to addressing the province's economic vulnerabilities by fostering domestic industry and investment and worked to ensure the French-speaking population had ample opportunity to participate in the management of these new ventures. Some of the measures that coincided with the Quiet Revolution included the creation in 1964 and 1965 of agencies to promote the development of Quebec's natural resources in mining and steel. In 1965 la Caisse de dépôt et placement was created. It used Quebecers' pension and savings investments to foster Quebec enterprises, as an alternative to the traditional banks that had been slow to invest. Other initiatives included nationalization of the Quebec electricity system and later, massive and controversial dam-building projects in the Cree-occupied territory of James Bay.

In 1964 the province established its first Ministry of Education and through it, took over control of schooling from the church. School 
attendance for 13-16-year olds went from 38 percent in 1951 to 96 percent by 1967 (Kahn 1986: 36). 1967 was also the year in which the province introduced the province's unique CGEP system, an extra educational level that bridged the transition between secondary school and university or work.

The image of Quebec as a rural-based population was not accurate even in Duplessis' time, but from 1960 onwards rising urbanization was coupled with pronounced rural depopulation and a shift out of agricultural employment. It is estimated, for instance, that two-thirds of would-be colonists in the northern settlements of the 1930s gave up on the experiment within a few years (Linteau et al. 1991: 21). By 1986 the percentage of the population living on farms had dropped to just above 2 percent and by 1971 over 80 percent of the population were living in urban centers. In 1986, one half of the entire population of Quebec lived within the Montreal area alone (Langlois et al. 1992: 13, 16). Beginning in 1960 Quebec's once legendary birthrate plummeted and has not risen above 1 percent since 1970 .

One element of the national character has remained in place, however, and has even gained in prominence because of its significance in marking the distinct character of the province within the Canadian and North American setting. The French language is still seen as an essential characteristic of the Quebec population, and maintaining the linguistic character of the province has been an explicit objective of successive governments. To this end, a series of controversial language laws were introduced with the goal of establishing French as the undisputed lingua franca of the province. ${ }^{4}$ This increase in legislative and political activism is in notable contrast with the Irish experience.

In sum, the period of social change in Quebec heralded by the Quiet Revolution marked the end of a compact between clerical deference and authoritarian government that rested heavily on the idea of national character. In its place came rising secularization, a broadening of the social and economic options for women, pronounced state activism, the promotion of education and educational resources, and plummeting birth and marriage rates. This period also witnessed the introduction of new efforts to legislate language use in recognition both of the marginalized place of French in economic matters and because of its significance to Quebec's recognition as a national minority.

\section{National character and social change}

More could be said about the process of change in these two communities, such as the impact of new communications media, changes in 
patterns of trade (including Ireland's 1973 entry to the EEC), or changes in labor relations and class structure. But my interest here is not so much to account for these changes as to illustrate their significance, especially as regards traits and patterns that have previously been cited as central to nationality. Yet there is a danger in highlighting this transition, between what gets cast as a kind of "dark ages" of the 1930s-1950s and a "grand enlightenment" of the 1960s-1990s (Kirby 2002). The danger is that this approach may obscure both the developments that took place in earlier periods, and the traditionalism that continues in the later one. The reality is more complex than that. However, there has been a marked change in the political and social ethos of these populations and I want to focus on this difference without leaving the impression that the Irish only just grasped liberal ideas, or that Quebec only recently discovered entrepreneurship.

Before I close this section I feel I need to say a word on the topic of minorities in these two cases. In either case there were minority populations identified by mother-tongue (anglophones in Quebec), religion (Protestants in the Republic of Ireland), or as national groups in their own right (Native populations in Quebec). Yet in neither case did the original definition of the national character make much attempt to take these resident minorities into consideration, and instead served to place them outside the bonds of co-nationality, leading to a sizeable exodus of those minorities with better exit options.

As the effort to maintain a strict definition of the national character has undergone transformation, however, opportunities to include these groups within the national frame of reference have increased, and minorities are increasingly at home within the larger population (Carens 1995b; Labelle and Salée 2001; White 2002: 36). The members of the Protestant minority that remained in the Republic of Ireland, for instance, have become so integrated in Irish society that one observer recently concluded "southern Protestants were an ethnic minority in the past...they are not today" (Coakley 1998: 101-2). Whether complete absorption is entirely desirable from a minority perspective is open to debate, and the decline in the standing of this particular minority may owe a great deal to the large numbers that chose to leave rather than live under an unresponsive national government. Nevertheless, to the extent that this pattern may also indicate the broadening of the terms of nationality to include a hitherto excluded group, it is still a remarkable development.

In both these cases the social, political, and economic habits of today's population no longer reflect a previous ideal once seen as crucial to that population's claim for national standing and its associated 


\section{Nationalism and social change}

benefits. These developments present us with a number of important questions. First, does the transformation in the national character indicate a decline in the attachment to, or sense of, nationality? Second, if national characteristics are associated with the legitimacy of the national claim, does a transformation in the national character imply a weakening of that claim? And finally, since a national political identity seems to have outlasted the cultural particulars from which it arose, is nationalism more political than it is cultural?

\section{The persistence of nationality}

There has been a profound change in the practices and institutions of these populations. These developments challenge the homogeneity that was associated with traditional forms of nationalism in these cases. Yet while it may have been "reformulated" in response to these changing circumstances (White 2002: 36-8), there is reason to believe that nationality remains a significant factor in Ireland and Quebec. The continued relevance of nationality manifests in at least two ways. First, it is a factor in the self-understanding of specific populations, and second it plays a part in their external relations, influencing how they negotiate the terms of coexistence and recognition with other powers. In short, if nationality is still a vital force in these cases, it should be evident from how the populations view their own community and how they wish that community to be regarded by others.

In one of the most direct measures of the continued significance of nationality, the 1990 European Values Survey reported that an impressive 78 percent of Irish say they are "very proud" of their nationality, as compared to a European average of 38 percent (Crotty 1998: 14). This is in spite of an almost across-the-board decline in confidence in particular public institutions such as the legislature, civil service, and police.

This capacity to combine a critical view of national institutions with a strong attachment to nationality is reflected in another area of Irish self-understanding, that of national scholarship. Starting in the late twentieth century, historical works began appearing that were increasingly critical of received accounts of Irish national (or nationalist) history. Works such as R.F. Foster's Modern Ireland are seen as marking a break with the previous mode under which, it was argued, history was presented as a "teleological" process culminating in Irish independence (Ó Tuathaigh 1994a: 318). Now termed "the revisionist controversy," this school of history has been characterized as an "iconoclastic assault" on the leading figures of Irish nationalism. 
So much so that revisionists have been criticized for distorting the history they mean to expose, by writing out the trauma involved and by "inverting the anachronism" to deny the deep-rootedness of the Irish identity (Bradshaw 1994: 191-216; Brady 1994; Boyce and O'Day 1996). The entire controversy received considerable public attention for what has been described as "a rather complex and arcane debate among academics" (Ó Tuathaigh 1994a: 307), suggesting that questions of national history still touch a powerful chord among the population.

Perhaps even more clearly than Ireland does, the Quebec case illustrates how an attachment to nationality can persist even in the face of dramatic changes in the fundamental social and economic patterns of a community. In a pointed test of the continued salience of nationality for the Quebec population, a 1990 poll found that 56 percent of respondents were prepared to vote for Quebec sovereignty if a referendum on the issue was held at that time (Langlois et al. 1992: 601). A referendum was actually held in 1995 and the sovereignty option lost by the narrowest of margins - less than 1 percent. While the proposal was defeated, what is significant about this result is that it was a significant shift from the result of a similar referendum in 1980, where the sovereignty option garnered 40 percent of the vote. In other words, these results appear to indicate an increased degree of comfort with the nationalist option.

In an interesting parallel with Ireland, Quebec historiography has also begun to reflect critically on its own national and nationalist history (Rudin 1997). As in Ireland the controversy revolves around the role of revisionism in attempting to "normalize" Quebec history by de-emphasizing previously central events - such as the conquest and survival under British rule - and instead focusing on the ways in which Quebec's development mirrored that of other North American populations. But this effort too has come in for criticism on the grounds that its focus on structural factors "denied any sense of a common identity" and overlooked or understated the distinct factors in the Quebec situation (Rudin 1997: 171-221). While debunking the hagiographical approach to history was part of social transformation in both Ireland and Quebec, there is a reluctance to allow the process obscure a fundamental sense of difference.

Turning from the domestic to the international scene, perhaps the most important developments in Irish external relations may not at first appear to be evidence of the continued role of nationality. In fact they may seem to support a post-nationalist thesis. But if we set aside the assumption that nationality is signified by stasis, then we can see 
that the transformation of nationality may be a factor behind some of the most important developments that have taken place in these communities in the past half-century.

For instance, Ireland's 1973 entry into the European Community was a key event in the reorientation of the country's foreign policy from isolationist neutrality to European and international participation. The Republic's new foreign policy goals involved presenting itself on the international stage as a non-aligned country with strong affinities for post-colonial concerns as well as humanitarian, human rights, and equality issues. One concrete example of this stance is Ireland's role in international peacekeeping, with Irish troops participating in 7 of the 12 UN missions between 1956 and 1970 (Tonra 2001: 104-27).

But Ireland's delayed entry into international affairs has not been without its note of caution. While the benefits of broader economic cooperation are certainly welcomed, the awareness of being a small player on a large stage, where its domestic interests can easily be marginalized, tends to cool the "europhoria" of leaders and laypeople alike. For instance, while 98 percent of Irish feel that Ireland has benefited from EU membership, only 40 percent would be willing to entertain the concept of European government, suggesting a continued desire to "protect national space" (Laffan 2002: 86).

A second and in many ways more remarkable development in external relations concerns the Republic's relations with the North of Ireland. In 1983, prompted by concerns over the persistent cycle of violence in the North, senior elected figures from the Republic and the North of Ireland participated in a series of meetings and consultations under the title of the New Ireland Forum. The initiative is significant because it helped pave the way for the current peace process in the North. It also contributed to the readiness of the Republic to rescind clauses in its constitution that laid claim to the entire island, thereby removing a long-standing source of conflict and concern between the communities. While at one level these developments reflect the rejection of a certain intransigent nationalism, they did not imply a complete rejection of national attachments. It was, instead, an attempt to re-negotiate the terms on which these attachments were maintained.

Looking into Quebec's external relations in the post-change period the first thing to note is that, like Ireland, one important development involved a certain territorial readjustment of the boundaries of nationality. The Quiet Revolution is seen as confirming a shift in the focus of French-Canadian nationalism from something with 
pan-Canadian attachments to one that is Quebec-centric. But rather than representing a blow to nationality, the development is associated with a new vitality in nationalism. With the nation so defined, for instance, political separatism became a viable option and there followed the rise and eventual election to power in 1976 of the Parti Québécois or PQ - a party devoted to the political autonomy option they termed "sovereignty association." 5

In the post-change period there were also escalating struggles between Quebec and the federal government over the extent of federal authority within the province, and over designs to repatriate the constitution. ${ }^{6}$ Ultimately the Canadian constitution was repatriated without Quebec becoming a signatory, and subsequent efforts to resolve this situation have resulted in a series of inconclusive interprovincial negotiations. While the constitutional landscape in Canada has become immeasurably more complex in the ensuing years, one of the key hurdles in the process has been the insistence that Quebec should be recognized as a "distinct society," within Canada, a measure supported in Quebec and resisted in other Canadian provinces.

\section{The national claim after social change}

For some observers the confluence of social and political change witnessed in these cases easily suggests a move into a post-nationalist era. In fact, this reading aligns post-nationalist theory with the most inflexible of national-character nationalism, as both approaches equate the loss of certain cultural traits with the decline or supersession of national attachments. If nationalism is genuinely about the preservation of cultural traits, so the argument goes, the failure to preserve these traits indicates the decline or failure of that nationality and the associated national claim.

It is implausible to make a national claim for a population that is already in the process of shedding its nationality. And if a population is demonstrating a markedly more liberal social structure, characterized by more diversity and less shared traits, then continued attachment to the nation may seem paradoxical (Kymlicka 1999: 121). Yet even if we can still detect attachment to the nation if the national character traditionally associated with it has become obsolete does this mean the nationality is living on borrowed time? The experience with social change in Ireland and Quebec suggests that changing cultural forms do not necessarily indicate a nationalism in trouble. If this is the case, then there is no reason then to think that the national claim should be regarded as weaker because populations have changed their characteristics. ${ }^{7}$ If it 
were true that the decline in certain national characteristics undermines a national claim this would imply that the Irish had a weaker case for enhanced political representation at the turn of the twentieth century because they had failed to revive Irish as a living language. Such a position hardly seems to do justice to the national claim.

Yet in Quebec a linguistic factor - the role of French - has recently come to be regarded as the central factor grounding the national claim for that population. Indeed the role of this characteristic in underpinning the claim to distinct status, and therefore to political accommodation, has if anything become more pronounced in the wake of social change (Carens 1995a: 29). French was only one of a range of characteristics originally identified with the Quebec national cause, and it originally played a secondary role to that of Catholicism, with French celebrated largely as "the guardian of the faith." If the national claim truly rests on national characteristics such as language and religion then we would today have to acknowledge that those grounds have been undermined, presumably undermining both Quebec nationality and its national claim. However, few would accept this reading. The fact that Quebec is now as secular and liberal as the rest of Canada does not mark the end of their nationality. Indeed Wayne Norman has commented on "the spectacular irrelevance of shared values to national unity" in the Canadian case (Norman 1995: 148).

The implications of this position are considerable when it comes to evaluating the national claim in Quebec. In the wake of social change the continued emphasis on French raises this question: If other characteristics could be set aside without prejudice to Quebec's national claim why do we still place so much emphasis on the persistence of French to justify Quebec's position? Having survived a change in religious attachments, is it so unthinkable that Quebec nationality could also survive a change in linguistic character? Or to put it in more pointed terms; can language legislation in Quebec be defended as necessary to uphold the province's status as a national minority? The very suggestion may seem troubling, as much for Canadian nationalists sold on the idea of bilingualism, as those in Quebec who aim at maintaining the French fact. Yet it cannot be avoided as an implication of this argument, and it was not so long ago that a cosmopolitan Ireland or a secularized Quebec was just as unthinkable.

\section{Conclusion}

Some might suggest that the only lesson we should take from these examples is that ideas about nationality or national character are 
ultimately illogical and ill-fated myths, and the sooner they are done away with the better. Undeniably, the attempt to construct and enforce a particular definition of the national character led to serious problems in these cases. However, it is not necessary to rule out the very idea of nationality in order to address the conduct of nationalist government. It is possible to acknowledge that the characteristics and self-understanding of a population matter, that they may even set them apart in a way that underpins calls for separate political institutions, without entailing that these characteristics be uniform, unchanging, and rooted in long-standing traditions.

If national character is intended as a reflection of a real society, then it seeks to reflect something that will always be in flux to a greater or lesser degree. The authentic character of any population represents a moving target, and any attempt to arrest that movement will require increasing degrees of coercion. If, in contrast, the character of national groups is understood as something that can weather great change without leading to the collapse of the nationality, then we can reasonably expect the populations and governments involved to remain open to constant revision of the terms of their nationality.

But understanding nationality in these terms will require a change in thinking, and not just among nationalists. We already know that in early efforts to demonstrate nationhood, national character was taken to mean that a finite set of characteristics was associated with the nation and that these characteristics could indicate the viability or validity of that nationality. This conviction led to authoritarian government and essentialist public policy, and if left unchallenged will continue to do so in the future. But it is not only nationalists who are guilty of this supposition. Those who defend the rights of national minorities can unwittingly encourage this stance by construing nationalism as the right to maintain particular cultural traits. And from a different end of the spectrum, post-nationalism too seems premised on an understanding of nationalism that sees it as incompatible with social evolution. In other words, it is the belief that social change indicates the demise of a nationality that creates the problems discussed earlier.

As long as the connection between cultural constancy and nationality goes unchallenged among nationalists and outsiders alike, an incentive remains for nationalists to oppose processes of change and evolution within their populations. The solution to this problem, I believe, lies not just in vigilance to abuse, but also in challenging the formula that links social transformation to the diminution of nationality, and that reads change among national populations in a way that compromises 


\section{Nationalism and social change}

their credibility as a national group. For if this idea is left stand then national populations that choose collective evolution over the reification of culture may face a penalty in terms of how their claims are received.

Not only is this position untenable from a practical perspective, it is neither theoretically nor historically warranted. The fact that the Irish population is today secular, urbanized, English-speaking, and attuned to the knowledge economy, is not evidence that Irish nationality or a distinctly Irish frame of reference has collapsed. Nor is it evidence that the Gaelic-based, rural, Catholic, agriculturally driven frame of reference was a myth. What it indicates is that a population's frame of reference can, and should, change over time.

Nor is it an option to say that we should set aside these thorny questions of cultural character and focus on the strictly political side of nationalism. Cultural features such as a sense of shared history and future, having a common idiom or sharing common social patterns, unavoidably matter for a population. The key is that these cultural features do not need to be static. We must be careful, therefore, that national recognition does not become a reward for cultural stability. Instead the kinds of social change and evolution that I have discussed here may well be the best evidence that nationality is alive and well in a population. 


\section{The ties that blind}

The writings and speeches of leading Irish and Quebec nationalists reveal a concern for the benefits of having a population share, among its members and with its government, a connection that I have described as a shared frame of reference. This frame of reference serves as the basis for a critical task of collective life - representation. The act of representation takes a familiar form in the political sphere. In modern democracies it takes the shape of an elected government and the administrative institutions that support it. But representation also takes place in the social or cultural realm, where it appears in the form of history, the arts, manners, language, and ways of life. The moral claim of nationalism, therefore, rests on the role nations can play as a resource through which we can address the challenges of representation and thereby create a shared political and cultural life. This is the main argument advanced in this volume.

Understood in this way, we can see why nationalism generated different formulations to address different aspects of our collective lives, and also why a related theme ran throughout the different styles of nationalist movement. We can also see where the limits of nationalism are reached, and we must acknowledge that a call to collective revision is also implied in this process. I have argued that a shared frame of reference can support a common idiom for communication and meaning, a cognitive mechanism for complexity reduction, and a reserve of historical precedents for inspiration. Nations are not the only frames of reference that pay such dividends, of course, but they encompass a territorial dimension that gives them particular political significance in a period when political authority is still highly territorialized and when political jurisdiction is still largely exercised within borders.

One implication of a representational approach to nationalism is that to continue to pay dividends a national frame of reference needs 
to stay in tune with the actual circumstances of the population that employs it. If not, the information and options it offers will become increasingly irrelevant and ill suited, and instead of improving a population's knowledge and efficacy, it can become an obstacle to them. Yet precisely because they bring together and integrate information on the key dimensions that inform our thinking and acting, the national frame of reference provides a way for a population to collectively revise the attachments, options, and information with which they work. Re-examining its nationality is therefore one way for a population to update the cultural and political resources available to its members.

Once we have identified the moral basis of nationalism, we are better able to critically assess the way nationalism unfolds in practice, and I have tried to illustrate how that might work with regard to Ireland and Quebec. The exercise revealed important qualifications on the kinds of nationalism that focus on changing the structures of governance, and those aimed at shaping the character of the populace. It also specified that consideration must be given to alternative frames of reference whether they operate within or beyond a given national population.

Although on the surface Ireland appears to be the more clear-cut and ultimately successful case of nationalism, the representational approach raises several doubts about how the process unfolded there. Quebec, in contrast, at first looks like a perpetually frustrated nationalism, as it has not attained the kind of resolution seen in Ireland. But this is to underestimate the achievements in the Quebec case, and to overestimate those in Ireland. By focusing our attention on the political and cultural resources available to a population, a representational approach argues that in Ireland partition was evidence that the national question had not been properly resolved. So long as the difficulties associated with that solution persist they are both the responsibility of, and a reflection on, the nationalism of the Republic. In Quebec in contrast, the ongoing federal project is evidence of an effort to develop representational resources that match the complexity of the Canada/Quebec situation. And a representational approach suggests that this kind of political and cultural resourcefulness, rather than the achievement of any particular political status, should be the final measure of success.

In reaching the conclusions discussed in this book I have to concede that I often made a distinction between two forms of nationalism, based on the arenas within which the process was played out. But I want to stress that this should not be taken as a suggestion that we 
can prioritize one form or formulation over the other, nor can we suppose one to have greater legitimacy, or to be inherently more benign than the other. And again I would reject any idea that the two can ever be neatly separated. They are complementary processes, concerned with the same basic condition of collective life. Where you find one, you are likely to find the other. The distinction between them is not in their moral standing, nor in their significance for representation, but merely in regard to their day-to-day expression. I have also argued that this day-to-day expression of nationalism can take on undesirable forms and for this reason we must be conscious of limits. Shaping culture through coercive or state-sponsored political measures can lead to a misshapen culture, while redesigning politics around cultural preservation can result in a stunted political order. We will need to think out limits that can apply specifically to each arena and setting, therefore, to ensure that accommodating representational resources does not become a license for political or cultural stagnation.

The project laid out in the preceding chapters is, as I acknowledged at the outset, an ambitious one. The claims I have made along the way are admittedly broad in scope. But I hope that they represent a reasonable attempt to consider what nations may mean for people, how they contribute to collective life, and under what conditions these advantages are best realized. Nonetheless, the approach to nationalism that sees it as a representational resource should not be taken as a claim about the "true" or "real" meaning of nationalism. Nationalism has many meanings for all those that adhere to it; all of them true for their own purposes. This theory, however, is a claim about one meaning of nationalism - a meaning that I argue has moral standing, and that resonates with the arguments and concerns of nationalists in at least two important cases.

Accommodating nationalism under these terms is not going to make every nationalist happy. Nor can it address all possible aspects that are associated with nationalism in a range of settings. But that was not the aim of the project. The aim was to ask what, if anything, we can recognize as morally significant about nationalism. Such recognition should also equip us to distinguish, and if necessary reject, national claims that fall short on some measure or another, and establish standards for what we consider acceptable and unacceptable expressions of those nationalisms we mean to accommodate. But of course these ideas are articulated into a field of theory already rich in findings and arguments, and its position within that field should be further clarified. 


\section{The ties that blind}

\section{Theories of nationalism: nationalism as representation}

In Chapter 2, I set out terms that a theory of nationalism should be expected to meet. I also addressed some of the strengths and weaknesses of prominent theories in the field. It is only fair then to ask how a representational approach to nationalism might measure up according to these criteria, as well as how it works with, or differs from, these leading theories.

Using the criteria from Chapter 2, I argue a representational approach to nationalism: (1) sets out criteria under which nationalism is legitimate by indicating that requirements for revisability, currency and relevancy, as well as equal respect for persons, act as limits on its claim. (2) It explains that nations are special kinds of groups because they provide a frame of reference that aligns with the current contours of our cultural, and particularly, our political lives. (3) It understands nations as contingent constructs that can and should change with changing circumstances, and therefore credits us with adaptive capacity to both revise and if necessary do without our nations. (4) It posits a base for social trust in the form of the representational facility supported within a population, and explains why its boundaries fall where they do. (5) It explains why we cannot approach nationalism as an individualizable claim, given the irreducibly collective aspect of representation. (6) It recognizes the collective as well as individual dimension of autonomy by recognizing nations as ways to collectively revise options and meanings. (7) Finally, it understands nationalism as the means by which populations can transform their cultural resources, as well as sustain them.

At the same time a theory of nationalism as representation does not suggest we should view nationalism as an inherent good. Instead, it argues that nations are instrumental to representation, while fully acknowledging that this process can be taken to lengths we would not wish to endorse. Even nationalism as representation, therefore, can have its dark side, calling for careful limits and evaluation. When it comes to the role of nations in restoration and remediation, nationalism as representation explains why it is important in cases of oppression or occupation to restore political or cultural autonomy to these populations. Not only because rights may have been violated, but also because a working representational system may have been rent from a population, leaving it disadvantaged in an unacceptable way. The role a shared frame of reference can play as a complexity reduction mechanism also explains why, in the increasingly complex setting of modern life, nations take on added significance, without becoming all-important. 
This account of nationalism can also help us understand the claim that nations are ethical communities, without taking this claim to mean they will always deliver ethical behavior. The claim that the same political or cultural national identity automatically boosts our willingness to share, or our concern for the fate of co-nationals, supposes a kind of inherent altruism to nationalism that just is not plausible. What is plausible, however, is that people who share a common frame of reference have a better basis for representing themselves to one another, and therefore a better chance for understanding each other's needs as valid. In other words, nationalism as representation explains why we have reason to hope for moral buy-in, rather than moral transformation.

Understanding nationalism as involving a shared frame of reference also explains why it can help negotiate esteem and identity issues, given the critical role that representation plays in these processes. A shared frame of reference also aligns with the idea that we need a context of choice for exercising autonomy, without making this context the final word in our autonomy options. Because it is a shared element of our representational repertoire, we can choose against this context on an individual basis, if we wish, and we can collectively revise the context as circumstances warrant. This revisability factor also explains why we can recognize a value to cultural heritage, without making its preservation a moral reason unto itself. Nationalism as representation avoids the temptation to fetishize the past, yet because cultures serve representational purposes, so long as those resources are still relevant to contemporary circumstances, they have significant forward-looking value. In this way, the approach de-emphasizes the role of particular cultural traits or their maintenance in favor of the evolving circumstances, interests, and attachments shared by a population on an ongoing basis.

A theory of nationalism as representation, therefore, has something to offer with regard to the criteria extrapolated from a survey of existing theories in the field. It also helps tie together many of the insights drawn from these theories while suggesting ways to resolve certain difficulties that they present. Most importantly perhaps, it points towards a new way of approaching the critical questions concerning how best to respond to and/or accommodate national claims when they are advanced.

\section{Implications of this account}

The implications of acknowledging a moral worth to nations are often thought to be both enormous, and enormously disruptive. But I 
believe that the implications of the account I have outlined in this work, while significant, are limited in important regards.

If we accept that nationalist claims can have moral standing based on their role as a representational resource, then there will be cases where we will need to accommodate these claims. This will most likely involve upheaval and change in the political order or the social life of the population. Either way there will inevitably be people who would prefer to avoid such change. But another implication of this account is that we should carefully consider which nationalisms merit accommodation and under what terms. So this is not a blanket endorsement of every nationalist claim. Under this account it is not merely a matter of what nationalists feel for their nation or co-nationals, nor is it a question of their attachment to certain ways of life, or even how distinct a group's culture appears. These feelings, attachments, and cultural differences may be considerable but we might still conclude that the nationalist measures being pursued are unlikely to yield the benefits that give nationalism its moral worth.

One consequence of this approach, therefore, is that while we may recognize nationalism as aiming at an outcome with moral worth, we cannot presume that every nationalism has equal standing. We need to investigate whether the conditions exist to realize the supposed benefits, and we need to be conscious of what can be lost through the changes that nationalism may seek. Such investigations are a science unto themselves and I have not set out to address them here, although to be fully operable a theory of nationalism should provide guidance in this area. For that reason it must be acknowledged that the account of nationalism provided in this work remains at a general level. Yet even at this level we can say that to recognize a moral worth to nations is not equivalent to endorsing every claim a nationalist might make.

By recognizing the role that nationalism plays in supporting representation, this approach differs from some of the recent literature on nationalism, in that it sees nationalism as the glue that holds politics and culture together, rather than the means by which they can be set apart. In doing so it can help address the potential for impasse developing in liberal-nationalism when it seeks to produce cultural-side or political-side accounts of the phenomenon. Instead, the link between the two sides is used to identify a deeper commonality. That insight is then used as a basis for both recognizing moral worth and setting limits, without suggesting we can prioritize, sever, or choose between political and cultural forms.

A representational approach also raises questions about postnationalist and patriotic-republican alternatives to nationalism. The 
chief problem here is that these alternatives either already assume the kinds of pre-political resources that nations have traditionally provided, particularly in terms of clarifying membership, or believe they can be generated in non-national ways without entailing the kinds of risks we at least recognize as associated with nationalism. The upshot of this stance, however, may be to escalate membership issues through neglect or ambivalence, while denying the political project the kinds of resources it needs to support a shared project.

There also seems to be a special relationship between a representational approach to nationalism and multiculturalist theory. This approach does not amount to an alternative to multiculturalism, as some might expect. Instead the two theories should be viewed as mutually modifying, with one proceeding from a concern with difference, the other from a concern with integration. They share a focus on representation, autonomy, and revisability, but each brings a unique set of theoretical tools to the table.

They also share a concern for the equality of persons and this is a significant enough normative requirement to posit a limit on nationalist claims. This condition not only focuses attention on the fate of minorities and individuals under a national frame of reference, it also makes reciprocity and respect for alternate frames of reference a condition of legitimacy. But unlike much recent normative theory concerning nationalism, a representational approach suggests that limits are not only derived from external sources. A representational approach to nationalism is inherently limited by requirements for currency and relevancy - yielding the revisability quality that is stipulated in liberal-nationalism but which is defended on liberal rather than national grounds. It also entails a minimum level of moral equality as an implication of a shared representational process. Thus a combination of inherent and external limits should apply even when we understand nationalism as playing a role in collective representation.

There is, however, one way in which the implications of this account lead to a broader view of the subject, rather than a more limited one. Will Kymlicka writes that there is a paradox inherent in all liberal-nationalism. The paradox is that while conventional nationalisms may offer a defined set of roles and priorities for a life, liberalnationalism requires us to loosen up those definitions in a way that ultimately thins out the nationalism involved. As he puts it "If such a thing as liberal nationalism exists, it can only be in this form of a deep attachment to a thin identity" (1999: 122). Liberalism, under this view, stands in a kind of trade-off relationship with the qualities we associate with nationalism. We may decide the trade off is well worth 
it, we may even decide that it is morally required, but it is a trade off nonetheless. By understanding nationalism as representation, however, we can avoid pitting these two claims against one another in this way.

Nationalism as representation suggests that we have a deep attachment, not to a particular mode of identity or collective life, but to the process of working out together the terms of a shared frame of reference, thin or otherwise. In this case it is the process of maintaining and employing a common representational resource that counts, more than its particulars.

\section{Implications for the cases involved}

In both cases I argued that this account of nationalism called for outcomes that in many ways look similar to the current status quo. In the Irish case I argued that independence had been an appropriate goal, but that efforts to change social patterns and practices had often been misguided. In the Quebec case I argued that there were grounds for efforts to preserve significant cultural traits, but that independence was not a clear-cut case because many in Quebec also share a frame of reference with other Canadians. To the extent that these findings endorse existing outcomes they may seem conventional. Yet this process also brought to light findings that almost directly contravene the standard position on these cases.

In the Irish case, for instance, understanding nationalism as a claim about representational resources implied that partition of the island to accommodate a Loyalist preference to opt out of an independent Irish political project was a morally justified measure. ${ }^{1}$ This is a controversial claim in the Irish context and can hardly be regarded as confirming the preferences of those concerned with Irish nationalism. While I have identified problems with partition as it was realized in Ireland, I have not tried to specify how this end might have been better achieved. I concede, therefore, that the requirement to allow an "opt out" option may prove profoundly complex to enact. Nor is the account outlined in this volume intended to suggest there are ready answers to these difficult questions, questions that must be carefully addressed in working out national accommodations. Necessary work though this is, it goes well beyond the scope of this project which has focused on the normative, rather than the institutional dimensions of accommodating nationalism. ${ }^{2}$

In the Quebec case, the account indicated that the population of Quebec (or at least those parts of it that want to participate) can legitimately choose to pursue either enhanced political independence 
or efforts to support traits that are genuinely widespread in the population. The independence route, because it may involve the loss or compromise of other frames of reference, has a more circumscribed moral claim, limited by attachments to other frames of reference. But the account also tells us that Canadians outside Quebec do not have a right to block these efforts, so long as they are within legitimate bounds. This is far from confirming the preferences of those who champion either Quebec sovereignty or Canadian unity.

More significantly, perhaps, the account challenges common dogma in discussing the Quebec case. It suggests that language legislation cannot be justified on the grounds of preserving a cultural trait against change. Granted, the importance of French to the contemporary population - either because of its actual use or symbolic attachment may call for certain measures of support. But nationalism cannot justify the legislated protection of any particular cultural trait against potential future change. By the same token, the linguistic practices of the Quebec population are not the sine qua non for grounding the national claim. Quebec culture, including its linguistic culture, is open to change and revision without supposing that the shared frame of reference that grounds the national claim must somehow be diminished.

In sum, a theory of nationalism as representation does, to some degree, confirm our existing approach to the nationalist claims made in Ireland and Quebec. But it also challenges those involved to come to terms with other conditions that are not so familiar. And it challenges all those who would recognize a moral worth to nations to come up with strategies for accommodating or living alongside those who, for one reason or another, fall outside the national project.

\section{Further research}

To provide a complete account of the moral worth of nations, more work is needed in two areas. First, the difficult matter of application must be worked out, and second, the larger moral and historical questions raised by this account should be addressed.

In terms of application, as already noted, this is an incomplete element of the argument. To be complete, we would need to be able to say with more precision what indicates the presence of a shared frame of reference, and to what degree it should differ from other frames of reference in order to qualify as a national one. We should also be able to articulate ways to accommodate nationalist claims without undue disruption, provide "opting-out" arrangements, and 
ensure that a national frame of reference stays reasonably in tune with a population's actual circumstances.

This account of nationalism also calls on us to consider the standing of nations and nationalism in a broader moral and historical context. On the moral side, we need to evaluate the nationalist claim vis-à-vis other things we value, such as individual freedom of choice, for instance. Will Kymlicka has proposed that societal cultures such as national minorities are a pre-condition for individual autonomy. But despite his prohibition on internal restrictions (1995: 37), I do not think we can avoid having autonomy and culture come into conflict sooner or later. To put it another way, there will always be some tension between our need to know who we are, and be whom we choose. This tension must be directly addressed as part of an effort to develop a complete account of the moral standing of nationalism.

On the historical side, there is another potential complication. If nations are historical artifacts, as Benedict Anderson has suggested and as a series of modernization theorists starting with Ernest Gellner have argued, then what if their day has already passed? What if something better suited to our ever-evolving social and material conditions one day takes the place of nationalism as a basis for a shared frame of reference? Although I doubt that this development has already arrived, I do not want to dispute the possibility that our dominant political and cultural forms are undergoing transformation. Indeed I find the question a compelling one. But recognizing the historical contingency of nationalism does not automatically undermine the moral claim involved, or place it on shifting foundations, because it is not nations per se that count. They are the latest manifestation of a larger process, and that process is a persistent element in collective life. It is this larger representational process that is doing the moral heavy lifting in this account. Nations can and should change over time, and may well become obsolete in favor of another type of framing system. But for so long as they are still a valuable resource for people, their moral standing should be acknowledged.

I do not think this line of questioning need diminish our interest in understanding nations, therefore, even when recognized as a potentially perishable resource. If anything, such research can only better prepare us for whatever comes next. Because we can assume that whatever the new arrangement is, it will need to meet the same representational needs that nations have. So while further work is required to develop the account of nationalism outlined in this work, a better understanding of the sources from which nations derive their moral standing can at a minimum provide a good starting point for these larger efforts. 
I began this project with an idea of nationalism that I had acquired in Ireland, as something that could be dangerous, but which could also yield important achievements. Among Canadians nationalism is viewed with a more dubious eye, because of a concern that nationalism can be a cover for xenophobia or discrimination. As I said at the outset, my goal was to articulate an understanding of nationalism that recognized its capacity to yield the achievements of which the Irish are justifiably proud, without endorsing the outcomes about which Canadians are justifiably concerned. My hope is that the ideas developed in this book can help contribute to such an understanding.

\section{Conclusion}

Nations are premised on the idea that common circumstances create a population with common reference points for their everyday experience. Being able to represent that commonality is the first step in any attempt to understand the population and the circumstances that it faces. And so nations are about representing and understanding our collective life. An analogy might be made to personal character, but more so than with the character of most individuals, the composition of a collectivity can change in unpredictable ways. In fact there really is no such thing as collective character if what we are looking for is a form of continuity over time. The character idea may be relevant at any given point in time, but the chances are that the reality will always outrun efforts at self-representation and self-understanding.

This means that because they are selective, frames of reference are always leaving out some aspect of reality, and sooner or later those aspects can come back to haunt their users. This is an inevitable problem with any representational system and it's worth noting that even in Plato's ideal realm, the perfect city cannot overcome its representational limitations. ${ }^{3}$ Because they rely, not on directly sourced divine knowledge, but on "calculations aided by sensation," the guardians fail to determine the appropriate reproduction rates for their republic. Their "ignorance" allows an error or omission to creep into the calculation on birthrates that eventually destabilizes the entire regime (1991: bk VIII, 546a-e).

We face a similar problem with nationalism. It serves as a resource upon which we can establish a representational order. But the very qualities that make it an effective instrument of representation - its built-in selectivity and limited scope - also create a system of omissions that has the potential to undermine the entire project. For every representation of reality that is made possible through a frame 


\section{The ties that blind}

of reference, in other words, there is at least some reality that will go un- or underrepresented. Creative adaptation and revision are the only tools we have in the face of this paradox and so we must take these tasks seriously and recognize them as part of the very process that nationalism aims to advance. Neglect this factor and we are likely to find ourselves stumbling from crisis to crisis.

We must never forget the inherently limited nature of this process, then. As Plato suggested, representation may indeed be a kind of crime against true understanding. But he also recognized that if we wish to live together, we are inevitably implicated in this transgression. The question that nationalism challenges us to face, therefore, is not one unique to the modern experience, even though it has taken on a uniquely modern form. That question is how best to manage the already imperfect process known as representation. 


\section{Notes}

\section{Introduction}

1 Kymlicka attempts to resolve this problem by accommodating those groups that have historical rights or grievances while saying immigrants have contracted away their right to their national attachments (1995: 95-6).

2 Nor can it be accounted for as a project of the privileged classes to which a docile population conforms. Instead Britain served,

as a bandwagon on which different groups and interests leaped so as to steer it in a direction that would benefit them. Being a patriot was a way of claiming the right to participate in British political life, and ultimately a means of demanding a much broader access to citizenship.

(Colley 1992: 5)

3 The New Oxford Dictionary of English defines "ethnic" as "denoting origin by birth or descent rather than by present nationality."

4 "Most of the potential nations," according to Gellner, "fail altogether even to raise their claim" (1983: 49).

5 Anthony D. Smith's “primordialist" theory of nationalism offers an account that stresses the ethnic origin of nations. His argument is that nations are older, with deeper roots than is generally recognized (Smith 1988). I think we could concede this and still maintain that ethnicity and nationality are distinct phenomena.

\section{The worth of nations}

1 Trudeau once argued that independence was not viable for Quebec because "French Canada is too culturally anaemic, too economically destitute, too intellectually retarded, too spiritually paralysed, to be able to survive more than a couple of decades of stagnation" (1968: 170).

2 As Kedourie put it, "the essence of nationalism is that the will of the individual should merge in the will of the nation" (1993: 105).

3 Admittedly secession is only one form of nationalism, but it is the only one Buchanan addresses (1991).

4 To the extent that Buchanan does contemplate the question, he expresses serious reservations about any doctrine that promotes national selfdetermination. However, I don't think this is enough to distance his 


\section{Notes}

remedial right arguments from arguments about nations and nationalism since most of the secession movements that he ends up legitimizing through his arguments are also nationalist movements. This is not to say that no groups other than nations can opt to secede from an existing political unit. But non-nationalist secession from state units is more the exception than the rule.

5 As Avishai Margalit and Joseph Raz wrote, "It is a natural fact about our world that it is a populated world with no unappropriated lands" (1990: 440).

6 Nairn says of inequality that it "has been the living marrow of actual development." He continues: "Had humankind remained more equal, or been less varied in a social-anthropological sense, then modern history might indeed have assumed the different forms forecast by big-battalion liberalism and socialism." But, he says, "Development could only be uneven" (1990: 29-32).

7 The possible exception to this is Tom Nairn, although I cannot say to what extent he intends his work to be prescriptive as opposed to descriptive.

8 Taylor, in fact, set himself the task of completing the functionalist account begun by Gellner by appending an account of our psychological needs. Taylor says he means to "plug the explanatory hole" in Gellner's work by advancing a complementary, Benedict Anderson-inspired account focusing on self-esteem (1999: 239).

9 Gellner himself does not go this far. However, my argument is that his theory could be used to support nationalism in this manner, casting it as a fundamental priority and calling for an expansive interpretation of its appropriate forms.

10 In response to this challenge Miller argues that the burden of proof is on the universalist to establish that "in widening the scope of ethical ties to encompass equally the whole of the human species, he does not also drain them of their binding force" (1995: 80). But if we accept Miller's suspicion as true, then we should only expect to achieve a limited range of coverage when it comes to certain moral relationships, and unfortunately the relationship that grounds the fundamentals of redistributive justice may not hold over great distances (1995: 80). Given that we know the global economy to be characterized by great international inequalities, we would do well to think carefully before accepting this account.

11 Miller uses this argument to explain why we have limited obligations to redistribute outside of our national group (1995: 73-9, 191). And while in addition to affective ties Miller and Tamir both recognize the significance of a shared history and culture in grounding social trust, these factors would also play against the claims of immigrants to inclusion.

12 The six criteria Margalit and Raz set out are: (1) the group has "a common character and a common culture." (2) "[P]eople growing up among members of the group will acquire the group culture, will be marked by its character." (3) Membership in the group "is, in part, a matter of mutual recognition." (4) [M]embers are "aware of their membership and typically regard it as an important clue in understanding who they are." (5) [M]embership "is a matter of belonging, not achievement." And (6) these are not "small face-to-face groups" but are "anonymous groups where mutual recognition is secured by the possession of general characteristics" (1990: 443-7). 
13 A suggestion might be made that if we can, in the abstract, identify circumstances under which a reasonable person would enjoy self-esteem, this could provide a normative standard for evaluating the significance of claims about psychological self-esteem experiences. So if you fail to enjoy self-esteem in the specified circumstances, you are by definition not being reasonable, and we can dismiss your concerns. Of course, the question is, who sets the standards for reasonableness?

14 It is important to note that I am not resurrecting the "Infeasibility Objection" here. I merely mean to point out that in this moral stalemate it becomes nearly impossible to do the right thing. This does not seem like a helpful or practical guide to moral conduct.

15 Kymlicka defines a culture as "synonymous with a 'nation' or a 'people'." He defines societal culture as "a culture which provides its members with meaningful ways of life across the full range of human activities, including social, educational, religious, recreational, and economic life, encompassing both public and private spheres" $(1995: 18,76)$. Because by culture he also means a nation, I will, for the sake of consistency, sometimes talk about his views in terms of nationalism rather than cultures. I acknowledge, though, that this is not his preferred term and that not all of the groups he is concerned with are nations or national minorities.

16 As Joseph Carens has pointed out, we shouldn't simply assume that immigrants are able to waive some of the rights associated with culture, even if they were prepared to do so (2000: 81).

17 Carens has suggested that Kymlicka's theory only allows us to move between societal cultures, but not live outside of them (2000: 52-87). This brings back the possibility of dysfunctionalism. But if what Kymlicka is requiring is that the individual have access to a socially furnished system of meaning, along with institutions that embody this system, then the possibilities could be quite broad indeed, and certainly exceed nation alone.

18 Kymlicka writes, "Diversity is valuable, but only if it operates within the context of certain common norms and institutions" (1998: 16).

19 If the language of recognition and respect sounds familiar, it's because these are the terms used to explain the self-esteem-based defense of nationalism. The difference is that here we are talking about the egos of those who have passed away, or perhaps about our own prospects for selfrespect in light of the potential conduct of future generations. Current instances of cultural abandonment may, for example, do harm by shaking the confidence of existing populations in their prospects for cultural immortality.

20 Gans acknowledges this unevenness when he describes a potential immigrant's desire to return to the homeland as a desire to move from a more "passive adherence" to culture to something more "active" (2003: 137).

21 This is a pressing issue in Gans' case because the more extended the political project the "more it needs precise criteria for membership" (Canovan 1996: 17). Given his ambitious inter-statist project then, we would need an extremely rigorous membership process.

\section{Nationalism in Ireland}

1 For a more comprehensive account of modern Irish history see Foster (1988), Lyons (1989), and Lee (1989), and on Irish nationalism see Boyce (1995). 
2 After the Act of Union, Ireland was governed by the Imperial Parliament, which was the British Parliament with one hundred Irish seats added in the House of Commons and twenty-eight Irish Peers in the House of Lords.

3 Grattan's terms - concerning the "interests" and "sympathy" of the Irish are the same as those used by Edmund Burke to define the grounds for representation of a population. When a population shares the same interests and sympathies, Burke explained, a competent elite might effectively represent them, even if they do not have a direct vote or direct representative. But where interests and sympathies are not in accord, there is a case for separate representation, in order to ensure these interests are granted a voice. For a discussion of Burke's ideas on the representation of interests, see Hannah Pitkin (1967).

4 It should be noted that the governing Irishmen that Grattan had in mind would not be members of the majority Catholic population, who could not sit in the legislature because of their religion. Likewise, few Catholics could vote because the Penal Laws limited their right to own property and to vote.

5 Under the Penal Laws designed to contain the Catholic threat to Protestantism Catholics lost the right to vote in Ireland in 1728. Yet though most Catholics could not own property, they could obtain the franchise through holding a "freehold" lease which was a kind of lease-for-life that, if the land involved exceeded forty shillings in value, entitled the holder to a vote. Due to inflation, as time went by more and more Catholics qualified under this provision but the loophole was closed in 1829.

6 O'Connell also warned that: "He who entrusts his business to others is sure to have it neglected," and argued that "Each nation has a sacred duty imposed on it, to attend to its own affairs" (1842: 40).

7 The term "boycott" describes the tactic applied to those who took over lands that had been cleared by evictions. New tenants would find that they were subject to social ostracism and were unable to hire farm hands, sell their produce at market, do business in the area, or otherwise interact with the local population. The tactic is named for one of its first targets, Captain Boycott.

8 Parnell's pact with the British Liberals under Gladstone led to the introduction of three Home Rule bills to establish a jurisdictionally limited parliament in Dublin. The first, in 1886, did not pass the House of Commons. The second, in 1893 passed in the House of Commons but was defeated in the House of Lords. After Gladstone reformed parliament and reduced the power of the House of Lords to a two-year suspensive veto, a third Home Rule bill was introduced in 1912. The House of Lords again rejected it, but this now amounted to only a two-year delay. The Bill went on the statute books in 1914 but was suspended until the end of what was expected to be a short war. Events overtook the legislation (including an Irish uprising in 1916), and by the end of the First World War Home Rule was no longer a viable option. The 1920 Government of Ireland Act promised a new system of autonomous government along with partition of the six northern counties, but it was rejected as inadequate in the rest of the island. So although the goal of a semi-independent parliament had been attained in 1914, Home Rule never saw the light of day. 
9 History is, of course, a "battlefield" for other peoples too. The important point to note here is that the Young Irelanders felt they had to prove that Ireland had any history worth thinking about, quite aside from normal debates about its interpretation.

10 Moran's disparagement of the "mongrel" identity is, of course, in marked contrast to the thinking of a contemporary writer like Salman Rushdie, who instead celebrates it as something that represents his own experience (Parekh 1990). While Rushdie's case proves that the mongrel identity need not stop anyone from achieving great things (indeed the experience can be the source of inspiration), we might still argue it is a demanding experience, and should not be forced on people when there are alternatives.

11 The vice-president of the Gaelic League, Eoin MacNeill, for instance, was later a founding member and Chief of Staff of the Irish Volunteers, a local defense organization that contained within it the secret council of the Irish Republican Brotherhood. It was this latter group which planned and carried out the 1916 Rising.

12 Although now celebrated as one of the great moments in Irish nationalism, the Rising was in fact the work of what has been called "a minority of a minority of a minority" (Ó Tuathaigh 1994b: 63).

13 Eamon de Valera and the anti-treaty Dáil members had previously abstained from the post-treaty Dáil legislature because of the oath. Fianna Fáil won the 1932 election, however, and de Valera decided that he could "sign the book" - what was needed to meet the oath requirement - without compromising his principles because at that point he felt it was an empty gesture. One of his government's first acts was to abolish the oath.

14 It could be argued that some kind of federal solution might also address these concerns. In fact what Grattan had in mind was not too far from such an idea. But the creation of separate forums for political representation, where they touch upon issues distinct to a particular population, on the grounds that these distinctions constitute national differences, to my mind amounts to a national solution, whatever institutional form it ends up taking.

\section{Nationalism in Quebec}

1 For more information on Quebec history see Linteau et al. (1983; 1991), and Behiels (2002), and on Quebec nationalism see Balthazar (1986).

2 New France was conquered in 1760, and its fate sealed in the 1763 Treaty of Paris when it was conceded to the British victors.

3 During the early period of nationalism in Quebec, the French-speaking portion of the population still thought of themselves as "Canadien." This later became modified to "French-Canadian" and then to "Québécois" (Balthazar 1986). A lingering ambivalence over the connection to "Canada" and being "Canadian" persists to this day in Quebec, however. For instance a 1992 poll found that 54 percent of respondents wanted Quebec to remain a province in Canada. But when asked how they would feel about an independent Quebec that was called by the name "Canada" and that kept the national anthem as "O Canada," the number who wanted Quebec to remain a province in the larger Canadian system dropped to 34 percent (Silver 1997: 265). 
4 English was used for want of a better term, to describe those individuals, sometimes from the British Isles, sometimes from other American colonies, or sometimes the descendants of these families, that made up the elite most connected to political authority in Lower Canada.

5 Papineau was a contemporary of Ireland's Daniel O'Connell and the careers of the two men bear a remarkable resemblance. Both were lawyers from established families. Both were elected to office where they were active on behalf of the national cause (mainly from the 1820s to the 1840s). Both were associated with resistance movements, but both drew the line at direct participation in revolutionary activities. Nevertheless both were accused of sedition and Papineau fled the country with a price on his head, while O'Connell was briefly imprisoned. Both were ultimately absolved of these charges and made a successful return to public life.

6 Another statement from the same period, delivered at a meeting of the Fils de la liberté, echoed Papineau's theme of local knowledge and attachments. It argues

Un conseil législatif dont les membres sont à la nomination d'une authorité ignorante des affaires de la colonie, et résident à une distance de 3,000 milles, composé en grande partie de personnes qui n'ont aucune sympathie avec le pays, existe encore actuellement comme un écran impuissant entre les gouvernants et les gouvernés, toujours prêt à nullifier toutes les tentatives d'une législation utile.

[A legislative council whose members are nominated by an authority ignorant of the affairs of the colony, and residing 3,000 miles away, made up in large part of persons with no attachment to the country, serves in reality as an ineffectual screen between the government and the governed, always ready to nullify every effort at useful legislation.]

(Ferretti and Miron 1992: 56)

7 A similar uprising had taken place in Upper Canada in the same period.

8 It should be noted that Durham was sympathetic to the Canadiens' situation and expressed regard for elements of their culture, even as he recommended its submergence. Along with assimilation he also recommended that responsible government (meaning a democratically accountable executive) should be granted to the colonies, but this was rejected by the Imperial authorities.

9 LaFontaine's counterpart was Robert Baldwin. No Canadien was included in the first executive under union, but the attempt at English political dominance proved unworkable.

10 Two other colonies joined Canada under Confederation, making a total of four original provinces: Ontario, Quebec, New Brunswick and Nova Scotia.

11 Riel had spent time in an asylum in Quebec believing he was a prophet. A.I. Silver proposes the theory that French-Canadian awareness of, and sympathy for, the Métis cause was largely a consequence of Quebec being wrongly blamed in the English-Canadian press for inciting the uprisings (Silver 1997).

12 This included efforts to expand Quebec's geographical boundaries, which were finally realized in 1898 . The province was expanded again in 1912. 
13 First in 1871 New Brunswick (with a sizeable French-speaking population of Acadians) restricted Catholic education rights. In 1890 Catholic and French language education rights which had been guaranteed under the Manitoba Act were abolished in that province, although they were restored on appeal to the Privy Council in 1895. In 1892 the Northwest Territories followed Manitoba's lead and overruled separate education rights, and finally in 1912 Ontario introduced "Regulation 17" which restricted the use of French as a language of instruction.

14 Bourassa also wrote: "so long as we have nothing to say, nothing to do, no opinion to express, no interest to show, in the conduct of the foreign affairs of the Empire; - so long as the rulers of Great Britain do not even think of us when they make their foreign treaties and entertain those foreign relations in support of which they need their army and their navy, - what moral claim, what legal claim, what equitable claim is there upon us that we should go and pay the piper?" (1970: 71).

15 There is, of course, a certain ambiguity in Bourassa's use of the term "Canada" for reasons I discuss supra at note 3.

16 Again, the ambiguity over "Canadian" re-appears. Of course, Bourassa may have been consciously using this ambiguity to connect the French-Canadian cause more intimately to the larger Canadian sphere.

17 Groulx wrote that Quebec must attain: "full self-government, full political power: that sum of powers which enables a people to keep its own attributes and national character and to ensure above all an organic life, a complete fulfilment of material and spiritual potential" (1973: 151).

\section{Bifurcated nationalism and the impasse in theory}

1 The civic/ethnic distinction can go under many names. Margaret Canovan, for instance, distinguishes between a Romantic-collectivist and a liberal-individualist nationalism along the same lines as sketched here (1996: 5-14). There are also theorists who deny that nationalism is anything but ethnic. Brian Barry for instance insists "Real nationalists typically regard a nation as (notionally) a descent group: one becomes a member of a nation purely by being born into it" (1999: 129).

2 Yack says that the relationship between civic and ethnic nationalism is difficult to negotiate "especially when one is fully aware of how they get mixed up with each other in actual political experience and rhetoric" (1995: 180). Rogers Brubaker calls the civic/ethnic dichotomy "analytically and normatively problematic" (1998: 257).

3 More bluntly still, Kai Neilsen explains the standard use of the dichotomy, saying, "good nationalisms are civic nationalism while the bad nationalisms are ethnic nationalism" (1999: 121).

4 Note that liberal-nationalist theorists are not the only ones that adopt a bifurcated approach. Alan Patten, in arguing against the claims of liberalnationalism suggests multicultural or multinational identity offers a better alternative because people "can think of different institutions and practices as representing the public, political expression of their identities, and they can think of themselves as having very different objective cultural characteristics" (2001: 297). 
5 One study, for instance, characterized "the reassertion of the Irish language and its associated cultural forms by the Irish Revival" as an act with "clear political and ideological weight" (Tymoczko and Ireland 2003: 8).

6 For an outline of the political dimension of the Gaelic Revival see Mathews (2000). Mathews defines a "self-help" movement as "a voluntary grouping organised outside the institutions of the State dedicated to a wider social or cultural programme, not to be confused with the current interest in the possibilities of self-rehabilitation" (2000: 13n).

7 The public sphere is for many theorists the central site for politics (Arendt 1958). Even Tamir herself sometimes seems to have trouble distinguishing it from the political sphere and on at least one occasion seems to use the terms interchangeably (1993: 141).

8 Margaret Moore also classes David Miller among those who offer a "cultural argument" for nationalism and positions her own work in contrast to his (2001: 52). While it's true that Miller shares many of the same concerns as other cultural-side theorists like Tamir, I believe that the weight of his argument is borne by political concerns such as solidarity and social justice, making his work harder to classify into one camp or the other. It may for this reason better reflect the reality of nationalism than those which more clearly line up along the political/cultural divide.

9 Again, it is instructive to consider the failure of eighteenth-century republicanism in Ireland, a failure that historians of political thought put down to its inability to reconcile a mandate to represent "the people" with ambivalent feelings about extending political membership to the mass of the population (Small 2002).

\section{Nationalism as representation}

1 While Grattan didn't specify what becoming a nation involved, he did announce in 1780: "The nation begins to form; we are moulding into a people" (1865: 48). And in 1782 at the opening of the Irish parliament he congratulated the Irish for "mould[ing] the jarring elements of your country into a nation" (1865: 71), evidence that for Grattan it's not just distinct circumstances that demonstrate nationhood but also solidarity.

2 Note the order of causality here: the nation is defined so as to provide goals for national mobilization. This is reminiscent of Gellner's claim that nationalism begets nations and not the other way around (1983: 55). But it also has something in common with a primordialist idea of nationalism, which holds that there is something prior to the nationalist drive that gets translated into a new, more discernible form, through the agency of nationalist mobilization (Smith 1998: 145-69). In either case what is clear is that for these nationalists the national character was a means to an end, the end being political recognition and self-representation.

3 The full fruition of this second mode is reached when political power is put at the service of the national character. The twentieth century also saw a new alliance forged between religion and nationalism. Religion and church authority was always strong in Ireland and Quebec, although there had been tense relations with nationalists. Giving the nation a religious mission evidently helped rally the population, but it wasn't until the idea 
of nationalism had reached this stage, that it became possible to create an effective hybrid with the religious cause.

4 There is a connection between this idea and what is known as the "frame problem" in computational intelligence. The frame problem deals with the difficulty of knowing what changes to expect, and therefore what we should pay attention to, in a dynamic environment. It turns out that it is very difficult for computers to determine what they should expect to stay constant when any one element in a real-life situation changes. Change even one item and a computer cannot know if it is dealing with an entirely new entity, requiring it to process its data entirely from scratch. This is a problem that as humans we seem to overcome without too much effort, but it has proven a stumbling block in attempts to model human cognition using computers (Ford and Hayes 1991). The problem boils down to one of focus and selectivity. How do we represent a changing world in such a way that it becomes intelligible without being overwhelming?

$5 \mathrm{I}$ am not trying to construe Arendt as defending nationalism. What I am suggesting is that her ideas about the nature of politics are relevant to understanding what brings nations into the political arena.

6 This is akin to Canovan's idea of nations as batteries, a largely dormant resource for political mobilization (1996: 72-5).

7 But note that this "fit" can be achieve in two ways, either the systems of representation can be changed to fit an existing frame of reference, or the collective frame of reference can be made to align with an existing representational system. In politics we think of the former as secessionist-style nationalism, the latter as nation building.

8 Perhaps properly one should speak of four dimensions, since space already counts for two, but it is not the geometric sense of the term I am invoking here.

9 As Innis put it: "Culture is concerned with the capacity of the individual to appraise problems in terms of space and time and with enabling him to take the proper steps at the right time" (1995: 375).

10 Innis himself was hostile to nationalism, it should be noted. He blamed it for the brutality of the modern era and the wanton destruction he witnessed in his experiences fighting in the Second World War.

11 This, for instance, is the factor that Jeremy Waldron overlooks in his version of cosmopolitan utopia, where everyone selects his or her own cultural baggage. But it is not simply that to have adequate cultural resources we should, for instance, hear some broad selection of childhood story-tales. What is important is that we hear the same stories that others around us hear. In this way we learn a common cultural vocabulary that we can trade on throughout our lives (Waldron 1992: 751-93).

\section{Evaluating nationalism as representation}

1 This question is used as the title of an essay by Allen Buchanan, where he find nations generally lack the moral standing to merit special political consideration (1996: 283-309). For a rejoinder to this question see Goodin (1988), who argues that that co-nationality offers a way to help us honor the kinds of obligations and relationships that we'd like to see prevail. 
2 Pettit acknowledges that there can be disagreement over membership, and that such disagreement may make it impossible for people to experience government interference as non-dominating, which is his republican ideal. In such cases, as he puts it, "it has to be possible for them to withdraw from the arrangement and encounter the authority, under a balance-of-power scenario" (1997: 68).

3 For example, Habermas models his patriotic alternative on the German political project. But this is one case where the membership issue is less prominent because in essence it is solved by the national frame of reference already in place, upon which Habermas erects his ideal of a patriotic community (Canovan 2000: 423). In other instances, where a national frame of reference cannot be taken as given, Canovan suggests we may be faced with highly intrusive efforts to cultivate the necessary loyalties for the patriotic project (Canovan 1996; 2000).

4 Brian Barry explains, "All too often, the appeal to culture is an attempt to legitimate ... the oppression of some member of a group by others within the group in the name of an internally inegalitarian and illiberal culture" (1999: 136).

\section{Applying the theory}

1 This phrasing intentionally echoes the title of an essay by Charles Taylor, "Why do nations have to become states?" where he discusses the need for recognition of collective identity. Even in this piece, however, Taylor concludes that while self-determination should be an option for nations under certain circumstances, a multi-national union is a "higher aspiration" (1995c: 58).

2 Moreover, if Quebec's continued participation in the Canadian union is pointed to as evidence that consent to current arrangements can now be taken as given, the province's refusal to sign on to a repatriated constitution would seem to point in the other direction. At the very least it suggests that a contract-based approach fails to establish clear grounds for objecting to Quebec's claim to national independence.

3 The final break with the crown took the form of withdrawal from the Commonwealth in 1949. The fact that it was an impromptu initiative announced quite possibly by accident while the Taoiseach was on tour in Canada seems to confirm that by this point the official trappings of the British connection were not a weighty matter either way.

4 Jacob Levy calls this the "retrospective" version of remedial right, and contrasts it with a "prospective" version, where remedial right secession is "only justified in terms of the risk of future injustices" $(2004,166)$. He is uncomfortable with the "never-expiring check" that the retrospective version implies, and argues for a position where the case for secession is sensitive to whether efforts are made within a political union to redress a minority's situation (2004, 167).

5 This position was succinctly articulated in the popular bumper sticker slogan that coincided with the 1995 referendum. It read: "My Canada includes Quebec." This position also appeals to a national frame of reference. It is the demand that "my Canada" should stay a fixed point of reference because for those involved it has become a basic component 
of how they view, understand, and act within, their world. What it illustrates is that there are important issues at stake here, and not just for the population of Quebec. But as with the national idea in the Quebec and Irish cases, this frame of reference cannot be considered immune to revision.

6 By 1941, over 61 percent of Quebec's population was already living in urban centers. By 1961 this number was over 74 percent (Bourdon and Lamarre 1998: 200).

7 Quebec's commitment to Catholicism as part of the national character, for instance, led to a regime that was inhospitable to minority religious populations such as the long-standing Quebec Jewish population and the Jehovah's Witnesses.

8 The Church objected to the program on the grounds that it represented "a ready-made instrument for future totalitarian aggression" (Hepburn 1980: 138).

9 Countess Constance Markievicz was elected to the British House of Commons in 1919. She not only joined the first Dáil Parliament meeting in Dublin, but also served as its Minister of Labour from 1919-1921.

10 Since 1923 the more progressively-minded Labour party has generally received in the range of ten percent of the popular vote.

11 Indeed Colley explicitly excludes Ireland from her study of British identity in the eighteenth and nineteenth century, even though it was closely economically and politically integrated during this period. She explains, "Ireland was never able or willing to play a satisfactory part" in the British experience, because that experience was "so closely bound up with Protestantism." For this reason the relationship with Ireland remained, as she put it, "deeply ambiguous" (1992: 8).

12 This assumes that these groups can lay claim to having a distinct frame of reference. I do not think it is difficult to make this case. Loyalists relate to a different national history and territory, and are concentrated in the northern counties of the island. And although in reality the social conduct of Loyalist Irish and any other Irish is not markedly different, especially when seen from outside, there are still important social meanings that are not held in common. In our second case, that of Natives in Quebec, they also have a distinct history and many live on identifiable territories within the province. Many must also deal with a legacy of social disruption and dislocation as well as ongoing discrimination in both Quebec and Canada at large.

\section{Nationalism and social change}

1 I owe this term to a conversation with Irish historian Gearoid Ó Tuathaigh.

2 Eamon de Valera led Ireland from 1932 to 1959, with only two three-year periods out of power.

3 Duplessis was first elected to the Premiership in 1936, and with the exception of one election in 1939, he won every provincial election held in Quebec until his death in 1959. The similarities between the leadership style and personal philosophies of Duplessis and de Valera are notable. Both were strong, some would say authoritarian, leaders who held 


\section{Notes}

socially conservative if not reactionary ideas yet who presided over a period of considerable modernization and growth in their societies. Both men had remarkable political staying power and were at the height of their influence between the 1930s and the 1950s.

4 In 1969 Bill 63 gave parents the right to enroll their children in Englishlanguage schools, but proposed that new arrivals to the province would need to master French. In 1974 Bill 22 made French the official language in Quebec, introduced measures to make French the language of the workplace in Quebec, and restricted francophones' access to Englishlanguage schooling. In 1977 Bill 101 added fines and penalties to language requirements, further restricted access to English-language schooling, and required that French be predominant on public signage (although parts of Bill 101 were subsequently declared unconstitutional by the Supreme Court of Canada). In 1988 Bill 178 was introduced to again establish the predominance of French in public signage, and in 1993 Bill 86 was introduced to permit English on public signage, under certain conditions.

5 Note also that this new Quebec-centered concept of nationality runs counter to post-nationalist predictions which say that we should expect a decline in the significance of territorial attachments.

6 Final responsibility for the Canadian constitution remained with the Privy Council in London until 1981.

7 In both cases this is not an argument about the status of these claims per se, rather it is an argument about the relative status of the claims whether they have lost some ground or moral power by the change in national character.

\section{The ties that blind}

1 This does not imply that all elements of the partition solution were justified.

2 One book that takes on and examines these issues directly is the edited collection by Avigail Eisenberg and Jeff Spinner-Halev, Minorities within Minorities (2005). This careful and thorough work does not manage to offer definitive conclusions on how to handle the situation of minorities within minorities either. But it does establish these demands as legitimate, if hitherto under-theorized, claims and stresses we must develop resources for addressing them.

3 Stanley Rosen argues that although he bans poets from the perfect city for the sin of imitation, Plato's real intent is to replace them with the figure of the philosopher, who will make man over in the imitation of Justice, and therefore render an even grander poetry. In this case, Plato is the representational philosopher par excellence (Rosen 1993). 


\section{References}

Adelman, H. (1995) "Quebec: The Morality of Secession," in J. Carens (ed.) Is Quebec Nationalism Just? Perspectives from Anglophone Canada, Montreal: McGill-Queen's University Press, pp. 82-96.

Anderson, B. (1991) Imagined Communities: Reflections on the Origin and Spread of Nationalism, rev. edn, London: Verso.

Arendt, H. (1958) The Human Condition, Chicago, IL: University of Chicago Press.

- (1968) "Truth and Politics," Between Past and Future, New York: Viking Press, pp. 227-64.

- (1972) "Lying in Politics," Crises of the Republic, San Diego, CA: HBJ, pp. 1-32.

Balthazar, L. (1986) Bilan du nationalisme au Québec, Montreal: L'Hexagone. Barry, B. (1999) "The Limits of Cultural Politics," in D.M. Clarke and C. Jones (eds) The Rights of Nations, New York: St. Martin's Press, pp. 127-44.

Baubock, R. (1994) Transnational Citizenship, Aldershot, UK: Edward Elgar. - (2000) "Why Stay Together? A Pluralist Approach to Secession and Federation," in W. Kymlicka and W. Norman (eds) Citizenship in Diverse Societies, Oxford: Oxford University Press, pp. 366-94.

(2001) "Cultural Citizenship, Minority Rights, and Self-Government," in T.A. Aleinikoff and D. Klusmeyer (eds) Citizenship Today, Washington, DC: Carnegie Endowment for International Peace, pp. 319-48.

Behiels, M.D. (2002) Quebec Since 1800, Toronto: Irwin Publishing.

Berlin, I. (2002) "Two Concepts of Liberty," in H. Hardy (ed.) Liberty, Oxford: Oxford University Press, pp. 166-217.

Boran, I. (2001) "Contra Moore: The Dependency of Identity on Culture," Critical Review of International Social and Political Philosophy 4: 26-44.

Bourassa, H. (1970) Henri Bourassa on Imperialism and Bi-culturalism 1900-1918, J. Levitt (ed.) Toronto: The Copp Clarke Publishing Company.

Bourdon, Y. and Lamarre J. (1998) Histoire du Québec: une société Nord Américaine, Quebec: Beauchemin.

Boyce, G. (1995) Nationalism in Ireland, London: Routledge.

Boyce, G.D. and O'Day, A. (eds) (1996) The Making of Modern Irish History, London: Routledge. 


\section{References}

Bradshaw, B. (1994) "Nationalism and Historical Scholarship in Modern Ireland," in C. Brady (ed.) Interpreting Irish History: The Debate on Historical Revisionism 1938-1994, Dublin: Irish Academic Press, pp. 191-216.

Brady, C. (ed.) (1994) Interpreting Irish History: The Debate on Historical Revisionism 1938-1994, Dublin: Irish Academic Press.

Brubaker, R. (1998) "Myths and Misconceptions in the Study of Nationalism," in M. Moore (ed.) National Self-determination and Secession, Oxford: Oxford University Press, pp. 233-65.

Brubaker, R. and Cooper, F. (2000) "Beyond 'Identity'," Theory and Society 29: 1-47.

Buchanan, A. (1991) Secession: The Morality of Political Divorce from Fort Sumpter to Lithuania and Quebec, Boulder, CO: Westview Press.

— (1996) “What's so Special about Nations?” in J. Couture, K. Nielsen, and M. Seymour (eds) Rethinking Nationalism, Calgary: University of Calgary Press, pp. 283-309.

- (1997) “Theories of Secession," Philosophy and Public Affairs 26: 31-61.

— (2003) “The Quebec Secession Issue: Democracy, Minority Rights, and the Rule of Law," in S. Macedo and A. Buchanan (eds) Secession and SelfDetermination, New York: New York University Press, pp. 238-71.

Canovan, M. (1996) Nationhood and Political Theory, Cheltenham, UK: Edward Elgar.

- (2000) "Patriotism is Not Enough," British Journal of Political Science 30: 413-32.

- (2001) "Sleeping Dogs, Prowling Cats and Soaring Doves: Three Paradoxes in the Political Theory of Nationalism," Political Studies 49: 203-15.

Carens, J. (1995a) "Immigration, Political Community, and the Transformation of Identity: Quebec's Immigration Policies in Critical Perspective," in J. Carens (ed.) Is Quebec Nationalism Just? Perspectives from Anglophone Canada, Montreal: McGill-Queen's University Press, pp. 20-81.

- (1995b) "Liberalism, Justice, and Political Community: Theoretical Perspectives on Quebec's Liberal Nationalism," in J. Carens (ed.) Is Quebec Nationalism Just? Perspectives from Anglophone Canada, Montreal: McGill-Queen's University Press, pp. 3-19.

- (2000) Culture, Citizenship, and Community: A Contextual Exploration of Justice as Evenhandedness, Oxford: Oxford University Press.

Castells, M. (2000) The Information Age: Economy, Society and Culture. Vol 1: The Rise of the Network Society, Oxford: Blackwell.

Coakley, J. (1998) "Religion, Ethnic Identity and the Protestant Minority in the Republic," in W. Crotty and D.E. Schmitt (eds) Ireland and the Politics of Change, New York: Longman, pp. 86-106.

Colley, L. (1992) Britons: Forging the Nation 1707-1837, New Haven, CT: Yale University Press. 
Crotty, W. (1998) "Democratisation and political development in Ireland," in W. Crotty and D.E. Schmitt (eds) Ireland and the Politics of Change, London: Longman, pp. 1-26.

Crotty, W. (2002) "Introduction: The Irish Way in World Affairs," in W. Crotty and D.E. Schmitt (eds) Ireland on the World Stage, New York: Pearson Education, pp. 1-26.

de Valera, E. (1980) Speeches and Statements by Eamon de Valera 1917-73, Maurice Moynihan (ed.) Dublin: Gill and Macmillan.

Dickinson, H.T. (1997) "Irish Radicalism in the Late Eighteenth Century," History 82: 266-84.

Durham, J.G. Lampton, Earl of. (1992) Lord Durham's Report (abridged), G.M. Craig (ed.), Ottawa: Carleton University Press.

Dworkin, R. (1986) Law's Empire, Cambridge: Cambridge University Press.

Eisenberg, A. (1999) "Trust, exploitation and multiculturalism," Paper read at the conference "Nationalism, Identity and Minority Rights," Bristol, UK, 16-19 September.

Eisenberg, A. and Spinner-Halev, J. (eds) (2005) Minorities within Minorities: Equality, Rights and Diversity, Cambridge: Cambridge University Press.

Fagan, G.H. (2003) "Globalised Ireland, or, Contemporary Transformations of National Identity?" in C. Coulter and S. Coleman (eds) The End of Irish History: Critical Reflections on the Celtic Tiger, Manchester: Manchester University Press, pp. 110-21.

Fahey, T. (1998) "Progress or Decline? Demographic Change in Political Context," in W. Crotty and D.E. Schmitt (eds) Ireland and the Politics of Change, New York: Longman, pp. 51-65.

Fanning, R. (1983) Independent Ireland, Dublin: Helicon Limited.

Ferretti, A. and Miron, G. (1992) Les grands textes indépendantistes: écrits, discours et manifestes québécois 1774-1992, Louisville, Québec: l'Hexagone.

Forbes, H.D. (ed.) (1985) Canadian Political Thought, Toronto: Oxford University Press.

Ford, K.M. and Hayes, P.J. (eds) (1991) Reasoning Agents in a Dynamic World, London: JAI Press.

Foster, R.F. (1988) Modern Ireland 1600-1972, London: Allen Lane.

Gagnon, A. and Montcalm, M.B. (1990) Quebec Beyond the Quiet Revolution, Scarborough, Ontario: Nelson Canada.

Galligan, Y. (1998) "The changing role of women," in W. Crotty and D.E. Schmitt (eds) Ireland and the Politics of Change, New York: Longman, pp. 107-21.

Gans, C. (2003) The Limits of Nationalism, Cambridge: Cambridge University Press.

Gellner, E. (1983) Nations and Nationalism, Ithaca, NY: Cornell University Press.

Goodin, R.E. (1988) "What is so special about our fellow countrymen?" Ethics 98: 663-86.

Grattan, H. (1865) The Speeches of the Right Hon. Henry Grattan, D.O. Madden (ed.), 2nd edn, Dublin: James Duffy. 


\section{References}

Greenfeld, L. (1992) Nationalism: Five Roads to Modernity, Cambridge, MA: Harvard University Press.

Groulx, L. (1943) "Why we are divided: an address delivered on November 19, 1943," pamphlet, Montreal: L'Action Nationale.

- (1973) Abbé Groulx: Variations on a Nationalist Theme, S.M. Trofimenkoff (ed.), Toronto: Copp Clark Publishing.

Habermas, J. (1992) "Citizenship and National Identity: Some Reflections on the Future of Europe," Praxis International 12: 1-19.

- (2001) "The Postnational Constellation and the Future of Democracy," The Postnational Constellation, Cambridge, MA: MIT Press, pp. 58-112.

Hardiman, N. and Whelan, C. (1998) "Changing Values," in W. Crotty and D.E. Schmitt (eds) Ireland and the Politics of Change, New York: Longman, pp. 122-43.

Hepburn, A.C. (ed.) (1980) The Conflict of Nationality in Modern Ireland, London: Edward Arnold.

Herder, J.G. (1966) "Essay on the Origin of Language," in J.-J. Rousseau and J.G. Herder (eds) Two Essays on the Origins of Language, Chicago, IL: University of Chicago Press, pp. 87-166.

Hoppen, K.T. (1999) Ireland Since 1800: Conflict and Conformity, New York: Longman.

Hyde, D. (1989) “The Necessity for De-Anglicising Ireland," in A. Mitchell and P. Ó Snodaigh (eds) Irish Political Documents 1869-1916, Dublin: Irish Academic Press, pp. 81-6.

Innis, H. (1995) Staples, Markets and Cultural Change, D. Drache (ed.), Montreal: McGill-Queen's University Press.

Kahn, L.S. (1986) "The Impact of Cultural Identity on Quebec Education," Quebec Studies 4: 28-48.

Kedourie, E. (1993) Nationalism, 4th edn, Oxford: Blackwell.

Kiberd, D. (1995) Inventing Ireland: The Literature of the Modern Nation, Cambridge, MA: Harvard University Press.

Kirby, P. (2002) "Contested Pedigrees of the Celtic Tiger," in P. Kirby, L. Gibbons, and M. Cronin (eds) Reinventing Ireland: Culture, Society and The Global Economy, London: Pluto Press, pp. 1-18.

Kymlicka, W. (1989) Liberalism, Community and Culture, Oxford: Clarendon Press.

— (1995) Multicultural Citizenship: A Liberal Theory of Minority Rights, Oxford: Clarendon Press.

- (1998) Finding Our Way: Rethinking Ethnocultural Relations in Canada, Oxford: Oxford University Press.

- (1999) "Minority Nationalism within Liberal Democracies," in D.M. Clarke and C. Jones (eds) The Rights of Nations, New York: St. Martin's Press, pp. 100-26.

- (2001) Politics in the Vernacular: Nationalism, Multiculturalism, and Citizenship, Oxford: Oxford University Press. 
- (2004) "Nationalism, Transnationalism and Postnationalism," in R. Dworkin (ed.) From Liberal Values to Democratic Transition, Budapest: CEU Press, pp. 227-68.

Labelle, M. and Salée, D. (2001) "Immigrant and Minority Representations of Citizenship in Quebec," in A.T. Aleinikoff and D. Klusmeyer (eds) Citizenship Today: Global Perspectives and Practices, Washington, DC: Carnegie Endowment for International Peace, pp. 278-315.

Laffan, B. (2002) "Ireland and the European Union," in W. Crotty and D.E. Schmitt (eds) Ireland on the World Stage, New York: Pearson Education, pp. 83-94.

Lamoureux, D. (1987) "Nationalism and Feminism in Quebec: An Impossible Attraction," in H.J. Maroney and M. Luxton (eds) Feminism and Political Economy: Women's Work, Women's Struggles, Toronto: Methuen, pp. 51-68.

Langlois, S., Baillargeon, J.-P., Caldwell, G., Fréchet, G., Gauthier, M., and Simard, J.-P. (1992) Recent Social Trends in Québec: 1960-1990, Montreal: Campus Verlag.

Lee, J.J. (1989) Ireland 1912-1985: Politics and Society, New York: Cambridge University Press.

Lemieux, D. (1994) "La condition féminine," in F. Dumont, S. Langlois, and Y. Martin (eds) Traité des problèmes sociaux, Quebec: Institut québécois de recherche sur la culture, pp. 473-98.

Levy, J. (2000) The Multiculturalism of Fear, Oxford: Oxford University Press. - (2004) "National Minorities Without Nationalism," in A. Dieckhoff (ed.) The Politics of Belonging: Nationalism, Liberalism, and Pluralism, New York: Lexington Books, pp. 155-73.

Linteau, P.-A., Durocher, R., and Robert, J.-C. (1983) Quebec: A History 1867-1929, trans. R. Chodos, Toronto: Lorimer.

Linteau, P.-A., Durocher, R., Robert, J.-C., and Ricard F. (1991) Quebec Since 1930, trans. R. Chodos and E. Garmaise, Toronto: Lorimer.

Locke, J. (1960) Two Treatises of Government, rev. edn, New York: Cambridge University Press.

Luhmann, N. (1979) Trust and Power, New York: John Wiley \& Sons.

Lyons, F.S.L. (1989) Ireland Since the Famine, London: Fontana Press.

McRoberts, K. (1997) Misconceiving Canada: The Struggle for National Unity, Oxford: Oxford University Press.

Margalit, A. and Halbertal, M. (1994) "Liberalism and the Right to Culture," Social Research 61: 491-510.

Margalit, A. and Raz, J. (1990) "National Self-Determination," The Journal of Philosophy 9: 439-61.

Mathews, P.J. (2000) "The Irish Revival: A Re-Appraisal," in P.J. Mathews (ed.) New Voices in Irish Criticism, Dublin: Four Courts Press, pp. 12-19. Mill, J.S. (1972) Utilitarianism, On Liberty and Considerations on Representative Government, London: Dent.

Miller, D. (1995) On Nationality, Oxford: Oxford University Press. 
Miller, D. (1998) "Secession and the Principle of Nationality," in M. Moore (ed.) National Self-Determination and Secession, Oxford: Oxford University Press, pp. 62-78.

- (2001) "Nationality in Divided Societies," in A.-G. Gagnon and J. Tully (eds) Multinational Democracies, Cambridge: Cambridge University Press, pp. 299-318.

Moore, M. (2001) The Ethics of Nationalism, Oxford: Oxford University Press.

Moran, D.P. (1901) “The Battle of Two Civilizations," in Lady A. Gregory (ed.) Ideals in Ireland, London: At the Unicorn, pp. 25-83.

Murphy, M. and Harty, S. (2003) "Post-Sovereign Citizenship," Citizenship Studies 7: 181-97.

Nairn, T. (1981) The Break-up of Britain: Crisis and Neo-Nationalism, London: Verso.

- (1990) "Beyond Big Brother," New Statesman and Society (June 15): 29-32.

Nielsen, K. (1999) "Cultural Nationalism, Neither Ethnic nor Civic," in R. Beiner (ed.) Theorizing Nationalism, New York: SUNY Press, pp. 119-30. Nietzsche, F. (1980) On the Advantage and Disadvantage of History for Life, trans. P. Preuss, Indianapolis, IN: Hackett Publishing Company.

Norman, W. (1995) "The Ideology of Shared Values: A Myopic Vision of Unity in the Multi-Nation State," in J. Carens (ed.) Is Quebec Nationalism Just? Perspectives from Anglophone Canada, Montreal: McGill-Queen's University Press, pp. 137-59.

O'Connell, D. (1842) "Observations on corn laws, on political pravity and ingratitude, and on clerical and personal slander: in the shape of a meek and modest reply to the second letter of the Earl of Shrewsbury, Waterford and Wexford, to Ambrose Lisle Phillipps, Esq.," pamphlet, National Library of Ireland.

(1868) Select Speeches of Daniel O’Connell, M.P., J. O'Connell (ed.), Dublin: James Duffy, 2 vols.

O’Day, A. and Stevenson, J. (eds) (1992) Irish Historical Documents Since 1800, Dublin: Gill and MacMillan.

O'Leary, B. (1996) "Insufficiently Liberal and Insufficiently Nationalist," Nations and Nationalism 2: 444-51.

Ó Riagáin, P. (1997) Language Policy and Social Reproduction: Ireland 1893-1993, Oxford: Clarendon Press.

Ó Tuathaigh, M.A.G. (1994a) "Irish Historical 'Revisionism': State Of The Art or Ideological Project?" in C. Brady (ed.) Interpreting Irish History: The Debate on Historical Revisionism 1938-1994, Dublin: Irish Academic Press, pp. 306-26.

- (1994b) "Nationalist Ireland 1912-1922: Aspects of Continuity and Change," in P. Collins (ed.) Nationalism and Unionism: Conflict in Ireland 1885-1921, The Queen's University of Belfast: The Institute of Irish Studies, pp. 47-73. 
Papineau, L.-J. (1837) "Speech of the Hon. L-J Papineau, at the meeting of the County of Montreal on May 15, 1837," Montreal: Louis Perrault, CIHM microfiche series, no 90031.

— (1970) Papineau: Textes, O. Fernand (ed.), Québec: Les Presses Universitaires Laval.

Papineau, L.-J. and Neilson, J. (1824) "Letter from J.L. [sic] Papineau and J. Neilson, Esqs., addressed to His Majesty's Undersecretary of State on the subject of the proposed union of the provinces of upper and lower Canada," London: W. Clowes. CIHM microfiche series, no. 38456.

Parekh, B. (1990) "The Rushdie Affair: research agenda for political philosophy," Political Studies 38: 695-709.

Patten, A. (2001) "Liberal citizenship in multinational societies" in A.-G. Gagnon and J. Tully (eds) Multinational Democracies, Cambridge: Cambridge University Press, pp. 279-98.

Pettit, P. (1997) Republicanism: A Theory of Freedom and Government, Oxford: Oxford University Press.

Phillips, A. (1995) The Politics of Presence: The Political Representation of Gender, Ethnicity and Race, Oxford: Oxford University Press.

Pitkin, H. (1967) The Concept of Representation, Berkeley, CA: University of California Press.

Plato (1991) The Republic of Plato, A. Bloom (ed.), 2nd edn, New York: Basic Books.

Renan, E. (1996) Qu'est-ce Qu'une Nation? What is a Nation? intro C. Taylor, trans. W.R. Taylor, Toronto: Tapir Press.

Rosen, S. (1993) “The Quarrel between Philosophy and Poetry,” The Quarrel Between Philosophy and Poetry, New York: Routledge, pp. 1-26.

Rudin, R. (1997) Making History in Twentieth-Century Quebec, Toronto: University of Toronto Press.

Schmitt, D.E. (1998) "Conclusion: Continuity, Change and Challenge" in W. Crotty and D.E. Schmitt (eds) Ireland and the Politics of Change, New York: Longman, pp. 210-22.

Scruton, R. (1990) The Philosopher on Dover Beach, Manchester: Carcanet.

Seymour, M., Couture, J., and Nielsen, K. (1996) "Introduction: Questioning the Ethnic/Civic Dichotomy," in J. Couture, K. Nielsen, and M. Seymour (eds) Rethinking Nationalism, Calgary: University of Calgary Press, pp. 1-60.

Shachar, A. (2001) Multicultural Jurisdictions: Cultural Differences and Women's Rights, Cambridge: Cambridge University Press.

Silver, A.I. (1997) The French-Canadian Idea of Confederation 1864-1900, 2nd edn, Toronto: University of Toronto Press.

Small, S. (2002) Political Thought in Ireland 1776-1798: Republicanism, Patriotism, and Radicalism, Oxford: Oxford University Press.

Smith, A.D. (1988) The Ethnic Origin of Nations, London: Basil Blackwell.

- (1998) Nationalism and Modernism, New York: Routledge.

Tamir, Y. (1993) Liberal Nationalism, Princeton, NJ: Princeton University Press. Taylor, C. (1975) Hegel, Cambridge: Cambridge University Press. 
Taylor, C. (1995a) "Shared and Divergent Values," in G. Laforest (ed.) Reconciling the Solitudes: Essays on Canadian Federalism and Nationalism, Montreal: McGill-Queen's University Press, pp. 53-76.

— (1995b) "The Politics of Recognition," in A. Gutmann (ed.) Multiculturalism: Examining the Politics of Recognition, Princeton, NJ: Princeton University Press, pp. 25-73.

— (1995c) "Why do Nations Have to Become States?" in G. Laforest (ed.) Reconciling the Solitudes: Essays on Canadian Federalism and Nationalism, Montreal: McGill-Queen's University Press, pp. 40-58.

_ (1999) "Nationalism and Modernity," in R. Beiner (ed.) Theorizing Nationalism, New York: SUNY Press, pp. 219-45.

Tone, T.W. (1998) The Life of Theobald Wolfe Tone, T. Bartlett (ed.), Dublin: The Lilliput Press.

Tonra, B. (2001) The Europeanisation of National Foreign Policy, Burlington, VT: Ashgate.

Tovey, H., Hannan, D., and Abramson, H. (1989) Why Irish? Language and Identity in Ireland Today, Dublin: Irish Language Board.

Trudeau, P. (1968) Federalism and the French Canadians, Toronto: McMillan.

Tymoczko, M. and Ireland, C. (2003) "Language and Identity in TwentiethCentury Ireland," Éire-Ireland 38: 4-22.

Viroli, M. (1995) For Love of Country: An Essay on Patriotism and Nationalism, Oxford: Clarendon Press.

Waldron, J. (1992) "Minority Cultures and the Cosmopolitan Alternative," University of Michigan Journal of Law Reform 25: 751-93.

Weinstock, D.M. (2005) "Beyond Exit Rights: Reframing the Debate," in A. Eisenberg and J. Spinner-Halev (eds) Minorities within Minorities: Equality, Rights and Diversity, Cambridge: Cambridge University Press, pp. 227-46.

Whitaker, R. (1995) Quebec's Self-Determination and Aboriginal SelfGovernment: Conflict and Reconciliation?" in J. Carens (ed.) Is Quebec Nationalism Just? Perspectives from Anglophone Canada, Montreal: McGill-Queen's, pp. 193-220.

White, T.J. (2002) "Nationalism vs. Liberalism in the Irish Context: From a Postcolonial Past to a Postmodern Future," Éire-Ireland 37: 25-38.

Williams, M.S. (1998) Voice, Trust, and Memory: Marginalized Groups and the Failings of Liberal Representation, Princeton, NJ: Princeton University Press.

Writers of The Nation (1844) The Voice of The Nation: A Manual of Nationality, 2nd edn, Dublin: James Duffy.

Yack, B. (1995) "Reconciling Nationalism and Liberalism," Political Theory 23: $166-82$.

— (1999) "The Myth of the Civic Nation," in R. Beiner (ed.) Theorizing Nationalism, New York: SUNY Press, pp. 103-18.

_ (2001) "Popular Sovereignty and Nationalism," Political Theory 29: $517-36$. 


\section{Index}

1916 Rising 41, 44, 82, 185 n.11, $185 \mathrm{n} .12$

adaptive capacity 34, 96, 172

Anderson, Benedict 23-4, 97-100, 178

Arendt, Hannah 7, 94-6, 189 n.5 assimilation 43, 59, 68, 72, 185 n.10 autonomy: collective $9,34,110$, 132, 172; individual 28-30, 34, 71, 121, 148, 178; and multiculturalism 28-30, 111; see also independence: political

Baubock, Rainer 67, 77, 82

belonging 2, 25-6, 73

Berlin, Isaiah 9

borders 98, 114, 169

boundaries 99-100, 102, 115, 172; see also borders

Bourassa, Henri 9, 58-61, 63, 78, 90

Britain 143; as frame of reference 139, 144; Imperial government 39-41, 129, 131, 184 n.2, 187

n.14; as multinational project 23 , 181 n.2; British nationalism 6, 140, 191 n.11; and Scotland 143

Brubaker, Rogers 67, 69, 71, 187 n.2

Buchanan, Allen 15, 181 n.4; on equal respect $26-7,189$ n.1; on remedial right $16-19,28-9$; on separatism 141, 146, 181 n.3

Burke, Edmund 94, 184 n.3

Butt, Isaac 40
Canada 58, 59, 147, 170; Canadian nationalism $60,141-2$;

Confederation 57, 186 n.10; constitution 165,190 n.2, 192 n.6; as frame of reference 132, 139, 141, 190 n.5; and Quebec 140-1, 144, 150

Canovan, Margaret 83, 94; on liberalism 69, 189 n.6; on nationalism 24, 130, 152-3, 187 n.1; on republicanism 70 , 117, 190 n.3

capitalism 98

Carens, Joseph 132, 183 n.16, 183 n. 17

Castells, Manuel 100

change 15-16, 111; see also social change

choice: and cultural context 28-30, 107, 148; and membership 65, 67-8; and representation 108, 178 citizenship 23, 114, 117, 118, 155 civic nationalism $13,50,69-70,72$; as dichotomy 64-6, 68, 70; and "good government" formulation 66, 68-9

Colley, Linda 6, 108, 140, 191 n.11 communications 100, 107, 160, 169

communitarianism 124

complexity reduction 101-3, 169,172

co-nationality 2, 110, 172, 189 n.1 Condillac, Etienne Bonnot de 94 conquest 18-19, 28, 129; see also

Quebec: conquest 


\section{Index}

consent $17-18$

contextualism 3

cosmopolitanism 108, 189 n.11

cultural nationalism 31-4, 42, $71-80,83,89,107$; and representation 86

culture $5,33-4,109,172$; as context of choice 28-30; and continuity $33-4,79,138,167-8$; see also nationalism: cultural preservation theories

currency 4, 6, 87, 109; as limiting condition 120,123, 172, 175

Dáil Éireann see parliament: Irish deliberation 113-14, 131

democracy 80, 131, 137

de Valera, Eamon 45, 185 n.13, 191 n.2, 191 n.3; and national character $45-6,50,154$

diasporas $31-2$

dichotomies 4, 6, 51, 63, 187 n.1; civic/ethnic 65-70, 117, 187 n.2, 187 n. 3 ; drawbacks of $64-5$, 84-5, 125; political/cultural $71-5,170-1,187$ n.4

dignity $26-7$

discrimination $101,122-3,125$, 190 n.4; gender 135-6, 158-9; history of 130, 132, 144, 150

Duplessis, Maurice 62, 134, 157-8, 160, 191 n.3

Durham Report 56-7, 60, 90, 140, 186 n.8

Dworkin, Ronald 22, 108

education 20,58; in Ireland 78, 154, 156; in Quebec 158-60 equal respect objection

$17-18,26$

equality $6,9,106,110,182$ n.6; in Ireland 135-6, 150, 155; as limiting condition 121-3, 125, $137-8,150,172$; and minorities 145,175 ; in Quebec 135, 138, $147-8,150,159$ essentialism 49-50, 91, 113, 121, 152, 167; and culture 79; ethnic 115 esteem see self-esteem ethnic nationalism 50, 67-70, 187 n.1; as dichotomy $64-5$, 67-70

ethnicity 10, 70, 117, $181 \mathrm{n} .3$

Europe 115, 164

exploitation 16, 24, 28, 34

\section{fate 98-9}

federalism 52, 57, 59, 170, 185 n.14 frames of reference 4-7, 102, 124, 142,168 ; in artificial intelligence 189 n.4; conditions for utility $103,109,120-1$; content of 97-9; and language 94, 137; and membership 108; multiple 114 , 122-5, 127, 139-44, 170; and nationalism 86, 95, 114-15, 169 , 172; and political independence 130-4, 143; and post-nationalism 115-16; and selective knowledge 99-103, 113-14, 179-80; and trust 102,173

French, language 59, 78, 137, 140, 166; legislation on 158,160 , 177, 192 n.4;

Gaelic League 42-4, 68, 78, 82, 185 n.11

Gaelic Revival 42, 62, 91

Gans, Chaim 31-2, 183 n.20, $183 \mathrm{n} .21$; on cultural preservation $31-4,74,78,109,138$; on social meaning 174, 192

Gellner, Ernest 1, 10, 13, 15, 182 n.8, 182 n.9; on modernity 20-2, 102, 178; on national mobilization 181 n.4, 188 n.2; on nation-state 128

gender 101; see also discrimination: gender

Germany 190 n.3

globalism 115, 125, 128

"good government" formulation 4, $64,73,95,130$; and civic nationalism 66, 68-9; and Ireland 36-7, 46-9, 145; and liberal-nationalism 77, 80; and pre-political context $80-2$; and Quebec 59,62, 63; and republicanism 49, 66 
Grattan, Henry 37-9, 46-7, 87-8, 184 n.4, 185 n.14; on cultural revival $47,66,77,88-9,188$ n.1; on shared interests 38,140 , 184 n.3

Greenfeld, Liah 88, 92-3

Groulx, Lionel 61-3, 67-8, 78, 134, 187 n.17

Habermas, Jurgen 119, 190 n.3 harm 130-1

Herder, Johann Gottfried 94 history 96, 100, 114; Ireland 42, 162-3, 183 n.1, 185 n.9; Quebec $61,163,185$ n.1

Hyde, Douglas 43, 59, 68

identity: and culture $76,79-80$, 107, 110, 112; multiple attachments 17-18, 105, 108, 125,143 ; national $65,74,82$, 119, 153; personal 45-7, 71, 107, 185 n.10; political 73, 107, 149; pre-political $81-2$; and republicanism 119

immigrants 2, 183 n.20; integration of $22,137-8,149,182$ n.11; rights of $24-5,29,181$ n.1, 183 n.16

imperialism 14

independence 91, 130, 146; Ireland 130-1, 149; legitimacy of 127-34; political 5, 9, 80; Quebec 131-2, 141, 148, 150, 177; and remedial right 18-19

infeasibility objection 15,17 , 183 n.14

Innis, Harold 100, 189 n.9, 189 n.10 integration 129; and immigrants $22,137-8,149,182$ n.11; and minorities 111-12, 149, 175

Ireland: Act of Union 38-40, 184 n.2; agriculture 78, 136, 154,156 ; armed conflict 41 , 44-5, 82, 185 n.11, 185 n.12; Catholicism 39-40, 88, 118, 154-5, 191 n.8; constitution $46,135,154-5$; cultural representations 90, 140; demographics $140,154-6$; early Irish state 45-6, 134-7, 144, 147, 149; economic development 130, 136-7, 139, 156; education $78,154,156$; equality in $135-6$, 150, 155; external relations 164 ; famine $40-1,130,140$; historical studies 42, 162-3, 183 n.1, 185 n.9; Home Rule 41, 44, 130, 184 n.8; land use 40-1, 88, 130, 140, 184 n.7; Loyalists 41, 44-5, 131, 145-7, 149, 191 n.12; minorities in $144-7,161$; national character $3,89-90$, 134-6, 154; national pride 162 ; and Northern Ireland 155, 164; oath of loyalty 45,185 n.13; parliament $37-8,44,128,136$, 139; partition 45, 131, 144, 146-7, 149, 170, 176; Penal Laws 38-40, 140, 184 n.5; political independence $130-1,149$, 190 n.3; and post-colonialism 3, 129; and post-nationalism 115; Protestant Ascendancy 38, 118; Protestants 37-8, 118, 135, 161; republicanism 37-8, 66, 117-19, 188 n.9; social change $5,154-7$; traditionalism 134, 137, 191 n.10; women in 135-6, 154-6; see also Irish, language Irish, language 40, 42-3, 45-6, 50, 78 ; usage $137,139-40,154,157$, 166,188 n.5

jurisdiction $73-4,82,114-15,169$

Kedourie, Elie 14-15, 128, 181 n.2 Kymlicka, Will 69, 71, 175, 181 n.1, 183 n.18; on nations 2 , 178 ; on social meaning 92,108 ; on societal cultures $12,28-30$, 183 n.15

LaFontaine, Louis-Hyppolyte $56-7$ language 94, 137-8; legislation 158, 160, 177, 192 n.4; and nation 74, 90, 98, 109, 166; see also Irish, language; see also French, language liberal culturalism $71-3,76,84$ 


\section{Index}

liberal-democracy 69, 106, 117

liberal-nationalism 4, 71-4, 79, 92; and dichotomies $65,73-5,106-7$; difficulties in $4,83-5,174$

liberalism 28, 94, 125, 175-6; and nationalism 24,124

limits 5, 20-2, 122-5, 127, 136, $150-1,171-1,175$

literature 90, 96, 140

local knowledge 48, 89; Daniel O'Connell on 39; Louis-Joseph Papineau on 55, 66, 180 n.6

Locke, John 15-16

Luhmann, Niklas 7, 101, 103

Mackenzie King, William Lyon 58

Margalit, Avishai 2, 26, 182 n.5, $182 \mathrm{n} .12$

Markievicz, Countess Constance 136, 191 n.9

membership 108, 175; by birth 32 , 67,69 ; by choice $65,67-8$; criteria for 182 n.12, 183 n.21; national $23-4,68-70,73,81,84$; and republicanism 37, 117-20, 190 n.2

Mercier, Honoré 58

Métis 57-8, 186 n.11

Mill, John Stuart 14, 48

Miller, David 2, 22-5, 121, 142, $188 \mathrm{n.8}$; on membership 65,70 ; on moral relationships 102 , 110, 182 n.10, 182 n.11; on multinationalism 142-3

minorities 28-30, 75, 77; dispersed $144-5,148,150$; in Ireland 144-7, 161; and national character 161, 167; and political independence $110,112,131-2$; in Quebec 144-9, 150, 161, 191 n.12; and representational approach to nationalism 144-9; within nations $5,110,122-3$, 127, 192 n.2; see also mixed populations misrepresentation 93, 96, 97; see also representation: failure of mixed populations $122-3,125$, 145-6, 150

modernity 19-22, 102-3, 172
Moore, Margaret 73-4, 79-83, 92, 107,188 n.8

moral relationships 22-3, 71, 102, 110, 173, 182 n.10, 182 n.11

Moran, D.P. 43, 68, 185 n.10

multiculturalism 5, 27-8, 105; and representational theory of nationalism 107, 109, 110-14, 125,175 ; and vulnerable groups 72,149

multinationalism 5, 19, 60, 127, 139, 150-1; and Britain 23, 143, 181 n.2; and Canada 142-4; see also frames of reference: multiple

Nairn, Tom 20, 182 n.6, 182 n.7 nation 7,92 national character $89,90-1$, 152-3; in Ireland 89-91, 134-6, 154; and national claim 162, 165-8; preservation of 127 , 134-8, 153, 167; in Quebec 134-4, 137-8, 147-8, 157, 160-1; see also "national character" formulation

"national character" formulation 4, 64, 68, 73, 96; and cultural approach to nationalism 76-8; and essentialism 49; and ethnic nationalism 67-9; and Ireland 37, 46-7, 49-50; and Quebec 59-60, 62-3; and social change 165

national claim 4, 8, 64, 86; accommodating 104, 148; assessment of 109-11, 126, 131, 148,174 ; legitimacy of 105,146 , 172; over-prioritizing 107-8; and representation 112, 122; and social change $113,162,165-7$

national consciousness $37,43,99$; see also national character national identity 8; see also identity: national

nationalism $6,8,11,36,42$; autonomy-based theories 12 , 28-30, 148-9; cultural preservation theories $12,31-4$; 
dark side theories 11, 13-16, 21; and discrimination 122-3, 125, 190 n.4; dysfunctionalist theories 12, 19-22; instrumental value 26-7, 80, 172; intergenerational $31-4,74,109$; inversion in 87 , 91; limits on $5,20-2,122-5$, 127, 136, 150-1, 171-2, 175; political/cultural dynamic 85 , 86-92, 105, 107, 120, 134, 150-1; primordialism 181 n.5, 188 n.2; remedial right theories 11, 16-19, 29, 131-2, 182 n.4, 190 n.4; self-esteem theories 12 , 25-8, 133; social trust theories $12,22-5$; study of $1-3,11-13$; see also civic nationalism; cultural nationalism; ethnic nationalism; political nationalism

nationalist argument $1,36,64,85$, $139,152,171$; in Ireland 36-7, 46-50, 145; in Quebec 53, 59-60, 62-3; see also "good government" formulation; "national character" formulation nationality $8,25-8,153,161-8$ nationhood $8,88,167$

neutrality $72,76-7,81,83$; wartime 46

Nielson, Kai 78, 187 n.3

Nietzsche, Friedrich 7, 96, 100-1

Norman, Wayne 166

Northern Ireland 41, 44-5, 115, 144

O’Connell, Daniel 184 n.6,

186 n.5; on local knowledge 39, 47 ; and popular mobilization 38-9, 88; on repeal of union 39-40; on shared interests 40 , $47,55,89$

Papineau, Louis-Joseph 9, 54, 56, 186 n.5; on Imperial government 54-5, 63; on local knowledge 55, 66, 186 n.6; and popular mobilization 77,88 ; on shared interests 55, 89

parliament: British 129, 139, 184 n.2; Irish 37-8, 44, 136, 139; members of 136; Quebec 53-4
Parnell, Charles Stewart 41, 184 n.8 participation 80,111

patriotism 106, 117, 125, 141, 174-5; see also republicanism

Pettit, Philip 119, 190 n.2

Phillips, Anne 112-14, 133

Pitkin, Hannah 92-3, 184 n.3

Plato 93, 179-80, 192 n.3

pluralism 9, 100, 115-16, 183 n.18, political nationalism $64-5,71-4$, 77-8, 79-82, 92

post-nationalism $5,106,125$, 174-5; examples of 115,142 ; and representation 115-16, 178; and social change 165,167 , 192 n.5

printing 98

progress 14

public policy $112-14$

public sphere $75-6,79,188$ n.7

Quebec: Catholicism 53-4, 57, 61, 135, 157-9, 166, 191 n.7;

conquest 53,87 ; cultural representations 90, 140; demographics 159-60; economic development 158-9; education 158-60; entente cordiale 56, 186 n.9; equality in 135,138 , 147-8, 150, 159; and federalism 52, 57; Fils de la liberté 56, 186 n.6; historical studies 61, 163, 185 n.1; Les Rouges 57; military participation 58-9; minorities in 144-9, 161; national character $134-5,137-8$, 147-8, 157, 160-1; nationalist argument 53, 59-60, 62-3; Natives in $145-6,150,161,191$ n.12; New France 53, 185 n.2; parliament 53-4; political independence 131-2, 141, 148, 150,177 ; political parties 54,56 , 58, 165; and post-colonialism 129; Quiet Revolution 14, 157, 158; rebellions 56; separatism 2, $62,128,163,165$; social change $5,158-60$; social services 61 , 135, 137, 157, 140; 


\section{Index}

Quebec (Continued) territory 164, 186 n.12; Union Act, 55-6; urbanization 135, 158, 160, 191 n.6; women in 158-9; see also Canada; French, language

racism 101; see also discrimination Raz, Joseph 2, 26, 182 n.5, 182 n. 12

reciprocity 123,175

recognition $32,70,142-3,147$; national $25,27,80,84,133$

redistribution $22,25,33-4$, 182 n. 10

referendums 143, 155, 163

Reil, Louis 57-8, 186 n.11

relativism 48

relevancy 4, 6, 87, 109; as limiting condition 120, 123, 172, 175

religion 90, 98-9, 109, 147, 188 n.3; see also Ireland:

Catholicism; Ireland: Protestants; Quebec: Catholicism

remedial right see nationalism: remedial right theories

Renan, Ernest 100

representation $5,86,92-3,97,103$; collective $124-5,149,172,175$; conditions for 94, 105-8, 122; cultural 90, 92, 95; failure of 130-3, 139, 151; as moral problem 93-7, 179-80; and multiculturalism 111; and nations 4, 86-7, 92, 105; political $80,91,110,131-2,138$; and post-nationalism $115-16,178$; and selectivity $179-80$ representational theory of nationalism 93, 97, 104, 152, 169-75; application 174, 176, 177-9; and liberal-nationalism 106-10, 124; limits, external 122-5; limits, internal 120-2, 125,175 ; limits on $5,127,136$, $150-1,171-2,175$; and minorities 144-9; and multiculturalism 105, 107, 109, 110-14, 125, 175; and multiple frames of reference 139-44; and national character $134-8$,
173; and political independence $128-34,151$; and post-nationalism $115-16,125$; and republicanism 116-20, 125; and social change $165-8$ representative government $88-9$, 92-3

republicanism 5, 174-5; and "good government" formulation 49, 66; in Ireland $37-8,66,117-19$, 188 n.9; and membership 37, 117-20, 190 n.2; and representational theory of nationalism 116-20, 125; see also patriotism revisability $107,109,111$; as limiting condition $121,125,170$, 172,175 ; and national character $135,138,173$

rights $8,11,71,79$; abuse 15 , 16-19; civil 117, 130, 147-8; remedial see nationalism: remedial right theories

Scotland 128, 142-3

secession 17-19, 181 n.3, 182 n.4; see also independence: political; separatism

selectivity $4,87,179-80$

self-determination $14,17,75-6$, 130; see also independence: political

self-esteem $2,25-8,96,182 \mathrm{n} .8$, 182 n.13; collective 97; intergenerational 183 n.19; see also nationalism: self-esteem theories

self-government 80,91 ; see also independence: political separatism 2, 62, 129, 133, 163, 165 ; see also independence: political; secession Shachar, Ayelet 72 simultaneity 98, 99, 100 Small, Stephen 118 Smith, A.D. 10, 181 n.5 social change $5,153,160-2,165-8$; in Ireland 154-5; in Quebec 158-60

social justice $94-5,110$

social relations 98, 101-2, 114 
social trust see trust

societal culture 12, 29-30, 148, 183 n. 15

solidarity $33,73,82,102-3,107$; prospects for 22, 110; rallying 89,188 n. 1

sovereignty $88-9,98,114-15,128$

sovereignty association 128, 165; see also Quebec: separatism space 100-1, 114; see also territory stability 14-15, 94, 96, 111, 113 stalemate, moral 2, 27-8, 29-30, 123-4

states $9,23,31-3,127-34$

Tamir, Yael 2, 22-5, 121;

and cultural approach to

nationalism 74-9, 80, 83, 107;

on membership $65-6,68,70$; on

public sphere $74,75-6,79$,

188 n.7; on social meaning 50, 92

Taylor, Charles 2, 190 n.1; on

representational failure 130,133 ; on self-esteem $25-6,182$ n.8 territory 81,182 n.5; and modern politics 98, 114, 125, 169; and remedial right 16-18; separation of 141,145 ; see also space

time 98-9, 100, 102

transnationalism 106, 116, 125

Trudeau, Pierre 14, 140, 181 n.1 trust $34,101-4,142,182$ n.11; and representation $110,125,131$, 172; see also nationalism: social trust theories

Viroli, Maurizio 119

Weinstock, Daniel 108

will 14, 15, 34, 181 n.2

Williams, Melissa 131, 133

Wolfe Tone, Theobald 38, 117

Yack, Bernard 13, 69, 77, 81; on dichotomies 71, 187 n.2

Young Irelanders 39, 41-2, 43, 77, 90, 185 n.9 

eBooks - at www.eBookstore.tandf.co.uk

\section{A library at your fingertips!}

eBooks are electronic versions of printed books. You can store them on your PC/laptop or browse them online.

They have advantages for anyone needing rapid access to a wide variety of published, copyright information.

eBooks can help your research by enabling you to bookmark chapters, annotate text and use instant searches to find specific words or phrases. Several eBook files would fit on even a small laptop or PDA.

NEW: Save money by eSubscribing: cheap, online access to any eBook for as long as you need it.

\section{Annual subscription packages}

We now offer special low-cost bulk subscriptions to packages of eBooks in certain subject areas. These are available to libraries or to individuals.

For more information please contact webmaster.ebooks@tandf.co.uk

We're continually developing the eBook concept, so keep up to date by visiting the website. 
